\title{
Modulation of rental ADMA handling in hypertension
}

Citation for published version (APA):

Ronden, R. A. (2013). Modulation of rental ADMA handling in hypertension. [Doctoral Thesis, Maastricht University]. Uitgeverij BOXPress. https://doi.org/10.26481/dis.20130912rr

Document status and date:

Published: 01/01/2013

DOI:

10.26481/dis.20130912rr

Document Version:

Publisher's PDF, also known as Version of record

\section{Please check the document version of this publication:}

- A submitted manuscript is the version of the article upon submission and before peer-review. There can be important differences between the submitted version and the official published version of record.

People interested in the research are advised to contact the author for the final version of the publication, or visit the DOI to the publisher's website.

- The final author version and the galley proof are versions of the publication after peer review.

- The final published version features the final layout of the paper including the volume, issue and page numbers.

Link to publication

\footnotetext{
General rights rights.

- You may freely distribute the URL identifying the publication in the public portal. please follow below link for the End User Agreement:

www.umlib.nl/taverne-license

Take down policy

If you believe that this document breaches copyright please contact us at:

repository@maastrichtuniversity.nl

providing details and we will investigate your claim.
}

Copyright and moral rights for the publications made accessible in the public portal are retained by the authors and/or other copyright owners and it is a condition of accessing publications that users recognise and abide by the legal requirements associated with these

- Users may download and print one copy of any publication from the public portal for the purpose of private study or research.

- You may not further distribute the material or use it for any profit-making activity or commercial gain

If the publication is distributed under the terms of Article $25 \mathrm{fa}$ of the Dutch Copyright Act, indicated by the "Taverne" license above, 
Modulation of renal ADMA handling in hypertension 
(C) Rianne Ronden, Heerlen 2013

Cover picture: Trichomanes reniforme/Kidney fern

Cover design: Jean Scheijen || www.vierdrie.nl

Production: Proefschriftmaken.nl || Uitgeverij BOXPress 's-Hertogenbosch

ISBN: 978-90-8891-673-1 


\title{
Modulation of renal ADMA handling in hypertension
}

\author{
PROEFSCHRIFT
}

\author{
Ter verkrijging van de graad van doctor aan de Universiteit Maastricht, \\ op gezag van de Rector Magnificus, prof. dr. L.L.G. Soete \\ volgens het besluit van het College van Decanen, \\ in het openbaar te verdedigen \\ op donderdag 12 september 2013 om 14.00 uur \\ door
}

Rianne Aimée Ronden 


\section{PROMOTOR}

Prof. dr. P.W. de Leeuw

\section{COPROMOTORES}

Dr. A.A. Kroon

Dr. A.J.H.M. Houben

\section{BEOORDELINGSCOMMISSIE}

Prof. dr. T. Unger (voorzitter)

Prof. dr. H.J.G.M. Crijns

Prof. dr. M.W. de Haan

Prof. dr. G.J. Navis (UMC Groningen)

Dr. C.T. Postma (UMC St. Radboud)

The research described in this thesis was supported by a grant of the Dutch Heart Foundation (DHF-2004T058)

Financial support by the Dutch Heart Foundation and SBOH, employer of GP trainees for the publication of this thesis is gratefully acknowledged.

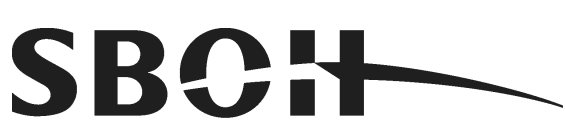
voor artsen in opleiding 


\section{Voor mijn oom John Janssens († 5 september 2012)}





\section{CONTENTS}

CHAPTER 1 General introduction and outline of the thesis 9

CHAPTER 2 Predictors of clinical outcome after stent placement in 33 atherosclerotic renal artery stenosis: a systematic review and meta-analysis of prospective studies

CHAPTER 3 Renal handling of asymmetric dimethylarginine in atherosclerotic renal artery stenosis

CHAPTER 4 Reduced renal plasma clearance does not explain increased plasma asymmetric dimethylarginine in hypertensive subjects with mild to moderate renal insufficiency

CHAPTER 5 The renal handling of asymmetric dimethylarginine in hypertensive patients: renal clearance vs. urinary clearance

CHAPTER 6 Acute effects of intrarenal eprosartan infusion on the renal handling of asymmetric dimethylarginine

CHAPTER 7 Salt intake does not influence the renal handling of asymmetric dimethylarginine in hypertensive Caucasians

CHAPTER 8 General discussion

Nederlandse samenvatting (Summary in Dutch)

Dankwoord (Acknowledgements)

Curriculum Vitae

Abbreviations 

1

General introduction and outline of the thesis 
CHAPTER 1 


\section{INTRODUCTION}

Since the discovery of $\omega-N^{G}, N^{G}$-asymmetric dimethylarginine (ADMA) as an endogenous inhibitor of the arginine-nitric oxide (NO) pathway two decades ago, ${ }^{1}$ our knowledge of this biomarker and its potential pathophysiological role in cardiovascular disease has increased substantially. ${ }^{2}$ However, it is not yet fully understood what the exact mechanisms are that cause the elevated ADMA plasma concentrations in patients with increased risk of and established cardiovascular diseases. Previous studies extensively addressed the role of the kidneys in plasma ADMA regulation and always emphasized the importance of the kidneys as a plasma ADMA clearing and regulating organ. Still, it is unknown whether differences or changes in the renal handling of ADMA can be responsible for increased plasma ADMA in patients. Therefore, this thesis focuses on modulation of renal ADMA handling and the influence on plasma concentrations of ADMA.

\section{ADMA AS A NITRIC OXIDE SYNTHASE INHIBITOR}

Nitric oxide is synthesized from L-arginine by three isoforms of nitric oxide synthase $(\mathrm{NOS})^{3,4}$ and plays a pivotal role as a regulator and mediator of numerous processes in the cardiovascular, gastrointestinal, immune, pulmonary and nervous systems. Production of NO by the endothelium-derived nitric oxide synthase (eNOS) is important for the regulation of regional blood flow and vascular tone ${ }^{5}$ and for inhibiting processes involved in atherogenesis like vascular smooth muscle cell proliferation, platelet aggregation and adhesion, monocyte adhesion, and oxidation of low-density lipoprotein (LDL) cholesterol. ${ }^{6}$ The inducible isoform of NOS (iNOS) is able to produce large amounts of NO during inflammation and NO derived from the neuronal NOS (nNOS) isoform is important in relaxation of smooth muscle cells but is also involved in learning and memory formation. ${ }^{7}$

The synthesis of NO by all NOS isoforms can be competitively inhibited by L-arginine analogues including ADMA and L- $N^{G}$-monomethyl-arginine (L-NMMA). ${ }^{1,8}$ Since plasma concentrations of ADMA are 5- to 10-fold higher as compared to plasma L-NMMA concentrations, ${ }^{9}$ ADMA is often considered as the principal inhibitor of NOS. ${ }^{1}$ Although it is important to emphasize that intracellular concentrations of L-NMMA and ADMA may differ between tissues and organs and that the contribution of L-NMMA to NO bioavailability may be of more importance in certain tissues. ${ }^{10} \omega-N^{G}, N^{\prime G}$-symmetric dimethylarginine (SDMA), the stereoisomer of ADMA, cannot directly inhibit the enzyme NOS but may interfere with NO synthesis by competing with L-arginine, ADMA, and L-NMMA for cellular transport across cationic amino acid transporters (CAT) of system $y^{+}{ }^{11,12}$ Figure 1.1 illustrates the molecular structures of L-arginine, L-NMMA, SDMA and ADMA. 

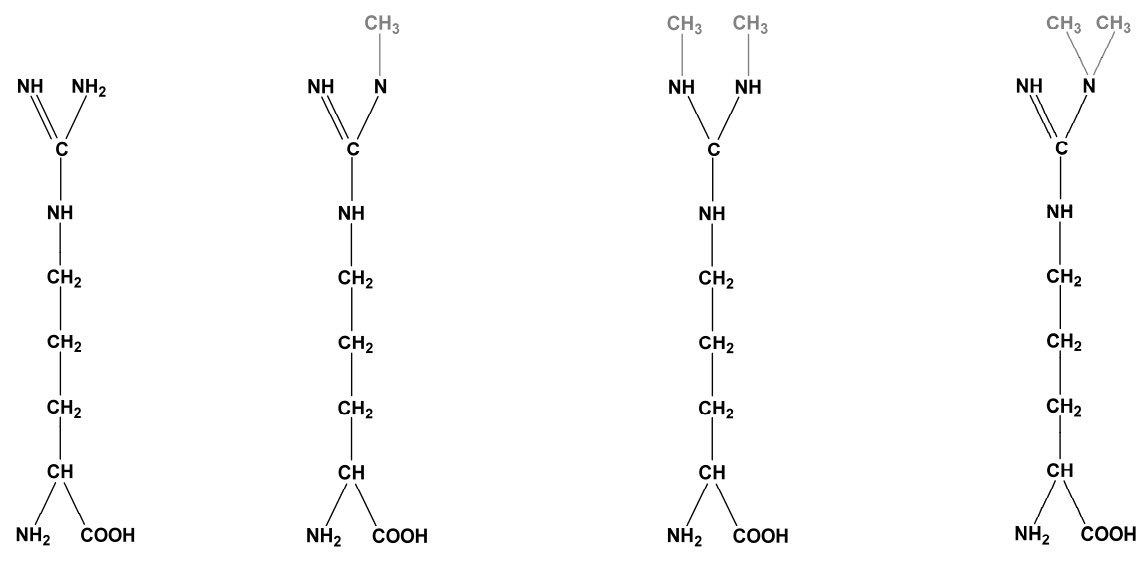

L-arginine

L-NG-monomethyl arginine (LNMMA) symmetric dimethylarginine (SDMA) asymmetric dimethylargInIne (ADMA)

Figure 1.1 Structures of L-arginine and methylarginines

\section{PLASMA AND CELLULAR CONCENTRATIONS OF ADMA}

In persons 50-75 years old, normal plasma concentrations of ADMA range between approximately 0.4 and $0.6 \mu \mathrm{mol} / \mathrm{I}^{13}$ whereas intracellular concentrations are 5-10 times higher. ${ }^{14}$ Recent studies have shown that despite the fact that intracellular concentrations of L-arginine are many magnitudes higher (millimolar range for Larginine vs. low micromolar range for ADMA) than those of intracellular ADMA, physiological concentrations of endogenous ADMA can significantly inhibit NOS. ${ }^{14,15}$ In fact, at physiological concentrations of ADMA and in the presence of L-arginine concentrations observed in healthy persons, endothelial NOS activity is subject to $\approx$ $10 \%$ tonic inhibition. ${ }^{14}$

\section{ADMA SYNTHESIS}

Figure 1.2 illustrates the synthesis of methylarginines ADMA, SDMA and L-NMMA. L-arginine residues are methylated (addition of methyl groups from the methyl donor methionine) by a group of enzymes called protein arginine methyltransferases (PRMTs). ${ }^{16,17}$ These methylated proteins are predominantly found in the nucleus and play a role in RNA processing and transcriptional control. ${ }^{18,19}$ Methylarginines are released into the cytosol during proteolysis and they are thereby, an obligatory product of normal protein turnover within cells. There are, two types of PRMTs; ADMA is formed by PRMT type 1 and SDMA is formed by PRMT type 2. Both types can form LNMMA. $^{20}$ Recent studies have shown that the activity of type 1 PRMTs, and consequently the amount of ADMA production can be increased by factors as oxidized $\mathrm{LDL}^{21}$ shear stress, ${ }^{22}$ and oxidative stress. ${ }^{23,24}$ 
Because there is no route for direct synthesis of methylarginine from free L-arginine and that protein methylation by PRMTs regulate a number of vital cellular functions, it appears unlikely that these enzymes act as the rate-limiting step in controlling ADMA. Nevertheless, it is clear that PRMT activity contributes considerably to plasma concentrations of ADMA. ${ }^{21,25,26}$ Finally, it should be noted that plasma ADMA concentrations represent spillover from cells and therefore may reflect the inhibitory concentrations at the site of action.

\section{CLEARANCE OF ADMA}

Healthy humans generate approximately $200-300 \mu \mathrm{mol}$ of ADMA per day, ${ }^{27,28}$ and it is estimated that $10-20 \%$ of ADMA is excreted unchanged in the urine. ${ }^{1,29}$ Approximately $80-90 \%$ per day is actively metabolized, predominantly by $N^{G}, N^{G}$-dimethylarginine dimethylaminohydrolase (DDAH). ${ }^{27,30,31}$

\section{Metabolism}

Two metabolic (degradation) pathways have been identified for methylarginines. The first and most important pathway by DDAH is specific for ADMA and L-NMMA whereas the second (minor) pathway by alanine-glyoxylate aminotransferase 2 (AGXT2) utilizes ADMA, L-NMMA and SDMA as substrates (Figure 1.2).

The intracellular enzyme DDAH degrades ADMA into citrulline and dimethylamine (Figure 1.2). DDAH is widely distributed in the human body but is particularly present in the kidney, endothelium, lung, pancreas, liver and brain. ${ }^{32,33}$ Interestingly, DDAH colocalizes with NOS isoforms which indirectly but strongly suggests that this enzyme provides a mechanism to control local availability of NO.

Two isoforms of DDAH have been identified, each with a different tissue distribution. ${ }^{34,35}$ Type 1 is found mainly in tissues expressing the neuronal NOS isoform such as liver, kidney cortex, and lung, these organs contribute the most quantitatively to ADMA metabolism. ${ }^{33,34,36}$ Type 2 is found mainly in tissues expressing eNOS and iNOS isoforms, and predominates in the endothelium and smooth muscle cells of the cardiovascular system but also in the kidney. ${ }^{33,34,36}$ This distinctive distribution pattern implies specific functions for each DDAH isoform. Indeed, a recent study indicates that DDAH type 1 is primary involved in the regulation of plasma concentrations of ADMA, and that DDAH type 2 is responsible for "local" ADMA concentrations like the regulation of the NO-mediated responses in the vascular endothelium. ${ }^{36}$ 
The importance of DDAH in the regulation of intracellular ADMA, and thus NOS activity, is corroborated by the prediction that without degradation by DDAH, there would be a daily ADMA increase of approximately $5 \mu \mathrm{mol} / \mathrm{I}^{27}$ Furthermore, inhibition of DDAH activity results in significant increase in plasma ADMA and reduced NOS activity, $^{37}$ while stimulation of DDAH activity results in a substantial reduction of plasma ADMA concentration and increased tissue NOS activity. ${ }^{38}$

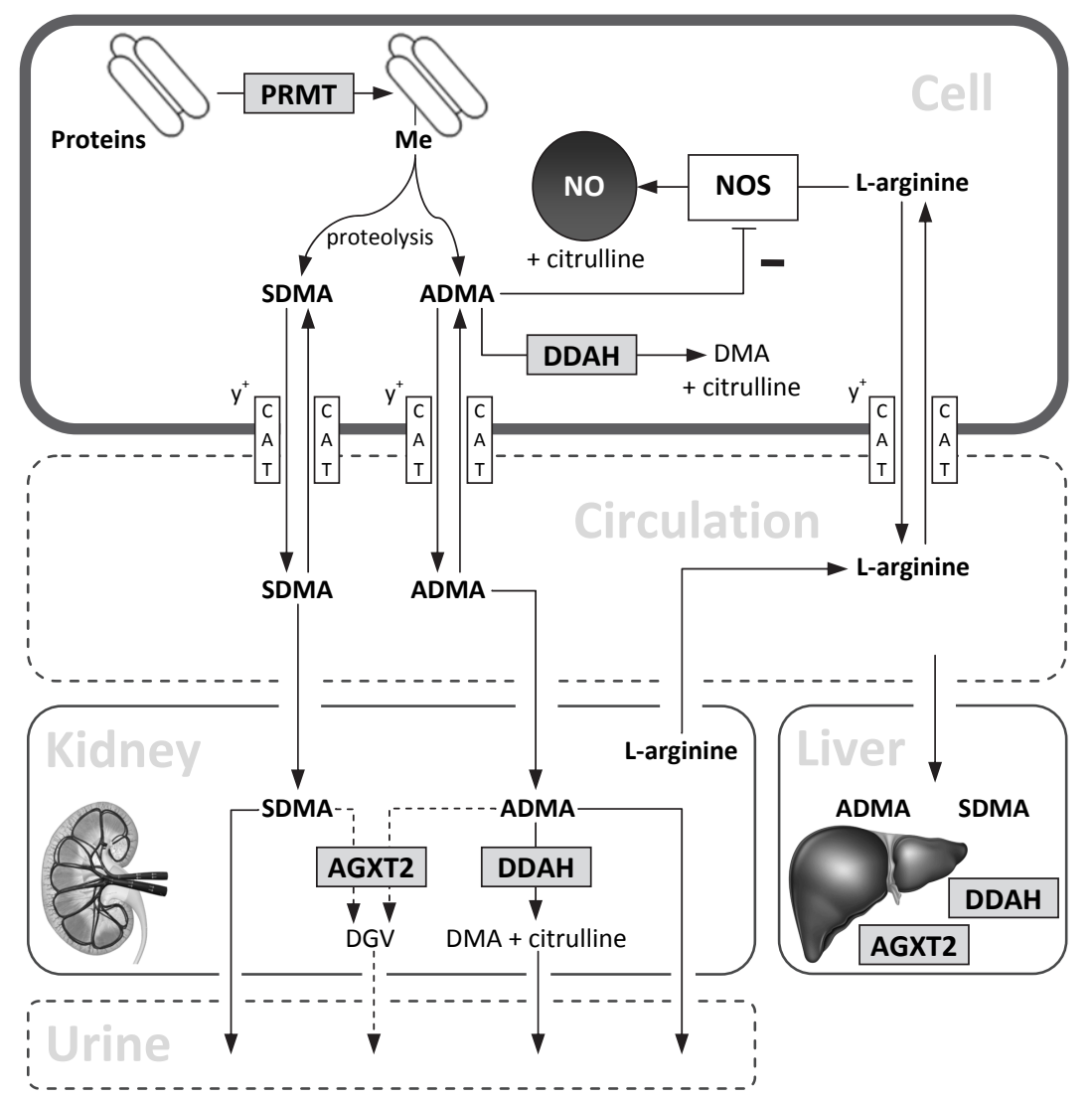

Figure 1.2 Synthesis, distribution, clearance and actions of methylarginines. L-NMMA (not shown for clarity) is thought to have similar actions, distribution, and degradation pathways to ADMA. Dotted arrows show metabolic pathways for which limited in vivo evidence is available. ADMA, asymmetric dimethylarginine; AGXT2, alanine-glyoxylate aminotransferase 2, CAT, cationic amino acid transporters; DDAH, $N^{G}, N^{G}$ dimethylarginine dimethylaminohydrolase; DGV, $\alpha$-keto- $\delta$-dimethylguanidino valeric acid; DMA, dimethylamine; Me, methylated; NO, nitric oxide; NOS, nitric oxide synthase; PRMT, protein arginine methyltransferases; SDMA, symmetric dimethylarginine 
DDAH activity has been shown to be altered by several of endocrine and cytokine factors, although the mechanisms are not totally clear yet. ${ }^{34}$ One of these is oxidative stress which is thought to inhibit both DDAH transcription and activity. ${ }^{24}$ Furthermore, consistent with the hypothesis that DDAH is an important regulator of plasma ADMA concentrations and thus NO synthesis, studies in animal models and humans have shown changes in DDAH expression and/or activity in various diseases in which impaired NO bioavailability has been implicated in pathophysiology. ${ }^{39-43}$

The second metabolic pathway involves AGXT2, a mitochondrial aminotransferase expressed primarily in the kidney but also in the liver (Figure 1.2). ${ }^{31,44,45}$ AGXT2 utilizes ADMA, SDMA and L-NMMA as substrate and forms $\alpha$-keto- $\delta$-dimethylguanidino valeric acid (DGV), which is excreted in the urine. A recent study showed that overexpression of AGXT2 decreased ADMA synthesis and increased NO synthesis in mice. ${ }^{45}$ However, the exact role and contribution of AGXT2 in the regulation of ADMA needs further investigation.

\section{Renal excretion}

Although it is generally accepted that the primary clearing pathway of ADMA is via DDAH, approximately $10-20 \%(30-50 \mu \mathrm{mol} /$ day) of the daily production is excreted unchanged into the urine. ${ }^{46-48}$ In contrast, SDMA is not degraded by DDAH ${ }^{30}$ and therefore urinary excretion of SDMA is considered to be the main eliminatory pathway of this substance. ${ }^{10}$ Both dimethylarginines are excreted in the urine in approximately equal amounts, but the extent to which this occurs is dependent upon glomerular filtration rate (GFR). ${ }^{1,46,49,50}$ L-arginine (which is actually synthesized for $\pm 60 \%$ by the kidneys ${ }^{51}$ ), ADMA, SDMA and L-NMMA are freely filtered at the glomerulus, but tubular reabsorption ensures that urinary excretion is minimal for L-arginine. Less than $1 \%$ of the filtered load is lost in the urine. ${ }^{52}$ Presently, there are no studies on the tubular reabsorption of ADMA, SDMA and L-NMMA but indirect evidence suggests that the tubular reabsorption of these substances is far less efficient than that of L-arginine. ${ }^{12,13,46}$

\section{REGULATION OF PLASMA ADMA BY THE KIDNEYS}

Kakimoto and coworkers isolated and fully characterized ADMA (and SDMA) in human urine for the first time in $1970 .^{48}$ In 1992, Vallance and coworkers were the first to describe the biological relevance of ADMA as an endogenous inhibitor of NOS. ${ }^{1}$ They reported that plasma ADMA concentrations are 8-fold higher in patients with endstage renal disease as compared to healthy controls and that ADMA inhibits NO production in vitro as well as in vivo. ${ }^{1}$ Al Banchaabouchi and coworkers further investigated the relationship between plasma ADMA, SDMA and urinary 
concentrations. They reported similar fractional excretion rates (clearance of dimethylarginines/divided by the clearance of creatinine) for ADMA and SDMA in healthy subjects $\left(68 \%\right.$ and $71 \%$, respectively). ${ }^{46}$ Moreover, they calculated that approximately $30 \%$ of both dimethylarginines was reabsorbed. The next clue for the kidneys as a plasma ADMA regulating organ came from a study that showed substantial renal clearance of $16 \%$ and $11 \%$ for ADMA and SDMA, respectively, as measured by arteriovenous concentration differences. ${ }^{53}$ Subsequently, the discovery of an additional metabolic ADMA degradation pathway by $\mathrm{DDAH}^{27,30,31}$ which is highly expressed in the kidneys, ${ }^{35,54-56}$ and probably the most important degradation pathway for ADMA, confirmed the significance of the kidneys as plasma ADMA regulating organ and explained the difference in renal clearance between ADMA and SDMA (SDMA can namely not be degraded by DDAH). Finally, the renal presence of AGXT2, the other metabolic degradation pathway of ADMA, illustrates that all routes of ADMA clearance are available in the kidneys. Nevertheless, the kidneys are not the only plasma ADMA regulating organ in humans, as the liver is also an important controller of ADMA (Figure 1.2). ${ }^{19,57}$

Since the kidneys display all known routes of ADMA clearance it is likely that changes in renal ADMA clearance or handling may affect plasma concentrations of ADMA. However, in humans, little is known about this possibility.

\section{ADMA IN CARDIOVASCULAR DISEASE}

Evidence for a pathophysiological role of ADMA in cardiovascular disease originates from studies in which infusion of exogenous ADMA resulted in increased systemic vascular resistance, increased mean arterial blood pressure, decreased heart rate, reduced cardiac output, renal blood flow, and increased renal vascular resistance. $^{58,59}$

Furthermore, there have been numerous (in vitro, in vivo, and clinical) studies addressing the role of ADMA in human health and (cardiovascular) disease. ${ }^{2}$ Generally, higher plasma ADMA concentrations have been found in case-control studies involving subjects with cardiovascular, endocrine, and immune-mediated diseases (Table 1.1). More compelling evidence for a pathophysiological role of ADMA comes from longitudinal cohort studies in which higher plasma ADMA has been associated with adverse cardiovascular events or mortality. ${ }^{60-75}$ Furthermore, in patients with chronic kidney disease (CKD), a higher plasma ADMA level has been associated with progression of kidney failure. ${ }^{66,76}$ Nevertheless, it is still hard to draw conclusions about ADMA as a possible cause of cardiovascular disease, as ADMA is also significantly associated with both traditional and nontraditional cardiovascular risk factors (Table 1.2). 


\section{ADMA and chronic kidney disease}

The first evidence for a role of ADMA in (cardiovascular) disease came from a study in patients with end-stage renal disease. ${ }^{1}$ However, there is a variable increase of plasma ADMA in CKD. ${ }^{1,49,52}$ Depending on the pathophysiological cause and severity of renal insufficiency, it is possible that a decline in renal excretory function is not paralleled by a reduction in renal DDAH activity.

Subsequently, dialysis patients with manifest atherosclerosis were shown to have higher plasma ADMA concentrations as compared to those without atherosclerotic disease and it was suggested that increased plasma ADMA may be responsible for hypertension and accelerated atherosclerosis in end-stage renal disease. ${ }^{79}$

Interestingly, plasma ADMA is also increased in patients with incipient primary renal disease, thus before a reduction in GFR, confirmed a relationship between ADMA and CKD beyond just renal function and decreased renal clearance. ${ }^{115} \mathrm{~A}$ role for ADMA in the evolution of progressive nephropathies was further supported by two longitudinal studies which showed that higher plasma ADMA is associated with the progression of kidney failure even in the earlier stages of CKD. ${ }^{66,76}$ However, mechanisms underlying this increase have not yet been completely elucidated.

Table 1.1 Disease states associated with increased plasma ADMA

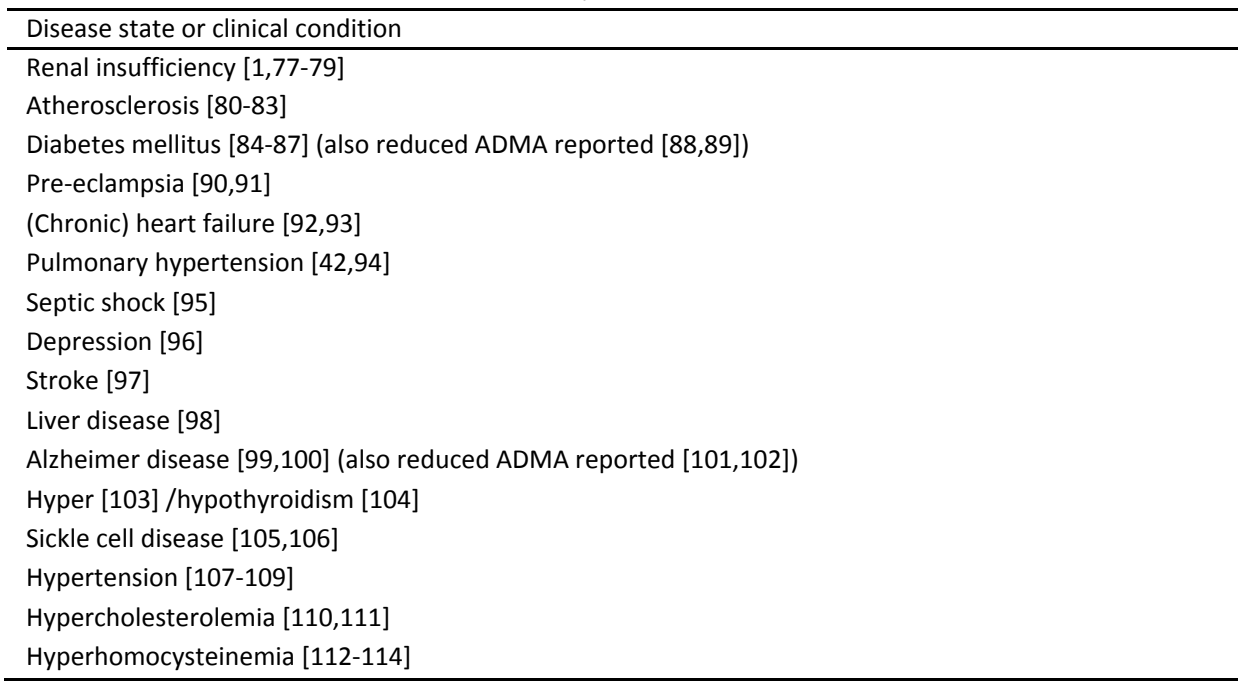




\section{ADMA and hypertension}

There is compelling evidence that NO plays an important role in the regulation of vascular tone and blood pressure. ${ }^{116-118}$ There are two possible mechanisms by which ADMA may be involved in the pathogenesis of hypertension. 1) ADMA may exert vasoconstrictor effects by inhibiting eNOS activity ${ }^{27,119}$ 2) ADMA may inhibit urinary sodium excretion by reducing renal NO synthesis. ${ }^{59,120}$ Therefore, it has been postulated that elevated plasma concentrations of ADMA are the underlying mechanism that may explain why excess salt intake impairs vasodilatation, resulting in reduction of blood flow and elevation of blood pressure. ${ }^{121-124}$ However, the relationship between ADMA and blood pressure is complex.

Table 1.2 Relationships between plasma ADMA and cardiovascular risk factors

\begin{tabular}{ll}
\hline Age & Associated with aging [13,80,125] \\
Sex & No association with aging [126] \\
& Higher in women [13] \\
Lipids & Association with higher total cholesterol $[69,100,126]$ \\
& Association with lower high-density lipoprotein and lower triglycerides [126] \\
Tobacco & Association with smoking status [69,126] \\
& No association with smoking status [80] \\
Blood pressure & Association with higher blood pressure [80,125] \\
& Association with lower systolic blood pressure [126] \\
Renal function & Association with renal function in subjects with renal disease [50,76,127] \\
& No association with renal function in subjects without renal diseases [110,126] \\
Obesity & Association with higher body mass index [69,126] \\
Diabetes Mellitus & Association with impaired glucose tolerance/lower plasma insulin $[80,126]$ \\
& Association with the presence of diabetes mellitus [86] \\
Homocysteine & Association with higher plasma homocysteine [126]
\end{tabular}

Various in vitro and in vivo studies show associations between ADMA and blood pressure in several experimental models (salt-sensitive rats, ${ }^{128}$ angiotensin II elicited reactive oxygen species in cultured cells ${ }^{22,129,130}$, and DDAH transgenic mouse ${ }^{33,38}$ ). In humans, some studies showed no correlation with blood pressure, while others did (Table 1.2). In addition, infusion of exogenous ADMA in healthy volunteers showed that high plasma concentrations of ADMA are needed to affect systemic blood pressure. $^{58}$ 


\section{PHARMACOLOGICAL MANIPULATION OF ADMA}

If ADMA, indeed, is of pathophysiological importance in cardiovascular disease, obvious treatment options would be to reverse the effects of increased ADMA or to reduce the ADMA plasma concentration. Theoretically, L-arginine should be able to displace ADMA and restore NOS activity and NO bioavailability. However, in humans, study outcomes are inconsistent, and potential therapeutic effects of L-arginine have not been established. ${ }^{108,131-133}$ Numerous cardiovascular drugs have been shown to influence ADMA plasma concentrations in humans (Table 1.3), with drugs that target the renin-angiotensin system showing the most consistent effects. Nevertheless, whether the changes in plasma ADMA are mediated by an effect on synthesis, distribution, or degradation has generally not been explored. Furthermore, much research is currently going on to lower ADMA by developing specific activators of DDAH as a therapy. ${ }^{134,135}$ However, to develop more specific ADMA-lowering therapies, first, all mechanisms leading to increased plasma ADMA in cardiovascular disease need to be better understood.

\section{CONCLUDING REMARKS}

There is increasing evidence that the endogenous NOS inhibitor ADMA plays a significant role in (cardiovascular) disease by reducing NO availability and inducing endothelial dysfunction. The ability of plasma ADMA to predict cardiovascular outcome and mortality in longitudinal studies demonstrates the potential of ADMA to act as a marker, if not mediator, of pathophysiology in (cardiovascular) disease. However, we need a better understanding about underlying mechanisms that lead to increased plasma ADMA. A focus point for this understanding could be the kidneys because they contain all routes of synthesis and degradation (clearance) of ADMA.

Table 1.3 Drugs and their influence on plasma ADMA

\begin{tabular}{ll}
\hline Angiotensin converting enzyme inhibitors & Reduced ADMA [136-141] \\
Angiotensin II type 1 receptor blockers & Reduced ADMA [136,141-144] \\
Other antihypertensive drugs & No effect $[137,145,146]$ \\
Statins & Reduced ADMA $[142,146-148]$ \\
Other lipid reducing therapies & No effect $[81,86,149-153]$ \\
& Reduced ADMA [145,154,155] \\
Hormone replacement therapy & No effect [156] \\
& Reduced ADMA [156-158] \\
Hypoglycemic drugs & Increased ADMA [159] \\
& Reduced ADMA [159-164] \\
& No effect [165-167] \\
\hline
\end{tabular}

ADMA, asymmetric dimethylarginine 


\section{OUTLINE OF THE THESIS}

In this thesis, we aim to answer several questions with regard to the renal handling of ADMA and the possible influence on plasma ADMA in hypertensive patients with mild to moderate renal insufficiency or atherosclerotic renal artery stenosis.

In CHAPTER 2 we describe the results of a systemic review and meta-analysis to answer the question whether there are predictors of clinical outcome after stent placement in atherosclerotic renal artery stenosis. Plasma ADMA is increased in patients with atherosclerosis but it is not known to what extent the kidney contributes to this effect. Therefore, in CHAPTER 3, we explored whether in atherosclerotic renal artery stenosis, renal plasma clearance of ADMA differs between the stenotic and the contralateral non-stenotic kidney in unilateral renal artery stenosis and between both stenotic kidneys in bilateral renal artery stenosis.

In patients with chronic kidney disease, ADMA and its structural isomer SDMA build up in plasma even in early stages of renal insufficiency. The exact mechanisms responsible for this increase of ADMA and SDMA, at these early stages of chronic kidney disease, have not been totally clarified but are likely to involve changes in the regulation of the plasma concentration by the kidneys (renal plasma clearance). In CHAPTER 4 we investigated the relationship between renal function, renal plasma clearance and (arterial) plasma concentrations of ADMA and SDMA in these early phases of renal impairment and in CHAPTER 5 we investigated the role of the urinary clearance in these relationships.

Clinical studies have reported that angiotensin II type 1 receptor blockers reduce plasma concentrations of ADMA in hypertensive patients. However, possible underlying mechanisms of this plasma ADMA-lowering effect are not fully understood. In CHAPTER 6, we used the human kidney as a model to explore the effects of direct intrarenal infusion of an angiotensin II type 1 receptor blocker (eprosartan) on plasma ADMA and the renal handling of ADMA.

High dietary salt intake negatively influences NO production and increases plasma concentrations of ADMA in non-Caucasian hypertensives. Furthermore, salt intake has a profound effect on renal hemodynamics and blood pressure. In CHAPTER 7 we investigate, in hypertensive Caucasians, the influence of dietary salt intake on the renal handling of ADMA and plasma ADMA.

Finally, in CHAPTER 8 we provide an overview of the main conclusions based on the studies described in this thesis and discuss possible issues for future research. 


\section{REFERENCES}

1. Vallance $\mathrm{P}$, Leone A, Calver A, Collier J, Moncada S. Accumulation of an endogenous inhibitor of nitric oxide synthesis in chronic renal failure. Lancet. 1992;339:572-575.

2. Caplin B, Leiper J. Endogenous nitric oxide synthase inhibitors in the biology of disease: markers, mediators, and regulators? Arterioscler Thromb Vasc Biol. 2012;32:1343-1353.

3. Forstermann U, Schmidt HH, Pollock JS, Sheng H, Mitchell JA, Warner TD, Nakane M, Murad F. Isoforms of nitric oxide synthase. Characterization and purification from different cell types. Biochem Pharmacol. 1991;42:1849-1857.

4. Forstermann U, Closs El, Pollock JS, Nakane M, Schwarz P, Gath I, Kleinert H. Nitric oxide synthase isozymes. Characterization, purification, molecular cloning, and functions. Hypertension. 1994;23:1121-1131.

5. Palmer RM, Ashton DS, Moncada S. Vascular endothelial cells synthesize nitric oxide from L-arginine. Nature. 1988;333:664-666.

6. Napoli C, Ignarro L. Nitric oxide and atherosclerosis. Nitric Oxide. 2001;5:88-97.

7. Forstermann U, Sessa WC. Nitric oxide synthases: regulation and function. Eur Heart J. 2012;33:829837, 837a-837d.

8. MacAllister RJ, Fickling SA, Whitley GS, Vallance P. Metabolism of methylarginines by human vasculature; implications for the regulation of nitric oxide synthesis. Br J Pharmacol. 1994;112:43-48.

9. Meyer J, Richter N, Hecker M. High-performance liquid chromatographic determination of nitric oxide synthase-related arginine derivatives in vitro and in vivo. Anal Biochem. 1997;247:11-16.

10. McDermott JR. Studies on the catabolism of Ng-methylarginine, $\mathrm{Ng}, \mathrm{Ng}$-dimethylarginine and $\mathrm{Ng}, \mathrm{Ng}$ dimethylarginine in the rabbit. Biochem J. 1976;154:179-184.

11. Closs El, Basha FZ, Habermeier A, Forstermann U. Interference of L-arginine analogues with L-arginine transport mediated by the $y+$ carrier hCAT-2B. Nitric Oxide. 1997;1:65-73.

12. Teerlink T, Luo Z, Palm F, Wilcox CS. Cellular ADMA: regulation and action. Pharmacol Res. 2009;60:448-460.

13. Teerlink T. HPLC analysis of ADMA and other methylated L-arginine analogs in biological fluids. J Chromatogr B Analyt Technol Biomed Life Sci. 2007;851:21-29.

14. Cardounel AJ, Cui H, Samouilov A, Johnson W, Kearns P, Tsai AL, Berka V, Zweier JL. Evidence for the pathophysiological role of endogenous methylarginines in regulation of endothelial NO production and vascular function. J Biol Chem. 2007;282:879-887.

15. Gold ME, Bush PA, Ignarro LJ. Depletion of arterial L-arginine causes reversible tolerance to endothelium-dependent relaxation. Biochem Biophys Res Commun. 1989;164:714-721.

16. Clarke S. Protein methylation. Curr Opin Cell Biol. 1993;5:977-983.

17. McBride $A E$, Silver PA. State of the arg: protein methylation at arginine comes of age. Cell. 2001;106:5-8.

18. Najbauer J, Johnson BA, Young AL, Aswad DW. Peptides with sequences similar to glycine, argininerich motifs in proteins interacting with RNA are efficiently recognized by methyltransferase(s) modifying arginine in numerous proteins. J Biol Chem. 1993;268:10501-10509.

19. Siroen MP, Teerlink T, Nijveldt RJ, Prins HA, Richir MC, van Leeuwen PA. The clinical significance of asymmetric dimethylarginine. Annu Rev Nutr. 2006;26:203-228.

20. Anthony S, Leiper J, Vallance P. Endogenous production of nitric oxide synthase inhibitors. Vasc Med. 2005;10 Suppl 1:S3-9.

21. Boger RH, Sydow K, Borlak J, Thum T, Lenzen H, Schubert B, Tsikas D, Bode-Boger SM. LDL cholesterol upregulates synthesis of asymmetrical dimethylarginine in human endothelial cells: involvement of Sadenosylmethionine-dependent methyltransferases. Circ Res. 2000;87:99-105.

22. Osanai $T$, Saitoh M, Sasaki S, Tomita H, Matsunaga T, Okumura K. Effect of shear stress on asymmetric dimethylarginine release from vascular endothelial cells. Hypertension. 2003;42:985-990. 


\section{CHAPTER 1}

23. Luo Z, Teerlink T, Griendling K, Aslam S, Welch WJ, Wilcox CS. Angiotensin II and NADPH oxidase increase ADMA in vascular smooth muscle cells. Hypertension. 2010;56:498-504.

24. Wilcox CS. Asymmetric dimethylarginine and reactive oxygen species: unwelcome twin visitors to the cardiovascular and kidney disease tables. Hypertension. 2012;59:375-381.

25. Pope AJ, Karuppiah K, Cardounel AJ. Role of the PRMT-DDAH-ADMA axis in the regulation of endothelial nitric oxide production. Pharmacol Res. 2009;60:461-465.

26. Vallance $P$, Leiper J. Cardiovascular biology of the asymmetric dimethylarginine:dimethylarginine dimethylaminohydrolase pathway. Arterioscler Thromb Vasc Biol. 2004;24:1023-1030.

27. Achan V, Broadhead M, Malaki M, Whitley G, Leiper J, MacAllister R, Vallance P. Asymmetric dimethylarginine causes hypertension and cardiac dysfunction in humans and is actively metabolized by dimethylarginine dimethylaminohydrolase. Arterioscler Thromb Vasc Biol. 2003;23:1455-1459.

28. Tsikas D, Thum T, Becker T, Pham VV, Chobanyan K, Mitschke A, Beckmann B, Gutzki FM, Bauersachs J, Stichtenoth DO. Accurate quantification of dimethylamine (DMA) in human urine by gas chromatography-mass spectrometry as pentafluorobenzamide derivative: evaluation of the relationship between DMA and its precursor asymmetric dimethylarginine (ADMA) in health and disease. J Chromatogr B Analyt Technol Biomed Life Sci. 2007;851:229-239.

29. Al Banchaabouchi M, Marescau B, D'Hooge R, Engelborghs S, De Deyn PP. Consequences of renal mass reduction on amino acid and biogenic amine levels in nephrectomized mice. Amino Acids. 2000;18:265-277.

30. Ogawa T, Kimoto M, Sasaoka K. Occurrence of a new enzyme catalyzing the direct conversion of NG,NG-dimethyl-L-arginine to L-citrulline in rats. Biochem Biophys Res Commun. 1987;148:671-677.

31. Ogawa $T$, Kimoto $M$, Sasaoka K. Purification and properties of a new enzyme, NG,NG-dimethylarginine dimethylaminohydrolase, from rat kidney. J Biol Chem. 1989;264:10205-10209.

32. Kimoto M, Whitley GS, Tsuji H, Ogawa T. Detection of NG,NG-dimethylarginine dimethylaminohydrolase in human tissues using a monoclonal antibody. J Biochem. 1995;117:237238.

33. Leiper J, Nandi M, Torondel B, Murray-Rust J, Malaki M, O'Hara B, Rossiter S, Anthony S, Madhani M, Selwood D, Smith C, Wojciak-Stothard B, Rudiger A, Stidwill R, McDonald NQ, Vallance P. Disruption of methylarginine metabolism impairs vascular homeostasis. Nat Med. 2007;13:198-203.

34. Palm F, Onozato ML, Luo Z, Wilcox CS. Dimethylarginine dimethylaminohydrolase (DDAH): expression, regulation, and function in the cardiovascular and renal systems. Am J Physiol Heart Circ Physiol. 2007;293:H3227-3245.

35. Leiper JM, Santa Maria J, Chubb A, MacAllister RJ, Charles IG, Whitley GS, Vallance P. Identification of two human dimethylarginine dimethylaminohydrolases with distinct tissue distributions and homology with microbial arginine deiminases. Biochem J. 1999;343 Pt 1:209-214.

36. Wang D, Gill PS, Chabrashvili T, Onozato ML, Raggio J, Mendonca M, Dennehy K, Li M, Modlinger P, Leiper J, Vallance P, Adler O, Leone A, Tojo A, Welch WJ, Wilcox CS. Isoform-specific regulation by $\mathrm{N}(\mathrm{G}), \mathrm{N}(\mathrm{G})$-dimethylarginine dimethylaminohydrolase of rat serum asymmetric dimethylarginine and vascular endothelium-derived relaxing factor/NO. Circ Res. 2007;101:627-635.

37. MacAllister RJ, Parry H, Kimoto M, Ogawa T, Russell RJ, Hodson H, Whitley GS, Vallance P. Regulation of nitric oxide synthesis by dimethylarginine dimethylaminohydrolase. $\mathrm{Br} J$ Pharmacol. 1996;119:1533-1540.

38. Dayoub H, Achan V, Adimoolam S, Jacobi J, Stuehlinger MC, Wang BY, Tsao PS, Kimoto M, Vallance P, Patterson AJ, Cooke JP. Dimethylarginine dimethylaminohydrolase regulates nitric oxide synthesis: genetic and physiological evidence. Circulation. 2003;108:3042-3047.

39. Akbar F, Heinonen S, Pirskanen M, Uimari P, Tuomainen TP, Salonen JT. Haplotypic association of DDAH1 with susceptibility to pre-eclampsia. Mol Hum Reprod. 2005;11:73-77. 
40. Ito A, Tsao PS, Adimoolam S, Kimoto M, Ogawa T, Cooke JP. Novel mechanism for endothelial dysfunction: dysregulation of dimethylarginine dimethylaminohydrolase. Circulation. 1999;99:30923095.

41. Matsuguma K, Ueda S, Yamagishi S, Matsumoto $Y$, Kaneyuki U, Shibata R, Fujimura T, Matsuoka H, Kimoto M, Kato S, Imaizumi T, Okuda S. Molecular mechanism for elevation of asymmetric dimethylarginine and its role for hypertension in chronic kidney disease. J Am Soc Nephrol. 2006;17:2176-2183.

42. Pullamsetti S, Kiss L, Ghofrani HA, Voswinckel R, Haredza P, Klepetko W, Aigner C, Fink L, Muyal JP, Weissmann N, Grimminger F, Seeger W, Schermuly RT. Increased levels and reduced catabolism of asymmetric and symmetric dimethylarginines in pulmonary hypertension. FASEB J. 2005;19:11751177.

43. Tatematsu S, Wakino S, Kanda T, Homma K, Yoshioka K, Hasegawa K, Sugano N, Kimoto M, Saruta T, Hayashi K. Role of nitric oxide-producing and -degrading pathways in coronary endothelial dysfunction in chronic kidney disease. J Am Soc Nephrol. 2007;18:741-749.

44. Lee IS, Muragaki Y, Ideguchi T, Hase T, Tsuji M, Ooshima A, Okuno E, Kido R. Molecular cloning and sequencing of a cDNA encoding alanine-glyoxylate aminotransferase 2 from rat kidney. $J$ Biochem. 1995;117:856-862.

45. Rodionov RN, Murry DJ, Vaulman SF, Stevens JW, Lentz SR. Human alanine-glyoxylate aminotransferase 2 lowers asymmetric dimethylarginine and protects from inhibition of nitric oxide production. J Biol Chem. 2010;285:5385-5391.

46. Al Banchaabouchi M, Marescau B, Possemiers I, D'Hooge R, Levillain O, De Deyn PP. NG, NGdimethylarginine and NG, NG-dimethylarginine in renal insufficiency. Pflugers Arch. 2000;439:524531.

47. Carnegie PR, Fellows FC, Symington GR. Urinary excretion of methylarginine in human disease. Metabolism. 1977;26:531-537.

48. Kakimoto $\mathrm{Y}$, Akazawa S. Isolation and identification of N-G,N-G- and N-G,N'-G-dimethyl-arginine, Nepsilon-mono-, di-, and trimethyllysine, and glucosylgalactosyl- and galactosyl-delta-hydroxylysine from human urine. J Biol Chem. 1970;245:5751-5758.

49. MacAllister RJ, Rambausek MH, Vallance P, Williams D, Hoffmann KH, Ritz E. Concentration of dimethyl-L-arginine in the plasma of patients with end-stage renal failure. Nephrol Dial Transplant. 1996;11:2449-2452.

50. Marescau B, Nagels G, Possemiers I, De Broe ME, Becaus I, Billiouw JM, Lornoy W, De Deyn PP. Guanidino compounds in serum and urine of nondialyzed patients with chronic renal insufficiency. Metabolism. 1997;46:1024-1031.

51. Wu G, Morris SM, Jr. Arginine metabolism: nitric oxide and beyond. Biochem J. 1998;336 ( Pt 1):1-17.

52. Brosnan ME, Brosnan JT. Renal arginine metabolism. J Nutr. 2004;134:2791S-2795S; discussion 2796S2797S.

53. Nijveldt RJ, Van Leeuwen PA, Van Guldener C, Stehouwer CD, Rauwerda JA, Teerlink T. Net renal extraction of asymmetrical (ADMA) and symmetrical (SDMA) dimethylarginine in fasting humans. Nephrol Dial Transplant. 2002;17:1999-2002.

54. Kimoto $M$, Tsuji $H$, Ogawa $T$, Sasaoka $K$. Detection of NG,NG-dimethylarginine dimethylaminohydrolase in the nitric oxide-generating systems of rats using monoclonal antibody. Arch Biochem Biophys. 1993;300:657-662.

55. Tran CT, Fox MF, Vallance $P$, Leiper JM. Chromosomal localization, gene structure, and expression pattern of DDAH1: comparison with DDAH2 and implications for evolutionary origins. Genomics. 2000;68:101-105. 


\section{CHAPTER 1}

56. Hu X, Atzler D, Xu X, Zhang P, Guo H, Lu Z, Fassett J, Schwedhelm E, Boger RH, Bache RJ, Chen Y. Dimethylarginine dimethylaminohydrolase-1 is the critical enzyme for degrading the cardiovascular risk factor asymmetrical dimethylarginine. Arterioscler Thromb Vasc Biol. 2011;31:1540-1546.

57. Siroen MP, van der Sijp JR, Teerlink T, van Schaik C, Nijveldt RJ, van Leeuwen PA. The human liver clears both asymmetric and symmetric dimethylarginine. Hepatology. 2005;41:559-565.

58. Kielstein JT, Impraim B, Simmel S, Bode-Boger SM, Tsikas D, Frolich JC, Hoeper MM, Haller H, Fliser D. Cardiovascular effects of systemic nitric oxide synthase inhibition with asymmetrical dimethylarginine in humans. Circulation. 2004;109:172-177.

59. Kielstein JT, Simmel S, Bode-Boger SM, Roth HJ, Schmidt-Gayk H, Haller H, Fliser D. Subpressor dose asymmetric dimethylarginine modulates renal function in humans through nitric oxide synthase inhibition. Kidney Blood Press Res. 2004;27:143-147.

60. Boger RH, Sullivan LM, Schwedhelm E, Wang TJ, Maas R, Benjamin EJ, Schulze F, Xanthakis V, Benndorf RA, Vasan RS. Plasma asymmetric dimethylarginine and incidence of cardiovascular disease and death in the community. Circulation. 2009;119:1592-1600.

61. Cavusoglu E, Ruwende C, Chopra V, Poludasu S, Yanamadala S, Frishman WH, Eng C, Pinsky DJ, Marmur JD. Relation of baseline plasma ADMA levels to cardiovascular morbidity and mortality at two years in men with diabetes mellitus referred for coronary angiography. Atherosclerosis. 2010;210:226231.

62. Cavusoglu E, Ruwende C, Chopra V, Yanamadala S, Eng C, Pinsky DJ, Marmur JD. Relationship of baseline plasma ADMA levels to cardiovascular outcomes at 2 years in men with acute coronary syndrome referred for coronary angiography. Coron Artery Dis. 2009;20:112-117.

63. Kielstein JT, Bode-Boger SM, Hesse G, Martens-Lobenhoffer J, Takacs A, Fliser D, Hoeper MM. Asymmetrical dimethylarginine in idiopathic pulmonary arterial hypertension. Arterioscler Thromb Vasc Biol. 2005;25:1414-1418.

64. Lajer $M$, Tarnow L, Jorsal A, Teerlink T, Parving HH, Rossing P. Plasma concentration of asymmetric dimethylarginine (ADMA) predicts cardiovascular morbidity and mortality in type 1 diabetic patients with diabetic nephropathy. Diabetes Care. 2008;31:747-752.

65. Lu TM, Ding YA, Lin SJ, Lee WS, Tai HC. Plasma levels of asymmetrical dimethylarginine and adverse cardiovascular events after percutaneous coronary intervention. Eur Heart J. 2003;24:1912-1919.

66. Ravani P, Tripepi G, Malberti F, Testa S, Mallamaci F, Zoccali C. Asymmetrical dimethylarginine predicts progression to dialysis and death in patients with chronic kidney disease: a competing risks modeling approach. J Am Soc Nephrol. 2005;16:2449-2455.

67. Schnabel R, Blankenberg S, Lubos E, Lackner KJ, Rupprecht HJ, Espinola-Klein C, Jachmann N, Post F, Peetz D, Bickel C, Cambien F, Tiret L, Munzel T. Asymmetric dimethylarginine and the risk of cardiovascular events and death in patients with coronary artery disease: results from the AtheroGene Study. Circ Res. 2005;97:e53-59.

68. Young JM, Terrin N, Wang X, Greene T, Beck GJ, Kusek JW, Collins AJ, Sarnak MJ, Menon V. Asymmetric dimethylarginine and mortality in stages 3 to 4 chronic kidney disease. Clin J Am Soc Nephrol. 2009;4:1115-1120.

69. Leong T, Zylberstein D, Graham I, Lissner L, Ward D, Fogarty J, Bengtsson C, Bjorkelund C, Thelle D. Asymmetric dimethylarginine independently predicts fatal and nonfatal myocardial infarction and stroke in women: 24-year follow-up of the population study of women in Gothenburg. Arterioscler Thromb Vasc Biol. 2008;28:961-967.

70. Maas R, Quitzau K, Schwedhelm E, Spieker L, Rafflenbeul W, Steenpass A, Luscher TF, Boger RH. Asymmetrical dimethylarginine (ADMA) and coronary endothelial function in patients with coronary artery disease and mild hypercholesterolemia. Atherosclerosis. 2007;191:211-219.

71. Valkonen VP, Paiva H, Salonen JT, Lakka TA, Lehtimaki T, Laakso J, Laaksonen R. Risk of acute coronary events and serum concentration of asymmetrical dimethylarginine. Lancet. 2001;358:2127-2128. 
72. Wilson AM, Shin DS, Weatherby C, Harada RK, Ng MK, Nair N, Kielstein J, Cooke JP. Asymmetric dimethylarginine correlates with measures of disease severity, major adverse cardiovascular events and all-cause mortality in patients with peripheral arterial disease. Vasc Med. 2010;15:267-274.

73. Krzyzanowska K, Mittermayer F, Wolzt M, Schernthaner G. Asymmetric dimethylarginine predicts cardiovascular events in patients with type 2 diabetes. Diabetes Care. 2007;30:1834-1839.

74. Mittermayer F, Krzyzanowska K, Exner M, Mlekusch W, Amighi J, Sabeti S, Minar E, Muller M, Wolzt $M$, Schillinger $M$. Asymmetric dimethylarginine predicts major adverse cardiovascular events in patients with advanced peripheral artery disease. Arterioscler Thromb Vasc Biol. 2006;26:2536-2540.

75. Boger RH, Maas R, Schulze F, Schwedhelm E. Asymmetric dimethylarginine (ADMA) as a prospective marker of cardiovascular disease and mortality--an update on patient populations with a wide range of cardiovascular risk. Pharmacol Res. 2009;60:481-487.

76. Fliser D, Kronenberg F, Kielstein JT, Morath C, Bode-Boger SM, Haller H, Ritz E. Asymmetric dimethylarginine and progression of chronic kidney disease: the mild to moderate kidney disease study. J Am Soc Nephrol. 2005;16:2456-2461.

77. Aucella F, Maas R, Vigilante M, Tripepi G, Schwedhelm E, Margaglione M, Gesualdo L, Boeger R, Zoccali $C$. Methylarginines and mortality in patients with end stage renal disease: a prospective cohort study. Atherosclerosis. 2009;207:541-545.

78. Zoccali C, Bode-Boger S, Mallamaci F, Benedetto F, Tripepi G, Malatino L, Cataliotti A, Bellanuova I, Fermo I, Frolich J, Boger R. Plasma concentration of asymmetrical dimethylarginine and mortality in patients with end-stage renal disease: a prospective study. Lancet. 2001;358:2113-2117.

79. Kielstein JT, Boger RH, Bode-Boger SM, Schaffer J, Barbey M, Koch KM, Frolich JC. Asymmetric dimethylarginine plasma concentrations differ in patients with end-stage renal disease: relationship to treatment method and atherosclerotic disease. J Am Soc Nephrol. 1999;10:594-600.

80. Miyazaki H, Matsuoka H, Cooke JP, Usui M, Ueda S, Okuda S, Imaizumi T. Endogenous nitric oxide synthase inhibitor: a novel marker of atherosclerosis. Circulation. 1999;99:1141-1146.

81. Schulze F, Lenzen H, Hanefeld C, Bartling A, Osterziel KJ, Goudeva L, Schmidt-Lucke C, Kusus M, Maas R, Schwedhelm E, Strodter D, Simon BC, Mugge A, Daniel WG, Tillmanns H, Maisch B, Streichert T, Boger RH. Asymmetric dimethylarginine is an independent risk factor for coronary heart disease: results from the multicenter Coronary Artery Risk Determination investigating the Influence of ADMA Concentration (CARDIAC) study. Am Heart J. 2006;152:493 e491-498.

82. Boger RH, Bode-Boger SM, Thiele W, Creutzig A, Alexander K, Frolich JC. Restoring vascular nitric oxide formation by L-arginine improves the symptoms of intermittent claudication in patients with peripheral arterial occlusive disease. J Am Coll Cardiol. 1998;32:1336-1344.

83. Boger RH, Bode-Boger SM, Thiele W, Junker W, Alexander K, Frolich JC. Biochemical evidence for impaired nitric oxide synthesis in patients with peripheral arterial occlusive disease. Circulation. 1997;95:2068-2074.

84. Abbasi F, Asagmi T, Cooke JP, Lamendola C, McLaughlin T, Reaven GM, Stuehlinger M, Tsao PS. Plasma concentrations of asymmetric dimethylarginine are increased in patients with type 2 diabetes mellitus. Am J Cardiol. 2001;88:1201-1203.

85. Altinova AE, Arslan M, Sepici-Dincel A, Akturk M, Altan N, Toruner FB. Uncomplicated type 1 diabetes is associated with increased asymmetric dimethylarginine concentrations. J Clin Endocrinol Metab. 2007;92:1881-1885.

86. Eid HM, Eritsland J, Larsen J, Arnesen H, Seljeflot I. Increased levels of asymmetric dimethylarginine in populations at risk for atherosclerotic disease. Effects of pravastatin. Atherosclerosis. 2003;166:279284.

87. Sugai M, Ohta A, Ogata Y, Nakanishi M, Ueno S, Kawata T, Saito N, Tanaka Y. Asymmetric dimethylarginine (ADMA) in the aqueous humor of diabetic patients. Endocr J. 2007;54:303-309. 


\section{CHAPTER 1}

88. Huemer M, Simma B, Mayr D, Muhl A, Rami B, Schober E, Ulmer H, Zanier U, Bodamer OA. Low levels of asymmetric dimethylarginine in children with diabetes mellitus type I compared with healthy children. J Pediatr. 2011;158:602-606 e601.

89. Sibal L, Agarwal SC, Schwedhelm E, Luneburg N, Boger RH, Home PD. A study of endothelial function and circulating asymmetric dimethylarginine levels in people with Type 1 diabetes without macrovascular disease or microalbuminuria. Cardiovasc Diabetol. 2009;8:27.

90. Pettersson A, Hedner T, Milsom I. Increased circulating concentrations of asymmetric dimethyl arginine (ADMA), an endogenous inhibitor of nitric oxide synthesis, in preeclampsia. Acta Obstet Gynecol Scand. 1998;77:808-813.

91. Savvidou MD, Hingorani AD, Tsikas D, Frolich JC, Vallance $P$, Nicolaides $\mathrm{KH}$. Endothelial dysfunction and raised plasma concentrations of asymmetric dimethylarginine in pregnant women who subsequently develop pre-eclampsia. Lancet. 2003;361:1511-1517.

92. Saitoh M, Osanai $T$, Kamada $T$, Matsunaga $T$, Ishizaka $H$, Hanada H, Okumura K. High plasma level of asymmetric dimethylarginine in patients with acutely exacerbated congestive heart failure: role in reduction of plasma nitric oxide level. Heart Vessels. 2003;18:177-182.

93. Usui M, Matsuoka H, Miyazaki H, Ueda S, Okuda S, Imaizumi T. Increased endogenous nitric oxide synthase inhibitor in patients with congestive heart failure. Life Sci. 1998;62:2425-2430.

94. Gorenflo $\mathrm{M}$, Zheng $\mathrm{C}$, Werle $\mathrm{E}$, Fiehn W, Ulmer HE. Plasma levels of asymmetrical dimethyl-L-arginine in patients with congenital heart disease and pulmonary hypertension. J Cardiovasc Pharmacol. 2001;37:489-492.

95. O'Dwyer MJ, Dempsey F, Crowley V, Kelleher DP, McManus R, Ryan T. Septic shock is correlated with asymmetrical dimethyl arginine levels, which may be influenced by a polymorphism in the dimethylarginine dimethylaminohydrolase II gene: a prospective observational study. Crit Care. 2006;10:R139.

96. Selley ML. Increased (E)-4-hydroxy-2-nonenal and asymmetric dimethylarginine concentrations and decreased nitric oxide concentrations in the plasma of patients with major depression. J Affect Disord. 2004;80:249-256.

97. Yoo JH, Lee SC. Elevated levels of plasma homocyst(e)ine and asymmetric dimethylarginine in elderly patients with stroke. Atherosclerosis. 2001;158:425-430.

98. Mookerjee RP, Dalton RN, Davies NA, Hodges SJ, Turner C, Williams R, Jalan R. Inflammation is an important determinant of levels of the endogenous nitric oxide synthase inhibitor asymmetric dimethylarginine (ADMA) in acute liver failure. Liver Transpl. 2007;13:400-405.

99. Arlt S, Schulze F, Eichenlaub M, Maas R, Lehmbeck JT, Schwedhelm E, Jahn H, Boger RH. Asymmetrical dimethylarginine is increased in plasma and decreased in cerebrospinal fluid of patients with Alzheimer's disease. Dement Geriatr Cogn Disord. 2008;26:58-64.

100. Selley ML. Increased concentrations of homocysteine and asymmetric dimethylarginine and decreased concentrations of nitric oxide in the plasma of patients with Alzheimer's disease. Neurobiol Aging. 2003;24:903-907.

101. Abe T, Tohgi H, Murata T, Isobe C, Sato C. Reduction in asymmetrical dimethylarginine, an endogenous nitric oxide synthase inhibitor, in the cerebrospinal fluid during aging and in patients with Alzheimer's disease. Neurosci Lett. 2001;312:177-179.

102. Mulder C, Wahlund LO, Blomberg M, de Jong S, van Kamp GJ, Scheltens P, Teerlink T. Alzheimer's disease is not associated with altered concentrations of the nitric oxide synthase inhibitor asymmetric dimethylarginine in cerebrospinal fluid. J Neural Transm. 2002;109:1203-1208.

103. Hermenegildo C, Medina P, Peiro M, Segarra G, Vila JM, Ortega J, Lluch S. Plasma concentration of asymmetric dimethylarginine, an endogenous inhibitor of nitric oxide synthase, is elevated in hyperthyroid patients. J Clin Endocrinol Metab. 2002;87:5636-5640. 
104. Ozcan O, Cakir E, Yaman H, Akgul EO, Erturk K, Beyhan Z, Bilgi C, Erbil MK. The effects of thyroxine replacement on the levels of serum asymmetric dimethylarginine (ADMA) and other biochemical cardiovascular risk markers in patients with subclinical hypothyroidism. Clin Endocrinol (Oxf). 2005;63:203-206.

105. Kato GJ, Wang Z, Machado RF, Blackwelder WC, Taylor JGt, Hazen SL. Endogenous nitric oxide synthase inhibitors in sickle cell disease: abnormal levels and correlations with pulmonary hypertension, desaturation, haemolysis, organ dysfunction and death. Br J Haematol. 2009;145:506513.

106. Schnog JB, Teerlink T, van der Dijs FP, Duits AJ, Muskiet FA. Plasma levels of asymmetric dimethylarginine (ADMA), an endogenous nitric oxide synthase inhibitor, are elevated in sickle cell disease. Ann Hematol. 2005;84:282-286.

107. Goonasekera CD, Rees DD, Woolard P, Frend A, Shah V, Dillon MJ. Nitric oxide synthase inhibitors and hypertension in children and adolescents. J Hypertens. 1997;15:901-909.

108. Perticone F, Sciacqua A, Maio R, Perticone M, Maas R, Boger RH, Tripepi G, Sesti G, Zoccali C. Asymmetric dimethylarginine, L-arginine, and endothelial dysfunction in essential hypertension. $J$ Am Coll Cardiol. 2005;46:518-523.

109. Surdacki A, Nowicki M, Sandmann J, Tsikas D, Boeger RH, Bode-Boeger SM, Kruszelnicka-Kwiatkowska $\mathrm{O}$, Kokot F, Dubiel JS, Froelich JC. Reduced urinary excretion of nitric oxide metabolites and increased plasma levels of asymmetric dimethylarginine in men with essential hypertension. J Cardiovasc Pharmacol. 1999;33:652-658.

110. Boger RH, Bode-Boger SM, Szuba A, Tsao PS, Chan JR, Tangphao O, Blaschke TF, Cooke JP. Asymmetric dimethylarginine (ADMA): a novel risk factor for endothelial dysfunction: its role in hypercholesterolemia. Circulation. 1998;98:1842-1847.

111. Vladimirova-Kitova L, Deneva T, Angelova E, Nikolov F, Marinov B, Mateva N. Relationship of asymmetric dimethylarginine with flow-mediated dilatation in subjects with newly detected severe hypercholesterolemia. Clin Physiol Funct Imaging. 2008;28:417-425.

112. Boger RH, Lentz SR, Bode-Boger SM, Knapp HR, Haynes WG. Elevation of asymmetrical dimethylarginine may mediate endothelial dysfunction during experimental hyperhomocyst(e)inaemia in humans. Clin Sci (Lond). 2001;100:161-167.

113. Stuhlinger MC, Oka RK, Graf EE, Schmolzer I, Upson BM, Kapoor O, Szuba A, Malinow MR, Wascher TC, Pachinger O, Cooke JP. Endothelial dysfunction induced by hyperhomocyst(e)inemia: role of asymmetric dimethylarginine. Circulation. 2003;108:933-938.

114. Sydow K, Schwedhelm E, Arakawa N, Bode-Boger SM, Tsikas D, Hornig B, Frolich JC, Boger RH. ADMA and oxidative stress are responsible for endothelial dysfunction in hyperhomocyst(e)inemia: effects of L-arginine and B vitamins. Cardiovasc Res. 2003;57:244-252.

115. Kielstein JT, Boger RH, Bode-Boger SM, Frolich JC, Haller H, Ritz E, Fliser D. Marked increase of asymmetric dimethylarginine in patients with incipient primary chronic renal disease. J Am Soc Nephrol. 2002;13:170-176.

116. Arnal JF, Michel JB, Harrison DG. Nitric oxide in the pathogenesis of hypertension. Curr Opin Nephrol Hypertens. 1995;4:182-188.

117. Dominiczak AF, Bohr DF. Nitric oxide and its putative role in hypertension. Hypertension. 1995;25:1202-1211.

118. Forstermann U. Nitric oxide and oxidative stress in vascular disease. Pflugers Arch. 2010;459:923-939.

119. MacAllister R, Vallance P. Nitric oxide in essential and renal hypertension. J Am Soc Nephrol. 1994;5:1057-1065.

120. Ruilope LM, Lahera V, Rodicio JL, Romero JC. Participation of nitric oxide in the regulation of renal function: possible role in the genesis of arterial hypertension. J Hypertens. 1994;12:625-631. 


\section{CHAPTER 1}

121. Campese VM, Amar M, Anjali C, Medhat T, Wurgaft A. Effect of L-arginine on systemic and renal haemodynamics in salt-sensitive patients with essential hypertension. J Hum Hypertens. 1997;11:527532.

122. Campese VM, Tawadrous M, Bigazzi R, Bianchi S, Mann AS, Oparil S, Raij L. Salt intake and plasma atrial natriuretic peptide and nitric oxide in hypertension. Hypertension. 1996;28:335-340.

123. Fujiwara N, Osanai $T$, Kamada $T$, Katoh $T$, Takahashi K, Okumura K. Study on the relationship between plasma nitrite and nitrate level and salt sensitivity in human hypertension : modulation of nitric oxide synthesis by salt intake. Circulation. 2000;101:856-861.

124. Osanai T, Fujiwara N, Saitoh M, Sasaki S, Tomita H, Nakamura M, Osawa H, Yamabe H, Okumura K. Relationship between salt intake, nitric oxide and asymmetric dimethylarginine and its relevance to patients with end-stage renal disease. Blood Purif. 2002;20:466-468.

125. Kielstein JT, Bode-Boger SM, Frolich JC, Ritz E, Haller H, Fliser D. Asymmetric dimethylarginine, blood pressure, and renal perfusion in elderly subjects. Circulation. 2003;107:1891-1895.

126. Juonala M, Viikari JS, Alfthan G, Marniemi J, Kahonen M, Taittonen L, Laitinen T, Raitakari OT. Brachial artery flow-mediated dilation and asymmetrical dimethylarginine in the cardiovascular risk in young Finns study. Circulation. 2007;116:1367-1373.

127. Nanayakkara PW, Teerlink T, Stehouwer CD, Allajar D, Spijkerman A, Schalkwijk C, ter Wee PM, van Guldener C. Plasma asymmetric dimethylarginine (ADMA) concentration is independently associated with carotid intima-media thickness and plasma soluble vascular cell adhesion molecule-1 (sVCAM-1) concentration in patients with mild-to-moderate renal failure. Kidney Int. 2005;68:2230-2236.

128. Matsuoka H, Itoh S, Kimoto M, Kohno K, Tamai O, Wada Y, Yasukawa H, Iwami G, Okuda S, Imaizumi T. Asymmetrical dimethylarginine, an endogenous nitric oxide synthase inhibitor, in experimental hypertension. Hypertension. 1997;29:242-247.

129. Guzik TJ, West NE, Black E, McDonald D, Ratnatunga C, Pillai R, Channon KM. Vascular superoxide production by $\mathrm{NAD}(\mathrm{P}) \mathrm{H}$ oxidase: association with endothelial dysfunction and clinical risk factors. Circ Res. 2000;86:E85-90.

130. Schulman IH, Zhou MS, Raij L. Nitric oxide, angiotensin II, and reactive oxygen species in hypertension and atherogenesis. Curr Hypertens Rep. 2005;7:61-67.

131. Blum A, Hathaway L, Mincemoyer R, Schenke WH, Kirby M, Csako G, Waclawiw MA, Panza JA, Cannon RO, 3rd. Effects of oral L-arginine on endothelium-dependent vasodilation and markers of inflammation in healthy postmenopausal women. J Am Coll Cardiol. 2000;35:271-276.

132. Chin-Dusting JP, Kaye DM, Lefkovits J, Wong J, Bergin P, Jennings GL. Dietary supplementation with Larginine fails to restore endothelial function in forearm resistance arteries of patients with severe heart failure. J Am Coll Cardiol. 1996;27:1207-1213.

133. Preli RB, Klein KP, Herrington DM. Vascular effects of dietary L-arginine supplementation. Atherosclerosis. 2002;162:1-15.

134. Leiper J, Nandi M. The therapeutic potential of targeting endogenous inhibitors of nitric oxide synthesis. Nat Rev Drug Discov. 2011;10:277-291.

135. Wadham C, Mangoni AA. Dimethylarginine dimethylaminohydrolase regulation: a novel therapeutic target in cardiovascular disease. Expert Opin Drug Metab Toxicol. 2009;5:303-319.

136. Delles C, Jacobi J, John S, Fleischmann I, Schmieder RE. Effects of enalapril and eprosartan on the renal vascular nitric oxide system in human essential hypertension. Kidney Int. 2002;61:1462-1468.

137. Ito A, Egashira K, Narishige T, Muramatsu K, Takeshita A. Renin-angiotensin system is involved in the mechanism of increased serum asymmetric dimethylarginine in essential hypertension. Jpn Circ J. 2001;65:775-778.

138. Ito A, Egashira K, Narishige T, Muramatsu K, Takeshita A. Angiotensin-converting enzyme activity is involved in the mechanism of increased endogenous nitric oxide synthase inhibitor in patients with type 2 diabetes mellitus. Circ J. 2002;66:811-815. 
139. Chen JW, Hsu NW, Wu TC, Lin SJ, Chang MS. Long-term angiotensin-converting enzyme inhibition reduces plasma asymmetric dimethylarginine and improves endothelial nitric oxide bioavailability and coronary microvascular function in patients with syndrome X. Am J Cardiol. 2002;90:974-982.

140. Napoli C, Sica V, de Nigris F, Pignalosa O, Condorelli M, Ignarro L, Liguori A. Sulfhydryl angiotensinconverting enzyme inhibition induces sustained reduction of systemic oxidative stress and improves the nitric oxide pathway in patients with essential hypertension. Am Heart J. 2004;148:e5.

141. Yilmaz MI, Saglam M, Sonmez A, Caglar K, Cakir E, Kurt Y, Eyileten T, Tasar M, Acikel C, Oguz Y, Vural A, Yenicesu M. Improving proteinuria, endothelial functions and asymmetric dimethylarginine levels in chronic kidney disease: ramipril versus valsartan. Blood Purif. 2007;25:327-335.

142. Aslam S, Santha T, Leone A, Wilcox C. Effects of amlodipine and valsartan on oxidative stress and plasma methylarginines in end-stage renal disease patients on hemodialysis. Kidney Int. 2006;70:2109-2115.

143. Tomiyama H, Yamada J, Koji Y, Shiina K, Yoshida M, Yamashina A. Effect of telmisartan on forearm postischemic hyperemia and serum asymmetric dimethylarginine levels. Am J Hypertens. 2007;20:1305-1311.

144. Xie QY, Wang YJ, Sun ZL, Yang TL. Effects of valsartan and indapamide on plasma cytokines in essential hypertension. Zhong Nan Da Xue Xue Bao Yi Xue Ban. 2006;31:629-634.

145. Oguz A, Uzunlulu M. Short term fluvastatin treatment lowers serum asymmetric dimethylarginine levels in patients with metabolic syndrome. Int Heart J. 2008;49:303-311.

146. Pasini AF, Garbin U, Stranieri C, Boccioletti V, Mozzini C, Manfro S, Pasini A, Cominacini M, Cominacini L. Nebivolol treatment reduces serum levels of asymmetric dimethylarginine and improves endothelial dysfunction in essential hypertensive patients. Am J Hypertens. 2008;21:1251-1257.

147. Alfieri AB, Briceno L, Fragasso G, Spoladore R, Palloshi A, Bassanelli G, Montano C, Arioli F, Cuko A, Ruotolo G, Margonato $A$. Differential long-term effects of carvedilol on proinflammatory and antiinflammatory cytokines, asymmetric dimethylarginine, and left ventricular function in patients with heart failure. J Cardiovasc Pharmacol. 2008;52:49-54.

148. Sen N, Tavil Y, Erdamar H, Yazici HU, Cakir E, Akgul EO, Bilgi C, Erbil MK, Poyraz F, Okyay K, Turfan M, Cemri M. Nebivolol therapy improves endothelial function and increases exercise tolerance in patients with cardiac syndrome X. Anadolu Kardiyol Derg. 2009;9:371-379.

149. Janatuinen $T$, Laakso J, Laaksonen R, Vesalainen R, Nuutila P, Lehtimaki T, Raitakari OT, Knuuti J. Plasma asymmetric dimethylarginine modifies the effect of pravastatin on myocardial blood flow in young adults. Vasc Med. 2003;8:185-189.

150. Paiva H, Laakso J, Lehtimaki T, Isomustajarvi M, Ruokonen I, Laaksonen R. Effect of high-dose statin treatment on plasma concentrations of endogenous nitric oxide synthase inhibitors. J Cardiovasc Pharmacol. 2003;41:219-222.

151. Panichi V, Mantuano E, Paoletti S, Santi S, Manca Rizza G, Cutrupi S, Pizzini P, Spoto B, Tripepi G, Zoccali C. Effect of simvastatin on plasma asymmetric dimethylarginine concentration in patients with chronic kidney disease. J Nephrol. 2008;21:38-44.

152. Young JM, Strey CH, George PM, Florkowski CM, Sies CW, Frampton CM, Scott RS. Effect of atorvastatin on plasma levels of asymmetric dimethylarginine in patients with non-ischaemic heart failure. Eur J Heart Fail. 2008;10:463-466.

153. Pereira EC, Bertolami MC, Faludi AA, Salem M, Bersch D, Abdalla DS. Effects of simvastatin and Larginine on vasodilation, nitric oxide metabolites and endogenous NOS inhibitors in hypercholesterolemic subjects. Free Radic Res. 2003;37:529-536.

154. Lu TM, Ding YA, Leu HB, Yin WH, Sheu WH, Chu KM. Effect of rosuvastatin on plasma levels of asymmetric dimethylarginine in patients with hypercholesterolemia. Am J Cardiol. 2004;94:157-161. 


\section{CHAPTER 1}

155. Vladimirova-Kitova LG, Deneva TI, Marinov B. Effect of moderate and high-dose simvastatin on asymmetric dimethylarginine-homocysteine metabolic pathways in patients with newly detected severe hypercholesterolemia. Cardiovasc Ther. 2011;29:340-348.

156. Dierkes J, Westphal S, Martens-Lobenhoffer J, Luley C, Bode-Boger SM. Fenofibrate increases the Larginine:ADMA ratio by increase of L-arginine concentration but has no effect on ADMA concentration. Atherosclerosis. 2004;173:239-244.

157. Nakamura T, Sato E, Fujiwara N, Kawagoe Y, Ueda Y, Suzuki T, Ueda S, Adachi H, Okuda S, Yamagishi S. Ezetimibe decreases serum levels of asymmetric dimethylarginine (ADMA) and ameliorates renal injury in non-diabetic chronic kidney disease patients in a cholesterol-independent manner. Pharmacol Res. 2009;60:525-528.

158. Yang TL, Chen MF, Xia X, Luo BL, Li YJ. Effect of fenofibrate on the level of asymmetric dimethylarginine in individuals with hypertriglyceridemia. Eur J Clin Pharmacol. 2006;62:179-184.

159. Bunck MC, Giltay EJ, Diamant M, Gooren LJ, Teerlink T. Differential effects of cross-sex hormonal treatment on plasma asymmetric dimethylarginine (ADMA) in healthy male-to-female and female-tomale transsexuals. Atherosclerosis. 2009;206:245-250.

160. Charitidou C, Farmakiotis D, Zournatzi V, Pidonia I, Pegiou T, Karamanis N, Hatzistilianou M, Katsikis I, Panidis D. The administration of estrogens, combined with anti-androgens, has beneficial effects on the hormonal features and asymmetric dimethyl-arginine levels, in women with the polycystic ovary syndrome. Atherosclerosis. 2008;196:958-965.

161. Kilic S, Yilmaz N, Erdogan G, Aydin M, Tasdemir N, Doganay M, Batioglu S. Effect of non-oral estrogen on risk markers for metabolic syndrome in early surgically menopausal women. Climacteric. 2010;13:55-62.

162. Leifke E, Kinzel M, Tsikas D, Gooren L, Frolich JC, Brabant G. Effects of normalization of plasma testosterone levels in hypogonadal men on plasma levels and urinary excretion of asymmetric dimethylarginine (ADMA). Horm Metab Res. 2008;40:56-59.

163. Teerlink T, Neele SJ, de Jong S, Netelenbos JC, Stehouwer CD. Oestrogen replacement therapy lowers plasma levels of asymmetrical dimethylarginine in healthy postmenopausal women. Clin Sci (Lond). 2003;105:67-71.

164. Verhoeven MO, Teerlink $T$, Kenemans $P$, Vogelvang TE, van der Mooren MJ. Effects on asymmetric dimethylarginine of HMR 3339, a novel selective estrogen receptor modulator: a 12-week, randomized, placebo-controlled, double-blind, dose-ranging study in healthy postmenopausal women. Menopause. 2007;14:235-242.

165. Gao HW, Xie C, Wang HN, Lin YJ, Hong TP. Beneficial metabolic effects of nateglinide versus acarbose in patients with newly-diagnosed type 2 diabetes. Acta Pharmacol Sin. 2007;28:534-539.

166. Kelly AS, Thelen AM, Kaiser DR, Gonzalez-Campoy JM, Bank AJ. Rosiglitazone improves endothelial function and inflammation but not asymmetric dimethylarginine or oxidative stress in patients with type 2 diabetes mellitus. Vasc Med. 2007;12:311-318.

167. Mittermayer F, Schaller G, Pleiner J, Krzyzanowska K, Kapiotis S, Roden M, Wolzt M. Rosiglitazone prevents free fatty acid-induced vascular endothelial dysfunction. J Clin Endocrinol Metab. 2007;92:2574-2580.

168. Asagami T, Abbasi F, Stuelinger M, Lamendola C, McLaughlin T, Cooke JP, Reaven GM, Tsao PS. Metformin treatment lowers asymmetric dimethylarginine concentrations in patients with type 2 diabetes. Metabolism. 2002;51:843-846.

169. Ozgurtas T, Oktenli C, Dede M, Tapan S, Kenar L, Sanisoglu SY, Yesilova Z, Yenen MC, Erbil MK, Baser I. Metformin and oral contraceptive treatments reduced circulating asymmetric dimethylarginine (ADMA) levels in patients with polycystic ovary syndrome (PCOS). Atherosclerosis. 2008;200:336-344. 
170. Wang TD, Chen WJ, Cheng WC, Lin JW, Chen MF, Lee YT. Relation of improvement in endotheliumdependent flow-mediated vasodilation after rosiglitazone to changes in asymmetric dimethylarginine, endothelin-1, and C-reactive protein in nondiabetic patients with the metabolic syndrome. Am J Cardiol. 2006;98:1057-1062. 



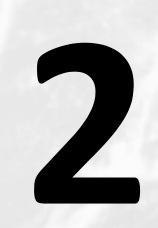

Predictors of clinical outcome after stent placement in atherosclerotic renal artery stenosis: a systematic review and meta-analysis of prospective studies

Rianne A. Ronden Alfons J.H.M. Houben

Alfons G. Kessels Coen D.A. Stehouwer Peter W. de Leeuw Abraham A. Kroon

J Hypertens 28: 2370-2377, 2010 


\section{ABSTRACT}

Objective - To determine clinical predictors for blood pressure and/or renal function improvement after renal artery stent placement in atherosclerotic renal artery stenosis (ARAS).

Method - We searched PubMed, EMBASE and Cochrane databases for prospective studies investigating clinical predictive variables for renal function and/or blood pressure improvement after stent placement in ARAS. Eleven studies (1552 participants) were selected for our systematic review and meta-analysis. Meta-regression analysis was performed to investigate heterogeneity and to determine independent predictors for the outcome variables. Bias was evaluated by use of the Cochrane risk of bias tool.

Results - Multivariate meta-regression analysis showed no predictors for renal function improvement. High baseline diastolic blood pressure (DBP) and pulse pressure were significantly associated with the decrease in blood pressure after intervention. These results were consistent with the predictors reported by the individual studies. Meta-analysis showed a nonsignificant decline in serum creatinine of $4.7 \mu \mathrm{mol} / /$ [ $95 \%$ confidence interval (Cl) -13.8 to 4.5 ]. Overall, systolic blood pressure (SBP) fell by $19.2 \mathrm{mmHg}(95 \% \mathrm{Cl}-22.7$ to -15.7$)$ and DBP decreased 8.9 $\mathrm{mmHg}(95 \% \mathrm{Cl}-10.8$ to -7.0$)$. Risk of bias was present in the majority of the studies.

Conclusion - The present review did not find a clinical characteristic that reliably predicts renal function outcome. High baseline pulse pressure predicted a smaller decrease in SBP after intervention and the best clinical predictor for a larger DBP reduction was a high pretreatment DBP. 


\section{INTRODUCTION}

Atherosclerotic renal artery stenosis (ARAS) is an important cause of renal dysfunction and secondary hypertension. ${ }^{1}$ Moreover, ARAS is associated with adverse cardiovascular events and increased mortality, independent of other conventional cardiovascular risk factors. ${ }^{2}$

The best approach towards treating ARAS is still a matter of debate. Therapeutical options include medical therapy and revascularization procedures. During the last two decades percutaneous transluminal renal angioplasty (PTRA) has been proven to be an efficient and well tolerated treatment for renovascular hypertension and renal function salvation, in comparison to surgical intervention. ${ }^{3,4}$ Despite high technical success percentages, PTRA, with or without stenting, fails in $20-40 \%$ of all treated patients to improve blood pressure or renal function. ${ }^{5}$ Therefore, the question is whether PTRA with stenting (PTRAS) is truly superior compared to aggressive medical therapy.

Several large randomized controlled trials (RCTs) have evaluated medical therapy versus PTRAS. ${ }^{6-8}$ The results of the STAR study showed no difference in progression of renal failure in patients with impaired renal function. ${ }^{6}$ This has been confirmed by the results of the ASTRAL study. ${ }^{8}$ A possible explanation for these findings is that these studies included patients who had little chance to improve anyway. Prior efforts to identify predictive factors that could differentiate between responders and nonresponders to PTRAS using several functional and imaging techniques have been disappointing. None of the investigated techniques could fulfill a satisfactory role as an outcome predictor. $^{9-12}$

Therefore, the aim of our systematic review was to evaluate, from prospective studies, whether clinical characteristics can predict improvement of blood pressure or renal function following renal artery stent placement in ARAS after a sufficiently long followup period.

\section{METHODS}

We performed our study according to the Preferred Reporting Items for Systematic reviews and Meta-Analyses (PRISMA) statement for studies that evaluate healthcare interventions. $^{13}$

\section{Search strategy and study selection}

We extensively searched the PubMed, EMBASE and Cochrane databases using the following terms: hypertension, renovascular or reno* hypertension* or renal artery obstruction or renal artery stenosis or atherosclerotic renal disease or atherosclerotic renovascular disease and PTRA or percutaneous transluminal renal angioplasty or 
angioplasty, balloon or stent* or revascularization and outcome. The starting date was determined as January 1991 and the search was updated until January 2010. Only studies published in English, German, French, or Dutch were selected. Articles were identified by means of titles and abstracts. Two reviewers (R.A.R. and A.A.K.) screened the abstracts of the selected articles according to a priori retrieved inclusion and exclusion criteria. The reference lists of the obtained articles and relevant reviews were hand searched for additional articles. If studies were based on the same population, the most recent published work or most suitable study for our research question was included.

\section{Articles were included in the systematic review if they fulfilled the following criteria}

1) The intervention for restoring lumen patency ( $\geq 50 \%$ stenosis) in unilateral, bilateral or solitary functioning kidneys with ARAS consisted of PTRAS without the use of a distal embolic protection device. 2) The inclusion of patients was consecutive and follow-up data were prospectively obtained after at least 6 months. 3) The indication for PTRAS was refractory hypertension, renal function deterioration or both and at least $90 \%$ of the population was hypertensive (blood pressure $>140 / 90 \mathrm{mmHg}$ or the use of antihypertensive medication). 4) Absolute blood pressures in $\mathrm{mmHg}$, serum creatinine concentrations ( $\mathrm{s} \mathrm{Cr}$ ) or estimated creatinine clearances (Cockcroft-Gault formula) were reported before and after intervention. 5) Predictors for blood pressure and/or renal function outcome had been statistically evaluated.

Studies were excluded when less than 25 patients were described at follow-up, in case ARAS was located in a transplant kidney or when other interventions (surgical revascularization, PTRA without stenting or medical therapy) than PTRAS had been investigated. Additionally, we analyzed studies fulfilling all inclusion criteria except for the prospective design.

\section{Data extraction}

Two reviewers (R.A.R. and A.A.K.) extracted all relevant data by use of a standardized form. From the selected studies, when available, the following data were extracted: patient selection criteria, lesion characteristics, antihypertensive medication use, complications, duration of follow-up, predictors of favorable outcome, and potential confounders.

\section{Risk of bias and data analysis}

Risk of bias was independently assessed by two of the authors (R.A.R. and A.A.K.); discrepancies between the two authors were resolved by consensus. We used the Cochrane risk of bias tool to quantify the studies as having low, unclear or high risk of 
bias. ${ }^{14}$ This risk of bias tool was originally designed for controlled studies, but we adapted the tool for the use of our noncontrolled intervention studies. The domains for risk of bias that we considered were: selection, treatment indication and outcome definitions, description of loss to follow-up, reporting outcome data and availability of intention-to-treat analysis. In case of RCTs, allocation sequence and blinding were additionally evaluated.

We performed a meta-analysis to determine the overall mean effect of PTRAS on blood pressure and renal function. Meta-regression analysis was used to investigate possible sources of heterogeneity and to identify predictors for renal function and/or blood pressure improvement. Before data pooling, the individual study standard errors of difference in means for $\mathrm{sCr}$, systolic blood pressure (SBP) and diastolic blood pressure (DBP) were calculated at mean follow-up time after intervention. One study did not provide standard deviations (SDs); in that case we imputed the mean SD of all included studies. To calculate the overall effect of the intervention on blood pressure and renal function, studies were weighted by inverse variances, using either a fixed or a random-effects model, depending on the presence of heterogeneity (Cochran's $Q$ statistic test, $\mathrm{P}$ value for significance; 0.10 or a $\mathrm{I}^{2}$ statistic of more than $50 \%$ ). We considered the following variables (design and population-dependent) as possible sources of heterogeneity and separately entered them into the meta-regression model: publication year, number of participants included, the follow-up period, loss to follow-up (\%), lesion characteristics (unilateral or bilateral, ostial or nonostial) and patient characteristics (age, cardiovascular co morbidity, diabetes mellitus, smoking, baseline blood pressure, pulse pressure and $\mathrm{s}(\mathrm{C}$ ). Due to missing data, we could not investigate all possible a priori defined sources. Furthermore, univariate and multivariate regression analyses were performed using the clinical covariates mentioned above. The selection criteria for multivariate regression analysis were based on univariate statistical significance. A P value less than 0.05 was considered significant.

Potential publication bias was assessed with the Egger test and represented graphically by use of funnel plots, plotting the effect size ( $\Delta$ blood pressure and $\Delta \mathrm{sCr}$ ) against the standard error. ${ }^{15}$ We contacted several corresponding authors for additional information but none of them responded. For statistical analyses we applied the STATA statistical program version 10.0 (StataCorp, College Station, Texas, USA), with the latest updates. 


\section{RESULTS}

Figure 2.1 illustrates the search strategy and selection process. We screened 890 published studies from PubMed. Subsequent searches in EMBASE, Cochrane Databases and reference lists of articles provided two additional relevant articles. Full text was successfully retrieved for all eligible studies. We excluded 14 studies that fulfilled all inclusion criteria other than a statistical analysis for outcome predictors (Figure 2.1). ${ }^{6,8,16-27}$ Eventually, 11 studies (1552 participants) were included in the present analysis. Table 2.1 summarizes the study, patient and lesion characteristics of the selected studies. ${ }^{28-38}$ Two were qualified as (randomized) controlled trials, ${ }^{30,38}$ others were observational studies. ${ }^{10,12,28,29,31-37}$ The mean follow-up period ranged from $6^{30}$ to 48 months. $^{35}$ All studies except one ${ }^{30}$ performed follow-up measurements after 12 months or more. The percentage of patients available for follow-up varied between 76 and $100 \%$ in most studies (Table 2.1). However, Zeller et al. ${ }^{35}$ reported percentages of only 28 and $33 \%$ for blood pressure and renal function outcome, respectively. These lower numbers are presumably due to a longer follow-up time.

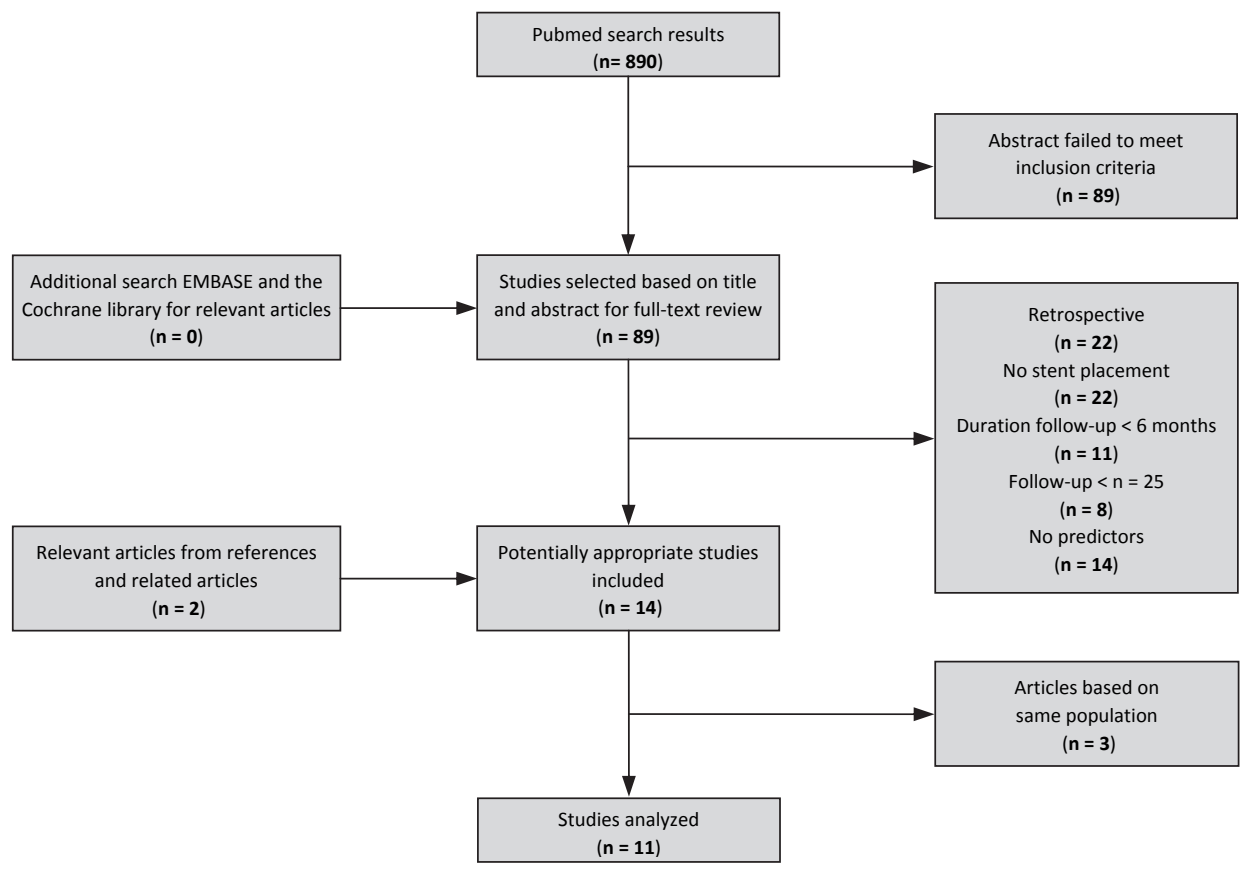

Figure 2.1 Search and selection of studies 


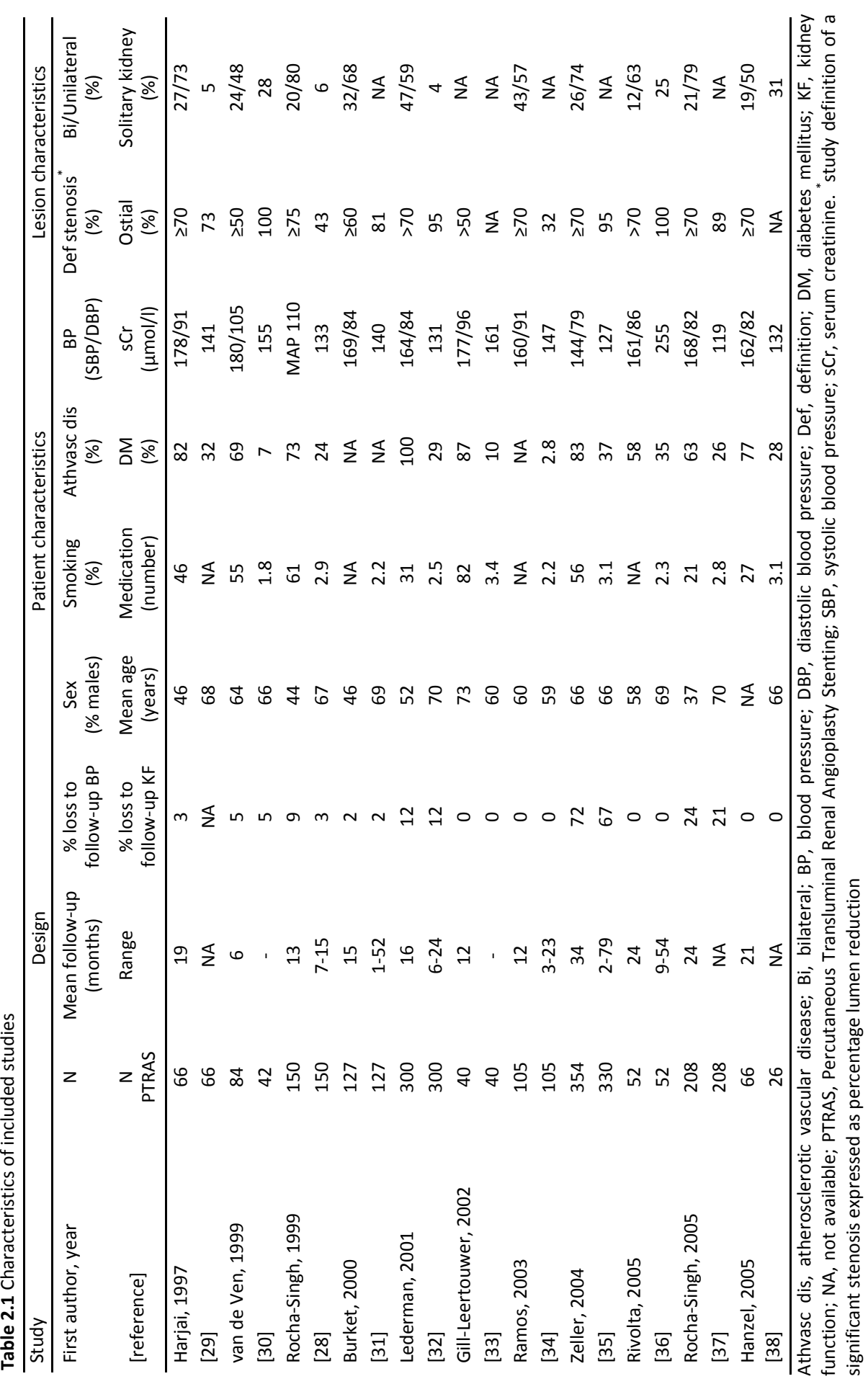




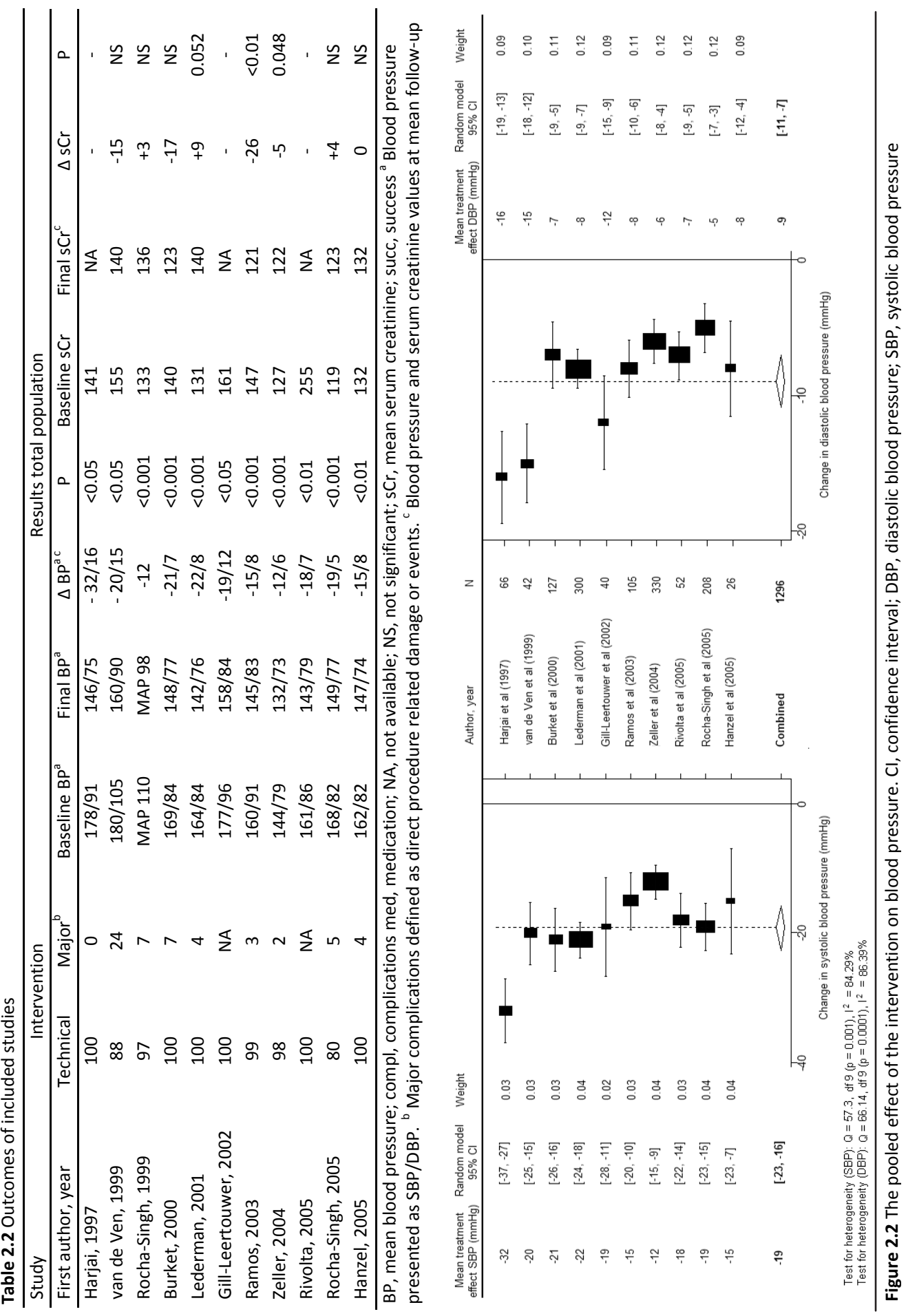




\section{Risk of bias}

The quality of the different study designs and reporting was variable. The domains 'selection' and 'treatment indication', and 'outcome definitions' constitute a plausible risk of bias that influenced the outcome of individual studies and the calculated overall effect size. Most studies described percentages of loss to follow-up but only 5 out of 11 reported the reasons. Three studies adhered to an intention-to-treat analysis; in others it was not clearly mentioned. ${ }^{30,31,37}$ The item reporting 'outcome' scored better with a majority score of low risk of bias. However, considering the focus of most studies on one outcome variable (renal function or blood pressure), the results were not always complete. The single RCT generated and concealed the allocation sequence sufficiently. ${ }^{30}$ The intended blinding of the analyzing personal was adequate. The funnel plot of the effect size (difference in SBP, DBP or creatinine) plotted against the standard error of the effect size indicated a low chance of an important publication bias (data not shown).

\section{Study and patient characteristics}

Table 2.1 shows the characteristics of included studies. The median blood pressure at baseline was 166/85 $\mathrm{mmHg}$ under medical treatment. The average $\mathrm{sCr}$ before intervention ranged from high normal to evidently increased (131-255 $\mu \mathrm{mol} / \mathrm{l})$. The indication for intervention varied between the different studies. Usually, the indication was (refractory) hypertension ${ }^{38}$ or a combination of hypertension and the prevention of further renal deterioration. ${ }^{28-35,37}$ Only one study selected patients for PTRAS based on chronic renal failure alone. ${ }^{36}$ Generally, stent placement was performed as a primary intervention; however, some studies included substantial percentages of patients for secondary intervention. ${ }^{29,30,32,37}$ Restenosis after PTRA or technical failure were the main reasons for the second intervention with stent placement.

The angiographic definition of a hemodynamically significant stenosis differed from $50 \%$ to more than $75 \%$ reduction in lumen diameter (Table 2.1 ). In two studies only ostial lesions were treated. ${ }^{30,37}$ All studies included patients with unilateral as well as bilateral renal artery stenosis. The initial technical success rate was more than $95 \%$ in nine articles. ${ }^{28,29,31-36,38}$ Two studies achieved initial success below 90\% (Table 2.2). ${ }^{30,37}$. However, these two studies showed the highest percentages of secondary intervention after prior PTRA.

Major complications were defined as procedure-related damage or events. The majority of studies described the complication rates, the most frequently reported complications being hemorrhage (access site, renal or retroperitoneal), stent-related (thrombosis and migration), procedure-related events (stroke, myocardial infarction, embolism and death) or dialysis. Overall, major complication rates did not exceed $7 \%$. Nonetheless, one study showed a complication rate of $24 \%$ (Table 2.2 ). ${ }^{30}$ 


\section{Blood pressure and renal function results}

The absolute changes in blood pressure of the individual studies are presented in Table 2.2. Ten studies were eligible for pooling blood pressure effects (SBP and DBP) of the intervention. Overall, SBP and DBP dropped significantly in all studies with similar or lower amounts of medication. Random-effects modeling showed a significant average decrease of $19.2 \mathrm{mmHg}$ [95\% confidence interval $(\mathrm{Cl})-22.7$ to $-15.7, \mathrm{P}<0.001$ ] in SBP and $8.9 \mathrm{mmHg}(95 \% \mathrm{Cl}-10.8$ to $-7.0, \mathrm{P}<0.001)$ in DBP. Details are shown in Figure 2.2. However, the SBP and DBP effects varied substantially between individual studies and both the $Q$ tests $\left(P<0.001\right.$ for SBP and DBP) as the $I^{2}$ statistics (heterogeneity quantities 84.3 and $86.4 \%$ for SBP and DBP, respectively) confirmed significant heterogeneity between studies. Meta-regression analysis provided four major causes of heterogeneity: the publication year, baseline SBP and baseline DBP for the effect on DBP. The publication year, baseline SBP, and baseline pulse pressure were significant causes of heterogeneity for the effect on SBP. Combining these variables demonstrated a considerable reduction in the quantity of heterogeneity after correction, which remained nonetheless still substantial (45.9 and $38.64 \%$ for SBP and DBP, respectively).

Eight studies reported $\mathrm{sCr}$ at baseline and follow-up (Table 2.2). The pooled effect of the intervention on renal function (represented as change in $\mathrm{sCr}$ ) was $-4.7 \mu \mathrm{mol} / \mathrm{l}(95 \%$ $\mathrm{Cl}-13.8$ to $4.5, \mathrm{P}=0.3$ ), using a random-effects model (Figure 2.3). The change in $\mathrm{s} \mathrm{Cr}$ differed substantially between individual studies. $Q$ statistics demonstrated significant evidence of heterogeneity $(P<0.001)$ and $I^{2}$ statistics showed that $77.1 \%$ of the renal function effect was caused by heterogeneity between studies. Meta-regression analysis of study characteristics showed that baseline serum creatinine concentration and age could explain a substantial part of heterogeneity between individual studies. $\mathrm{I}^{2}$ statistics decreased to $17.0 \%$ after correcting for these variables.

\section{Outcome predictors from individual studies}

Table 2.3 shows the results of the analyses for predictors performed by the 11 individual studies included in this review. Nine out of 11 studies evaluated predictors for renal function improvement, defined by the difference in $\mathrm{sCr}$ between baseline and follow-up. ${ }^{28,30-37}$ Six described no significant predictors, ${ }^{28,30-32,36,37}$ whereas the other three found several independent predictors for renal function improvement (Table 2.3). ${ }^{33-35}$ Ten out of 11 studies evaluated predictors for blood pressure decrease. ${ }^{28-}$ $35,37,38$ Four found no significant predictors. ${ }^{29,32,33,37}$ However, six studies reported various predictors for blood pressure (Table 2.3). 


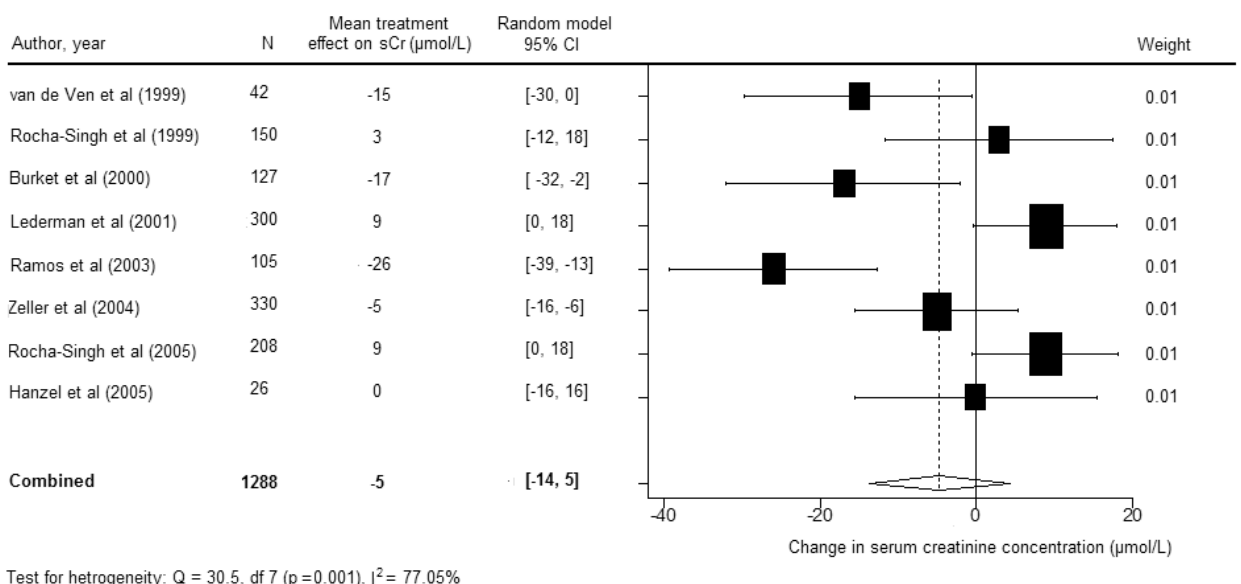

Figure 2.3 The pooled effect of the intervention on renal function. $\mathrm{Cl}$, confidence interval; sCR. serum creatinine

\section{Outcome predictors from the meta-regression analysis}

Univariate meta-regression analyses showed that the following clinical covariates were associated with the estimated PTRAS effect on blood pressure: baseline SBP (regression coefficient $0.36 ; 95 \% \mathrm{Cl} 0.10$ to $0.62, \mathrm{P}=0.01$ and $0.25 ; 95 \% \mathrm{Cl} 0.05$ to 0.44 , $\mathrm{P}=0.019$ for the effect on SBP and DBP, respectively), baseline DBP (regression coefficient $0.39 ; 95 \% \mathrm{Cl} 0.17$ to $0.60, \mathrm{P}=0.004$ for the effect on $\mathrm{DBP}$ ) and pulse pressure (regression coefficient $-0.53 ; 95 \% \mathrm{Cl}-0.89$ to $-0.16, \mathrm{P}=0.011$ for the effect on SBP). Age (regression coefficient $-2.87 ; 95 \% \mathrm{Cl}-5.12$ to $-0.62, \mathrm{P}=0.021$ ) and baseline $\mathrm{sCr}$ (regression coefficient $-0.90 ; 95 \% \mathrm{Cl}-1.62$ to $-0.19, \mathrm{P}=0.021$ ) were associated with the intervention effect on renal function. Multivariate analysis revealed that baseline pulse pressure (regression coefficient $-0.38 ; 95 \% \mathrm{Cl}-0.74$ to $0.02, \mathrm{P}=0.046$ ) was an independent negative predictor for the SBP effect. Furthermore, baseline DBP (regression coefficient $0.30 ; 95 \% \mathrm{Cl} 0.03$ to $0.63, \mathrm{P}=0.048$ ) was an independent positive predictor for the decrease in DBP after intervention. This indicates that patients with high pretreatment pulse pressures respond with a worse SBP reduction after intervention compared to patients with lower baseline pulse pressures, that is a 10 $\mathrm{mmHg}$ higher baseline pulse pressure results in a $3.8 \mathrm{mmHg}$ smaller SBP reduction. Patients with high baseline DBP respond with the largest DBP reduction, that is each 10 $\mathrm{mmHg}$ above a baseline DBP of $90 \mathrm{mmHg}$ results in $3.0 \mathrm{mmHg}$ more DBP decrease after intervention. No clinical covariate was significantly associated with renal function outcome after multivariate analysis. 
PREDICTORS OF ARAS TREATMENT OUTCOME

Table 2.3 Positive and negative predictors for renal or blood pressure outcome reported by individual studies

\begin{tabular}{lcc}
\hline & Positive predictor $(\mathrm{n})$ & Negative predictor $(\mathrm{n})$ \\
\hline No predictors & \multicolumn{2}{c}{ Blood pressure } \\
\cline { 2 - 3 } High baseline blood pressure & \multicolumn{2}{c}{4 studies [29,32,33,37] } \\
Bilateral lesions & $4[28,30,31,38]$ & - \\
Number of antihypertensive medication & $1[28]$ & - \\
Renal insufficiency & $1[35]$ & $1[34]$ \\
\hline & - & Negative predictor $(\mathrm{n})$ \\
\hline & Positive predictor (n) \\
No predictors & \multicolumn{2}{c}{ Renal function } \\
Renal insufficiency & \multicolumn{2}{c}{6 studies [28,30-32,36,37] } \\
History of cardiovascular disease & $2[34,35]$ & $1[35]$ \\
Bilateral lesions & - & - \\
\% Stenosis & $1[35]$ & - \\
\hline
\end{tabular}

n, number of studies

\section{DISCUSSION}

Our systematic review and meta-analysis of prospective studies has shown that PTRA and stenting significantly improves blood pressure in the average patient, whereas mean renal function stabilizes in selected ones, but overall does not improve significantly. Substantial risk of bias was present within and across studies. Heterogeneity in indication criteria, patient characteristics and outcome definitions can explain a large part of the differences in outcome. For renal function improvement there are no valid clinical predictors that could predict favorable outcome. This is in agreement with the results of the individual studies in which baseline renal insufficiency also proved inconclusive among studies as a negative or positive predictor for the renal function improvement. ${ }^{18-20}$ However, high pretreatment DBP is associated with a larger DBP reduction and high baseline pulse pressure is associated with a smaller SBP decrease after PTRA and stent placement. Furthermore, the individual study results confirm that high pretreatment blood pressure is an independent predictor for a larger blood pressure effect. ${ }^{13,15,16,23}$

\section{Strengths and limitations}

The literature review has several limitations. Similar to every systematic review consisting of noncontrolled published studies, our study results are probably influenced by selection bias (population and study-based). Heterogeneity and variable quality of the studies make a general conclusion about the effect size and predictors of outcome truly difficult. ${ }^{39}$ By the use of random-effect modeling, we tried to diminish the effects of heterogeneity to a certain extent. Moreover, the main reason we 
performed the meta-analysis was to investigate possible sources of heterogeneity between studies to explain the large differences in effect size. Particularly for renal function outcome, the meta-regression analyses for heterogeneity demonstrated that baseline population characteristics like age and baseline creatinine actually are relevant for the differences in effect size $\left(I^{2}\right.$ reduced from 71.1 to $\left.17 \%\right)$. Unfortunately, our analyses could not resolve the cause of discrepancies between studies concerning the question whether a deteriorated or good renal function favorably predicts renal function outcome. Balk et al. ${ }^{40}$ also investigated predictors for clinical outcome in a systematic review literature of the literature. They concluded that the evidence is insufficient to suggest whether clinical characteristics can predict renal outcome.

Another limitation is a nonstructured medication policy after intervention. Stricter medication policy, different classes of antihypertensive medication or higher doses of medication after intervention could explain the overall effect on blood pressure and renal function, but also the predictors for favorable outcome. Nevertheless, the medication number decreased or did not differ in all studies reporting medication use.

\section{Retrospective studies}

Additional analysis of seven retrospective studies (770 patients) that also met our inclusion criteria, but were not included in the data analysis, supported the results of predictors from our prospective studies and meta-regression analysis. ${ }^{41-47}$ Two smaller studies focused especially on renal salvage of solitary kidney renal artery stenosis. They reported age and extra-renal atherosclerotic disease as negative predictors and low baseline $\mathrm{sCr}$ as a positive predictor for renal function outcome. ${ }^{42,45}$ Among the other studies with mixed intervention indications, only one study investigated predictors for blood pressure outcome. This study reported high baseline blood pressure as an independent predictor for blood pressure outcome. ${ }^{46}$ Interesting, Dieter et al. ${ }^{47}$ showed high pulse pressure as predictor for worse blood pressure and renal outcome. They suggest that this simple clinical characteristic could reflect advanced vascular disease and stiffness in the renal vascular bed with irreversible pathologic changes. Our multivariate meta-regression analysis confirmed these findings for blood pressure. However, we could not reproduce the results concerning renal function. This discrepancy may be caused by a so-called 'ecological bias' resulting from the difference between individual patient versus group-level data regression analysis. ${ }^{48}$ In accordance with our prospective studies, the renal function outcome data from these retrospective studies were conflicting regarding the question whether a low or a high baseline serum creatinine predicts a beneficial renal outcome. ${ }^{41,43,44,46}$ 


\section{In context and future work}

So far, evidence from RCTs is limited supporting the benefit of renal stent placement over aggressive medical therapy alone. Renal function, blood pressure, risk of cardiovascular events or mortality did not significantly differ between groups after at least 1 year of follow-up. ${ }^{6,8}$ This is in contrast to our blood pressure findings, but also in contrast with the results of the single meta-analysis comparing RCTs of balloon angioplasty versus medical therapy. ${ }^{49}$ Although these ${ }^{6,8}$ recent large RCTs fulfill the highest criterion of evidence-based medicine, a selection bias, including patient selection, ${ }^{8}$ questionable functional relevance of the included stenoses ${ }^{50}$ and the use of different sorts of imaging techniques, ${ }^{51,52}$ could partly explain the modest results. Moreover, there is emerging evidence about ARAS causing subtle intrarenal hemodynamic alterations and inflammation even in an early disease stage that already permanently damages the renal vascular bed and parenchyma. Revascularization in a late stage of disease will obviously not lead to renal function salvation or blood pressure improvement. ${ }^{53}$ Therefore, analyses of subpopulations of these large trials should give additional patient-level information about which individual characteristics are associated with a better blood pressure and renal function response. Despite the limitations of the present systematic review and meta-analysis, our results indicate that careful selection of patients should improve blood pressure and renal function outcome after PTRAS. Analyses of clinical predictors and subpopulations in the recently published large RCTs and upcoming trials ${ }^{7,54}$ could define the PTRAS responders more robustly and give additional information about which patients are most likely to benefit. Until then, the question whether PTRA with stenting is really superior compared to aggressive medical therapy still remains unsatisfactorily answered. 


\section{CHAPTER 2}

\section{REFERENCES}

1. Safian RD, Textor SC. Renal-artery stenosis. N Engl J Med. 2001;344:431-442.

2. Edwards MS, Craven TE, Burke GL, Dean RH, Hansen KJ. Renovascular disease and the risk of adverse coronary events in the elderly: a prospective, population-based study. Arch Intern Med. 2005;165:207-213.

3. Alhadad A, Ahle M, Ivancev K, Gottsater A, Lindblad B. Percutaneous transluminal renal angioplasty (PTRA) and surgical revascularisation in renovascular disease--a retrospective comparison of results, complications, and mortality. Eur J Vasc Endovasc Surg. 2004;27:151-156.

4. Galaria, II, Surowiec SM, Rhodes JM, Illig KA, Shortell CK, Sternbach Y, Green RM, Davies MG. Percutaneous and open renal revascularizations have equivalent long-term functional outcomes. Ann Vasc Surg. 2005;19:218-228.

5. Leertouwer TC, Gussenhoven EJ, Bosch JL, van Jaarsveld BC, van Dijk LC, Deinum J, Man In 't Veld AJ. Stent placement for renal arterial stenosis: where do we stand? A meta-analysis. Radiology. 2000;216:78-85.

6. Bax L, Woittiez AJ, Kouwenberg HJ, Mali WP, Buskens E, Beek FJ, Braam B, Huysmans FT, Schultze Kool L, Rutten MJ, Doorenbos CJ, Aarts JC, Rabelink TJ, Plouin PF, Raynaud A, van Montfrans GA, Reekers JA, van den Meiracker AH, Pattynama PM, van de Ven PJ, Vroegindeweij D, Kroon AA, de Haan MW, Postma CT, Beutler JJ. Stent placement in patients with atherosclerotic renal artery stenosis and impaired renal function: a randomized trial. Ann Intern Med. 2009;150:840-848, W150-841.

7. Schwarzwalder $U$, Hauk M, Zeller T. RADAR - A randomised, multi-centre, prospective study comparing best medical treatment versus best medical treatment plus renal artery stenting in patients with haemodynamically relevant atherosclerotic renal artery stenosis. Trials. 2009;10:60.

8. Wheatley K, Ives N, Gray R, Kalra PA, Moss JG, Baigent C, Carr S, Chalmers N, Eadington D, Hamilton G, Lipkin $\mathrm{G}$, Nicholson A, Scoble J. Revascularization versus medical therapy for renal-artery stenosis. $N$ Engl J Med. 2009;361:1953-1962.

9. Zeller T, Muller C, Frank U, Burgelin K, Horn B, Schwarzwalder U, Cook-Bruns N, Neumann FJ. Stent angioplasty of severe atherosclerotic ostial renal artery stenosis in patients with diabetes mellitus and nephrosclerosis. Catheter Cardiovasc Interv. 2003;58:510-515.

10. Radermacher J, Chavan A, Bleck J, Vitzthum A, Stoess B, Gebel MJ, Galanski M, Koch KM, Haller H. Use of Doppler ultrasonography to predict the outcome of therapy for renal-artery stenosis. N Engl J Med. 2001;344:410-417.

11. Krijnen P, van Jaarsveld BC, Deinum J, Steyerberg EW, Habbema JD. Which patients with hypertension and atherosclerotic renal artery stenosis benefit from immediate intervention? J Hum Hypertens. 2004;18:91-96.

12. van Jaarsveld BC, Krijnen $P$, Pieterman $H$, Derkx FH, Deinum J, Postma CT, Dees A, Woittiez AJ, Bartelink AK, Man in 't Veld AJ, Schalekamp MA. The effect of balloon angioplasty on hypertension in atherosclerotic renal-artery stenosis. Dutch Renal Artery Stenosis Intervention Cooperative Study Group. N Engl J Med. 2000;342:1007-1014.

13. Liberati A, Altman DG, Tetzlaff J, Mulrow C, Gotzsche PC, loannidis JP, Clarke M, Devereaux PJ, Kleijnen J, Moher D. The PRISMA statement for reporting systematic reviews and meta-analyses of studies that evaluate health care interventions: explanation and elaboration. J Clin Epidemiol. 2009;62:e1-34.

14. Higgins J, Altman D. Cochrane handbook for systematic reviews of interventions version 5.0.0.Chapter 8: Assessing risk of bias in included studies. In: Collaboration TC, ed; 2008.

15. Egger M, Smith G, Altman D. Systematic reviews in health care: meta-analysis in context. 2001;

16. Blum U, Krumme B, Flugel P, Gabelmann A, Lehnert T, Buitrago-Tellez C, Schollmeyer P, Langer M. Treatment of ostial renal-artery stenoses with vascular endoprostheses after unsuccessful balloon angioplasty. N Engl J Med. 1997;336:459-465. 
17. Bucek RA, Puchner S, Reiter M, Dirisamer A, Minar E, Lammer J. Long-term follow-up after renal artery stenting. Wien Klin Wochenschr. 2003;115:788-792.

18. Dangas G, Laird JR, Jr., Mehran R, Lansky AJ, Mintz GS, Leon MB. Intravascular ultrasound-guided renal artery stenting. J Endovasc Ther. 2001;8:238-247.

19. Dorros G, Jaff M, Mathiak L, He T. Multicenter Palmaz stent renal artery stenosis revascularization registry report: four-year follow-up of 1,058 successful patients. Catheter Cardiovasc Interv. 2002;55:182-188.

20. Gray BH, Olin JW, Childs MB, Sullivan TM, Bacharach JM. Clinical benefit of renal artery angioplasty with stenting for the control of recurrent and refractory congestive heart failure. Vasc Med. 2002; 7:275-279.

21. Gross CM, Kramer J, Waigand J, Uhlich F, Olthoff H, Luft FC, Dietz R. Ostial renal artery stent placement for atherosclerotic renal artery stenosis in patients with coronary artery disease. Cathet Cardiovasc Diagn. 1998;45:1-8.

22. Harden PN, MacLeod MJ, Rodger RS, Baxter GM, Connell JM, Dominiczak AF, Junor BJ, Briggs JD, Moss JG. Effect of renal-artery stenting on progression of renovascular renal failure. Lancet. 1997;349:11331136.

23. Henry M, Henry I, Klonaris C, Polydorou A, Rath P, Lakshmi G, Rajacopal S, Hugel M. Renal angioplasty and stenting under protection: the way for the future? Catheter Cardiovasc Interv. 2003;60:299-312.

24. lannone LA, Underwood PL, Nath A, Tannenbaum MA, Ghali MG, Clevenger LD. Effect of primary balloon expandable renal artery stents on long-term patency, renal function, and blood pressure in hypertensive and renal insufficient patients with renal artery stenosis. Cathet Cardiovasc Diagn. 1996;37:243-250.

25. Kennedy DJ, Colyer WR, Brewster PS, Ankenbrandt M, Burket MW, Nemeth AS, Khuder SA, Thomas WJ, Shapiro Jl, Cooper CJ. Renal insufficiency as a predictor of adverse events and mortality after renal artery stent placement. Am J Kidney Dis. 2003;42:926-935.

26. Tuttle KR, Chouinard RF, Webber JT, Dahlstrom LR, Short RA, Henneberry KJ, Dunham LA, Raabe RD. Treatment of atherosclerotic ostial renal artery stenosis with the intravascular stent. Am J Kidney Dis. 1998;32:611-622.

27. White CJ, Ramee SR, Collins TJ, Jenkins JS, Escobar A, Shaw D. Renal artery stent placement: utility in lesions difficult to treat with balloon angioplasty. J Am Coll Cardiol. 1997;30:1445-1450.

28. Rocha-Singh KJ, Mishkel GJ, Katholi RE, Ligon RA, Armbruster JA, McShane KJ, Zeck KJ. Clinical predictors of improved long-term blood pressure control after successful stenting of hypertensive patients with obstructive renal artery atherosclerosis. Catheter Cardiovasc Interv. 1999;47:167-172.

29. Harjai K, Khosla S, Shaw D, Collins T, Jenkins S, White C, Ramee S. Effect of gender on outcomes following renal artery stent placement for renovascular hypertension. Cathet Cardiovasc Diagn. 1997;42:381-386.

30. van de Ven PJ, Kaatee R, Beutler JJ, Beek FJ, Woittiez AJ, Buskens E, Koomans HA, Mali WP. Arterial stenting and balloon angioplasty in ostial atherosclerotic renovascular disease: a randomised trial. Lancet. 1999;353:282-286.

31. Burket MW, Cooper CJ, Kennedy DJ, Brewster PS, Ansel GM, Moore JA, Venkatesan J, Henrich WL. Renal artery angioplasty and stent placement: predictors of a favorable outcome. Am Heart $J$. 2000;139:64-71.

32. Lederman RJ, Mendelsohn FO, Santos R, Phillips HR, Stack RS, Crowley JJ. Primary renal artery stenting: characteristics and outcomes after 363 procedures. Am Heart J. 2001;142:314-323.

33. Gill-Leertouwer TC, Gussenhoven EJ, Bosch JL, Deinum J, van Overhagen H, Derkx FH, Pattynama PM. Predictors for clinical success at one year following renal artery stent placement. J Endovasc Ther. 2002;9:495-502. 


\section{CHAPTER 2}

34. Ramos F, Kotliar C, Alvarez D, Baglivo $H$, Rafaelle $P$, Londero $H$, Sanchez R, Wilcox CS. Renal function and outcome of PTRA and stenting for atherosclerotic renal artery stenosis. Kidney Int. 2003;63:276282.

35. Zeller T, Frank U, Muller C, Burgelin K, Sinn L, Horn B, Flugel PC, Schwarzwalder U, Roskamm H, Neumann FJ. Stent-supported angioplasty of severe atherosclerotic renal artery stenosis preserves renal function and improves blood pressure control: long-term results from a prospective registry of 456 lesions. J Endovasc Ther. 2004;11:95-106.

36. Rivolta R, Bazzi C, Stradiotti P, Paparella M. Stenting of renal artery stenosis: is it beneficial in chronic renal failure? J Nephrol. 2005;18:749-754.

37. Rocha-Singh K, Jaff MR, Rosenfield K. Evaluation of the safety and effectiveness of renal artery stenting after unsuccessful balloon angioplasty: the ASPIRE-2 study. J Am Coll Cardiol. 2005;46:776783.

38. Hanzel G, Balon H, Wong O, Soffer D, Lee DT, Safian RD. Prospective evaluation of aggressive medical therapy for atherosclerotic renal artery stenosis, with renal artery stenting reserved for previously injured heart, brain, or kidney. Am J Cardiol. 2005;96:1322-1327.

39. Morganti A. The impact of meta-analyses on clinical practice: the benefits. J Nephrol. 2007;20 Suppl 12:S1-3.

40. Balk E, Raman G, Chung M, Ip S, Tatsioni A, Alonso A, Chew P, Gilbert SJ, Lau J. Effectiveness of management strategies for renal artery stenosis: a systematic review. Ann Intern Med. 2006;145:901912.

41. Bates MC, Campbell JE, Broce M, Lavigne PS, Riley MA. Serum creatinine stabilization following renal artery stenting. Vasc Endovascular Surg. 2008;42:40-46.

42. Chatziioannou A, Mourikis D, Agroyannis B, Katsenis K, Pneumaticos S, Antoniou A, Dimakakos P, Vlachos L. Renal artery stenting for renal insufficiency in solitary kidney in 26 patients. Eur J Vasc Endovasc Surg. 2002;23:49-54.

43. Kashyap VS, Sepulveda RN, Bena JF, Nally JV, Poggio ED, Greenberg RK, Yadav JS, Ouriel K. The management of renal artery atherosclerosis for renal salvage: does stenting help? J Vasc Surg. 2007;45:101-108; discussion 108-109.

44. Rundback JH, Gray RJ, Rozenblit G, Poplausky MR, Babu S, Shah P, Butt K, Tomasula J, Garrick R, Goodman A, Dolmatch B, Horton K. Renal artery stent placement for the management of ischemic nephropathy. J Vasc Interv Radiol. 1998;9:413-420.

45. Shannon HM, Gillespie IN, Moss JG. Salvage of the solitary kidney by insertion of a renal artery stent. AJR Am J Roentgenol. 1998;171:217-222.

46. Tagle R, Acevedo M, Xu M, Pohl M, Vidt D. Use of endovascular stents in atherosclerotic renovascular stenosis: blood pressure and renal function changes in hypertensive patients. J Clin Hypertens (Greenwich). 2007;9:608-614.

47. Dieter RS, Darki A, Nanjundappa A, Chhokar VS, Khadim G, Morshedi-Meibodi A, Freihage JH, Steen L, Lewis $B$, Leya $F$. Usefulness of wide pulse pressure as a predictor of poor outcome after renal artery angioplasty and stenting. Am J Cardiol. 2009;104:732-734.

48. Berlin JA, Santanna J, Schmid CH, Szczech LA, Feldman HI. Individual patient- versus group-level data meta-regressions for the investigation of treatment effect modifiers: ecological bias rears its ugly head. Stat Med. 2002;21:371-387.

49. Nordmann AJ, Woo K, Parkes R, Logan AG. Balloon angioplasty or medical therapy for hypertensive patients with atherosclerotic renal artery stenosis? A meta-analysis of randomized controlled trials. Am J Med. 2003;114:44-50.

50. Schwarzwalder $U$, Zeller T. Critical review of indications for renal artery stenting: do randomized trials give the answer? Catheter Cardiovasc Interv. 2009;74:251-256. 
51. Patel ST, Mills JL, Sr., Tynan-Cuisinier G, Goshima KR, Westerband A, Hughes JD. The limitations of magnetic resonance angiography in the diagnosis of renal artery stenosis: comparative analysis with conventional arteriography. J Vasc Surg. 2005;41:462-468.

52. Stacul F, Gava S, Belgrano M, Cernic S, Pagnan L, Pozzi Mucelli F, Cova MA. Renal artery stenosis: comparative evaluation of gadolinium-enhanced MRA and DSA. Radiol Med. 2008;113:529-546.

53. Wierema TK, de Leeuw PW. Renal artery stenosis: today's questions. Curr Opin Pharmacol. 2006;6:197-201.

54. Cooper CJ, Murphy TP, Matsumoto A, Steffes M, Cohen DJ, Jaff M, Kuntz R, Jamerson K, Reid D, Rosenfield K, Rundback J, D'Agostino R, Henrich W, Dworkin L. Stent revascularization for the prevention of cardiovascular and renal events among patients with renal artery stenosis and systolic hypertension: rationale and design of the CORAL trial. Am Heart J. 2006;152:59-66. 


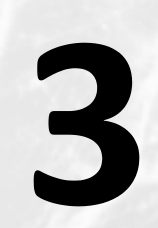

Renal handling of asymmetric dimethylarginine in atherosclerotic renal artery stenosis

\author{
Rianne A. Ronden \\ Alfons J.H.M. Houben \\ Tom Teerlink \\ Jaap A. Bakker \\ Jörgen Bierau \\ Michiel W. de Haan \\ Coen D.A. Stehouwer \\ Peter W. de Leeuw \\ Abraham A. Kroon
}

Submitted 


\section{ABSTRACT}

Background and objectives - Plasma asymmetric dimethylarginine (ADMA) is increased in patients with atherosclerosis but it is not known to what extent the kidney contributes to this increase. Therefore, we explored whether in atherosclerotic renal artery stenosis (ARAS) renal ADMA and L-arginine plasma clearance (RPCL) differ between stenotic and contralateral nonstenotic kidneys in unilateral ARAS and both stenotic kidneys in bilateral ARAS.

Methods - In 41 patients with either unilateral or bilateral ARAS and 41 matched essential hypertensives (controls), we drew blood from the aorta, renal veins and measured mean renal blood flow ( ${ }^{133}$ Xenon washout) to calculate the RPCL.

Results - Plasma ADMA was higher in ARAS patients as compared to controls $(0.51 \pm 0.06$ vs. $0.45 \pm 0.06 \mu \mathrm{mol} / \mathrm{l}, \mathrm{P}<0.001)$, L-arginine did not differ. RPCL differed between the stenotic and non-stenotic kidney in unilateral ARAS; 9.1 (interquartile range 3.1-18.3) vs. 13.8 (5.6-22.6) $\mathrm{ml} / \mathrm{min} / 100 \mathrm{~g}$ kidney, $\mathrm{P}=0.042$. But renal ADMA clearance of both kidneys together was similar as compared to controls. In bilateral ARAS, RPCL was comparable between both kidneys but renal ADMA clearance of both kidneys together was lower as compared to controls; 23.8 (10.6-35.1) vs. 38.4 (19.8-48.7) $\mathrm{ml} / \mathrm{min} / 100 \mathrm{~g}$ kidney, $\mathrm{P}=0.021$. $\mathrm{RPCL}$ of $\mathrm{L}$-arginine did not differ.

Conclusion - Plasma ADMA is higher in ARAS patients. However, in unilateral ARAS this is not related to reduced renal ADMA clearance, since the contralateral non-stenotic kidney compensates for lower renal ADMA clearance in the stenotic kidney. In bilateral ARAS, renal ADMA clearance is indeed lower; therefore, this may contribute to higher plasma ADMA in bilateral ARAS. 


\section{INTRODUCTION}

Increased plasma concentrations of the endogenous nitric oxide synthase (NOS) inhibitor asymmetric dimethylarginine (ADMA) correlate with the presence and severity of systemic and carotid atherosclerosis. ${ }^{1-4}$ Although it is very likely that this also holds true for atherosclerotic renal artery stenosis (ARAS), to the best of our knowledge, plasma concentrations of ADMA have never been investigated in patients with ARAS. This is remarkable because 1 ) the kidneys probably play an important role in the plasma regulation of $A D M A^{5-7}$ and 2 ) the presence of an atherosclerotic plaque in the renal artery has a profound effect on renal hemodynamics and functioning of the kidneys, which may influence the renal handling of ADMA and increase plasma concentrations of ADMA. Therefore, investigating the renal handling of ADMA in patients with ARAS will add to our understanding of its pathophysiological role under these circumstances.

Previously, we demonstrated that, compared to patients with essential hypertension, renal blood flow is more nitric oxide (NO) dependent in the contralateral non-stenotic kidney of patients with unilateral ARAS ${ }^{8}$ and that under ischemic conditions like ARAS, NO bioavailability decreases in the stenotic kidney. ${ }^{8-10}$ One possible cause of the dissimilarity in NO availability between the stenotic and the non-stenotic kidney is substrate (L-arginine) limitation in the stenotic kidney. Another cause could be an increased plasma concentration of ADMA that inhibits NO synthesis, by competing with L-arginine at the active site of NOS.

We hypothesized that the renal handling of the endogenous NOS inhibitor ADMA differed between the stenotic and non-stenotic kidney, which would be relevant for the systemic plasma concentration of ADMA in ARAS. Therefore, we conducted the present study to examine, in patients with unilateral and bilateral ARAS and control subjects with essential hypertension, 1) systemic plasma concentrations of ADMA and L-arginine and 2) the renal handling (measured by arteriovenous concentration differences) of ADMA and L-arginine in stenotic and contralateral non-stenotic kidneys, respectively.

\section{METHODS}

Over a six-year period, we prospectively gathered data from 301 hypertensive patients who underwent a diagnostic renal angiography for the exclusion of renal artery stenosis according to a standardized clinical protocol as described in the expanded methods of the Data Supplement. The investigations were performed in accordance with the principles outlined in the Declaration of Helsinki. All patients gave their written informed consent prior to inclusion and the institutional ethics committee approved the study. 


\section{Study measurements}

After one night admission to our ward and an overnight fast, arterial and venous access was acquired through the common femoral artery and vein, respectively. Subsequently, we drew blood samples from the aorta and renal veins simultaneously for the measurement of ADMA, SDMA, L-arginine and creatinine. Subsequently, we measured mean renal blood flow (MRBF) using the ${ }^{133}$ Xenon washout technique (detailed information in the Data Supplement). During MRBF measurements, heart rate and intra-arterial blood pressure were monitored continuously. No contrast agents were administered before the blood sampling and renal blood flow measurements had been completed. Thereafter, the renal angiography, using a digital subtraction system, was performed. An experienced radiologist who was unaware of the results from the renal blood flow and blood sample measurements reported the site and nature of renal (artery) anomalies according to a standardized form.

\section{Biochemical analyses}

In the blood samples drawn from the aorta and both renal veins, we assessed plasma concentrations of ADMA, SDMA and L-arginine using an Acquity ultra-performance liquid chromatography (UPLC) separation module coupled to a Quattro Premier Electrospray Ionisation Tandem Mass Spectrometry (ESI-MSMS, Waters, Etten-Leur, The Netherlands). ${ }^{11}$ Intra- and inter-assay variations at physiological concentrations were less than 5\% for ADMA, SDMA and L-arginine. Standard clinical chemistry methods were used for assessment of fasting glucose, creatinine, and lipid profile.

\section{Calculations}

The ${ }^{133}$ Xenon washout curves were analyzed as described earlier (information in the Data Supplement). ${ }^{12}$ We calculated the single kidney fractional renal extraction (FRE) of the variables as $(A-V) / A \times 100 \%{ }^{6,7}$ where $A$ and $V$ represent arterial (aorta) and renal vein (left or right) plasma concentrations, respectively. Additionally, we calculated renal plasma clearance (RPCL) of the left or right kidney $(\mathrm{ml} / \mathrm{min} / 100 \mathrm{~g}$ kidney) as $\mathrm{MRPF}_{\text {left kidney }} \times \mathrm{FRE}_{\text {left kidney }}$ or $\mathrm{MRPF}_{\text {right kidney }} \times \mathrm{FRE}_{\text {right kidney }}$ where MRPF represents the mean renal plasma flow calculated as MRBF $x$ (1 - hematocrit). FRE or $\mathrm{RPCL}$ of both kidneys together was calculated as described previously. ${ }^{13}$ The Larginine/ADMA ratio was calculated as well. ${ }^{14}$ 


\section{Statistical analyses}

Normally distributed variables were analyzed using parametric tests and expressed as mean \pm standard deviation (SD). Skewed distributed variables were analyzed using non-parametric tests and expressed as median (interquartile range). A two-tailed $\mathrm{P}<0.05$ was considered statistically significant. Data were analyzed using SPSS software (release 15.0; SPSS Inc. Chicago, IL, USA).

\section{RESULTS}

From the 301 patients who had undergone renal angiography, 211 patients did not have renal artery abnormalities and were classified as having essential hypertension, since other causes of secondary hypertension had already been ruled out. In 90 patients (30\%) renal artery stenosis was present (22 patients with $<50 \%$ unilateral ARAS, 27 patients with $>50 \%$ unilateral ARAS, 14 patients with $>50 \%$ bilateral ARAS, 10 patients with unilateral occlusion of the renal artery and 17 patients with fibromuscular dysplasia). The analyses presented in this paper will be confined to the groups with $>50 \%$ (luminal reduction) unilateral ARAS and bilateral ARAS. Furthermore, we selected, for each patient with ARAS, a patient with essential hypertension, strictly matched for sex, age ( \pm 5 years) and eGFR category (eGFR $\geq 90$, eGFR 60-89 and eGFR $30-59 \mathrm{ml} / \mathrm{min} / 1.73 \mathrm{~m}^{2}$ ) as control. Control groups are presented as control group 1 for unilateral ARAS and control group 2 for bilateral ARAS. Table 3.1 shows the clinical characteristics of all patients with ARAS and controls. In line with protocol procedures there were no significant differences in clinical characteristics between both groups except for the presence of extra-renal atherosclerosis $(P<0.05)$.

Table 3.1: Clinical characteristics of 41 patients with ARAS and 41 matched hypertensive controls

\begin{tabular}{lcc}
\hline & ARAS & Controls \\
\hline Number (male/female) & $41(22 / 19)$ & $41(22 / 19)$ \\
Age (years) & $62.9 \pm 7.7$ & $63.3 \pm 8.1$ \\
Body mass index $\left(\mathrm{kg} / \mathrm{m}^{2}\right)$ & $26.8 \pm 4.8$ & $28.4 \pm 5.3$ \\
Current smoking & $17(42 \%)$ & $10(24 \%)$ \\
Diabetes Mellitus & $9(22 \%)$ & $9(22 \%)$ \\
History of cardiovascular events & $9(22 \%)$ & $4(10 \%)$ \\
24-h systolic blood pressure $(\mathrm{mmHg})$ & $164 \pm 23$ & $163 \pm 23$ \\
24-h diastolic blood pressure $(\mathrm{mmHg})$ & $92 \pm 12$ & $92 \pm 15$ \\
24-h mean arterial pressure $(\mathrm{mmHg})$ & $116 \pm 16$ & $116 \pm 14$ \\
Fasting glucose (mmol/l) & $5.9 \pm 1.1$ & $6.0 \pm 1.7$ \\
Total cholesterol (mmol/l) & $4.9 \pm 1.2$ & $5.2 \pm 01.5$ \\
Estimated glomerular filtration rate $\left(\mathrm{ml} / \mathrm{min} / 1.73 \mathrm{~m}^{2}\right)$ & $60 \pm 20$ & $64 \pm 18$ \\
Extra-renal atherosclerosis & $19(49 \%)$ & $9(22 \%)$ \\
\hline
\end{tabular}

Data are presented as number (\%) or mean \pm standard deviation. ARAS, atherosclerotic renal artery stenosis 


\section{Systemic ADMA and L-arginine in patients with ARAS}

Overall, in patients with ARAS, the systemic (arterial sample from the aorta) ADMA concentration was significantly higher compared to the control group $(0.51 \pm 0.01$ vs. $0.45 \pm 0.01 \mu \mathrm{mol} / \mathrm{l}, \mathrm{P}<0.001)$ whereas L-arginine did not differ between groups $(84 \pm 19$ vs. $77 \pm 18 \mu \mathrm{mol} / \mathrm{l}, \mathrm{P}=0.138$, in ARAS and controls, respectively). Creatinine, SDMA and the L-arginine/ADMA ratio were comparable between both groups (Table 3.S1 in the Data Supplement). Both ADMA and L-arginine were not significantly different in control patients or ARAS patients with and without extra-renal atherosclerosis $(P>0.05$ for all variables).
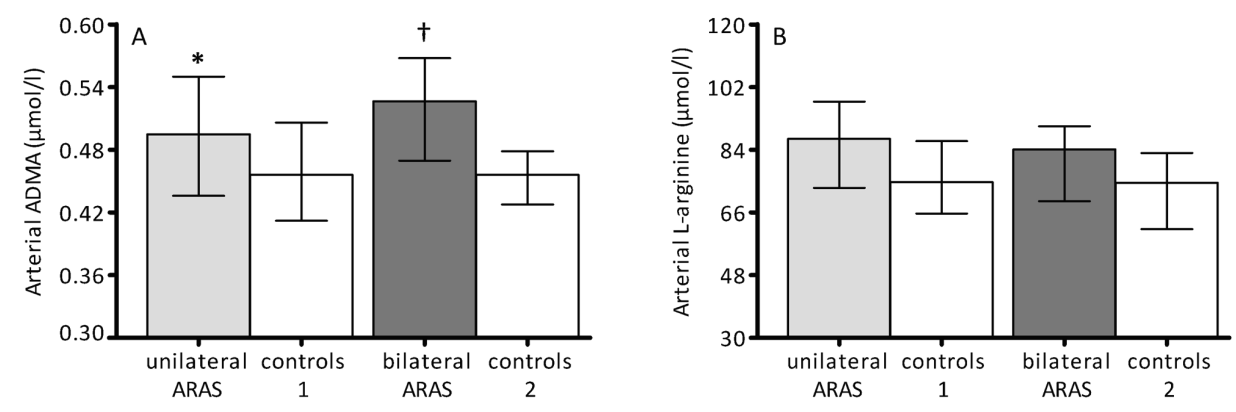

Figure 3.1 Systemic (arterial) ADMA and L-arginine of the ARAS groups and their matched controls. Bars represent medians and error bars represent the interquartile range. ${ }^{*} \mathrm{P}=0.03,+\mathrm{P}=0.005$ vs. controls (MannWhitney $\mathrm{U}$ test). ADMA, asymmetric dimethylarginine; ARAS, atherosclerotic renal artery stenosis

When patients with unilateral and bilateral ARAS were considered separately, ADMA was higher compared to controls in both groups (Figure 3.1A) whereas L-arginine did not significantly differ between patients with unilateral or bilateral ARAS and controls (Figure 3.1B). There were no differences with respect to systemic (arterial) creatinine, SDMA and the L-arginine/ADMA ratio between patients with unilateral ARAS and their controls and patients with bilateral ARAS and their controls (data not shown). The results section and Figure 3.S1 of the Data supplement show the MRBF in the ARAS and control groups. 
Table 3.2 FRE and RPCL of L-arginine (both kidneys together) in patients with ARAS and hypertensive controls

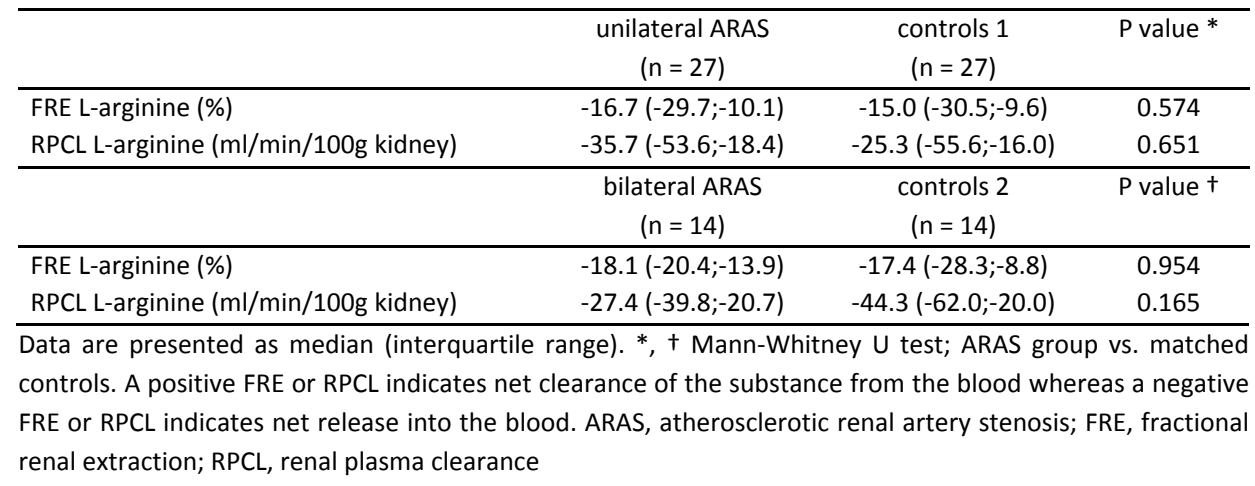

\section{Renal handling of ADMA and L-arginine in unilateral ARAS}

Patients with unilateral ARAS showed neither a difference in FRE of ADMA and Larginine (both kidneys together) nor a difference in RPCL of ADMA (both kidneys together) and L-arginine as compared to their matched controls (Table 3.2 and Figure 3.2).

However, there was a significant difference in FRE of ADMA (Table 3.3) and RPCL of ADMA (Figure 3.3A) between the stenotic and contralateral non-stenotic kidney. Fractional renal ADMA extraction and RPCL of the contralateral non-stenotic kidney was significantly higher compared to the stenotic kidney. FRE and RPCL of L-arginine did not differ between both kidneys (Table 3.3 and Figure 3.3B). In control group 1, FRE and RPCL of both ADMA, and L-arginine showed no difference between the left and right kidney (Table 3.3, Figure 3.3A and 3.3B).

\section{Renal handling of ADMA and L-arginine in bilateral ARAS}

Patients with bilateral ARAS showed a lower FRE and RPCL of ADMA (both kidneys together) as compared to their matched controls (Figure 3.2). There was neither a difference in FRE nor in RPCL (both kidneys together) of L-arginine between patients with bilateral ARAS and controls (Table 3.2).

At the kidney level, neither FRE of ADMA nor RPCL of ADMA differed between the left stenotic and right stenotic kidney (Table 3.3 and Figure 3.3B). FRE and RPCL of Larginine did not differ between the left stenotic and right stenotic kidney in the group with bilateral ARAS (Table 3.3 and Figure 3.3D). In control group 2, both FRE (Table 3.3) and RPCL (Figure 3.3B) of ADMA showed no difference between the left and right kidney whereas both FRE and RPCL of L-arginine did (Table 3.3 and Figure 3.3D). 
CHAPTER 3

Table 3.3 Fractional renal extraction of ADMA and L-arginine at the kidney level in patients with ARAS and hypertensive controls

\begin{tabular}{|c|c|c|c|c|c|c|}
\hline & \multicolumn{3}{|c|}{ unilateral ARAS ( $n=27)$} & \multicolumn{3}{|c|}{ controls $1(n=27)$} \\
\hline & stenotic & non-stenotic & $\mathrm{P} *$ & left & right & $P+$ \\
\hline \multirow[t]{2}{*}{ FRE ADMA (\%) } & 10.7 & 15.4 & 0.015 & 13.3 & 14.9 & 0.192 \\
\hline & $(3.1 ; 15.2)$ & $(7.2 ; 20.2)$ & & $(4.5 ; 22.1)$ & $(8.2-22.2)$ & \\
\hline \multirow[t]{4}{*}{ FRE L-arg (\%) } & -14.2 & -15.1 & 0.459 & -16.4 & -15.0 & 0.387 \\
\hline & $(-21.5 ;-7.0)$ & $(-26.7 ;-7.6)$ & & $(-26.7 ; 7.9)$ & $(-25.1 ;-2.5)$ & \\
\hline & \multicolumn{3}{|c|}{ bilateral ARAS $(n=14)$} & \multicolumn{3}{|c|}{ controls $2(n=14)$} \\
\hline & left & right & $P \ddagger$ & left & right & $P \pm$ \\
\hline \multirow[t]{2}{*}{ FRE ADMA (\%) } & 12.2 & 13.0 & 0.753 & 16.5 & 16.2 & 0.552 \\
\hline & $(7.5 ; 15.3)$ & $(5.1 ; 19.6)$ & & $(8.7 ; 20.5)$ & $(11.6 ; 22.2)$ & \\
\hline \multirow[t]{2}{*}{ FRE L-arg (\%) } & -14.4 & -17.6 & 0.221 & -16.6 & -20.5 & 0.030 \\
\hline & $(-19.2 ;-11.9)$ & $(-25.2 ;-11.6)$ & & $(-24.9 ;-12.3)$ & $(-31.6 ;-11.9)$ & \\
\hline
\end{tabular}

Data are presented as median (interquartile range). * Wilcoxon signed rank test; stenotic kidney vs. contralateral non-stenotic kidney. $\dagger, \ddagger, \pm$ Wilcoxon signed rank test; left kidney vs. right kidney. A positive FRE indicates net clearance of the substance from the blood whereas a negative FRE indicates net release into the blood. ADMA, asymmetric dimethylarginine; ARAS, atherosclerotic renal artery stenosis; FRE, fractional renal extraction; L-arg, L-arginine
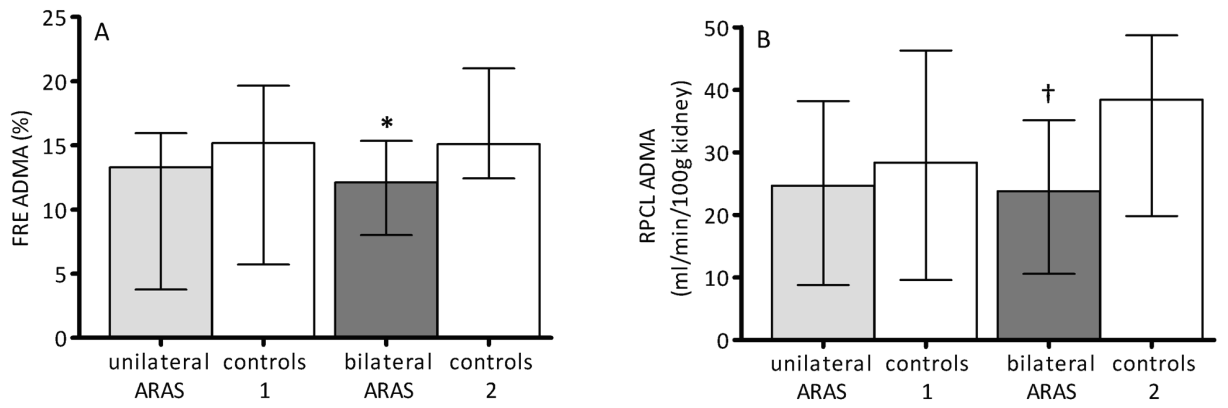

Figure 3.2 FRE and RPCL of ADMA (both kidneys together) in patients with ARAS and hypertensive controls. Bars represent medians and error bars represent the interquartile range. ${ }^{*} P=0.042$ vs. total ADMA FRE of the controls $+\mathrm{P}=0.021$ vs. total ADMA RPCL of the controls (Mann-Whitney $U$ test). A positive FRE or RPCL indicates net clearance of the substance from the blood whereas a negative FRE of RPCL indicates net release into the blood. ADMA, asymmetric dimethylarginine; ARAS, atherosclerotic renal artery stenosis; $\mathrm{FRE}$, fractional renal extraction; RPCL, renal plasma clearance 


\section{Renal handling of creatinine and SDMA in patients with ARAS}

The results of the renal creatinine and SDMA handling in patients with ARAS and controls are described in the results section of the Data Supplement (Table 3.S2 and Table 3.S3).
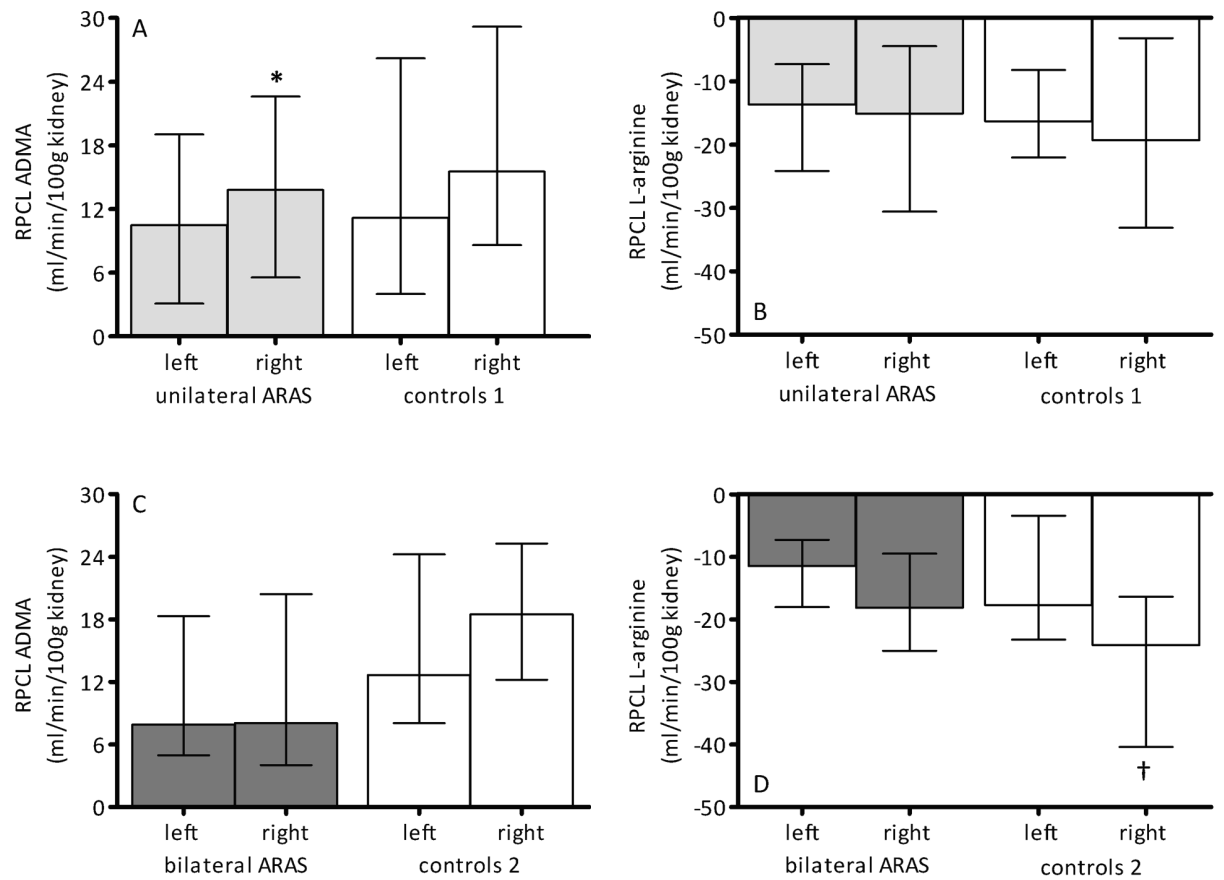

Figure 3.3 RPCL of ADMA and L-arginine at the kidney level in patients with ARAS and hypertensive controls. Bars represent medians and error bars represent the interquartile range. ${ }^{*} \mathrm{P}=0.041$ vs. the stenotic kidney $+P=0.008$ vs. left kidney of the controls (Wilcoxon signed-rank test). A positive RPCL indicates net clearance of the substance from the blood whereas a negative RPCL indicates net release into the blood. ADMA, asymmetric dimethylarginine; ARAS, atherosclerotic renal artery stenosis

\section{DISCUSSION}

This study, in patients with ARAS, has three main findings. First, plasma ADMA is higher in patients with ARAS as compared to patients with essential hypertension whereas Larginine does not differ between both groups. Second, in patients with unilateral ARAS, renal clearance of ADMA is lower in the stenotic kidney as compared to the contralateral non-stenotic one. However, the apparent compensatory effect of the 
contralateral kidney results in a similar renal clearance of both kidneys combined relative to controls. Third, contrary to patients with unilateral ARAS, renal ADMA clearance of both kidneys combined is lower in patients with bilateral ARAS as compared to patients with essential hypertension whereas renal L-arginine clearance was similar in both groups.

Although several studies reported increased plasma ADMA in patients with peripheral arterial disease ${ }^{1,4}$ and coronary artery disease ${ }^{2,3,15}$, the present study showed for the first time that plasma ADMA is increased in patients with ARAS as well. Theoretically, this increase could be caused by (mild) renal impairment, which has been suggested as the cause of increased plasma ADMA in coronary artery disease. ${ }^{3,16}$ However, we carefully matched our groups for eGFR which makes a role for decreased renal function very unlikely. In addition, plasma ADMA is also higher in patients with a normal renal function and atherosclerosis as compared to patients with a normal renal function without atherosclerosis, which suggest a relation between atherosclerosis and plasma ADMA beyond renal impairment. ${ }^{17}$

Arterial ADMA in our study population ranged between $0.41-0.78 \mu \mathrm{mol} / \mathrm{l}$ in patients with ARAS and between 0.29-0.57 $\mu \mathrm{mol} / \mathrm{l}$ in patients with essential hypertension. These plasma concentrations appear lower than those reported before in other hypertensive populations and are within the "normal" range of ADMA in healthy adults when one applies the same ${ }^{18}$ or comparable analytical methods. ${ }^{19,20}$ Yet, we drew arterial samples from the aorta and venous samples from the renal veins (which showed even lower plasma concentrations of ADMA) while the aforementioned studies investigated blood samples derived from the antecubital vein. This makes it difficult to compare the ADMA plasma concentrations. To the best of our knowledge, there is no reference material on the "normal" range of arterial (aorta) ADMA plasma concentration. Two previous studies investigated arterial samples from the aorta in patients undergoing coronary angiography ${ }^{6}$ or hepatic surgery. ${ }^{7}$ Both studies showed arterial ADMA plasma concentrations comparable (or slightly lower) to those in our control group. Furthermore, a study by Joyal et al. showed that there are substantial differences between plasma ADMA concentrations in the antecubital vein and locally at a coronary plaque, and that local ADMA concentrations did not correlate with "systemic" concentrations. ${ }^{21}$ Apparently, plasma concentrations of ADMA differ between vascular beds and therefore, "systemic" ADMA concentrations may reflect generalized endothelial function in patients whereas local concentrations at the plaque site provide more detailed information about local processes. 
Systemic L-arginine was not different between patients with ARAS and controls. This is in agreement with other studies in different populations with atherosclerosis. ${ }^{2,3}$ The fact that the L-arginine/ADMA ratio in our study was numerically not different between patients with ARAS and controls is most likely due to the variance of both variables (L-arginine and ADMA) in this relatively small group when added in the calculation. Still, it is clear that the renal handling of L-arginine is not affected in patients with ARAS as compared to patients with essential hypertension.

The present study had a unique design as we have the opportunity to investigate the effect of an atherosclerotic lesion in the renal artery on the renal handling of ADMA in both kidneys separately. Interestingly, we observed that in unilateral ARAS, renal clearance of ADMA is lower in the stenotic kidney as compared to the contralateral non-stenotic kidney. Based on the formula for renal (plasma) clearance there are several possible explanations. First, a lower MRBF in the stenotic kidney as compared to the contralateral non-stenotic one. However, in the group with unilateral ARAS, there was no significant difference in renal blood or plasma flow between both kidneys. Second, substantially lower filtration, reabsorption or secretion (or a combination) of ADMA in the post-stenotic kidney. This should result in a larger increase of plasma ADMA concentration in the renal vein as compared to the increase of plasma ADMA concentration in the blood sample from the aorta. This was actually the case in the stenotic kidney. Still, this explanation is unlikely since renal clearance of creatinine and SDMA (both markers of renal function ${ }^{22}$ ) were not significantly different between the stenotic and non-stenotic kidney. There is another possible explanation for the larger plasma ADMA concentration increase in the renal vein of the stenotic kidney, as there may be decreased renal activity of the intracellular enzyme $N^{G} N^{G}$ dimethylarginine dimethylaminohydrolase (DDAH) in the stenotic kidney. This enzyme degradates ADMA into dimethylamine and citrulline and is the main elimination pathway for ADMA (SDMA cannot be degradated by DDAH and is almost entirely

excreted in the urine ${ }^{22}$ ). Furthermore, DDAH is highly expressed in the kidney. ${ }^{23-25}$ Renal DDAH activity may be decreased in several conditions associated with (renal) atherosclerosis i.e. increased oxidative stress and renal damage. ${ }^{26-28}$ The fourth possibility is ADMA synthesis by the atherosclerotic plaque which has already been demonstrated in coronary plaques. ${ }^{21}$ Regrettably, we were not able to measure the ADMA gradient across the stenosis nor DDAH activity and therefore it is difficult to draw robust conclusions about these underlying mechanisms explaining the difference in renal ADMA handling between the stenotic and the contralateral nonstenotic one. 
Another interesting finding is the role of the contralateral non-stenotic kidney in the renal handling of ADMA. Despite the clear difference in renal (plasma) clearance of ADMA between the stenotic and contralateral non-stenotic one, the renal ADMA clearance of both kidneys together was not significantly different from that in hypertensive control subjects. This suggests a compensatory effect of the contralateral kidney. We previously demonstrated that renal blood flow is dependent on NOS activity in the renal vasculature of patients with essential hypertension. ${ }^{8}$ However, in unilateral ARAS, renal blood flow is no longer NO-dependent in the stenotic kidney, as opposed to the non-stenotic kidney, in which renal blood flow is strongly NO dependent. We hypothesize that ADMA synthesis by the plaque and/or lower renal clearance of ADMA are associated with this observed difference in NO-dependency of renal blood flow between the stenotic and non-stenotic kidney. With respect to patients with bilateral ARAS, however, this compensatory mechanism cannot easily be tallied with our previous observations.

There are some limitations to our study. First, because of the relatively small size and substantial differences between both ARAS groups we could not investigate whether there was an association between ARAS severity and plasma ADMA. Second, there was a substantial difference in the presence of extra-renal atherosclerosis between groups with ARAS and controls which may have influenced our results on systemic concentrations of ADMA. However, additional statistical analyses showed that there was no significant difference in plasma ADMA between controls with or without extrarenal atherosclerosis.

In conclusion, systemic plasma concentrations of ADMA are higher in patients with ARAS. However, in unilateral ARAS this is not related to a reduced renal ADMA clearance, since the contralateral non-stenotic kidney compensates for lower renal ADMA clearance in the stenotic kidney. In bilateral ARAS, total renal ADMA clearance is indeed lower; therefore, this may contribute to the higher plasma concentrations of ADMA in this population.

\section{Acknowledgements}

The authors gratefully acknowledge M. Fuss-Lejeune for her assistance in the blood sampling and measurements during renal angiography. This study was supported by a "clinical established investigator" grant from the Dutch Heart Foundation (DHF; Grant No. 2004T058) obtained by Dr. A.A. Kroon. 


\section{REFERENCES}

1. Boger RH, Bode-Boger SM, Thiele W, Junker W, Alexander K, Frolich JC. Biochemical evidence for impaired nitric oxide synthesis in patients with peripheral arterial occlusive disease. Circulation. 1997;95:2068-2074.

2. Lu TM, Ding YA, Charng MJ, Lin SJ. Asymmetrical dimethylarginine: a novel risk factor for coronary artery disease. Clin Cardiol. 2003;26:458-464.

3. Sahinarslan A, Cengel A, Biberoglu G, Hasanoglu A, Turkoglu S, Timurkaynak T. Plasma asymmetric dimethylarginine level and extent of lesion at coronary angiography. Coron Artery Dis. 2006;17:605609.

4. Wilson AM, Shin DS, Weatherby C, Harada RK, Ng MK, Nair N, Kielstein J, Cooke JP. Asymmetric dimethylarginine correlates with measures of disease severity, major adverse cardiovascular events and all-cause mortality in patients with peripheral arterial disease. Vasc Med. 2010;15:267-274.

5. Kakimoto $\mathrm{Y}$, Akazawa S. Isolation and identification of N-G,N-G- and N-G,N'-G-dimethyl-arginine, Nepsilon-mono-, di-, and trimethyllysine, and glucosylgalactosyl- and galactosyl-delta-hydroxylysine from human urine. J Biol Chem. 1970;245:5751-5758.

6. Nijveldt RJ, Van Leeuwen PA, Van Guldener C, Stehouwer CD, Rauwerda JA, Teerlink T. Net renal extraction of asymmetrical (ADMA) and symmetrical (SDMA) dimethylarginine in fasting humans. Nephrol Dial Transplant. 2002;17:1999-2002.

7. Siroen MP, van der Sijp JR, Teerlink T, van Schaik C, Nijveldt RJ, van Leeuwen PA. The human liver clears both asymmetric and symmetric dimethylarginine. Hepatology. 2005;41:559-565.

8. Wierema TK, Houben AJ, Kroon AA, Koster D, van der Zander K, van Engelshoven JM, de Leeuw PW. Nitric oxide dependence of renal blood flow in patients with renal artery stenosis. J Am Soc Nephrol. 2001;12:1836-1843.

9. Sigmon $\mathrm{DH}$, Beierwaltes $\mathrm{WH}$. Degree of renal artery stenosis alters nitric oxide regulation of renal hemodynamics. J Am Soc Nephrol. 1994;5:1369-1377.

10. Sigmon DH, Beierwaltes WH. Influence of nitric oxide in the chronic phase of two-kidney, one clip renovascular hypertension. Hypertension. 1998;31:649-656.

11. Waterval WA, Scheijen JL, Ortmans-Ploemen MM, Habets-van der Poel CD, Bierau J. Quantitative UPLC-MS/MS analysis of underivatised amino acids in body fluids is a reliable tool for the diagnosis and follow-up of patients with inborn errors of metabolism. Clin Chim Acta. 2009;407:36-42.

12. Hollenberg NK, Mangel R, Fung HY. Assessment of intrarenal perfusion with radioxenon: a critical review of analytical factors and their implications in man. Semin Nucl Med. 1976;6:193-216.

13. Rennenberg RJ, Schurgers LJ, Vermeer C, Scholte JB, Houben AJ, de Leeuw PW, Kroon AA. Renal handling of matrix Gla-protein in humans with moderate to severe hypertension. Hypertens Res. 2008;31:1745-1751.

14. Siroen MP, Teerlink T, Nijveldt RJ, Prins HA, Richir MC, van Leeuwen PA. The clinical significance of asymmetric dimethylarginine. Annu Rev Nutr. 2006;26:203-228.

15. Ilhan $\mathrm{N}$, Seckin $\mathrm{D}$, Ozbay $\mathrm{Y}$. Abnormal asymmetric dimethylarginine/nitric oxide balance in patients with documented coronary artery disease: relation to renal function and homocysteine. J Thromb Thrombolysis. 2007;23:205-211.

16. Wang J, Sim AS, Wang XL, Salonikas C, Moriatis M, Naidoo D, Wilcken DE. Relations between markers of renal function, coronary risk factors and the occurrence and severity of coronary artery disease. Atherosclerosis. 2008;197:853-859.

17. Kielstein JT, Boger RH, Bode-Boger SM, Schaffer J, Barbey M, Koch KM, Frolich JC. Asymmetric dimethylarginine plasma concentrations differ in patients with end-stage renal disease: relationship to treatment method and atherosclerotic disease. J Am Soc Nephrol. 1999;10:594-600. 


\section{CHAPTER 3}

18. Di Gangi IM, Chiandetti L, Gucciardi A, Moret V, Naturale M, Giordano G. Simultaneous quantitative determination of $\mathrm{N}(\mathrm{G}), \mathrm{N}(\mathrm{G})$-dimethyl-L-arginine or asymmetric dimethylarginine and related pathway's metabolites in biological fluids by ultrahigh-performance liquid chromatography/electrospray ionization-tandem mass spectrometry. Anal Chim Acta. 2010;677:140148.

19. Schwedhelm E, Xanthakis V, Maas R, Sullivan LM, Schulze F, Riederer U, Benndorf RA, Boger RH, Vasan RS. Asymmetric dimethylarginine reference intervals determined with liquid chromatography-tandem mass spectrometry: results from the Framingham offspring cohort. Clin Chem. 2009;55:1539-1545.

20. Teerlink T. HPLC analysis of ADMA and other methylated L-arginine analogs in biological fluids. J Chromatogr B Analyt Technol Biomed Life Sci. 2007;851:21-29.

21. Joyal D, Leya F, Obada Al-Chekakie M, Arab D, Dieter RS, Morshedi-Meibodi A, Lewis B, Steen L, Fareed J, Hoppenstead D, Akar JG. Presence of asymmetric dimethylarginine gradients across highgrade lesions in patients with coronary artery disease. Coron Artery Dis. 2007;18:471-475.

22. Kielstein JT, Salpeter SR, Bode-Boeger SM, Cooke JP, Fliser D. Symmetric dimethylarginine (SDMA) as endogenous marker of renal function--a meta-analysis. Nephrol Dial Transplant. 2006;21:2446-2451.

23. Hu X, Atzler D, Xu X, Zhang P, Guo H, Lu Z, Fassett J, Schwedhelm E, Boger RH, Bache RJ, Chen Y. Dimethylarginine dimethylaminohydrolase-1 is the critical enzyme for degrading the cardiovascular risk factor asymmetrical dimethylarginine. Arterioscler Thromb Vasc Biol. 2011;31:1540-1546.

24. Kimoto $M$, Tsuji $H$, Ogawa $T$, Sasaoka $K$. Detection of NG,NG-dimethylarginine dimethylaminohydrolase in the nitric oxide-generating systems of rats using monoclonal antibody. Arch Biochem Biophys. 1993;300:657-662.

25. Leiper JM, Santa Maria J, Chubb A, MacAllister RJ, Charles IG, Whitley GS, Vallance P. Identification of two human dimethylarginine dimethylaminohydrolases with distinct tissue distributions and homology with microbial arginine deiminases. Biochem J. 1999;343 Pt 1:209-214.

26. Luo Z, Teerlink T, Griendling K, Aslam S, Welch WJ, Wilcox CS. Angiotensin II and NADPH oxidase increase ADMA in vascular smooth muscle cells. Hypertension. 2010;56:498-504.

27. Oberg BP, McMenamin E, Lucas FL, McMonagle E, Morrow J, Ikizler TA, Himmelfarb J. Increased prevalence of oxidant stress and inflammation in patients with moderate to severe chronic kidney disease. Kidney Int. 2004;65:1009-1016.

28. Wilcox CS. Asymmetric dimethylarginine and reactive oxygen species: unwelcome twin visitors to the cardiovascular and kidney disease tables. Hypertension. 2012;59:375-381. 


\section{DATA SUPPLEMENT}

\section{Expanded methods of study protocol}

This standardized clinical protocol includes selective renal blood sampling of the aorta, left and right renal veins, renal blood flow measurements of the left and right kidney, and renal angiography. Prior to angiography, other (secondary) causes of hypertension were ruled out based on clinical clues and additional investigations. Patients were angiographically evaluated for suspicion of renal artery stenosis based on one or more of the following clinical clues: hypertension despite treatment with at least three antihypertensive agents, (recent) hypertensive crisis, or hypertension with evident peripheral vascular disease, the presence of an abdominal bruit or unexplained renal function deterioration, e.g. in response to antihypertensive treatment.

For reasons of standardization, all antihypertensive medication was discontinued for three weeks and patients were requested to adhere to a sodium-restricted (55 $\mathrm{mmol} / 24-\mathrm{h}$ ) diet during one week prior to renal angiography. One day preceding renal angiography, a non-invasive ambulatory 24-h blood pressure measurement was performed (SpaceLabs, ambulatory blood pressure monitor, Redmond, WA, USA). We performed all study measurements and the renal angiography in the angiographic suite of the department of radiology, which is equipped with an x-ray system and a scintillation counter. After an overnight fast, arterial and venous access was acquired through the common femoral artery and vein, respectively. Subsequently, we simultaneously drew blood samples from the aorta and the renal veins for the assessment of asymmetric dimethylarginine (ADMA), symmetric dimethylarginine (SDMA, a structural isomer of ADMA that does not inhibit NOS), L-arginine and creatinine. After centrifugation, plasma samples were immediately stored at $-80{ }^{\circ} \mathrm{C}$ until analysis. Additionally, we sampled venous blood from the antecubital vein for the measurements of fasting glucose, lipid profile and serum creatinine. The latter was used for the calculation of estimated glomerular filtration rate (eGFR in $\mathrm{ml} / \mathrm{min} / 1.73$ $\mathrm{m}^{2}$ ) by the Chronic Kidney Disease Epidemiology Collaboration equation (CKD-EPI). ${ }^{1}$ Subsequently, we measured selective mean renal blood flow (MRBF) by means of the ${ }^{133}$ Xenon washout technique, as described below. ${ }^{2,3}$

\section{${ }^{133}$ Xenon washout}

After the blood sampling, we measured selective MRBF using the ${ }^{133}$ Xenon washout technique, as described previously. ${ }^{4}$ In short, after infusion of a bolus of ${ }^{133}$ Xenon (37 $\mathrm{MBq}, \mathrm{IDB}$ Holland bv, Baarle-Nassau, The Netherlands) directly into the renal artery,

${ }^{133}$ Xenon washout curves were recorded using an extra corporeal scintillation counter. The ${ }^{133}$ Xenon washout curves were analyzed off-line. After subtraction of background radiation, the disappearance of ${ }^{133}$ Xenon from the kidney was analyzed mathematically 
using either a two-phase or one-phase exponential decay model, depending on which one fits best (using Graphpad Software (Graphpad Software, Inc., San Diego, CA)). From this model we calculated MRBF and mean renal plasma flow (MRPF, calculated as MRBF $x$ (1 - hematocrit)) both expressed as $\mathrm{ml} / \mathrm{min} / 100 \mathrm{~g}$ kidney. The ${ }^{133}$ Xenon washout technique provides accurate estimates of renal blood flow and, in our hands, has a coefficient of variation of $8 \%$ for repeated measurements. Each patient underwent the same procedure, by which we measured first baseline MRBF in the left and thereafter in the right kidney.

\section{Angiographic evaluation}

An experienced radiologist who was unaware of the results from the renal blood flow and blood sample measurements reported the site and nature of renal (artery) anomalies according to a standardized form. In case of atherosclerotic renal artery stenosis (ARAS), maximum stenosis was determined by means of two-dimensional electronic coronal plain views of zoomed images of the renal arteries and measured as: ( 1 - (narrowest diameter/diameter of the normal distal main artery)) $\times 100 \%$. Patients without any abnormalities of the renal arteries were classified as having essential hypertension since other causes of hypertension had already been ruled out.

\section{Results: Mean renal blood flow}

Baseline MRBF was lower in the stenotic kidney of patients with unilateral ARAS as compared to the kidney with the highest flow of controls ( $P=0.027$, Figure 3.S1A) whereas baseline MRBF was significantly lower in both stenotic kidneys of patients with bilateral ARAS as compared to controls $(P=0.045$ for the left kidney and $P=0.039$ for the right kidney, Figure 3.S1B). In patients with unilateral ARAS, MRBF did not differ between the stenotic and contralateral non-stenotic kidney (Figure 3.S1A). Neither was there a difference between the left and right stenotic kidney in patients with bilateral ARAS (Figure 3.S1B). In contrast, both control groups showed a significant difference between the left and right kidney, in favor of a higher renal blood flow in the right kidney (Figure 3.S1A and B).

\section{Results: Renal handling of creatinine and SDMA in patients with ARAS}

Patients with ARAS showed no significant difference in fractional renal extraction (FRE) or renal plasma clearance (RPCL) of creatinine and SDMA as compared to their matched controls (Table 3.S2). However, renal SDMA clearance (FRE and RPCL) of both kidneys together showed a trend for lower renal SDMA clearance in unilateral and bilateral ARAS groups as compared to the controls (Table 3.S2). 
All control groups showed a significant difference in RPCL of creatinine between the left and right kidney in favor of a higher RPCL of creatinine in the right kidney. Apart from the RPCL of creatinine in the control groups, none of the groups (different degrees of ARAS and controls) showed a difference in the renal handling (FRE or RPCL) of creatinine and SDMA between the stenotic and non-stenotic kidney or left and right kidney (Table 3.S3).
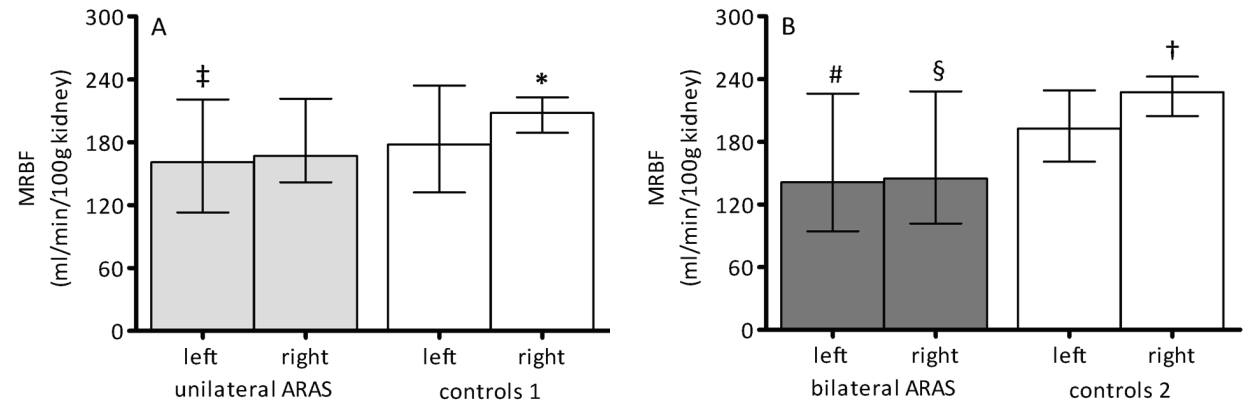

Figure 3.S1 MRBF of the separate kidneys in patient with ARAS and controls. Bars represent medians and error bars represent the interquartile range. $\ddagger P=0.027$ vs. MRBF of the controls, ${ }^{*} P=0.023$ vs. MRBF of the left kidneys (controls 1 ), \# $P=0.045$ vs. MRBF left of the controls, $\S P=0.039$ vs. MRBF right of the controls, $\dagger$ $P=0.023$ vs. MRBF of the left kidneys (controls 2). ARAS, atherosclerotic renal artery stenosis; MRBF, mean renal blood flow

Table 3.S1: Systemic (arterial) plasma concentrations of ADMA, creatinine, L-arginine, L-arginine/ADMA ratio and SDMA

\begin{tabular}{lccc}
\hline & ARAS $(\mathrm{n}=41)$ & controls $(\mathrm{n}=41)$ & Pvalue $^{*}$ \\
\hline ADMA $(\mu \mathrm{mol} / \mathrm{l})$ & $0.51 \pm 0.06$ & $0.45 \pm 0.06$ & $<0.001$ \\
SDMA $(\mu \mathrm{mol} / \mathrm{l})$ & $0.69 \pm 0.23$ & $0.63 \pm 0.18$ & 0.24 \\
L-arginine $(\mu \mathrm{mol} / \mathrm{l})$ & $84 \pm 19$ & $77 \pm 18$ & 0.08 \\
L-arginine/ADMA ratio & $167 \pm 37$ & $170 \pm 31$ & 0.68 \\
Creatinine $(\mu \mathrm{mol} / \mathrm{l})$ & $99 \pm 33$ & $91 \pm 26$ & 0.24 \\
\hline
\end{tabular}

Data are presented as mean \pm standard deviation. ${ }^{*}$ independent Student's t-test. ADMA, asymmetric dimethylarginine; ARAS, atherosclerotic renal artery stenosis; SDMA, symmetric dimethylarginine 
CHAPTER 3

Table 3.S2 Fractional extraction and renal plasma clearance of creatinine and SDMA (both kidneys together) in patients with ARAS and hypertensive controls

\begin{tabular}{lccc}
\hline & $\begin{array}{c}\text { unilateral ARAS } \\
(\mathrm{n}=27)\end{array}$ & $\begin{array}{c}\text { controls } 1 \\
(\mathrm{n}=27)\end{array}$ & P value * \\
\hline FRE creatinine (\%) & $18.1(15.6 ; 21.1)$ & $20.9(14.9 ; 23.3)$ & 0.30 \\
RPCL creatinine (ml/min/100g kidney) & $34.9(26.1 ; 51.3)$ & $39.3(31.3 ; 51.1)$ & 0.23 \\
FRE SDMA (\%) & $11.9(8.5 ; 14.9)$ & $19.3(10.7 ; 21.9)$ & 0.06 \\
RPCL SDMA (ml/min/100g kidney) & $20.2(9.9 ; 26.8)$ & $33.2(15.8-50.9)$ & 0.08 \\
\hline & bilateral ARAS & controls 2 & P value ${ }^{*}$ \\
\hline FRE creatinine (\%) & $(\mathrm{n}=14)$ & $(\mathrm{n}=14)$ & \\
RPCL creatinine (ml/min/100g kidney) & $18.0(13.4 ; 21.3)$ & $18.3(16.5 ; 22.0)$ & 0.37 \\
FRE SDMA (\%) & $25.6(18.2 ; 44.5)$ & $42.8(27.9-54.5)$ & 0.08 \\
RPCL SDMA (ml/min/100g kidney) & $10.5(5.3 ; 12.9)$ & $14.0(9.3 ; 16.6)$ & 0.09 \\
\hline Dat & $17.1(10.1 ; 22.9)$ & $28.8(18.8 ; 42.8)$ & 0.051 \\
\hline
\end{tabular}

Data are presented as median (interquartile range). ${ }^{*},+$ Mann-Whitney $U$ test; ARAS group vs. matched controls. A positive FRE or RPCL indicates net clearance of the substance from the blood whereas a negative FRE or RPCL indicates net release into the blood. ARAS, atherosclerotic renal artery stenosis; FRE, fractional extraction rate (\%); RPCL, renal plasma clearance (ml/min/100g kidney); SDMA, symmetric dimethylarginine

Table 3.S3 Fractional renal extraction of creatinine and SDMA at the kidney level in patients with ARAS and hypertensive controls

\begin{tabular}{|c|c|c|c|c|c|c|}
\hline & \multicolumn{3}{|c|}{ unilateral ARAS $(n=27)$} & \multicolumn{3}{|c|}{ controls $1(n=27)$} \\
\hline & stenotic & non-stenotic & P value * & left & right & $\mathrm{P}$ value ${ }^{\dagger}$ \\
\hline FRE creatinine & 18.2 & 19.4 & 0.20 & 17.1 & 20.3 & 0.14 \\
\hline 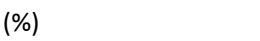 & $(10.1 ; 22.2)$ & $(15.9 ; 23.1)$ & & $(15.2 ; 22.6)$ & $(15.3 ; 27.4)$ & \\
\hline RPCL creatinine & 14.3 & 21.8 & 0.76 & 15.7 & 24.0 & 0.04 \\
\hline (ml/min/100g kidney) & $(10.2 ; 28.7)$ & $(13.3 ; 23.6)$ & & $(12.8 ; 23.9)$ & $(16.5 ; 28.5)$ & \\
\hline FRE SDMA & 8.1 & 12.6 & 0.40 & 13.6 & 16.3 & 0.14 \\
\hline (\%) & $(3.6 ; 13.2)$ & $(7.3 ; 16.1)$ & & $(6.6 ; 19.0)$ & $(9.8 ; 21.9)$ & \\
\hline RPCL SDMA & 5.7 & 10.6 & 0.93 & 10.9 & 17.0 & 0.07 \\
\hline \multirow[t]{3}{*}{ (ml/min/100g kidney) } & $(3.1 ; 12.5)$ & $(3.9 ; 20.3)$ & & $(4.4 ; 18.1)$ & $(9.1 ; 24.4)$ & \\
\hline & \multicolumn{3}{|c|}{ bilateral ARAS $(n=14)$} & \multicolumn{3}{|c|}{ controls $2(n=14)$} \\
\hline & left & right & $P$ value $\ddagger$ & left & right & $\mathrm{P}$ value \pm \\
\hline FRE creatinine & 17.4 & 18.2 & 0.88 & 16.1 & 19.8 & 0.11 \\
\hline (\%) & $(10.1 ; 27.5)$ & $(9.5 ; 25.7)$ & & $(13.8 ; 21.3)$ & $(16.0 ; 24.5)$ & \\
\hline RPCL creatinine & 13.4 & 14.5 & 0.25 & 15.5 & 24.0 & 0.03 \\
\hline (ml/min/100g kidney) & $(8.7 ; 19.9)$ & $(8.1 ; 27.5)$ & & $(11.0 ; 30.4)$ & $(17.1 ; 28.8)$ & \\
\hline FRE SDMA & 7.4 & 9.3 & 0.42 & 12.8 & 12.7 & 0.93 \\
\hline (\%) & $(2.8 ; 15.8)$ & $(4.9 ; 15.3)$ & & $(9.1 ; 17.3)$ & $(8.4 ; 16.8)$ & \\
\hline RPCL SDMA & 6.5 & 10.2 & 0.64 & 10.7 & 14.9 & 0.27 \\
\hline (ml/min/100g kidney) & $(2.7 ; 11.8)$ & $(2.7 ; 15.0)$ & & $(6.7 ; 18.0)$ & $(10.7 ; 21.1)$ & \\
\hline
\end{tabular}

Data are presented as median (interquartile range). ${ }^{*}$ Wilcoxon signed rank test; stenotic kidney vs. contralateral non-stenotic kidney. $\dagger, \ddagger, \pm$ Wilcoxon signed rank test; left kidney vs. right kidney. A positive FRE indicates net clearance of the substance from the blood whereas a negative FRE indicates net release into the blood. ARAS, atherosclerotic renal artery stenosis; FRE, fractional extraction rate; SDMA, symmetric dimethylarginine; RPCL, renal plasma clearance 


\section{REFERENCES}

1. Levey AS, Stevens LA, Schmid CH, Zhang YL, Castro AF, 3rd, Feldman HI, Kusek JW, Eggers P, Van Lente $\mathrm{F}$, Greene T, Coresh J. A new equation to estimate glomerular filtration rate. Ann Intern Med. 2009;150:604-612.

2. de Leeuw PW, Birkenhager WH. Use of the xenon-133 washout technique in diagnosing renovascular disease in hypertension. Nephron. 1986;44 Suppl 1:5-7.

3. Wierema TK, Houben AJ, Kroon AA, Koster D, van der Zander K, van Engelshoven JM, de Leeuw PW. Nitric oxide dependence of renal blood flow in patients with renal artery stenosis. J Am Soc Nephrol. 2001;12:1836-1843.

4. Blaufox MD, Fromowitz A, Gruskin A, Meng $\mathrm{CH}$, Elkin M. Validation of use of xenon 133 to measure intrarenal distribution of blood flow. Am J Physiol. 1970;219:440-444. 



\section{4}

Reduced renal plasma clearance does not explain increased plasma asymmetric dimethylarginine in hypertensive subjects with mild to moderate renal insufficiency

Rianne A. Ronden

Alfons J.H.M. Houben

Tom Teerlink

Jaap A. Bakker

Jörgen Bierau

Coen D.A. Stehouwer

Peter W. de Leeuw

Abraham A. Kroon

Am J Physiol Renal Physiol 303: F149-F156, 2012 


\section{CHAPTER 4}

ABSTRACT

Background and objective - Plasma concentrations of the nitric oxide synthase inhibitor asymmetric dimethylarginine (ADMA) and symmetric dimethylarginine (SDMA) increase already in the early stages of renal insufficiency. There is no agreement as to whether reduced renal plasma clearance (RPCL) contributes to this increase. Therefore, we investigated the relationship between estimated glomerular filtration rate (eGFR), RPCL, and plasma ADMA and SDMA in essential hypertensive patients with mild to moderate renal insufficiency.

Methods - In 171 patients who underwent renal angiography, we drew blood samples from the aorta and both renal veins and measured mean renal blood flow (MRBF) using the ${ }^{133}$ Xenon washout technique. RPCL was calculated using arteriovenous concentration differences and MRBF.

Results - After correction for potential confounders, reduced eGFR was associated with higher plasma ADMA and SDMA [standardized regression coefficient $(\beta)=-0.22$ ( $95 \%$ confidence interval (Cl): $-0.41 ;-0.04)$ and $\beta=-0.66$ (95\% $\mathrm{Cl}-0.83 ;-0.49)$, respectively]. However, eGFR was not independently associated with RPCL of ADMA. Moreover, reduced RPCL of ADMA was not associated with higher plasma ADMA. Contrary to ADMA, reduced eGFR was indeed associated with lower RPCL of SDMA [ $\beta=0.21(95 \% \mathrm{Cl} 0.02 ; 0.40)]$.

Conclusion - Our findings indicate that RPCL of ADMA is independent of renal function in hypertensive patients with mild to moderate renal insufficiency. Unlike the case for SDMA, reduced RPCL of ADMA is of minor importance for the increase in plasma ADMA in these patients, which indicates that increased plasma ADMA in this population is not a direct consequence of the kidneys failing as a plasma ADMA-regulating organ. 


\section{INTRODUCTION}

In patients with chronic kidney disease (CKD), the endogenous nitric oxide synthase inhibitor asymmetric dimethylarginine (ADMA) and its structural isomer symmetric dimethylarginine (SDMA) build up in plasma even in the early stages of renal insufficiency. ${ }^{1-3}$ Moreover, ADMA already rises in incipient CKD. The exact mechanisms responsible for this increase of ADMA and SDMA at these early stages of CKD have not been totally clarified but are likely to involve changes in the regulation of the plasma concentration by the kidneys' renal plasma clearance (RPCL). ${ }^{4,5}$

The kidneys play an important role in the plasma concentration regulation of ADMA and SDMA. By measuring arteriovenous concentration differences, a previous study demonstrated that the kidneys clear substantial amounts of ADMA and SDMA from the circulation. ${ }^{4}$ Furthermore, both dimethylarginines are excreted in the urine in amounts, which are dependent on the glomerular filtration rate (GFR) ${ }^{5-8}$ However, the main elimination pathway for ADMA is intracellular degradation into citrulline and dimethylamine by the enzyme $N^{G}, N^{G}$-dimethylarginine dimethylaminohydrolase (DDAH), which is highly expressed in the kidney. ${ }^{9-12}$ Nevertheless, DDAH is also expressed in other organs, such as the pancreas, liver, lungs, and endothelium. Contrary to ADMA, SDMA is almost entirely eliminated from the plasma by excretion into the urine and cannot be eliminated by DDAH. ${ }^{3}$ Therefore, it has been proposed that the plasma concentration of SDMA is more affected by reduced GFR and changes in RPCL than the plasma concentration of ADMA. ${ }^{13}$

On the other hand, small amino acids, like these dimethylarginines (molecular weight: $0.2 \mathrm{kDa}$ ), are usually able to freely pass the glomerular barrier, and normally their RPCL does not decrease until glomerular filtration has fallen substantially (moderate to severe CKD). ${ }^{14-16}$ Furthermore, based on their identical molecular weight (a main determinant of RPCL), the dependence of RPCL on GFR should be similar for both dimethylarginines. ${ }^{17}$

Although some studies have addressed the $\mathrm{RPCL}^{4,18}$ or urinary clearance ${ }^{5-8}$ of ADMA and SDMA, these studies have only been performed in subjects with either "severe" CKD or "normal" renal function. Moreover, the studies that measured RPCL by arteriovenous concentration differences did not investigate the relationship with GFR. Accordingly, we performed the present study in a large cohort of hypertensive patients with mild to moderate renal insufficiency to unravel the mechanistic relationship among GFR, RPCL (measured by renal arteriovenous concentration differences), and (arterial) plasma concentrations of ADMA and SDMA in the early phases of renal impairment. 


\section{CHAPTER 4}

\section{METHODS}

\section{Patients and study protocol}

Between May 2002 and July 2008, 326 Caucasian patients underwent diagnostic renal angiography for the exclusion of renal artery stenosis according to a standardized clinical protocol. This protocol includes selective renal blood sampling (for the assessment of ADMA and SDMA) of the aorta, left and right renal veins, selective mean renal blood flow (MRBF) measurements, and renal angiography. Suspicion for renal artery stenosis was based on the following clinical clues: hypertension despite treatment with at least three antihypertensive agents, accelerated hypertension, evident peripheral vascular disease, and the presence of an abdominal bruit or unexplained renal function deterioration, e.g., in response to antihypertensive treatment.

For reasons of standardization, all antihypertensive medication was discontinued for three weeks, and patients were requested to adhere to a sodium-restricted (55 $\mathrm{mmol} / 24-\mathrm{h}$ ) diet during the one wk before renal angiography. In patients with diabetes mellitus (DM), the use of metformin was discontinued two days before renal angiography to lower the risk of contrast medium-induced nephropathy. Other medication, including statins, was allowed. One day before renal angiography, a noninvasive ambulatory 24-h blood pressure measurement was performed (ambulatory blood pressure monitor, SpaceLabs, Redmond, WA), and 24-h urine was collected for the assessment of sodium and urinary albumin excretion (UAE).

After a one-night admission to our ward and an overnight fast, we cannulated the aorta and both renal veins via the femoral route. Subsequently, we drew blood samples simultaneously from the aorta and both renal veins for the assessment of ADMA and SDMA. After centrifugation, plasma samples were immediately stored at $80^{\circ} \mathrm{C}$ until analysis. In addition, we sampled blood for the determination of fasting glucose, serum creatinine, and lipid profile. Subsequently, we measured selective MRBF using the ${ }^{133}$ Xenon washout technique, as previously described. ${ }^{19-21}$ After an intra-arterial administration of ${ }^{133}$ Xenon (IDB Holland, Baarle-Nassau, The Netherlands) into the renal artery, we measured the disappearance of ${ }^{133}$ Xenon from the kidney by an extracorporeal scintillation counter during $180 \mathrm{~s}$. Subsequently, the obtained

${ }^{133}$ Xenon washout curves of the left and right kidney were analyzed offline (using Graphpad Prism 5, Graphpad Software, San Diego, CA). In brief, after the subtraction of background radiation, curves were analyzed mathematically by means of a two-phase exponential decay. MRBF was calculated as the weighted average of the fast and slow component. ${ }^{22}$ Occasionally, a monophasic decline in activity was observed, and the curve was analyzed accordingly. 
During MRBF measurements, heart rate and intra-arterial blood pressure were monitored continuously. MRBF and mean renal plasma flow (MRPF), calculated as MRBF x (1 - hematocrit), were expressed as milliliters per minute per $100 \mathrm{~g}$ of kidney. No contrast agents were administered before the blood sampling and flow measurements were completed. Eventually, intra-arterial renal angiography was performed using a digital subtraction system. An experienced radiologist reported renal (artery) anomalies. The investigations were performed in accordance with the principles outlined in the Declaration of Helsinki. All patients gave their informed consent before inclusion in the study, and the local ethical committee approved the study.

\section{Biochemical analyses}

In the blood samples drawn from the aorta and both renal veins, we assessed plasma concentrations of ADMA and SDMA using an Acquity ultraperformance liquid chromatography separation module coupled to a Quattro Premier Electrospray Ionisation Tandem Mass Spectrometry (Waters, Etten-Leur, The Netherlands). ${ }^{23,24}$ Intra- and interassay variations at physiological concentrations were less than $5 \%$ for ADMA and SDMA. Standard clinical methods were used for the assessment of fasting glucose, serum creatinine, and lipid profile.

\section{Calculations}

GFR was estimated by the CKD Epidemiology Collaboration equation. ${ }^{25}$ Patients were divided into three estimated GFR (eGFR) groups (eGFR $\geq 90$, eGFR 60-89, and eGFR 3059). RPCL (in $\mathrm{ml} / \mathrm{min} / 100 \mathrm{~g}$ kidney) of both kidneys of ADMA and SDMA was calculated as follows: $\{$ MRPF right $x[(A-V$ right $) / A]\}+\{$ MRPF left $x[(A-V$ left $) / A]\}$, where $A$ and $V$ are the arterial and renal vein plasma concentrations, respectively. This calculation corrects a possible overestimation of the fractional renal extraction calculated as: $\{[(A$ $\mathrm{V}) / \mathrm{A})] \times 100 \%\}^{4,18,26}$ in cases of a low renal plasma flow. ${ }^{27}$ A positive RPCL indicates net clearance of the substance from the blood, whereas a negative RPCL indicates net release into the blood.

\section{Statistical analysis}

Normally distributed variables are expressed as mean $\pm \mathrm{SD}$; variables with a skewed distribution are given as medians and interquartile ranges. Variables with a skewed distribution were log transformed before further analyses (UAE and RPCL of ADMA and SDMA). Multiple linear regression analyses were used to investigate: 1) the association between eGFR and arterial plasma concentrations of ADMA and SDMA, 2) the association between eGFR and RPCL of both dimethylarginines, and 3) between RPCL 
of both dimethylarginines and arterial plasma concentrations of ADMA and SDMA. All associations were first analyzed without adjustments and then with adjustments for potential confounders: age, sex, history of cardiovascular events, DM, LDL-cholesterol, smoking, intra-arterial mean arterial pressure (MAP), and UAE. Finally, analyses were adjusted for total renal blood flow (RBF; left MRBF + right MRBF) and/or eGFR, as appropriate. All results are expressed in [standardized regression coefficients $95 \%$ confidence intervals $(\mathrm{Cls})$ ] to allow comparison of the strength of the association between different variables. Two-tailed $P$ values of $<0.05$ were considered significant. Analyses were performed using the SPSS statistical software package (version 15.0, SPSS, Chicago, IL).

\section{RESULTS}

From the 326 patients who had undergone renal angiography, 171 patients were judged eligible for this study by fulfilling the following criteria: essential hypertension (no renovascular abnormalities), complete selective blood sampling for the assessment of ADMA and SDMA, and complete RBF measurements. Baseline characteristics of the included patients did not differ significantly from the total patient group (data not shown). The renal function of the study population ranged between "normal" (eGFR $\geq 90 \mathrm{ml} / \mathrm{min} / 1.73 \mathrm{~m}^{2}$ and no microalbuminuria) and mild to moderate renal insufficiency (stage 2 and 3 CKD according to the National Kidney Foundation Kidney Disease Outcomes Quality Initiative CKD classification). ${ }^{28}$

Table 4.1 Clinical characteristics of the 171 hypertensive patients, divided according to eGFR groups

\begin{tabular}{|c|c|c|c|}
\hline & $\begin{array}{l}\text { eGFR } \geq 90 \\
(n=58)\end{array}$ & $\begin{array}{c}\text { eGFR 60-89 } \\
(n=75)\end{array}$ & $\begin{array}{c}\text { eGFR 30-59 } \\
(n=38)\end{array}$ \\
\hline Age (years) & $44 \pm 13$ & $57 \pm 11$ & $59 \pm 11$ \\
\hline Sex (male/female, \%) & $53 / 47$ & $63 / 37$ & $50 / 50$ \\
\hline Body Mass index $\left(\mathrm{kg} / \mathrm{m}^{2}\right)$ & $27 \pm 5$ & $28 \pm 4$ & $29 \pm 4$ \\
\hline Current smoking (\%) & 29 & 41 & 29 \\
\hline Diabetes Mellitus (\%) & 12 & 12 & 18 \\
\hline Statin use (\%) & 31 & 43 & 50 \\
\hline History of cardiovascular events (\%) & 12 & 17 & 18 \\
\hline 24-h systolic blood pressure ( $\mathrm{mmHg}$ ) & $156 \pm 19$ & $162 \pm 20$ & $162 \pm 18$ \\
\hline 24-h diastolic blood pressure ( $\mathrm{mmHg}$ ) & $97 \pm 10$ & $98 \pm 13$ & $97 \pm 14$ \\
\hline Fasting glucose $(\mathrm{mmol} / \mathrm{l})$ & $5.5 \pm 1.0$ & $5.6 \pm 0.8$ & $5.7 \pm 0.9$ \\
\hline Low-density lipoprotein cholesterol & $3.2 \pm 1.1$ & $3.0 \pm 1.0$ & $3.3 \pm 1.0$ \\
\hline High-density lipoprotein cholesterol & $1.3 \pm 0.5$ & $1.2 \pm 0.4$ & $1.1 \pm 0.3$ \\
\hline Urinary albumin excretion (mg/24-h) & $12(7-19)$ & $53(32-91)$ & $109(44-245)$ \\
\hline
\end{tabular}

Data are presented as means \pm SD, medians (interquartile ranges), or numbers (\%group). eGFR, estimated glomerular filtration rate (in $\mathrm{ml} / \mathrm{min} / 1.73 \mathrm{~m}^{2}$ ) 
Table 4.1 shows the characteristics of the 171 Caucasian hypertensive patients (mean age: $53 \pm 13 \mathrm{yr}, 97$ men and 74 women, mean 24-h blood pressure: 160/97 mmHg without antihypertensive medication) divided into three eGFR groups. The mean values of the eGFR of the different groups (eGFR $\geq 90$, eGFR 60-89, and eGFR 30-59) were $101 \pm 10,79 \pm 7$, and $53 \pm 7 \mathrm{ml} / \mathrm{min} / 1.73 \mathrm{~m}^{2}$, respectively. The prevalence of patients with microalbuminuria $(30-300 \mathrm{mg} / 24-\mathrm{h})$ was $54 \%$ in the overall population. Microalbuminuria was mainly present in patients with an eGFR of $\leq 90 \mathrm{ml} / \mathrm{min} / 1.73 \mathrm{~m}^{2}$. The prevalence of statin use was $40 \%$, and none of the 23 patients with type 2 DM used thiazolidinediones.

Table 4.2 shows arterial and venous plasma concentrations of ADMA and SDMA divided according to eGFR groups. With declining eGFR, arterial and venous (left and right kidney) plasma concentrations of both dimethylarginines increased (Table 2). Contrast tests revealed that the eGFR 60-89 group had significantly higher arterial ADMA and SDMA compared with the eGFR $\geq 90$ group $(P<0.001$ and $P<0.001$, respectively). Moreover, the eGFR 30-59 group showed significantly higher arterial ADMA and SDMA compared with the eGFR $60-89$ group $(P=0.036$ and $P<0.001$, respectively). MRBF (left and right) decreased with declining eGFR, whereas intraarterial MAP did not differ between the eGFR groups.

Furthermore, with declining eGFR, RPCL of both dimethylarginines decreased (Table 4.2). Post hoc analyses showed that RPCL of SDMA significantly decreased across different eGFR groups (eGFR $\geq 90$ vs. eGFR 60-89, P<0.01; and eGFR 60-89 vs. eGFR 30$59, P<0.001)$, whereas $R P C L$ of ADMA only differed significantly between eGFR $\geq 90$ and eGFR 30-59 ( $P=0.014)$. The RPCL of ADMA and SDMA did not differ yet in the group with eGFR $\geq 90 \mathrm{ml} / \mathrm{min} / 1.73 \mathrm{~m}^{2}$. However, in the groups of eGFR 60-89 and eGFR 30-59 $\mathrm{ml} / \mathrm{min} / 1.73 \mathrm{~m}^{2}$, a significant difference between RPCL of ADMA and SDMA was found (Table 4.2).

\section{eGFR and arterial plasma concentrations of ADMA and SDMA}

eGFR and arterial plasma concentrations of both dimethylarginines were inversely associated (Figure 4.1). However, whereas the associations between eGFR and both dimethylarginines were significant, adjustments for potential confounders (age, sex, history of cardiovascular events, DM, LDL, smoking, intra-arterial MAP, UAE, and total RBF) showed a more robust association between eGFR and SDMA [standardized regression coefficient $(\beta)=-0.66(95 \% \mathrm{Cl}:-0.83 ;-0.49), P<0.001]$ compared with ADMA $[\beta=-0.22(-0.41 ;-0.04), P=0.019]$. 
Table 4.2 Renal assessments, divided according to eGFR groups

\begin{tabular}{lcccc}
\hline & $\begin{array}{c}\text { eGFR } \geq 90 \\
(\mathrm{n}=58)\end{array}$ & $\begin{array}{c}\text { eGFR 60-89 } \\
(\mathrm{n}=75)\end{array}$ & $\begin{array}{c}\text { eGFR 30-59 } \\
(\mathrm{n}=38)\end{array}$ & $\begin{array}{c}\text { P value } \\
\text { (trend) }\end{array}$ \\
\hline Arterial ADMA $(\mu \mathrm{mol} / \mathrm{l})$ & $0.44 \pm 0.07$ & $0.47 \pm 0.05$ & $0.49 \pm 0.07$ & 0.001 \\
Arterial SDMA $(\mu \mathrm{mol} / \mathrm{l})$ & $0.49 \pm 0.08$ & $0.55 \pm 0.09$ & $0.67 \pm 0.10$ & $<0.001$ \\
Left renal vein ADMA $(\mu \mathrm{mol} / \mathrm{l})$ & $0.37 \pm 0.06$ & $0.40 \pm 0.05$ & $0.42 \pm 0.07$ & $<0.001$ \\
Left renal vein SDMA $(\mu \mathrm{mol} / \mathrm{l})$ & $0.43 \pm 0.08$ & $0.49 \pm 0.08$ & $0.61 \pm 0.11$ & $<0.001$ \\
Right renal vein ADMA $(\mu \mathrm{mol} / \mathrm{l})$ & $0.37 \pm 0.05$ & $0.40 \pm 0.06$ & $0.42 \pm 0.07$ & $<0.001$ \\
Right renal vein SDMA $(\mu \mathrm{mol} / \mathrm{l})$ & $0.43 \pm 0.08$ & $0.48 \pm 0.09$ & $0.61 \pm 0.11$ & $<0.001$ \\
Left MRBF $(\mathrm{ml} / \mathrm{min} / 100 \mathrm{~g}$ kidney) & $237 \pm 68$ & $206 \pm 55$ & $174 \pm 68$ & $<0.001$ \\
Right MRBF $(\mathrm{ml} / \mathrm{min} / 100 \mathrm{~g}$ kidney) & $279 \pm 86$ & $240 \pm 67$ & $211 \pm 59$ & $<0.001$ \\
Intra-arterial MAP $(\mathrm{mmHg})$ & $126 \pm 17$ & $127 \pm 20$ & $132 \pm 18$ & 0.296 \\
RPCL of ADMA (ml/min/100 g kidney) & $39(26-56)$ & $35(27-45)^{*}$ & $30(18-39)^{*}$ & 0.019 \\
RPCL of SDMA (ml/min/100 g kidney) & $38(28-47)$ & $31(16-44)$ & $17(11-29)$ & $<0.001$ \\
\hline
\end{tabular}

Data are presented as means \pm SD or medians (interquartile ranges). Comparisons of renal measurements across eGFR groups (eGFR $\geq 90$, eGFR 60-89, and eGFR 30-59) were performed using one-way ANOVA. ADMA, asymmetric dimethylarginine; SDMA, symmetric dimethylarginine; MRBF, mean renal blood flow; RPCL, renal plasma clearance. ${ }^{*} \mathrm{P}<0.01$ by paired Student's $t$-test compared with RPCL of SDMA in the same eGFR group

\section{eGFR and renal plasma clearance of ADMA and SDMA}

Table 4.3 shows that the positive association between eGFR and RPCL of ADMA (model 1) was not statistically significant after adjustments for potential confounders (models 2 and 3). In contrast, the positive association between eGFR and RPCL of SDMA (model 1) remained significant even after adjustments for the same confounders in models 2 and 3 [Table 4.3, model 2, $\beta=0.27$ (0.08;0.47), $P=0.007$; model $3, \beta=0.21(0.02 ; 0.40)$, $\mathrm{P}=0.034]$.

\section{Renal plasma clearance of ADMA and SDMA and arterial plasma concentrations of ADMA and SDMA}

Figure 4.2A and Table 4.4 show that there was no significant association between RPCL and the arterial plasma concentration of ADMA. Adjustments for age, sex, history of cardiovascular events, DM, LDL-cholesterol, smoking, intra-arterial MAP, and UAE in model 2 did not change these results (Table 4.4). However, additional adjustments for total RBF and GFR in models 3 and 4 enhanced the association to some extent, but the association remained statistically nonsignificant. 


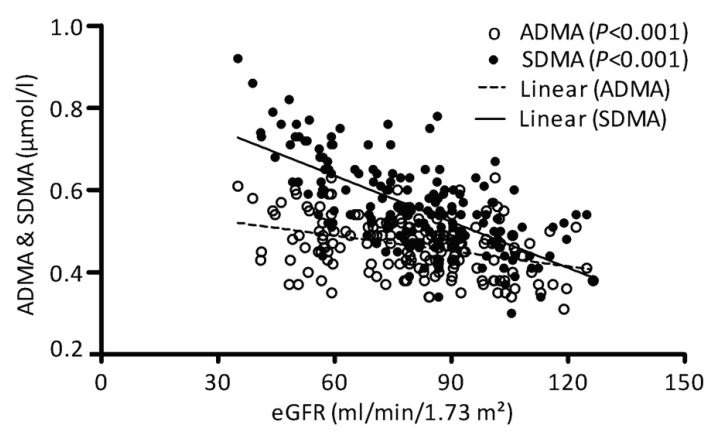

Figure 4.1 Crude linear regression between estimated glomerular filtration rate (eGFR) and arterial plasma concentrations of asymmetric dimethylarginine (ADMA) and symmetric dimethylarginine (SDMA). [Standardized linear regression coefficients $(\beta)$ for ADMA and SDMA were -0.36 ( $95 \%$ confidence interval: $0.51 ;-0.21), P<0.001$ and $\beta=-0.65(-0.77 ;-0.52), P<0.001$, respectively]. This means that for every 1 SD decrease in eGFR, there was a 0.36 SD increase in ADMA and a 0.65 SD increase in SDMA

Crude analysis revealed an inverse association between RPCL and the arterial plasma concentration of SDMA (Table 4.4, model 1, and Fig. 4.2B). Adjustments for potential confounders in model 2 did not materially change the strength of the association (Table 4.4). Finally, after additional adjustments for total RBF and eGFR, the association between RPCL of SDMA and the arterial plasma concentration of SDMA diminished to a large extent [Table $4.4, \beta$ from $-0.20(-0.35 ;-0.05), P=0.009$, in model 2 to $-0.08(-0.21 ; 0.05), P=0.239$, in model 4$]$.

Table 4.3 Associations between eGFR and renal plasma clearance of ADMA and SDMA

\begin{tabular}{|c|c|c|c|c|c|c|}
\hline & \multicolumn{3}{|c|}{ Renal plasma clearance ADMA } & \multicolumn{3}{|c|}{ Renal plasma clearance SDMA } \\
\hline & $\beta^{*}$ & $95 \% \mathrm{Cl}$ & $P$ value & $\beta^{*}$ & $95 \% \mathrm{Cl}$ & P value \\
\hline \multicolumn{7}{|l|}{ eGFR } \\
\hline Model 1 & 0.24 & $0.08 ; 0.39$ & 0.003 & 0.45 & $0.31 ; 0.59$ & $<0.001$ \\
\hline Model 2 & 0.18 & $-0.03 ; 0.40$ & 0.096 & 0.27 & $0.08 ; 0.47$ & 0.007 \\
\hline Model 3 & 0.10 & $-0.11 ; 0.31$ & 0.367 & 0.21 & $0.02 ; 0.40$ & 0.034 \\
\hline
\end{tabular}

${ }^{*} \beta$ standardized regression coefficient indicates an increase (in SDs) of the renal plasma clearance of asymmetric dimethylarginine (ADMA) or symmetric dimethylarginine (SDMA) variable per 1 SD increase in eGFR. Cl, confidence interval; Model 1, crude analysis; Model 2, adjustments for age, sex, history of cardiovascular events, diabetes mellitus, low-density lipoprotein cholesterol, smoking, intra-arterial mean arterial pressure, and urinary albumin excretion; Model 3, model $2+$ total renal blood flow 


\section{CHAPTER 4}

Table 4.4 Association between renal plasma clearances and plasma concentrations of ADMA and SDMA

\begin{tabular}{lcccc}
\hline Independent variables & \multicolumn{4}{c}{ Dependent variable: arterial ADMA } \\
\cline { 2 - 5 } & Model & $\beta^{*}$ & $95 \% \mathrm{Cl}$ & P value \\
\hline Renal plasma clearance ADMA & 1 & -0.01 & $-0.17 ; 0.15$ & 0.866 \\
& 2 & 0.03 & $-0.11 ; 0.17$ & 0.708 \\
& 3 & 0.09 & $-0.05 ; 0.24$ & 0.216 \\
& 4 & 0.11 & $-0.04 ; 0.25$ & 0.150 \\
\hline Renal plasma clearance SDMA & Model & $\beta^{*}$ & $95 \%$ Cl & P value \\
& 1 & -0.26 & $-0.42 ;-0.11$ & 0.001 \\
& 2 & -0.20 & $-0.35 ;-0.05$ & 0.009 \\
& 3 & -0.12 & $-0.27 ; 0.04$ & 0.139 \\
& 4 & -0.08 & $-0.21 ; 0.05$ & 0.239
\end{tabular}

${ }^{*} \beta$ standardized regression coefficient indicate an increase (in SDs) of asymmetric dimethylarginine (ADMA) or symmetric dimethylarginine (SDMA) variable per 1 SD increase in renal plasma clearance of ADMA or SDMA. Cl, confidence intervals; Model 1, crude analysis; Model 2, adjustments for age, sex, history of cardiovascular events, diabetes mellitus, low-density lipoprotein cholesterol, smoking, intra-arterial mean arterial pressure, and urinary albumin excretion; Model 3, model $2+$ total renal blood flow; Model 4, model3 + eGFR
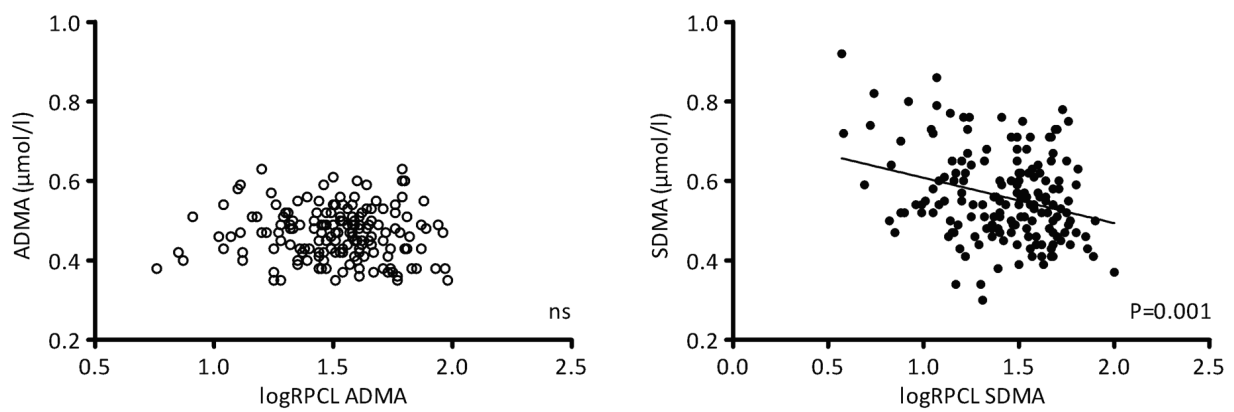

Figure 4.2 Crude linear regression between log renal plasma clearance (RPCL) of asymmetric dimethylarginine (ADMA) and symmetric dimethylarginine (SDMA) and arterial plasma concentrations of ADMA and SDMA. [Standardized linear regression coefficients $(\beta)$ values for ADMA and SDMA were -0.01 (95\% coincidence interval: $-0.17 ; 0.15), P=0.866$ and $-0.26(-0.42 ;-0.11), P=0.001)$, respectively]. This means that for every 1 SD decrease in $\operatorname{logRPCL}$ of ADMA, there was a 0.01 SD increase in ADMA. For every 1-SD decrease in $\operatorname{logRPCL}$ of SDMA, there was a 0.26 SD increase in SDMA; ns, not significant

\section{Additional analyses}

In the aforementioned analyses, we showed an independent association between eGFR and RPCL of SDMA (Table 3, model 3), and we showed that the association between RPCL and the arterial plasma concentration of SDMA could be explained (mediated) to a large extent by eGFR and total RBF in this population (Table 4, models 
3 and 4). Therefore, we additionally investigated the extent to which the association between eGFR and the arterial plasma concentration of SDMA could be explained (mediated) by RPCL of SDMA. Additional adjustment for RPCL of SDMA (after adjustments for potential confounders) in the association between eGFR and the arterial plasma concentration of SDMA attenuated the association to some extent [ $\beta$ from $-0.66(-0.83 ;-0.49), P<0.001$, to $-0.48(-0.73 ;-0.22), P<0.001]$. RPCL of SDMA explained $27 \%$ (change of $\beta$ from -0.66 to -0.48 ) of the association between eGFR and the arterial concentration of SDMA.

The association between eGFR and plasma concentrations of ADMA and SDMA did not differ according sex $(\mathrm{P}=0.304$ and $\mathrm{P}=0.226$ for sex interaction, respectively). Furthermore, we found no effect modification by sex in any of the other investigated associations, i.e., in the associations between eGFR and RPCL of both dimethylarginines and in the associations between RPCL of both dimethylarginines and their plasma concentrations.

\section{DISCUSSION}

The present study is the first in a large group of hypertensive patients with mild to moderate renal insufficiency that directly measured arteriovenous ADMA and SDMA concentration differences of both kidneys in combination with selective MRBF measurements to investigate the relationship between renal function (eGFR), RPCL, and (arterial) plasma concentrations of both dimethylarginines. We found that plasma concentrations of ADMA and SDMA increased with declining renal function. However, the RPCL of ADMA was independent of renal function in this population. Moreover, a lower RPCL of ADMA was not associated with a higher arterial concentration of ADMA. On the other hand, reduced renal function was indeed associated with lower RPCL of SDMA, and the association between lower RPCL of SDMA and higher plasma concentration of SDMA could be explained by the combination of renal function and RBF. Taken together, these data suggest, first, that reduced renal function does not necessarily result in decreased RPCL of ADMA, whereas it does result in decreased RPCL of SDMA at these stages of renal insufficiency. Second, decreased RPCL of ADMA does not explain the increase in plasma concentration of ADMA in this hypertensive population with mild to moderate renal insufficiency, whereas a decreased RPCL of SDMA does so for the increase in the plasma concentration of SDMA.

Increased ADMA plasma concentration has been reported in a wide range of cardiovascular disorders. ${ }^{29-32}$ Among these conditions, ADMA plasma concentration is particularly high in patients with $C K D .^{5}$ Although the association between reduced renal function and accumulation of ADMA in CKD has been addressed in several studies, $^{6,8,33,34}$ findings have been variable and studies could not always confirm the 
existence of an independent association. ${ }^{2,4,35}$ This is not surprising considering the fact that ADMA is $80 \%$ eliminated via intracellular enzymatic degradation by $D^{2} H^{36}$ and not primary by urinary excretion, which is probably more GFR dependent. Notably, DDAH activity is not confined to the kidney but also present in the liver and other organs. Moreover, it is conceivable that depending on the pathophysiological cause and severity of renal insufficiency, the decline in renal excretory function is not paralleled by a reduction in renal DDAH activity. Finally, other mechanisms involved in the plasma regulation of ADMA, synthesis of ADMA by posttranscriptional methylation of proteins catalyzed by protein arginine methyltransferases (PRMT), ${ }^{37}$ protein turnover, transcellular transport of ADMA by cationic amino acid transporters (CAT), ${ }^{38}$ and metabolism by alanine-glyoxylate aminotransferase $2^{39,40}$ may or may not be affected and contribute to the accumulation of ADMA in a particular population of CKD. ${ }^{41,42}$

The results of previous studies ${ }^{2,3,6,8,33,34,43}$ regarding the association between reduced GFR and higher plasma SDMA concentration are more consistent and generally demonstrated, similar to our study, a much stronger association between GFR and SDMA compared with the association with ADMA. A meta-analysis of these studies even suggested that SDMA is a reliable endogenous marker of renal function. ${ }^{3}$ However, considering the fact that SDMA is almost entirely eliminated from the plasma by excretion in the urine, our finding that reduced RPCL explains only $27 \%$ of the rise in plasma SDMA concentration in this population is less than we expected. This indicates that the plasma clearance of SDMA is not exclusively assigned to the kidney and implies that the plasma concentration of SDMA is not solely regulated by the balance between production and clearance. Siroen et al. showed that the human liver also takes up substantial amounts of SDMA (and ADMA) from the portal and systemic circulation, which shows that the liver also contributes to the plasma clearance of SDMA. ${ }^{18}$ However, the results of a study in subjects with hepatorenal syndrome suggested that renal dysfunction is the main determinant of increased SDMA concentration. ${ }^{44}$ Accordingly, the increased synthesis of SDMA by type II PRMT in our study may explain that the increased plasma concentration in this population is not exclusively assigned to the kidneys and RPCL. Unfortunately, the specific contribution of increased PRMT activity on increasing plasma concentration of SDMA in humans with CKD is unknown.

The first key finding of the present study is that in contrast to the RPCL of SDMA, the RPCL of ADMA was independent of renal function in our population. From a theoretical point of view, these findings seem surprising. Assuming that the RPCL of both ADMA and SDMA is determined mainly by their molecular weight (similar weight of $0.2 \mathrm{kDa}$ ), one would expect an equal dependency of the RPCL on renal function. ${ }^{17}$ Indeed, 
previous studies showed that the RPCL of comparable small proteins is independent of renal function until glomerular filtration has fallen substantially (moderate to severe CKD). ${ }^{14,15}$ On the other hand, steric or electrostatic factors could play a role in determining a difference in RPCL between ADMA and SDMA. ${ }^{17}$ Indeed, some studies in patients with end-stage renal disease showed that SDMA, although of similar molecular weight, could be much more easily removed by dialysis than ADMA.,45-47 We must also bear in mind that the calculation of RPCL using arteriovenous concentration differences represents the net amount of substance extracted from the plasma by both kidneys. The outcome of the RPCL calculation is a result of the net balance between all possible mechanisms in the kidney contributing to the regulation of the plasma concentration of a substance. This includes not only the three main routes of renal ADMA clearance from the plasma by 1) uptake by cells via transport by CAT followed by intracellular degradation by $\mathrm{DDAH}^{38,48}$, 2) metabolism by alanineglyoxylate aminotransferase $2^{39,40}$, and 3 ) urinary excretion but also the release of ADMA into the plasma. Our results, although indirectly, indicate that the net effect of all these renal plasma ADMA regulating mechanisms is independent from renal function in hypertensive patients with mild to moderate renal insufficiency, whereas RPCL of SDMA is renal function dependent at these stages of renal insufficiency. Perhaps RPCL of ADMA will be dependent of renal function at more advanced stages of renal insufficiency.

Our second key finding contradicts the commonly held notion that impaired renal (plasma) clearance of ADMA accounts, at least in part, for the increase in plasma ADMA concentration in patients with mild to moderate renal insufficiency. The combination of the frequently reported inverse correlation between impaired renal function and elevated ADMA plasma concentration and substantially decreased urinary excretion of ADMA suggested a causal relation between reduced renal function and elevated ADMA plasma concentration. However, the present study shows that reduced $R P C L$ of ADMA cannot explain the increase of plasma ADMA concentration in our population. Previous studies in subnephrectomized ${ }^{37}$ and totally nephrectomized ${ }^{49}$ rats are in line with our data, lending further credibility to our results. First, plasma concentration of ADMA increased in proportion to the degree of nephrectomy despite a marked increased RPCL of ADMA. ${ }^{37}$ Contrary to ADMA, RPCL of SDMA was indeed impaired in subnephrectomized rats. Second, both liver and kidney gene expression of PRMT increased, whereas DDAH protein expression decreased in subnephrectomized rats. $^{37}$ These results indicate that probably the enzymatic changes rather than decreased GFR and RPCL caused the increased plasma concentration of ADMA. Finally, the study in totally nephrectomized rats demonstrated that total plasma clearance of ADMA did not change after total nephrectomy and the plasma concentration of ADMA 
even decreased, which suggests a role for (compensatory) systemic ADMA metabolism in this acute condition. ${ }^{49}$ Therefore, the increase in the plasma concentration of ADMA may be a marker (or consequence) of systemic endothelial dysfunction, increased oxidative stress, or atherosclerosis in our population with mild to moderate renal insufficiency rather than the result of reduced RPCL. 50,51

There are limitations to our study. First, we cannot establish whether the associations are causal due to the cross-sectional design of the study. Unfortunately, the invasive nature of the selective renal blood sampling and renal plasma flow measurements prohibit a longitudinal study design and more robust conclusions. Second, in the present study, the calculated RPCL represents the net amount of substance extracted from the plasma by both kidneys. This calculation includes all possible mechanisms in the kidney contributing to the net clearance of ADMA from the plasma (metabolic mechanisms ${ }^{38,40}$ and urinary excretion ${ }^{5-8}$ ). Unfortunately, in this study, we were not able to differentiate between these mechanisms, partly because we did not analyze the 24-h urine for ADMA and SDMA. Furthermore, plasma concentrations of dimethylarginines are the result of many other processes at the intracellular and organ levels besides the kidneys. Third, we used arterial plasma concentrations of both dimethylarginines from the aorta for our analyses and associations, which makes comparison with plasma concentrations of venous blood derived from the antecubital vein difficult. Therefore, we cannot determine whether the range of our ADMA and SDMA plasma concentrations in this hypertensive population with mild to moderate renal insufficiency is considered "normal" or "increased" compared with "healthy" adults. ${ }^{4,18,52}$ Furthermore, associations made in an apparently "normal" range of ADMA plasma concentration may elicit the absence of specific associations. However, additional analyses in the highest quartile of ADMA plasma concentration still revealed no independent association between RPCL of ADMA and the plasma concentration of ADMA or eGFR and RPCL of ADMA in this population.

In conclusion, in this study of hypertensive patients with mild to moderate renal insufficiency, RPCL of ADMA is independent of renal function after correction for several cardiovascular risk factors. Moreover, the contribution of decreased RPCL appears to be of minor importance in the relationship between renal function and increase in the plasma concentration of ADMA. This suggests that other, possibly extrarenal, mechanisms than decreased RPCL play a key role in the relationship between renal function and the increase in the plasma ADMA concentration. In contrast, reduced RPCL of SDMA was found to play a significant role in the relationship between renal function and the increase of plasma SDMA concentration in this population. 


\section{Perspectives}

Because the plasma concentration of ADMA increases in patients with CKD $^{5}$ and the kidneys play an important role in the plasma concentration regulation of ADMA, ${ }^{4}$ reduced $\mathrm{RPCL}$ appears a logical explanation for the increase in this population. The present study, however, indicated that the increased plasma ADMA concentration is not a direct consequence of the kidneys failing but merely a result of extrarenal changes in the regulation of ADMA related to reduced renal function in patients with mild to moderate CKD. Indeed, in addition to the kidneys, the liver is an important plasma ADMA-clearing (and regulating) organ. ${ }^{18,53}$ An animal study has indicated that after subtotal nephrectomy, liver gene expression of type I PRMT activity (responsible for ADMA synthesis) increased, whereas liver expression levels of DDAH decreased. ${ }^{37}$ However, more studies in patients with CKD are needed to unravel the interaction between the kidneys and liver as plasma ADMA-regulating organs in humans. An alternative extrarenal explanation for our finding of increased plasma ADMA is an overall increased production initiated by oxidative stress. In the presence of cardiovascular risk factors such as hypertension, hypercholesterolemia, smoking, DM, aging, and end-stage CKD, oxidative stress is increased. Interestingly, oxidative stress has already been reported in CKD stage 3 patients. ${ }^{54}$ Recent studies investigating the interaction between reactive oxygen species (ROS) and ADMA showed that ROS can increase type I PRMT activity, decrease DDAH activity, and decrease CAT activity, thereby increasing cellular ADMA concentrations. ${ }^{51,55,56}$ Over time, this could be accompanied by an increase in the plasma concentration of ADMA, like in our study population. ${ }^{38}$ Although a role for oxidative stress in the increase in the plasma concentration of ADMA in a population of patients with mild to moderate CKD is plausible, more studies are needed to confirm this hypothesis.

\section{Acknowledgements}

The authors gratefully acknowledge M. Fuss-Lejeune for assistance with the blood sampling and measurements during renal angiography and $W$. Waterval for the analyses of plasma dimethylarginines. This study was supported by a "clinical established investigator" grant from the Dutch Heart Foundation (DHF; Grant No. 2004T058) obtained by Dr. A.A. Kroon. 


\section{CHAPTER 4}

\section{REFERENCES}

1. Caglar K, Yilmaz MI, Sonmez A, Cakir E, Kaya A, Acikel C, Eyileten T, Yenicesu M, Oguz Y, Bilgi C, Oktenli C, Vural A, Zoccali C. ADMA, proteinuria, and insulin resistance in non-diabetic stage I chronic kidney disease. Kidney Int. 2006;70:781-787.

2. Kielstein JT, Boger RH, Bode-Boger SM, Frolich JC, Haller H, Ritz E, Fliser D. Marked increase of asymmetric dimethylarginine in patients with incipient primary chronic renal disease. J Am Soc Nephrol. 2002;13:170-176.

3. Kielstein JT, Salpeter SR, Bode-Boeger SM, Cooke JP, Fliser D. Symmetric dimethylarginine (SDMA) as endogenous marker of renal function--a meta-analysis. Nephrol Dial Transplant. 2006;21:2446-2451.

4. Nijveldt RJ, Van Leeuwen PA, Van Guldener C, Stehouwer CD, Rauwerda JA, Teerlink T. Net renal extraction of asymmetrical (ADMA) and symmetrical (SDMA) dimethylarginine in fasting humans. Nephrol Dial Transplant. 2002;17:1999-2002.

5. Vallance $P$, Leone A, Calver A, Collier J, Moncada S. Accumulation of an endogenous inhibitor of nitric oxide synthesis in chronic renal failure. Lancet. 1992;339:572-575.

6. Al Banchaabouchi M, Marescau B, Possemiers I, D'Hooge R, Levillain O, De Deyn PP. NG, NGdimethylarginine and NG, NG-dimethylarginine in renal insufficiency. Pflugers Arch. 2000;439:524531.

7. MacAllister RJ, Rambausek MH, Vallance P, Williams D, Hoffmann KH, Ritz E. Concentration of dimethyl-L-arginine in the plasma of patients with end-stage renal failure. Nephrol Dial Transplant. 1996;11:2449-2452.

8. Marescau B, Nagels G, Possemiers I, De Broe ME, Becaus I, Billiouw JM, Lornoy W, De Deyn PP. Guanidino compounds in serum and urine of nondialyzed patients with chronic renal insufficiency. Metabolism. 1997;46:1024-1031.

9. Kimoto $M$, Tsuji $H$, Ogawa $T$, Sasaoka $K$. Detection of NG,NG-dimethylarginine dimethylaminohydrolase in the nitric oxide-generating systems of rats using monoclonal antibody. Arch Biochem Biophys. 1993;300:657-662.

10. Leiper JM, Santa Maria J, Chubb A, MacAllister RJ, Charles IG, Whitley GS, Vallance P. Identification of two human dimethylarginine dimethylaminohydrolases with distinct tissue distributions and homology with microbial arginine deiminases. Biochem J. 1999;343 Pt 1:209-214.

11. Tran CT, Fox MF, Vallance $\mathrm{P}$, Leiper JM. Chromosomal localization, gene structure, and expression pattern of DDAH1: comparison with DDAH2 and implications for evolutionary origins. Genomics. 2000;68:101-105.

12. Hu X, Atzler D, Xu X, Zhang P, Guo H, Lu Z, Fassett J, Schwedhelm E, Boger RH, Bache RJ, Chen Y. Dimethylarginine dimethylaminohydrolase-1 is the critical enzyme for degrading the cardiovascular risk factor asymmetrical dimethylarginine. Arterioscler Thromb Vasc Biol. 2011;31:1540-1546.

13. Kielstein JT, Fliser D, Veldink H. Asymmetric dimethylarginine and symmetric dimethylarginine: axis of evil or useful alliance? Semin Dial. 2009;22:346-350.

14. Buijs MM, de Leeuw PW, Houben AJ, Kroon AA, Frolich M, Pijl H, Meinders AE. Renal contribution to increased clearance of exogenous growth hormone in obese hypertensive patients. $J$ Clin Endocrinol Metab. 2005;90:795-799.

15. Fogteloo AJ, Meinders AE, Pijl H, Kroon AA, Frolich M, De Leeuw PW. Renal clearance of endogenous leptin in hypertensive humans with or without renal artery stenosis. Am J Physiol Endocrinol Metab. 2001;281:E400-404.

16. Rennenberg RJ, Schurgers L, Vermeer C, Scholte JB, Houben AJ, de Leeuw PW, Kroon AA. Renal handling of matrix Gla-protein in humans with moderate to severe hypertension. Hypertens Res. 2008;31:1745-1751.

17. Maack T, Johnson V, Kau ST, Figueiredo J, Sigulem D. Renal filtration, transport, and metabolism of low-molecular-weight proteins: a review. Kidney Int. 1979;16:251-270. 
18. Siroen MP, van der Sijp JR, Teerlink T, van Schaik C, Nijveldt RJ, van Leeuwen PA. The human liver clears both asymmetric and symmetric dimethylarginine. Hepatology. 2005;41:559-565.

19. de Leeuw PW, Birkenhager WH. Use of the xenon-133 washout technique in diagnosing renovascular disease in hypertension. Nephron. 1986;44 Suppl 1:5-7.

20. Ladefoged J. Measurements of the renal blood flow in man with the 133 xenon wash-out technique. A description of the method. Scand J Clin Lab Invest. 1966;18:299-315.

21. Wierema TK, Houben AJ, Kroon AA, Koster D, van der Zander K, van Engelshoven JM, de Leeuw PW. Nitric oxide dependence of renal blood flow in patients with renal artery stenosis. J Am Soc Nephrol. 2001;12:1836-1843.

22. Hollenberg NK, Mangel R, Fung HY. Assessment of intrarenal perfusion with radioxenon: a critical review of analytical factors and their implications in man. Semin Nucl Med. 1976;6:193-216.

23. Martens-Lobenhoffer J, Bode-Boger SM. Chromatographic-mass spectrometric methods for the quantification of L-arginine and its methylated metabolites in biological fluids. J Chromatogr B Analyt Technol Biomed Life Sci. 2007;851:30-41.

24. Waterval WA, Scheijen JL, Ortmans-Ploemen MM, Habets-van der Poel CD, Bierau J. Quantitative UPLC-MS/MS analysis of underivatised amino acids in body fluids is a reliable tool for the diagnosis and follow-up of patients with inborn errors of metabolism. Clin Chim Acta. 2009;407:36-42.

25. Levey AS, Stevens LA, Schmid CH, Zhang YL, Castro AF, 3rd, Feldman HI, Kusek JW, Eggers P, Van Lente $\mathrm{F}$, Greene T, Coresh J. A new equation to estimate glomerular filtration rate. Ann Intern Med. 2009;150:604-612.

26. Yeung KK, De Gouyon Matignon C, Renwarin L, Tjon AFMR, Teerlink T, van Leeuwen PA, Musters RJ, Wisselink W, Tangelder GJ. Hypothermic renal perfusion during aortic surgery reduces the presence of lipocalin-2 and preserves renal extraction of dimethylarginines in rats. Am J Physiol Renal Physiol. 2011;301:F1231-1241.

27. Andersson LG, Bratteby LE, Ekroth R, Wesslen O, Hallhagen S. Calculation of renal extraction during high diuresis and low renal plasma flow conditions. Clin Physiol. 1994;14:79-85.

28. Levey AS, Coresh J, Balk E, Kausz AT, Levin A, Steffes MW, Hogg RJ, Perrone RD, Lau J, Eknoyan G. National Kidney Foundation practice guidelines for chronic kidney disease: evaluation, classification, and stratification. Ann Intern Med. 2003;139:137-147.

29. Boger RH, Bode-Boger SM, Szuba A, Tsao PS, Chan JR, Tangphao O, Blaschke TF, Cooke JP. Asymmetric dimethylarginine (ADMA): a novel risk factor for endothelial dysfunction: its role in hypercholesterolemia. Circulation. 1998;98:1842-1847.

30. Miyazaki H, Matsuoka H, Cooke JP, Usui M, Ueda S, Okuda S, Imaizumi T. Endogenous nitric oxide synthase inhibitor: a novel marker of atherosclerosis. Circulation. 1999;99:1141-1146.

31. Tarnow L, Hovind $\mathrm{P}$, Teerlink T, Stehouwer CD, Parving $\mathrm{HH}$. Elevated plasma asymmetric dimethylarginine as a marker of cardiovascular morbidity in early diabetic nephropathy in type 1 diabetes. Diabetes Care. 2004;27:765-769.

32. Zoccali C, Bode-Boger S, Mallamaci F, Benedetto F, Tripepi G, Malatino L, Cataliotti A, Bellanuova I, Fermo I, Frolich J, Boger R. Plasma concentration of asymmetrical dimethylarginine and mortality in patients with end-stage renal disease: a prospective study. Lancet. 2001;358:2113-2117.

33. Fliser D, Kronenberg F, Kielstein JT, Morath C, Bode-Boger SM, Haller H, Ritz E. Asymmetric dimethylarginine and progression of chronic kidney disease: the mild to moderate kidney disease study. J Am Soc Nephrol. 2005;16:2456-2461.

34. Nanayakkara PW, Teerlink T, Stehouwer CD, Allajar D, Spijkerman A, Schalkwijk C, ter Wee PM, van Guldener C. Plasma asymmetric dimethylarginine (ADMA) concentration is independently associated with carotid intima-media thickness and plasma soluble vascular cell adhesion molecule-1 (sVCAM-1) concentration in patients with mild-to-moderate renal failure. Kidney Int. 2005;68:2230-2236. 


\section{CHAPTER 4}

35. Fleck C, Schweitzer F, Karge E, Busch M, Stein G. Serum concentrations of asymmetric (ADMA) and symmetric (SDMA) dimethylarginine in patients with chronic kidney diseases. Clin Chim Acta. 2003;336:1-12.

36. Achan V, Broadhead M, Malaki M, Whitley G, Leiper J, MacAllister R, Vallance P. Asymmetric dimethylarginine causes hypertension and cardiac dysfunction in humans and is actively metabolized by dimethylarginine dimethylaminohydrolase. Arterioscler Thromb Vasc Biol. 2003;23:1455-1459.

37. Matsuguma K, Ueda S, Yamagishi S, Matsumoto Y, Kaneyuki U, Shibata R, Fujimura T, Matsuoka H, Kimoto $\mathrm{M}$, Kato S, Imaizumi T, Okuda S. Molecular mechanism for elevation of asymmetric dimethylarginine and its role for hypertension in chronic kidney disease. J Am Soc Nephrol. 2006;17:2176-2183.

38. Teerlink T, Luo Z, Palm F, Wilcox CS. Cellular ADMA: regulation and action. Pharmacol Res. 2009;60:448-460.

39. Ogawa T, Kimoto M, Sasaoka K. Dimethylarginine:pyruvate aminotransferase in rats. Purification, properties, and identity with alanine:glyoxylate aminotransferase 2. J Biol Chem. 1990;265:2093820945.

40. Rodionov RN, Murry DJ, Vaulman SF, Stevens JW, Lentz SR. Human alanine-glyoxylate aminotransferase 2 lowers asymmetric dimethylarginine and protects from inhibition of nitric oxide production. J Biol Chem. 2010;285:5385-5391.

41. Zoccali $C$. Endothelial dysfunction and the kidney: emerging risk factors for renal insufficiency and cardiovascular outcomes in essential hypertension. J Am Soc Nephrol. 2006;17:S61-63.

42. Ueda S, Yamagishi S, Okuda S. New pathways to renal damage: role of ADMA in retarding renal disease progression. J Nephrol. 2010;23:377-386.

43. Bode-Boger SM, Scalera F, Kielstein JT, Martens-Lobenhoffer J, Breithardt G, Fobker M, Reinecke H. Symmetrical dimethylarginine: a new combined parameter for renal function and extent of coronary artery disease. J Am Soc Nephrol. 2006;17:1128-1134.

44. Lluch P, Mauricio MD, Vila JM, Segarra G, Medina P, Del Olmo JA, Rodrigo JM, Serra MA. Accumulation of symmetric dimethylarginine in hepatorenal syndrome. Exp Biol Med (Maywood). 2006;231:70-75.

45. Anderstam B, Katzarski K, Bergstrom J. Serum levels of NG, NG-dimethyl-L-arginine, a potential endogenous nitric oxide inhibitor in dialysis patients. J Am Soc Nephrol. 1997;8:1437-1442.

46. Bergamini S, Vandelli L, Bellei E, Rota C, Manfredini P, Tomasi A, Albertazzi A, lannone A. Relationship of asymmetric dimethylarginine to haemodialysis hypotension. Nitric Oxide. 2004;11:273-278.

47. Kalousova M, Kielstein JT, Hodkova M, Zima T, Dusilova-Sulkova S, Martens-Lobenhoffer J, BodeBoger SM. No benefit of hemodiafiltration over hemodialysis in lowering elevated levels of asymmetric dimethylarginine in ESRD patients. Blood Purif. 2006;24:439-444.

48. Teerlink T. ADMA metabolism and clearance. Vasc Med. 2005;10 Suppl 1:S73-81.

49. Carello KA, Whitesall SE, Lloyd MC, Billecke SS, D'Alecy LG. Asymmetrical dimethylarginine plasma clearance persists after acute total nephrectomy in rats. Am J Physiol Heart Circ Physiol. 2006;290:H209-216.

50. Perticone F, Maio R, Tripepi G, Zoccali C. Endothelial dysfunction and mild renal insufficiency in essential hypertension. Circulation. 2004;110:821-825.

51. Wilcox CS. Asymmetric dimethylarginine and reactive oxygen species: unwelcome twin visitors to the cardiovascular and kidney disease tables. Hypertension. 2012;59:375-381.

52. Di Gangi IM, Chiandetti L, Gucciardi A, Moret V, Naturale M, Giordano G. Simultaneous quantitative determination of $\mathrm{N}(\mathrm{G}), \mathrm{N}(\mathrm{G})$-dimethyl-L-arginine or asymmetric dimethylarginine and related pathway's metabolites in biological fluids by ultrahigh-performance liquid chromatography/electrospray ionization-tandem mass spectrometry. Anal Chim Acta. 2010;677:140148. 
53. Nijveldt RJ, Siroen MP, Teerlink T, van Leeuwen PA. Elimination of asymmetric dimethylarginine by the kidney and the liver: a link to the development of multiple organ failure? J Nutr. 2004;134:2848S2852S; discussion 2853S.

54. Oberg BP, McMenamin E, Lucas FL, McMonagle E, Morrow J, Ikizler TA, Himmelfarb J. Increased prevalence of oxidant stress and inflammation in patients with moderate to severe chronic kidney disease. Kidney Int. 2004;65:1009-1016.

55. Boger RH, Sydow K, Borlak J, Thum T, Lenzen H, Schubert B, Tsikas D, Bode-Boger SM. LDL cholesterol upregulates synthesis of asymmetrical dimethylarginine in human endothelial cells: involvement of Sadenosylmethionine-dependent methyltransferases. Circ Res. 2000;87:99-105.

56. Luo Z, Teerlink T, Griendling K, Aslam S, Welch WJ, Wilcox CS. Angiotensin II and NADPH oxidase increase ADMA in vascular smooth muscle cells. Hypertension. 2010;56:498-504. 



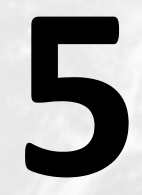

The renal handling of asymmetric dimethylarginine in hypertensive patients: renal plasma clearance vs. urinary clearance

Rianne A. Ronden

Marian J. Hommels

Alfons J.H.M. Houben

Tom Teerlink

Coen D.A. Stehouwer

Peter W. de Leeuw

Abraham A. Kroon 


\section{CHAPTER 5}

\section{ABSTRACT}

Background and objective - When plasma concentrations of a substance increase in patients with chronic kidney disease (CKD) and the kidneys are known as a clearing organ of the particular substance, reduced renal clearance of the substance appears a logical explanation for the increase in plasma concentration. Yet, in the case of ADMA this relation is not as straightforward as it seems. Therefore, we investigated the role of urinary clearance and renal plasma clearance of ADMA in the relation between renal function and plasma concentrations of ADMA.

Methods - In 87 patients who underwent renal angiography, we drew blood samples from the aorta and both renal veins, collected 24-h urine and measured mean renal blood flow (MRBF) using the ${ }^{133}$ Xenon washout technique. From these measurements we calculated the renal plasma clearance and urinary clearance of ADMA.

Results - Reduced eGFR was associated with higher plasma ADMA [standardized regression coefficient $(\beta)=-0.27$ (95\% confidence interval $(\mathrm{Cl})$ : -0.52;-0.03)]. Urinary ADMA clearance explained about $22 \%$ (change of $\beta$ from -0.27 to -0.21 ) of this association. Moreover, reduced RPCL of ADMA was not associated with higher plasma ADMA.

Conclusion - Our findings indicate that renal plasma clearance of ADMA is mainly determined by the metabolic degradation processes of ADMA and this is mainly independent of renal function. Furthermore, increased plasma ADMA in a hypertensive population with mild to moderate renal insufficiency is not due to failure of the kidney as a plasma ADMA clearing organ. 


\section{INTRODUCTION}

Plasma concentrations of the endogenous nitric oxide synthase inhibitor asymmetric dimethylarginine (ADMA) already increase in early phases of renal insufficiency. ${ }^{1-3} \mathrm{~A}$ plausible explanation for this phenomenon would be that the kidneys fail as a plasma ADMA clearing organ. However, a previous study by our group demonstrated that renal plasma clearance (RPCL) of ADMA, the net outcome of all clearing mechanisms that contribute to plasma ADMA clearance by the kidneys, is of minor importance in the association between renal function and plasma ADMA in hypertensive patients with mild to moderate renal insufficiency. ${ }^{4}$ Unfortunately, in that study, we did not measure urinary excretion of ADMA which limited the conclusions regarding the separate clearing mechanisms (metabolic degradation processes, ${ }^{5,6}$ and urinary excretion ${ }^{7-10}$ ) of the kidneys. Therefore, we performed the present study in a comparable cohort of hypertensive patients with mild to moderate renal insufficiency to unravel: first, the role of urinary ADMA excretion in the relationship between renal function, and (arterial) plasma concentrations of $A D M A$; and second, the contribution of urinary ADMA excretion to total renal plasma clearance of ADMA in the early phases of renal impairment.

\section{METHODS}

\section{Patients and study protocol}

Over a two-year period, 126 patients underwent diagnostic renal angiography for the exclusion of renal artery stenosis in our hospital according to the same standardized clinical protocol. This protocol includes selective blood sampling of the aorta, left and right renal veins, selective mean renal blood flow (MRBF) measurements, and renal angiography. Patients were angiographically evaluated for suspicion of renal artery stenosis based on one or more of the following clinical clues: hypertension despite treatment with at least three antihypertensive agents, (recent) hypertensive crisis, or hypertension with evident peripheral vascular disease, the presence of an abdominal bruit or renal function deterioration in response to antihypertensive treatment.

All antihypertensive medication was discontinued for three weeks prior to the angiography and patients were requested to adhere to a sodium-restricted (55 $\mathrm{mmol} / 24-\mathrm{h}$ ) diet during one week prior to renal angiography. In patients with diabetes mellitus, the use of metformin was discontinued two days before renal angiography to lower the risk of contrast medium-induced nephropathy. Other medication was continued. One day before renal angiography, we performed a non-invasive ambulatory 24-h blood pressure measurement (SpaceLabs, ambulatory blood pressure monitor, Redmond, WA, USA) and patients collected 24-h urine, in which we measured the amounts of sodium (dietary compliance), (micro)albumin and the urinary 
concentration of ADMA. Furthermore, patients filled in a questionnaire on smoking habits, cardiovascular history and use of medication. Only patients without a history of cardiovascular events were included in the study. The investigations were performed in accordance with the principles outlined in the Declaration of Helsinki. All patients gave their written informed consent prior to inclusion and the institutional ethics committee approved the study.

After an overnight fast, the aorta and both renal veins were cannulated via the femoral route. Subsequently, we simultaneously drew blood samples from the aorta and the renal veins for the assessment of ADMA and creatinine. After centrifugation, plasma samples were immediately stored at $-80{ }^{\circ} \mathrm{C}$ until analysis. Additionally, we sampled venous blood from the antecubital vein for the measurement of fasting glucose, lipid profile and serum creatinine. The latter was used for the calculation of estimated glomerular filtration rate (eGFR in $\mathrm{ml} / \mathrm{min} / 1.73 \mathrm{~m}^{2}$ ) by the Chronic Kidney Disease Epidemiology Collaboration equation (CKD-EPI). ${ }^{11}$ Subsequently, we measured selective MRBF by means of the ${ }^{133}$ Xenon washout technique, as described previously. ${ }^{12,13}$ Each patient underwent the same procedure, by which we measured MRBF in the left kidney first and thereafter in the right one. The whole ${ }^{133}$ Xenon washout procedure for both kidneys is completed within approximately 15 minutes. During MRBF measurements, heart rate and intra-arterial blood pressure were continuously monitored. No contrast agents were administered before blood sampling and renal blood flow measurements had been completed. Thereafter, renal angiography, using a digital subtraction system, was performed. An experienced radiologist reported renal (artery) anomalies.

\section{Biochemical analyses}

Plasma concentrations of ADMA and urinary concentrations of ADMA were determined by high-performance liquid chromatography with fluorescence detection and modified chromatographic separation conditions, as described previously. ${ }^{14,15}$ The intra-assay and inter-assay coefficients of variation were $<2 \%$ and $<4 \%$, respectively. Standard clinical chemistry methods were used for assessment of fasting glucose, creatinine, urinary albumin excretion, urinary sodium excretion and lipid profile.

\section{Calculations}

The ${ }^{133}$ Xenon washout curves were analyzed as described earlier. ${ }^{16}$ In short, after subtraction of background radiation, the disappearance of ${ }^{133}$ Xenon (IBD Holland, Baarle-Nassau, The Netherlands) from the kidney, measured by an extra corporeal scintillation counter, was analyzed mathematically using either a two-phase or onephase exponential decay model, depending on which model fitted best (Graphpad 
Prism 5, Graphpad Software, Inc., San Diego, CA)). From this model we calculated MRBF and mean renal plasma flow (MRPF, calculated as MRBF x (1 - hematocrit)) both expressed in $\mathrm{ml} / \mathrm{min} / 100 \mathrm{~g}$ kidney.

Fractional renal extraction (FRE) of both kidneys together was calculated as: (total arterial delivery - total venous efflux) / (total arterial delivery) x 100\%, as described previously. ${ }^{17} \mathrm{RPCL}$ of both kidneys together was calculated as: $\left(\mathrm{MRPF}_{\text {left kidney }} \times \mathrm{FRE}_{\text {left }}\right.$

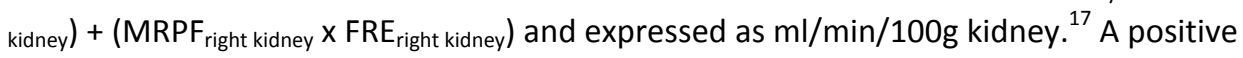
FRE or RPCL indicates net clearance of the substance from the blood whereas a negative FRE or RPCL indicates net release into the blood. Urinary clearance (UCL) in $\mathrm{ml} / \mathrm{min}$ of ADMA or creatinine was calculated as $=(U \times V) / P$ where $U$ is the concentration of the substance in urine, $\mathrm{P}$ concentration of the substance in arterial plasma and $V$ the urine flow rate per unit of time. Finally, the fractional excretion (\%) of ADMA was calculated as: (urinary ADMA clearance / urinary creatinine clearance) $x$ $100 \%$.

\section{Statistical analyses}

Normally distributed variables are expressed as mean \pm standard deviation (SD); variables with a skewed distribution are given as medians and interquartile range. In the table that shows the renal data according to eGFR groups, calculated renal ADMA and creatinine clearance are presented as medians (interquartile range) to allow comparison. Variables with a skewed distribution were log transformed prior to further analyses (RPCL and urinary clearance of ADMA). Multiple linear regression analyses were used to investigate: first, the association between eGFR and arterial plasma concentration of ADMA; second, the association between eGFR and both UCL and RPCL of ADMA, third, the association between RPCL of ADMA and arterial plasma concentration of ADMA; and fourth, between UCL of ADMA and RPCL of ADMA. All associations were first analyzed without adjustments and then with adjustments for potential confounders: age, sex, smoking and cholesterol. Finally, analyses were adjusted for MRBF, eGFR or both. All results are expressed in standardized regression coefficients [95\% Cls] to allow comparison of the strength of the association between different variables. A two-tailed $P$ value $<0.05$ was considered significant. Analyses were performed using the statistical software package SPSS version 18.0 (SPSS, Chicago, Illinois, USA). 


\section{CHAPTER 5}

\section{RESULTS}

From the 126 patients who had undergone renal angiography, 87 were judged eligible for this study by fulfilling the following criteria: discontinuation of all antihypertensive medication, complete selective blood sampling for assessment of ADMA and creatinine, and complete renal blood flow measurements. Table 5.1 shows the characteristics of the 87 hypertensive patients with mild to moderate reduced renal function. Table 5.2 shows the renal data of the patients divided by tertiles of eGFR. With declining eGFR, arterial and venous concentrations of ADMA and creatinine increased whereas MRBF decreased. All renal clearance variables decreased significantly with decreasing eGFR except for the FRE of creatinine and ADMA, urinary creatinine excretion and both RPCL and fractional excretion of ADMA.

Table 5.1 Clinical characteristics of the 87 included hypertensive patients

\begin{tabular}{lc}
\hline Number (men/women) & $40(46 \%) / 47(54 \%)$ \\
Age (years) & $54 \pm 14$ \\
Body Mass Index $\left(\mathrm{kg} / \mathrm{m}^{2}\right)$ & $28 \pm 5$ \\
Current smoking & $18(21 \%)$ \\
Diabetes Mellitus & $17(20 \%)$ \\
24-h Systolic blood pressure (mmHg) & $163 \pm 23$ \\
24-h Diastolic blood pressure (mmHg) & $97 \pm 14$ \\
Total cholesterol (mmol/l) & $5.1 \pm 1.4$ \\
Estimated glomerular filtration rate $\left(\mathrm{ml} / \mathrm{min} / 1.73 \mathrm{~m}^{2}\right)$ & $75 \pm 22$ \\
Urinary sodium excretion (mmol/24-h) & $56(33-105)$ \\
Urinary albumin excretion (mg/24-h) & $26(12-76)$ \\
Atherosclerotic renal artery stenosis & $23(26 \%)$ \\
\hline Data are presented as mean \pm standard deviation, median (interquartile range) or number (\%of group)
\end{tabular}

\section{eGFR and arterial concentration of ADMA}

Crude analysis showed an inverse association between eGFR and arterial plasma concentration of ADMA (Figure 5.1). After adjustments for potential confounders (age, sex, smoking, total cholesterol and MRBF) this association remained present $(\beta=-0.27$ $[-0.52 ;-0.03], P=0.031)$. 


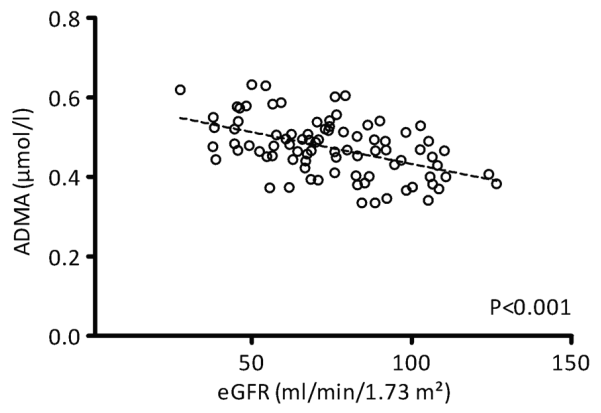

Figure 5.1 Crude linear regression between eGFR and arterial plasma concentrations of ADMA. The linear regression coefficients $\beta$ for ADMA was -0.44 [95\% $\mathrm{Cl}-0.64 ;-0.24],(P<0.001)$. This means that for every 1 SD decrease in eGFR, there was a 0.44 SD increase in ADMA. ADMA, asymmetric dimethylarginine; eGFR, estimated glomerular filtration rate

Table 5.2 Renal data, divided according to eGFR groups

\begin{tabular}{|c|c|c|c|c|}
\hline Renal measurements & $\begin{array}{c}\text { Tertile } 1 \\
\text { ( eGFR } \geq 84)\end{array}$ & $\begin{array}{c}\text { Tertile } 2 \\
\text { ( eGFR 65-83) }\end{array}$ & $\begin{array}{c}\text { Tertile } 3 \\
\text { ( eGFR } \leq 64)\end{array}$ & $\mathrm{P}^{*}$ \\
\hline MRBF left (ml/min/100g kidney) & $245 \pm 69$ & $215 \pm 54$ & $173 \pm 41$ & $<0.001$ \\
\hline MRBF right (ml/min/100g kidney) & $290 \pm 89$ & $269 \pm 53$ & $205 \pm 62$ & $<0.001$ \\
\hline Intra-arterial MAP & $118 \pm 21$ & $120 \pm 14$ & $115 \pm 16$ & 0.149 \\
\hline \multicolumn{5}{|l|}{ Creatinine } \\
\hline Arterial (mmol/l) & $69 \pm 12$ & $82 \pm 13$ & $102 \pm 22$ & $<0.001$ \\
\hline Venous left (mmol/l) & $58 \pm 11$ & $68 \pm 13$ & $87 \pm 22$ & $<0.001$ \\
\hline Venous right $(\mathrm{mmol} / \mathrm{l})$ & $56 \pm 11$ & $65 \pm 15$ & $86 \pm 20$ & $<0.001$ \\
\hline Fractional renal extraction (\%) & $17(12-23)$ & $17(15-23)$ & $18(9-23)$ & 0.387 \\
\hline RPCL (ml/min/100g kidney) & $48(37-63)$ & $45(37-54)$ & $36(21-50)$ & 0.023 \\
\hline Urinary excretion (mmol/24-h) & $12(10-15)$ & $12(9-15)$ & $11(9-16)$ & 0.639 \\
\hline Urinary clearance (ml/min) & $116(99-132)$ & $96(76-108)$ & $79(58-95)$ & $<0.001$ \\
\hline \multicolumn{5}{|l|}{ ADMA } \\
\hline Arterial $(\mu \mathrm{mol} / \mathrm{I})$ & $0.43 \pm 0.06$ & $0.48 \pm 0.06$ & $0.51 \pm 0.07$ & $<0.001$ \\
\hline Venous left $(\mu \mathrm{mol} / \mathrm{l})$ & $0.37 \pm 0.05$ & $0.41 \pm 0.07$ & $0.45 \pm 0.07$ & $<0.001$ \\
\hline Venous right ( $\mu \mathrm{mol} / \mathrm{I})$ & $0.37 \pm 0.05$ & $0.40 \pm 0.05$ & $0.45 \pm 0.07$ & $<0.001$ \\
\hline Fractional renal extraction (\%) & $15(12-17)$ & $16(13-18)$ & $11(6-17)$ & 0.090 \\
\hline RPCL (ml/min/100g kidney) & $39(35-48)$ & $37(32-49)$ & $23(10-34)$ & 0.098 \\
\hline Urinary excretion (mmol/24-h) & $46(35-61)$ & $45(38-54)$ & $32(20-43)$ & 0.001 \\
\hline Urinary clearance (ml/min) & $40(36-72)$ & $37(29-60)$ & $27(24-32)$ & $<0.001$ \\
\hline Fractional excretion (\%) & $40(31-62)$ & $39(31-69)$ & $36(29-50)$ & 0.539 \\
\hline
\end{tabular}

Data are presented as mean \pm standard deviation or median (interquartile range). ${ }^{*}$ Comparisons of renal measurements across eGFR tertiles or were performed using one-way ANOVA or Kruskal-Wallis test, as appropriate. ADMA, asymmetric dimethylarginine; eGFR, estimated glomerular filtration rate in $\mathrm{ml} / \mathrm{min} / 1.73$ $\mathrm{m}^{2}$; MRBF, mean renal blood flow; RPCL, renal plasma clearance 


\section{eGFR and urinary ADMA clearance}

Crude analysis showed a positive association between eGFR and urinary ADMA clearance (Figure 5.2 and Table 5.3, model 1). Adjustments for potential confounders in model 2 attenuated the association to some extent but the association remained present (Table 5.3). Finally, after adjustment for MRBF, the association between eGFR and urinary ADMA clearance lost statistical significance (Table 5.3, model 3). This means that MRBF explained about 36\% (change of $\beta$ from 0.33 to 0.21 ) of the association between eGFR and urinary ADMA clearance.

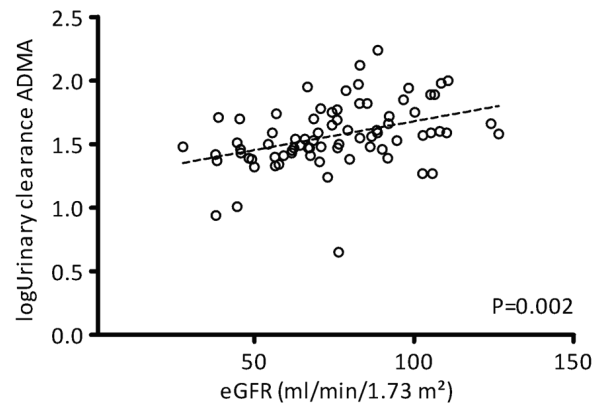

Figure 5.2 Crude linear regression between eGFR and logUrinary clearance of ADMA. The linear regression coefficients $\beta$ for ADMA was 0.37 [95\% $\mathrm{Cl} 0.14 ; 0.59$ ], ( $P=0.001)$. This means that for every 1 SD increase in eGFR, there was a 0.37 SD increase in logUrinary clearance of ADMA. ADMA, asymmetric dimethylarginine; eGFR, estimated glomerular filtration rate

Table 5.3: Association between eGFR and renal clearance of ADMA

\begin{tabular}{|c|c|c|c|c|c|c|}
\hline & \multicolumn{3}{|c|}{ Urinary CL ADMA } & \multicolumn{3}{|c|}{ Renal plasma clearance ADMA } \\
\hline & $\beta^{*}$ & $95 \% \mathrm{Cl}$ & $P$ value & $\beta^{*}$ & $95 \% \mathrm{Cl}$ & $P$ value \\
\hline \multicolumn{7}{|l|}{ eGFR } \\
\hline Model 1 & 0.37 & $0.14 ; 0.59$ & 0.002 & 0.32 & $0.09 ; 0.55$ & 0.008 \\
\hline Model 2 & 0.33 & $0.05 ; 0.61$ & 0.022 & 0.26 & $-0.08 ; 0.60$ & 0.158 \\
\hline Model 3 & 0.21 & $-0.05 ; 0.48$ & 0.144 & 0.19 & $-0.21 ; 0.61$ & 0.445 \\
\hline
\end{tabular}

* $\beta$, standardized regression coefficient: indicates increase (in SDs) of arterial ADMA per 1 SD increase in eGFR. ADMA, asymmetric dimethylarginine; $\mathrm{Cl}$, confidence interval; $\mathrm{CL}$, clearance; eGFR, estimated glomerular filtration rate; MRBF, mean renal blood flow. Model 1: Crude analysis; Model 2: Adjustments for age, sex, smoking, total cholesterol; Model 3: Model 2 and MRBF 


\section{Renal ADMA clearance and arterial concentration of ADMA}

Figure 5.2 and Table 5.4 (model 1) show that there was no significant association between RPCL and arterial plasma concentration of ADMA. Adjustments for age, sex, smoking, cholesterol, MRBF and eGFR did not change these results (Table 5.4, model 2, 3 and 4).

Table 5.4: Associations between renal clearance of ADMA and arterial ADMA

\begin{tabular}{lcccc}
\hline Independent Variables & \multicolumn{4}{c}{ Dependent variable: Arterial ADMA } \\
\cline { 2 - 5 } & Model & $\beta^{*}$ & $95 \%$ Cl & P value \\
\hline RPCL ADMA & 1 & -0.08 & $-0.31 ; 0.15$ & 0.484 \\
& 2 & -0.10 & $-0.31 ; 0.11$ & 0.337 \\
& 3 & -0.01 & $-0.22 ; 0.20$ & 0.920 \\
\hline
\end{tabular}

* $\beta$, standardized regression coefficient: indicates increase (in SDs) of arterial ADMA per 1 SD increase in RPCL of ADMA. ADMA, asymmetric dimethylarginine; $\mathrm{Cl}$, confidence interval; $\mathrm{CL}$; clearance; eGFR, estimated glomerular filtration rate; MRBF; mean renal blood flow; RPCL, renal plasma clearance. Model 1: Crude analysis; Model 2: Adjustments for age, sex, smoking, total cholesterol; Model 3: Model 2 and MRBF + eGFR

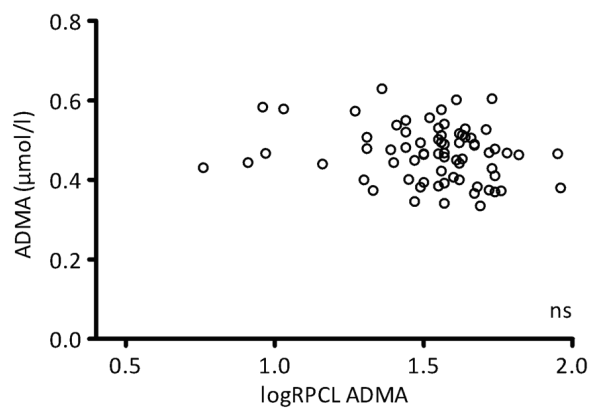

Figure 5.3 Crude linear regression between logRPCL of ADMA and arterial plasma concentrations of ADMA. The linear regression coefficients $\beta$ for $\operatorname{logRPCL}$ of $A D M A$ and arterial plasma concentration of ADMA was -0.08 [-0.31;0.15], $(P=0.484)$. This means that for every 1 SD decrease in logRPCL of $A D M A$, there was a 0.08 increase in ADMA. ADMA, asymmetric dimethylarginine; ns, non significant; RPCL, renal plasma clearance 
CHAPTER 5

Table 5.5: Associations between Urinary clearance of ADMA and RPCL of ADMA

\begin{tabular}{lcccc}
\hline Variables & \multicolumn{4}{c}{ RPCL ADMA } \\
\cline { 2 - 5 } & Model & $\beta^{*}$ & $95 \%$ Cl & P value \\
\hline Urinary CL ADMA & 1 & 0.19 & $0.08 ; 0.30$ & 0.001 \\
& 2 & 0.18 & $0.06 ; 0.29$ & 0.003 \\
& 3 & 0.08 & $-0.05 ; 0.20$ & 0.220 \\
\hline
\end{tabular}

* $\beta$, standardized regression coefficient: indicates increase (in SDs) of RPCL of ADMA per 1 SD increase in Urinary $\mathrm{CL}$ of $\mathrm{ADMA}$. ADMA, asymmetric dimethylarginine; $\mathrm{Cl}$, confidence interval; $\mathrm{CL}$, clearance; eGFR, estimated glomerular filtration rate; MRBF, mean renal blood flow; RPCL, renal plasma clearance. Model 1: Crude analysis; Model 2: Adjustments for age, sex, smoking, total cholesterol; Model 3: Model 2 and MRBF + eGFR

\section{Urinary ADMA clearance and RPCL of ADMA}

Table 5.5 shows that there was a positive association between urinary ADMA clearance and RPCL of ADMA (model 1), even after adjustments for age, sex, smoking and total cholesterol (model 2). However, after additional adjustments for MRBF and eGFR, the association between urinary ADMA clearance and RPCL of ADMA diminished to a large extent (Table 5.5, $\beta$ from 0.18 [0.06;0.29], $P=0.003$, in model 2 to 0.08 [$0.05 ; 0.20], P=0.220$ in model 3 ). This means that MRBF and eGFR together, explained about $55 \%$ (change of $\beta$ from 0.18 to 0.08 ) of the association between urinary ADMA clearance and RPCL of ADMA.

\section{Additional analyses}

We additionally investigated the extent to which the association between eGFR and arterial plasma concentration of ADMA could be explained (mediated) by urinary ADMA clearance. Additional adjustment for urinary ADMA clearance in the association between eGFR and arterial plasma concentration of ADMA attenuated the association to some extent ( $\beta$ from $=-0.27[-0.52 ;-0.03], P=0.031$ to $-0.21[-0.48 ; 0.05], P=0.116$ ). Urinary ADMA clearance explained about $22 \%$ (change of $\beta$ from -0.27 to -0.21 ) of the association between eGFR and arterial concentration of ADMA.

We found no significant effect modification by sex or the presence of atherosclerotic renal artery stenosis in the association between eGFR and arterial concentrations of ADMA ( $P=0.143$ and $P=0.507)$. Furthermore, we found no effect modification by sex or the presence of atherosclerotic renal artery stenosis in any of the other investigated associations, i.e. in the associations between eGFR and urinary ADMA clearance and in the associations between urinary ADMA clearance and arterial concentrations of ADMA. This indicates that the associations were similar for men and women or hypertensive patients with or without atherosclerotic renal artery stenosis. 


\section{DISCUSSION}

As far as we know, the present study is the first that measured RPCL of ADMA by arteriovenous concentration differences in combination with urinary ADMA clearance to investigate the relationship between renal function (eGFR), urinary ADMA clearance and (arterial) plasma concentrations of ADMA and the relationship between urinary ADMA clearance and RPCL of ADMA in a population of hypertensive patients with early renal impairment. We demonstrated that the urinary clearance of ADMA is only partly involved in the relationship between renal function and arterial ADMA. On the other hand, in this population of hypertensive patients with mild to moderate renal insufficiency, the renal ADMA clearing capacity is not dependent upon renal function and therefore, increased plasma ADMA concentration in this population cannot be explained by failure of the kidney as a plasma ADMA clearing organ.

There are several definitions applicable to the term "renal clearance" of a substance. One often used description is "clearance is the volume of plasma required to supply the quantity $x$ excreted in urine each minute time", as illustrated by the clearance equation of $(U \times V) / P$ where $U$ is the concentration of the substance in urine, $P$ the concentration of the substance in plasma and $\mathrm{V}$ the urine flow rate per unit of time. ${ }^{18}$ This clearance equation and description has to be understood as referring specifically to substances which are cleared from the plasma by the kidney exclusively via the urinary excretion route, and are not valid for substances which are metabolized or synthesized by the kidney. ${ }^{18,19}$ ADMA is not only metabolized (degradated) in the kidneys by the enzymes $N^{G}, N^{G}$-dimethylarginine dimethylaminohydrolase (DDAH) and alanine-glyoxylate aminotransferase $2^{5,20}$ but also synthesized in the kidneys by posttranscriptional methylation of L-arginine residues and this process is catalyzed by protein arginine methyltransferases (PRMT). ${ }^{21}$ Therefore, ideally, the term renal clearance should be defined as renal plasma clearance by the product $\mathrm{E} \times \mathrm{MRPF}$ where $E$ is the FRE of the substance and MRPF is the mean renal plasma flow. In this study we used this equation for the calculation of renal ADMA clearance and compared this with UCL. Still, we must bear in mind that renal production of ADMA may have influenced our results. Indeed, several studies indicated that there is increased PRMT activity in damaged kidneys. ${ }^{21,22}$ Therefore, greater production of ADMA in the patients with more advanced renal insufficiency may have biased our results. Still, the observed increased plasma is not the result of a decreased renal plasma clearance of ADMA.

We previously demonstrated that RPCL of ADMA, the net outcome of all clearing mechanisms (metabolic degradation processes ${ }^{5,6}$ and urinary excretion ${ }^{7-10}$ ) that contribute to plasma ADMA clearance by the kidneys, is of minor importance in the association between renal function and plasma ADMA in hypertensive patients with mild to moderate renal insufficiency. ${ }^{4}$ Interestingly, there appears to be a small role for 
urinary ADMA clearance in the relation between renal function and plasma ADMA in this population. This implies first, that the metabolic ADMA degradation processes determine the total clearing capacity of the kidneys and that these processes are not solely dependent of renal function. Second, the role of urinary ADMA clearance in the relation between renal function and plasma ADMA is probably partly influenced by the tight relationship between renal function, renal blood flow and urinary clearance.

Obviously, our study has some limitations. The absence of knowledge about kidney volume precludes a direct comparison between RPCL of ADMA in $\mathrm{ml} / \mathrm{min} / 100 \mathrm{~g}$ kidney and $U C L$ of ADMA in $\mathrm{ml} / \mathrm{min}$. Furthermore, in our study population of patients who underwent diagnostic renal angiography, patients with more advanced stages of CKD are either excluded (stage 5) or relatively underrepresented (stage 3 and 4).

In conclusion, our findings indicate that RPCL of ADMA is mainly determined by the metabolic degradation processes of ADMA and not so much by UCL of ADMA. Furthermore, the presence of increased plasma ADMA in a hypertensive population with mild to moderate renal insufficiency is not likely due to failure of the kidney as a plasma ADMA clearing organ.

\section{Acknowledgements}

The authors gratefully acknowledge M. Fuss-Lejeune for her assistance in the blood sampling and measurements during renal angiography. This study was supported by a "clinical established investigator" grant from the Dutch Heart Foundation (DHF; Grant No. 2004T058) obtained by Dr. A.A. Kroon. 


\section{REFERENCES}

1. Caglar K, Yilmaz MI, Sonmez A, Cakir E, Kaya A, Acikel C, Eyileten T, Yenicesu M, Oguz Y, Bilgi C, Oktenli C, Vural A, Zoccali C. ADMA, proteinuria, and insulin resistance in non-diabetic stage I chronic kidney disease. Kidney Int. 2006;70:781-787.

2. Kielstein JT, Boger RH, Bode-Boger SM, Frolich JC, Haller H, Ritz E, Fliser D. Marked increase of asymmetric dimethylarginine in patients with incipient primary chronic renal disease. J Am Soc Nephrol. 2002;13:170-176.

3. Kielstein JT, Salpeter SR, Bode-Boeger SM, Cooke JP, Fliser D. Symmetric dimethylarginine (SDMA) as endogenous marker of renal function--a meta-analysis. Nephrol Dial Transplant. 2006;21:2446-2451.

4. Ronden RA, Houben AJ, Teerlink T, Bakker JA, Bierau J, Stehouwer CD, De Leeuw PW, Kroon AA. Reduced renal plasma clearance does not explain increased plasma asymmetric dimethylarginine in hypertensive subjects with mild to moderate renal insufficiency. Am J Physiol Renal Physiol. 2012;303:F149-156.

5. Rodionov RN, Murry DJ, Vaulman SF, Stevens JW, Lentz SR. Human alanine-glyoxylate aminotransferase 2 lowers asymmetric dimethylarginine and protects from inhibition of nitric oxide production. J Biol Chem. 2010;285:5385-5391.

6. Teerlink T, Luo Z, Palm F, Wilcox CS. Cellular ADMA: regulation and action. Pharmacol Res. 2009;60:448-460.

7. Al Banchaabouchi M, Marescau B, Possemiers I, D'Hooge R, Levillain O, De Deyn PP. NG, NGdimethylarginine and NG, NG-dimethylarginine in renal insufficiency. Pflugers Arch. 2000;439:524531.

8. MacAllister RJ, Rambausek MH, Vallance P, Williams D, Hoffmann KH, Ritz E. Concentration of dimethyl-L-arginine in the plasma of patients with end-stage renal failure. Nephrol Dial Transplant. 1996;11:2449-2452.

9. Marescau B, Nagels G, Possemiers I, De Broe ME, Becaus I, Billiouw JM, Lornoy W, De Deyn PP. Guanidino compounds in serum and urine of nondialyzed patients with chronic renal insufficiency. Metabolism. 1997;46:1024-1031.

10. Vallance $P$, Leone A, Calver A, Collier J, Moncada S. Accumulation of an endogenous inhibitor of nitric oxide synthesis in chronic renal failure. Lancet. 1992;339:572-575.

11. Levey AS, Stevens LA, Schmid CH, Zhang YL, Castro AF, 3rd, Feldman HI, Kusek JW, Eggers P, Van Lente $\mathrm{F}$, Greene T, Coresh J. A new equation to estimate glomerular filtration rate. Ann Intern Med. 2009;150:604-612.

12. de Leeuw PW, Birkenhager WH. Use of the xenon-133 washout technique in diagnosing renovascular disease in hypertension. Nephron. 1986;44 Suppl 1:5-7.

13. Wierema TK, Houben AJ, Kroon AA, Koster D, van der Zander K, van Engelshoven JM, de Leeuw PW. Nitric oxide dependence of renal blood flow in patients with renal artery stenosis. J Am Soc Nephrol. 2001;12:1836-1843.

14. de Jong S, Teerlink T. Analysis of asymmetric dimethylarginine in plasma by HPLC using a monolithic column. Anal Biochem. 2006;353:287-289.

15. Teerlink T, Nijveldt RJ, de Jong S, van Leeuwen PA. Determination of arginine, asymmetric dimethylarginine, and symmetric dimethylarginine in human plasma and other biological samples by high-performance liquid chromatography. Anal Biochem. 2002;303:131-137.

16. Hollenberg NK, Mangel R, Fung HY. Assessment of intrarenal perfusion with radioxenon: a critical review of analytical factors and their implications in man. Semin Nucl Med. 1976;6:193-216.

17. Rennenberg RJ, Schurgers LJ, Vermeer C, Scholte JB, Houben AJ, de Leeuw PW, Kroon AA. Renal handling of matrix Gla-protein in humans with moderate to severe hypertension. Hypertens Res. 2008;31:1745-1751.

18. Natochin YV. Evolutionary aspects of renal function. Kidney Int. 1996;49:1539-1542. 


\section{CHAPTER 5}

19. Maack T, Johnson V, Kau ST, Figueiredo J, Sigulem D. Renal filtration, transport, and metabolism of low-molecular-weight proteins: a review. Kidney Int. 1979;16:251-270.

20. Ogawa T, Kimoto M, Sasaoka K. Dimethylarginine:pyruvate aminotransferase in rats. Purification, properties, and identity with alanine:glyoxylate aminotransferase 2. J Biol Chem. 1990;265:2093820945.

21. Matsuguma K, Ueda S, Yamagishi S, Matsumoto $Y$, Kaneyuki U, Shibata R, Fujimura T, Matsuoka $H$, Kimoto M, Kato S, Imaizumi T, Okuda S. Molecular mechanism for elevation of asymmetric dimethylarginine and its role for hypertension in chronic kidney disease. J Am Soc Nephrol. 2006;17:2176-2183.

22. Carello KA, Whitesall SE, Lloyd MC, Billecke SS, D'Alecy LG. Asymmetrical dimethylarginine plasma clearance persists after acute total nephrectomy in rats. Am J Physiol Heart Circ Physiol. 2006;290:H209-216. 


\section{6}

Acute effects of intrarenal eprosartan infusion on the renal handling of asymmetric dimethylarginine

Rianne A. Ronden Alfons J.H.M. Houben

Carolien Hazelaar Marian J. Hommels

Tom Teerlink Guy J.M. Mostard Jaap A. Bakker Jörgen Bierau Coen D.A. Stehouwer Peter W. de Leeuw Abraham A. Kroon

Submitted 


\section{CHAPTER 6}

\section{ABSTRACT}

Background and objective - Clinical studies show that angiotensin II type 1 receptor blockers lower plasma concentrations of the nitric oxide synthase inhibitor asymmetric dimethylarginine (ADMA). However, underlying mechanisms are not fully understood. One suggested mechanism is an increase of renal ADMA plasma clearance. We investigated from a mechanistic point of view, the acute effects of short-term intrarenal eprosartan infusion on the renal ADMA handling.

Methods - In 81 hypertensive patients scheduled for renal angiography, we drew blood samples from the aorta and both renal veins for measurement of dimethylarginines and L-arginine, before and after 30 minutes of eprosartan or vehicle control infusion. Renal blood flow was measured using ${ }^{133}$ Xenon washout, renal plasma clearance was calculated using arteriovenous concentration differences and renal blood flow. After exclusion of patients with renal vascular anomalies we used the results of 53 patients ( $n=43$ eprosartan and $n=10$ control) for further analyses.

Results - Arterial ADMA decreased after infusion of eprosartan whereas venous ADMA increased and renal blood flow increased $(\Delta+33 \mathrm{ml} / \mathrm{min} / 100 \mathrm{~g}$ kidney, $\mathrm{P}=0.008)$. Renal plasma clearance shifted from net renal clearance of ADMA into net renal release of ADMA.

Conclusion - Short-term intrarenal eprosartan infusion lowers ADMA in hypertensive patients. However, this effect is not the result of an increased renal ADMA plasma clearance which in fact decreased, but probably due to extra-renal changes in the metabolism. 


\section{INTRODUCTION}

Clinical studies have reported that angiotensin II type 1 receptor blockers (ARBs) reduce plasma concentrations of the endogenous nitric oxide (NO) synthase inhibitor asymmetric dimethylarginine (ADMA) in (hypertensive) patients. ${ }^{1-5}$ However, in humans, possible underlying mechanisms of this plasma ADMA-lowering effect are not fully understood. Given the fact that 1) ARBs have a profound effect on renal hemodynamics $^{6-8}$ and 2 ) the kidneys play an essential role in the plasma regulation of ADMA ${ }^{9,10}$ one of the possible plasma ADMA lowering mechanisms is by increasing the renal plasma clearance (RPCL) of ADMA.

Substantial net renal ADMA clearance from the circulation has been demonstrated in humans by measuring arteriovenous concentration differences. ${ }^{10,11}$ Under normal circumstances the clearing effect of the kidneys is mainly based on two mechanisms: 1) uptake by cells from the plasma by cationic amino acid transporters (CAT) followed by intracellular degradation by $N^{G} N^{G}$-dimethylarginine dimethylaminohydrolase (DDAH), ${ }^{12}$ which is highly expressed in the kidney ${ }^{13,14}$ and 2) urinary excretion. ${ }^{15-18}$ Nevertheless, the influence of an ARB on the RPCL of ADMA in humans is unknown.

Therefore, we conducted the present study from a mechanistic point of view using the human kidney as (pathophysiological) model to investigate the effects of direct intrarenal eprosartan, the only suitable ARB for intrarenal use, on the RPCL of ADMA calculated by the arteriovenous concentration differences and thereby testing the hypothesis that, eprosartan lowers plasma concentrations of ADMA by increasing renal plasma clearance (RPCL) of ADMA. Additionally, we investigated the effects of eprosartan on the renal handling of symmetric dimethylarginine (SDMA, a structural isomer of ADMA that does not inhibit NO synthase), the NO synthase substrate Larginine and Citrulline (degradation product of L-arginine).

\section{METHODS}

\section{Patients}

This study was performed in 81 consecutive hypertensive patients who underwent diagnostic renal angiography to exclude renal artery stenosis according to a standardized clinical protocol as described in the expanded methods of the Data Supplement. In short, this protocol includes discontinuation of all antihypertensive medication for three weeks, discontinuation of metformin for two days, a sodiumredistricted diet for one-week, non-invasive ambulatory 24-h blood pressure measurement, and collection of 24-h urine one day before renal angiography. The investigations were performed in accordance with the principles outlined in the Declaration of Helsinki. All patients gave their written informed consent prior to inclusion and the institutional ethics committee approved the study. 


\section{Study measurements}

After one night admission to our ward and an overnight fast, we cannulated the aorta and both renal veins via the femoral route. Subsequently, we drew blood samples from the aorta and renal veins simultaneously for the measurement of ADMA, SDMA, Larginine and Citrulline. In addition, blood samples for determination of fasting glucose, serum creatinine ( $\mathrm{SCR}$ ), lipid profile, and hematocrit were drawn.

Subsequently, we measured mean renal blood flow (MRBF) using the ${ }^{133}$ Xenon washout technique (detailed information in the Data Supplement). After the aforementioned baseline data had been obtained, we started the intervention study with 30 minutes intrarenal infusion of eprosartan (dissolved in $5 \%$ glucose solution with a dose of $6,5 \mu \mathrm{g} / \mathrm{kg} / \mathrm{min}$ (total dose $195 \mu \mathrm{g} / \mathrm{kg}$ ), Solvay Pharma B.V., Weesp, the Netherlands, $n=70$ ) or vehicle control (a single intra-arterial bolus of $7.5 \mathrm{ml} 5 \%$ glucose solution, $\mathrm{n}=11$ ) in the right kidney (through the arterial catheter). The intrarenal eprosartan or vehicle control infusion occurred with a constant volume flow of 1 $\mathrm{ml} / \mathrm{min}$. After the 30 minutes we measured MRBF of the right kidney and we drew arterial (aorta (A) and venous (right kidney, (V)) blood samples for the determination of ADMA, SDMA, L-arginine and Citrulline. We chose this relatively low dose to minimize the effect on systemic blood pressure (BP). ${ }^{19}$ Furthermore, at the start and at the end of the infusion, supine BP was measured oscillometrically using a Dinamap on the upper arm (Critikon; GE Healthcare, Hoevelaken, the Netherlands). We administered no contrast agents before blood sampling and renal blood flow measurements were completed. After completion of previous mentioned investigations we performed the renal angiography. An experienced radiologist reported renal (artery) anomalies. Control patients were included at the end of the study after the 70 patients that received eprosartan infusion. Further detailed information on the study measurements is provided in the Data Supplement.

\section{Biochemical analyses}

Plasma concentrations of ADMA, SDMA, and L-arginine were determined using an Acquity ultra-performance liquid chromatography (UPLC) separation module coupled to a Quattro Premier Electrospray Ionisation Tandem Mass Spectrometry (ESI-MSMS, Waters, Etten-Leur, The Netherlands). ${ }^{20}$ Intra- and inter-assay variations at physiological concentrations were less than $5 \%$. Standard clinical chemistry methods were used for assessment of fasting glucose, $\mathrm{s} C r$ and lipid profile.

\section{Calculations and (statistical) analyses}

Glomerular filtration rate (GFR in $\mathrm{ml} / \mathrm{min} / 1.73 \mathrm{~m}^{2}$ ) was estimated by the Chronic Kidney Disease Epidemiology Collaboration equation (CKD-EPI). ${ }^{21}$ We calculated the fractional renal extraction (FRE) in the right kidney as ( $\mathrm{A}-\mathrm{V}$ right) / $\mathrm{A} \times 100 \%{ }^{10,11}$ where 
$\mathrm{A}$ and $\mathrm{V}$ represent arterial and renal vein plasma concentrations, respectively. Additionally, we calculated RPCL of the right kidney $(\mathrm{ml} / \mathrm{min} / 100 \mathrm{~g}$ kidney) as mean renal plasma flow right $x((A-V$ right $) / A))$, before and after infusion. This equation corrects a possible overestimation of the FRE in cases of a low renal plasma flow. ${ }^{22} \mathrm{~A}$ positive FRE and RPCL indicate net clearance of the substance from the blood whereas a negative FRE and RPCL indicate net release into the blood. The L-arginine/ADMA ratio was calculated, because NO production is determined by both substrate availability (L-arginine) and the presence of inhibitor (ADMA), which may be adequately reflected by this ratio. ${ }^{23}$

For normally distributed variables (eprosartan group) we used parametric tests (paired Student's t-test). For non-normally distributed variables (control group) we used nonparametric tests (Wilcoxon signed rank test). In the tables that represent data from both the eprosartan and control group, variables are presented as median (interquartile range) to allow comparison between groups. We used a Mann-Whitney $U$ test for the comparisons between the eprosartan and the control group. Correlation was tested using Pearson's R or Spearman. A two-tailed $\mathrm{P}<0.05$ was considered statistically significant. Data were analyzed using SPSS software (release 15.0; SPSS Inc. Chicago, IL, USA).

\section{RESULTS}

From the 81 initially included hypertensive patients that underwent renal angiography ( $n=70$ intrarenal eprosartan infusion and $n=11$ intrarenal vehicle control infusion), we excluded 22 patients for the presence of renal artery stenosis or fibromuscular dysplasia. Subsequently, we excluded 6 patients for incomplete blood sampling or incomplete MRBF measurements of the right kidney caused by technical difficulties. As expected, the excluded patients had a significantly lower estimated glomerular filtration rate (GFR) mainly due to the presence of renal artery stenosis and higher prevalence of cardiovascular events compared to the total patient group. Table 6.1 shows the baseline clinical characteristics of the hypertensive patients that received intrarenal infusion of eprosartan or vehicle control. Baseline characteristics of both groups were comparable, except for the presence of diabetes mellitus. Detailed information on antihypertensive drug treatment and concomitant diseases is provided in Table 6.S1 of the Data Supplement. 
Table 6.1 Clinical characteristics of the 53 included patients

\begin{tabular}{lcc}
\hline & Eprosartan & Vehicle control \\
\hline Number (male/female) & $43(28 / 15)$ & $10(5 / 5)$ \\
Age (years) & $55.5(46.2-61.8)$ & $46.5(37.2-64.0)$ \\
Body Mass Index $\left(\mathrm{kg} / \mathrm{m}^{2}\right)$ & $28.7(25.5-30.2)$ & $29.4(27.2-33.3)$ \\
Current smoking & $13(30 \%)$ & $2(20 \%)$ \\
Diabetes Mellitus & $6(14 \%)$ & $0(0 \%)$ \\
History of cardiovascular events & $7(16 \%)$ & $1(10 \%)$ \\
24-h systolic blood pressure $(\mathrm{mmHg})$ & $158(149-182)$ & $167(152-181)$ \\
24-h diastolic blood pressure $(\mathrm{mmHg})$ & $99(91-109)$ & $104(97-113)$ \\
24-h mean arterial pressure $(\mathrm{mmHg})$ & $120(114-133)$ & $124(117-133)$ \\
24-h heart rate (beats/min) & $74(68-81)$ & $77(70-87)$ \\
Fasting glucose (mmol/l) & $5.5(5.1-6.1)$ & $5.3(5.1-5.6)$ \\
Total cholesterol (mmol/l) & $5.3(4.1-6.2)$ & $5.6(4.5-6.3)$ \\
Low-density lipoprotein cholesterol $(\mathrm{mmol} / \mathrm{l})$ & $3.3(2.6-4.1)$ & $3.6(3.3-4.3)$ \\
Glomerular filtration rate $\left(\mathrm{ml} / \mathrm{min} / 1.73 \mathrm{~m}^{2}\right)$ & $79(59-90)$ & $72(56-100)$ \\
Urinary albumin excretion $(\mathrm{mg} / 24-\mathrm{h})$ & $27(9-158)$ & $33(19-80)$ \\
\hline
\end{tabular}

Data are presented as median (interquartile range) to allow comparison between groups or number (\% of group)

\section{ADMA, SDMA, L-arginine and Citrulline before and after eprosartan or vehicle control}

Baseline venous ADMA, SDMA, L-arginine and Citrulline did not differ significantly between the right and left kidney in both the eprosartan and the vehicle control group (data not shown). Baseline arterial and venous ADMA, SDMA, L-arginine and Citrulline were comparable between both groups (Table 6.2, $\mathrm{P}>0.05$ for all variables).

After eprosartan infusion, the arterial ADMA, SDMA and Citrulline decreased whereas concentrations in the renal vein increased (Table 6.2). Arterial L-arginine increased slightly after eprosartan infusion although this difference was not statistically significant $(P=0.178)$. The concentration of $L$-arginine in the renal vein decreased after infusion $(P<0.001)$. As a result of the changes in $L$-arginine and $A D M A$, arterial $L$ arginine/ADMA ratio increased, whereas venous L-arginine/ADMA ratio decreased (Table 6.2). In the control group infusion showed neither an effect on the arterial nor an effect on the venous ADMA, SDMA, L-arginine or Citrulline (Table 6.2). After infusion, only arterial ADMA, Citrulline and the L-arginine/ADMA ratio in the arterial samples differed between the eprosartan and the control group. Venous concentrations of all variables differed between both intervention groups after infusion (Table 6.2)

\section{The effect of eprosartan or vehicle control on renal blood flow and blood pressure}

Baseline MRBF significantly differed between the right and left kidney in both intervention groups (data not shown), in favor of a higher flow at the right side, which 
has been reported previously. ${ }^{24}$ However, baseline MRBF, renal vascular resistance (RVR) and BP were comparable between both intervention groups ( $P>0.05$ for all variables).

Eprosartan infusion led to a significant increase in MRBF $(\Delta+33 \mathrm{ml} / \mathrm{min} / 100 \mathrm{~g}$ kidney, Figure 6.1, left figure) of the right kidney. Systemic (upper arm cuff) mean arterial pressure (MAP, $\mathrm{P}=0.001$ ) decreased significantly after 30 minutes intrarenal infusion of eprosartan. However, this decrease was not statistically different from the control group $(P=0.094)$. Heart rate remained stable $(P=0.784)$. RVR of the right kidney decreased significantly ( $P=0.002$, Figure 6.S1, Data Supplement).

Table 6.2 Plasma concentrations of ADMA, SDMA, L-arginine and Citrulline before and after eprosartan and vehicle control

\begin{tabular}{|c|c|c|c|c|c|c|c|c|}
\hline & \multicolumn{3}{|c|}{ Eprosartan $(n=43)$} & \multicolumn{3}{|c|}{ Vehicle control $(n=10)$} & \multirow[b]{2}{*}{$P \neq$} & \multirow[b]{2}{*}{$P \S$} \\
\hline & Baseline & After & $\mathrm{P}^{*}$ & Baseline & After & $\mathrm{P}+$ & & \\
\hline \multicolumn{9}{|c|}{ ADMA } \\
\hline \multirow[t]{2}{*}{ A } & 0.48 & 0.43 & $<0.001$ & 0.51 & 0.49 & 0.515 & 0.420 & 0.003 \\
\hline & $(0.43-0.56)$ & $(0.39-0.46)$ & & $(0.49-0.52)$ & $(0.47-0.51)$ & & & \\
\hline \multirow[t]{2}{*}{ V } & 0.42 & 0.51 & $<0.001$ & 0.41 & 0.41 & 0.508 & 0.699 & 0.018 \\
\hline & $(0.39-0.46)$ & $(0.43-0.53)$ & & $(0.39-0.43)$ & $(0.39-0.44)$ & & & \\
\hline \multicolumn{9}{|c|}{ SDMA } \\
\hline \multirow[t]{2}{*}{ A } & 0.59 & 0.54 & 0.001 & 0.55 & 0.55 & 0.332 & 0.334 & 0.995 \\
\hline & $(0.48-0.73)$ & $(0.46-0.66)$ & & $(0.44-0.66)$ & $(0.45-0.67)$ & & & \\
\hline \multirow[t]{2}{*}{ V } & 0.51 & 0.58 & $<0.001$ & 0.48 & 0.48 & 0.721 & 0.290 & 0.004 \\
\hline & $(0.45-0.66)$ & $(0.52-0.78)$ & & $(0.39-0.55)$ & $(0.39-0.55)$ & & & \\
\hline \multicolumn{9}{|c|}{ L-arginine } \\
\hline \multirow[t]{2}{*}{ A } & 80 & 83 & 0.178 & 801 & 80 & 0.386 & 0.858 & 0.426 \\
\hline & $(67-95)$ & $(71-98)$ & & $(77-87)$ & $(72-87)$ & & & \\
\hline \multirow[t]{2}{*}{ V } & 97 & 69 & $<0.001$ & 95 & 92 & 0.074 & 0.633 & 0.001 \\
\hline & $(80-107)$ & $(62-85)$ & & $(87-100)$ & (82-99) & & & \\
\hline \multicolumn{9}{|c|}{ L-arg/ADMA } \\
\hline \multirow[t]{2}{*}{ A } & 159 & 196 & $<0.001$ & 165 & 168 & 0.445 & 0.946 & 0.005 \\
\hline & $(136-204)$ & $(175-225)$ & & $(145-179)$ & $(144-180)$ & & & \\
\hline \multirow[t]{2}{*}{ V } & 228 & 143 & $<0.001$ & 234 & 230 & 0.508 & 0.803 & $<0.001$ \\
\hline & $(189-255)$ & $(131-161)$ & & $(204-252)$ & (209-239) & & & \\
\hline \multicolumn{9}{|c|}{ Citrulline } \\
\hline \multirow[t]{2}{*}{ A } & 31 & 18 & $<0.001$ & 29 & 31 & 0.508 & 0.900 & $<0.001$ \\
\hline & $(22-37)$ & $(16-21)$ & & $(24-32)$ & $(24-32)$ & & & \\
\hline \multirow[t]{2}{*}{ V } & 18 & 27 & $<0.001$ & 18 & 17 & 0.878 & 0.919 & $<0.001$ \\
\hline & $(13-23)$ & $(22-32)$ & & $(15-20)$ & $(14-23)$ & & & \\
\hline
\end{tabular}

Data are presented as median (interquartile range) to allow comparison between groups. ${ }^{*}$ vs. baseline eprosartan group. † vs. baseline vehicle control group. ‡ Baseline eprosartan group vs. control group. § After infusion values eprosartan group vs. control group. A, arterial; ADMA, asymmetric dimethylarginine; L-arg, Larginine; SDMA, symmetric dimethylarginine; $V$, right renal vein 
We found no correlation between the \% change in BP (SBP, DBP and MAP) and \% change in dimethylarginines (arterial and venous ADMA and SDMA) due to eprosartan (Figure 6.S2 in the Data Supplement). Furthermore, there was no correlation between the \% change in MRBF and \% change in dimethylarginines. Finally, there was no correlation between the \% change in MRBF and \% change in BP. As expected, the control group (right kidney) showed no significant changes in MRBF (Figure 6.1, right figure), MAP and RVR (data not shown).

The effect of eprosartan on renal clearance of ADMA, SDMA, L-arginine and Citrulline Fractional renal extraction (right kidney) of ADMA (14.4 \pm 8.9 to $-17.4 \pm 12.8 \%, \mathrm{P}<0.001$ ), SDMA $(11.9 \pm 8.9$ to $-14.2 \pm 12.9 \%, \mathrm{P}<0.001)$ and Citrulline $(37.8 \pm 14.1$ to $-55.4 \pm 32.1 \%$, $\mathrm{P}<0.001)$ showed an inversion after intrarenal infusion of eprosartan. Fractional renal extraction of L-arginine showed the opposite and changed from $-18.4 \pm 15.7$ to $12.9 \pm 15.0 \%, \mathrm{P}<0.001$.
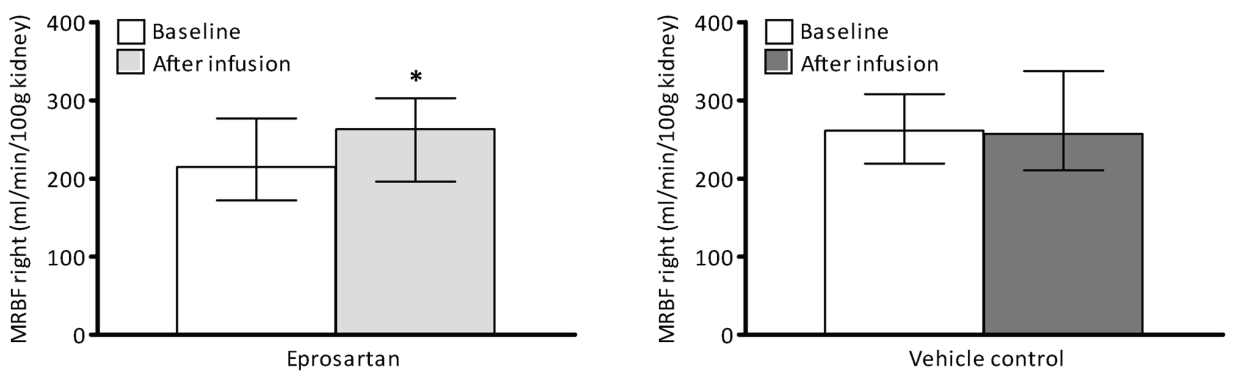

Figure 6.1 The effect of 30 minutes infusion of eprosartan (left figure) and vehicle control (right figure) on the MRBF. Bars represent medians and error bars represent interquartile ranges. The white bar indicates baseline MRBF and the grey bar indicates MRBF after eprosartan infusion. ${ }^{*} \mathrm{P}=0.008$ vs. baseline MRBF. MRBF, mean renal blood flow

Figure 6.2 illustrates the eprosartan-related changes in RPCL (right kidney) of ADMA, and SDMA. As expected, RPCL of ADMA, SDMA and Citrulline (Figure 6.2A, 6.2B and Figure 6.S3A in the Data Supplement, respectively) showed a similar inversion as FRE after infusion of eprosartan. This indicates an eprosartan-related shift from net renal clearance of both dimethylarginines and Citrulline from the blood to net renal release of both dimethylarginines and Citrulline into the blood. Again, RPCL of L-arginine showed the opposite pattern and shifted from net renal release into the blood to net renal clearance from the blood (Figure 6.S3B). 

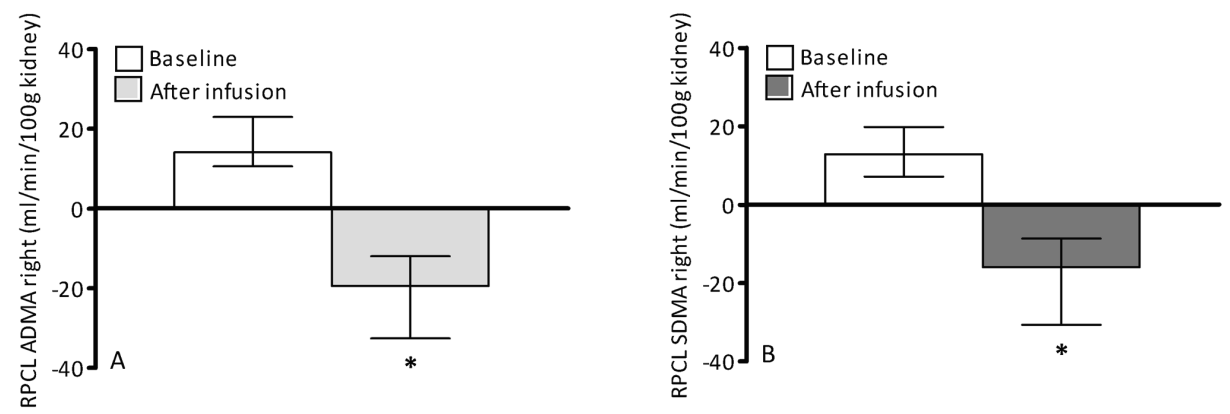

Figure 6.2 The effect of 30 minutes infusion of eprosartan on RPCL (right kidney) of ADMA (A) and SDMA (B). Bars represent means and error bars represent standard deviations. The white bar indicates baseline RPCL and the grey bar indicates RPCL after eprosartan infusion. ${ }^{*} \mathrm{P}<0.001$ vs. baseline RPCL. A positive RPCL indicates net renal clearance of the substance from the blood whereas a negative RPCL indicates net renal release into the blood. ADMA, asymmetric dimethylarginine; RPCL, renal plasma clearance; SDMA, symmetric dimethylarginine

\section{Additional analyses}

The \% change in MRBF, BP (SBP, DBP and MAP), plasma ADMA and RPCL of ADMA were neither significantly different between men and women nor between obese subjects (body mass index $>27 \mathrm{~kg} / \mathrm{m}^{2}$ ) and non-obese subjects (data not shown).

\section{DISCUSSION}

This study in essential hypertensive patients has two main findings. First, short-term intrarenal infusion of the $A R B$, eprosartan, leads to an acute shift from net renal clearance of ADMA from the blood to net renal release of ADMA into the blood. Second, despite this shift, systemic (arterial) ADMA decreased after intrarenal infusion of eprosartan. We conclude, therefore, that eprosartan can lower plasma ADMA in essential hypertensive patients, but this effect is not due to an increased renal plasma clearance of ADMA.

The calculated RPCL represents the net outcome of the balance between all possible renal mechanisms contributing to the clearance and synthesis of a substance. We observed that the kidney transformed from a net clearing organ of ADMA, SDMA and Citrulline at baseline into a net producer of both dimethylarginines and Citrulline after renal infusion of eprosartan. Interestingly, the kidney showed an opposite transformation regarding L-arginine from a producing organ into a netto clearing organ. Therefore, it is worthwhile to elaborate on possible renal mechanisms that may explain these findings. 
ADMA is an endogenous inhibitor of all isoforms of NO synthase (NOS), which convert L-arginine into Citrulline and NO. ADMA and its structural isomer symmetric dimethylarginine (SDMA, which has no effect on NOS) are synthesized during posttranscriptional methylation of protein arginine residues catalyzed by protein arginine methyltransferases (PRMTs). The kidneys have an important role in the regulation of plasma ADMA, SDMA, L-arginine and Citrulline. Overall, the kidneys are net producers of L-arginine ( $>60 \%$ of netto L-arginine synthesis). ${ }^{25}$ On the other hand, they can clear substantial amounts of ADMA, SDMA and Citrulline from the circulation. ${ }^{10,11,26}$ However, there is an essential difference in the main elimination pathway of these dimethylarginines by the kidney. ADMA is excreted in the urine but is primarily eliminated through intracellular degradation into Citrulline and dimethylamine by the enzyme DDAH, which is highly expressed in the kidney. ${ }^{13,14,27}$ Contrary to ADMA, SDMA cannot be degradated by DDAH and is almost entirely eliminated from the plasma by excretion into the urine. ${ }^{10}$ Interestingly, DDAH is also expressed in other organs like the pancreas, liver, lungs and endothelium.

How could these renal mechanisms explain our results? First, ARBs may increase overall PRMT activity and consequently the production of both dimethylarginines by the kidney. However, in rats, ARBs showed a decrease ${ }^{28}$ in or no effect ${ }^{29}$ on renal PRMT activity. Furthermore, PRMT activity cannot explain the change in RPCL of L-arginine. Second, ARBs possibly decrease renal DDAH activity and thereby lower RPCL of ADMA. However, given the fact that arterial (systemic) ADMA decreased after eprosartan infusion, an enhanced DDAH activity by ARBs is more likely. This is supported by animal studies that showed an increase in (renal) DDAH activity after treatment with ARBs. ${ }^{28,29}$ Moreover, simply a change in renal DDAH activity cannot explain the changes in RPCL of SDMA, L-arginine and Citrulline. Third, ARBs influence renal CAT expression or activity. CAT provide the transcellular transport of both ADMA and SDMA from their intracellular site of origin to the plasma and vice versa, in exchange for L-arginine. ${ }^{12}$ Furthermore, ADMA and SDMA compete for this bidirectional transcellular transport with L-arginine. ${ }^{12}$ Although there are no available studies in humans, studies in rats support the hypothesis that eprosartan influenced CAT expression or activity and thereby we hypothesize that this may have resulted in the shift in the RPCL of (dimethyl)arginine(s). ${ }^{30,31}$ Fourth, ARBs affect the urinary excretion of both dimethylarginines and L-arginine by influencing the tubular reabsorption. ADMA, SDMA and L-arginine are freely filtered through the glomerulus but tubular reabsorption ensures that urinary excretion is minimized. Presently, there are no direct studies of the tubular reabsorption of dimethylarginines. Yet, lto et al. demonstrated no effect of renin-angiotensin system (RAS) blockade on urinary ADMA. ${ }^{32}$ On the other hand, increased production of SDMA and/or decreased urinary excretion are the only 
mechanisms that could explain the shift from the RPCL of SDMA. Fifth, the shift in RPCL of the dimethylarginines and Citrulline may be a passive consequence of the changes in MRBF and RVR. However, the opposite shift of L-arginine makes this unlikely. In sum, the observed changes in RPCL of both dimethylarginines, L-arginine and Citrulline after eprosartan infusion are difficult to explain by a single renal mechanism. Still, the combination of the changes in RPCL of L-arginine and Citrulline may indicate that eprosartan may favor intrarenal NO production and NO availability, which are often reported effects of ARBs on the kidneys. ${ }^{7,8,33}$ Furthermore, it is obvious that systemic plasma concentration of ADMA did not decrease by an increased RPCL of ADMA.

Despite the remarkable shift from net renal clearance to net renal release of ADMA into the blood after ARB infusion, we did not observe an increase in ADMA due to this change in RPCL. Interestingly, we even observed the opposite, ADMA decreased after infusion. These results suggest a role for (compensatory) systemic ADMA metabolism when RPCL of ADMA changes and emphasizes that plasma concentrations of ADMA are the result of many other processes at intracellular and organ levels besides the kidney. ${ }^{11,12,34}$

We chose for intrarenal infusion of a relatively low dose eprosartan that showed no blood pressure effects in a previous study of our research group. ${ }^{19}$ Although in the present larger study BP fell, this was not different between both groups. Therefore, changes in BP after eprosartan infusion cannot explain our results at least not in full. In addition, we found no correlation between changes in BP and changes in ADMA plasma concentrations. Furthermore, other studies showed that the ADMA-lowering effect of ARBs, ACE inhibitors and calcium channel blockers (CCB) was independent of blood pressure reduction. ${ }^{1-3,35}$ Taken together, this makes a blood-pressure-related effect and a specific angiotensin type I receptor or angiotensin II mediated effect as an explanation for the decrease in ADMA plasma concentrations less likely. Another suggested mechanism may be a reductive effect of these antihypertensive drugs on oxidative stress which is known for the inhibitory effect on the intracellular degradation of ADMA by DDAH. However, a reduced inactivation of DDAH would not be expected to yield the reduction of plasma SDMA concentrations by our study. For that reason, parallel reduction of both dimethylarginine may indicate a limiting effect on the production by PRMTs. At present, in human, there is little or no data available on these plasma regulating mechanisms and the interaction with ARBs. Therefore, at present, robust conclusions about mechanisms underlying the ADMA lowering effect of ARBs, other than the currently investigated RPCL, cannot be made. 
There are some limitations to our study. We did not measure the influence of intrarenal eprosartan infusion on both kidneys, thus we could not calculate the total renal plasma clearance after infusion of eprosartan. The absence of comparable renal measurements with other vasoactive substances such as other ARBs, ACE inhibitors and/or CCB limits our conclusion to the effect of merely eprosartan on renal plasma clearance and plasma ADMA. However, this study was not designed as a clinical one but rather to unravel a pathophysiological mechanism. Furthermore, presently it is not possible to perform a study like ours with such types of drugs because these are not available in a suitable form for infusion into the kidney. Future investigation should elucidate whether our results could be extrapolated to ARBs in general and to other antihypertensive drugs. Finally, a possible limitation of the present study is that shortterm intrarenal infusion of eprosartan cannot be compared to (chronic) oral administration of an ARB.

In conclusion, in this study of hypertensive patients, short-term intrarenal infusion of eprosartan results in decreased systemic (arterial) ADMA plasma concentration. This effect is not the result of an increased RPCL of ADMA, but probably due to extra-renal changes in the plasma regulation of ADMA.

\section{Perspectives}

In the present study we demonstrated that the plasma ADMA regulating function of the kidneys is not involved in the plasma ADMA lowering effect of eprosartan. This suggests that an extra-renal mechanism was responsible for the effect. Furthermore, this study provides further evidence that the regulation of plasma ADMA is not primarily determined by renal clearance but must be related to the balance of enzymatic synthesis by PRMTs and degradation by DDAH. Further studies are necessary to elucidate the trigger for acute changes in this balance. Our data also suggest that the kidney is (passively) compensating for alteration in ADMA balance due to processes elsewhere in the body. Therefore, more research should be directed towards the crosstalk between the kidneys and the rest of the body regarding the regulation of ADMA.

\section{Acknowledgements}

The authors gratefully acknowledge M. Fuss-Lejeune for her assistance in the blood sampling and measurements during renal angiography. This study was supported by a "clinical established investigator" grant from the Dutch Heart Foundation (DHF; Grant No. 2004T058) obtained by Dr. A.A. Kroon. Eprosartan was kindly supplied by Solvay Pharma B.V., Weesp, the Netherlands. 


\section{REFERENCES}

1. Aslam S, Santha $T$, Leone A, Wilcox C. Effects of amlodipine and valsartan on oxidative stress and plasma methylarginines in end-stage renal disease patients on hemodialysis. Kidney Int. 2006;70:2109-2115.

2. Delles $C$, Schneider MP, John S, Gekle M, Schmieder RE. Angiotensin converting enzyme inhibition and angiotensin II AT1-receptor blockade reduce the levels of asymmetrical N(G), N(G)-dimethylarginine in human essential hypertension. Am J Hypertens. 2002;15:590-593.

3. Ito A, Egashira K, Narishige T, Muramatsu K, Takeshita A. Renin-angiotensin system is involved in the mechanism of increased serum asymmetric dimethylarginine in essential hypertension. Jpn Circ J. 2001;65:775-778.

4. Tomiyama H, Yamada J, Koji Y, Shiina K, Yoshida M, Yamashina A. Effect of telmisartan on forearm postischemic hyperemia and serum asymmetric dimethylarginine levels. Am J Hypertens. 2007;20:1305-1311.

5. Xie QY, Wang YJ, Sun ZL, Yang TL. Effects of valsartan and indapamide on plasma cytokines in essential hypertension. Zhong Nan Da Xue Xue Bao Yi Xue Ban. 2006;31:629-634.

6. Delic-Brkljacic D, Galesic K, Ivanac G, Manola S, Pintaric H, Stambuk K, Gacina P, Radeljic V. Influence of ATII blockers and calcium channel blockers on renal vascular resistance in patients with essential hypertension. Coll Antropol. 2009;33:1129-1138.

7. Delles C, Jacobi J, John S, Fleischmann I, Schmieder RE. Effects of enalapril and eprosartan on the renal vascular nitric oxide system in human essential hypertension. Kidney Int. 2002;61:1462-1468.

8. Frank H, Schobel HP, Vitkowsky J, Schmieder RE, Heusser K. Effects of angiotensin II receptor antagonism on the renal hemodynamic response to cardiovascular stress. Kidney Int. 2003;63:617623.

9. Kakimoto $\mathrm{Y}$, Akazawa $\mathrm{S}$. Isolation and identification of N-G,N-G- and N-G,N'-G-dimethyl-arginine, Nepsilon-mono-, di-, and trimethyllysine, and glucosylgalactosyl- and galactosyl-delta-hydroxylysine from human urine. J Biol Chem. 1970;245:5751-5758.

10. Nijveldt RJ, Van Leeuwen PA, Van Guldener C, Stehouwer CD, Rauwerda JA, Teerlink T. Net renal extraction of asymmetrical (ADMA) and symmetrical (SDMA) dimethylarginine in fasting humans. Nephrol Dial Transplant. 2002;17:1999-2002.

11. Siroen MP, van der Sijp JR, Teerlink T, van Schaik C, Nijveldt RJ, van Leeuwen PA. The human liver clears both asymmetric and symmetric dimethylarginine. Hepatology. 2005;41:559-565.

12. Teerlink T, Luo Z, Palm F, Wilcox CS. Cellular ADMA: regulation and action. Pharmacol Res. 2009;60:448-460.

13. Leiper JM, Santa Maria J, Chubb A, MacAllister RJ, Charles IG, Whitley GS, Vallance P. Identification of two human dimethylarginine dimethylaminohydrolases with distinct tissue distributions and homology with microbial arginine deiminases. Biochem J. 1999;343 Pt 1:209-214.

14. Tran CT, Fox MF, Vallance $P$, Leiper JM. Chromosomal localization, gene structure, and expression pattern of DDAH1: comparison with DDAH2 and implications for evolutionary origins. Genomics. 2000;68:101-105.

15. Al Banchaabouchi M, Marescau B, Possemiers I, D'Hooge R, Levillain O, De Deyn PP. NG, NGdimethylarginine and NG, NG-dimethylarginine in renal insufficiency. Pflugers Arch. 2000;439:524531.

16. MacAllister RJ, Rambausek MH, Vallance P, Williams D, Hoffmann KH, Ritz E. Concentration of dimethyl-L-arginine in the plasma of patients with end-stage renal failure. Nephrol Dial Transplant. 1996;11:2449-2452.

17. Marescau B, Nagels G, Possemiers I, De Broe ME, Becaus I, Billiouw JM, Lornoy W, De Deyn PP. Guanidino compounds in serum and urine of nondialyzed patients with chronic renal insufficiency. Metabolism. 1997;46:1024-1031. 


\section{CHAPTER 6}

18. Vallance P, Leone A, Calver A, Collier J, Moncada S. Accumulation of an endogenous inhibitor of nitric oxide synthesis in chronic renal failure. Lancet. 1992;339:572-575.

19. Dielis AW, Smid M, Spronk HM, Houben AJ, Hamulyak K, Kroon AA, Ten Cate H, de Leeuw PW. Changes in fibrinolytic activity after angiotensin II receptor blockade in therapy-resistant hypertensive patients. J Thromb Haemost. 2007;5:1509-1515.

20. Waterval WA, Scheijen JL, Ortmans-Ploemen MM, Habets-van der Poel CD, Bierau J. Quantitative UPLC-MS/MS analysis of underivatised amino acids in body fluids is a reliable tool for the diagnosis and follow-up of patients with inborn errors of metabolism. Clin Chim Acta. 2009;407:36-42.

21. Levey AS, Stevens LA, Schmid CH, Zhang YL, Castro AF, 3rd, Feldman HI, Kusek JW, Eggers P, Van Lente $\mathrm{F}$, Greene T, Coresh J. A new equation to estimate glomerular filtration rate. Ann Intern Med. 2009;150:604-612.

22. Andersson LG, Bratteby LE, Ekroth R, Wesslen O, Hallhagen S. Calculation of renal extraction during high diuresis and low renal plasma flow conditions. Clin Physiol. 1994;14:79-85.

23. Siroen MP, Teerlink T, Nijveldt RJ, Prins HA, Richir MC, van Leeuwen PA. The clinical significance of asymmetric dimethylarginine. Annu Rev Nutr. 2006;26:203-228.

24. van Onna M, Houben AJ, Kroon AA, Wierema TK, Koster D, van Engelshoven JM, de Leeuw PW. Asymmetry of renal blood flow in patients with moderate to severe hypertension. Hypertension. 2003;41:108-113.

25. Tizianello A, De Ferrari G, Garibotto G, Gurreri G, Robaudo C. Renal metabolism of amino acids and ammonia in subjects with normal renal function and in patients with chronic renal insufficiency. $J$ Clin Invest. 1980;65:1162-1173.

26. van Guldener C, Donker AJ, Jakobs C, Teerlink T, de Meer K, Stehouwer CD. No net renal extraction of homocysteine in fasting humans. Kidney Int. 1998;54:166-169.

27. Kimoto M, Tsuji $H$, Ogawa $T$, Sasaoka $K$. Detection of NG,NG-dimethylarginine dimethylaminohydrolase in the nitric oxide-generating systems of rats using monoclonal antibody. Arch Biochem Biophys. 1993;300:657-662.

28. Onozato ML, Tojo A, Leiper J, Fujita T, Palm F, Wilcox CS. Expression of NG,NG-dimethylarginine dimethylaminohydrolase and protein arginine $\mathrm{N}$-methyltransferase isoforms in diabetic rat kidney: effects of angiotensin II receptor blockers. Diabetes. 2008;57:172-180.

29. Chen GF, Wagner L, Sasser JM, Zharikov S, Moningka NC, Baylis C. Effects of angiotensin type 1 receptor blockade on arginine and ADMA synthesis and metabolic pathways in fawn-hooded hypertensive rats. Nephrol Dial Transplant. 2010;25:3518-3525.

30. Helle F, Hultstrom M, Skogstrand T, Palm F, Iversen BM. Angiotensin II-induced contraction is attenuated by nitric oxide in afferent arterioles from the nonclipped kidney in 2K1C. Am J Physiol Renal Physiol. 2009;296:F78-86.

31. Hultstrom M, Helle F, Iversen BM. AT(1) receptor activation regulates the mRNA expression of CAT1, CAT2, arginase-1, and DDAH2 in preglomerular vessels from angiotensin II hypertensive rats. Am J Physiol Renal Physiol. 2009;297:F163-168.

32. Ito A, Egashira K, Narishige T, Muramatsu K, Takeshita A. Angiotensin-converting enzyme activity is involved in the mechanism of increased endogenous nitric oxide synthase inhibitor in patients with type 2 diabetes mellitus. Circ J. 2002;66:811-815.

33. Schmieder RE, Delles C, Mimran A, Fauvel JP, Ruilope LM. Impact of telmisartan versus ramipril on renal endothelial function in patients with hypertension and type 2 diabetes. Diabetes Care. 2007;30:1351-1356.

34. Ronden RA, Houben AJ, Teerlink T, Bakker JA, Bierau J, Stehouwer CD, De Leeuw PW, Kroon AA. Reduced renal plasma clearance does not explain increased plasma asymmetric dimethylarginine in hypertensive subjects with mild to moderate renal insufficiency. Am J Physiol Renal Physiol. 2012;303:F149-156. 
35. Kawata T, Daimon M, Hasegawa R, Teramoto K, Toyoda T, Sekine T, Yamamoto K, Uchida D, Himi T, Yoshida K, Komuro I. Effect of angiotensin-converting enzyme inhibitor on serum asymmetric dimethylarginine and coronary circulation in patients with type 2 diabetes mellitus. Int J Cardiol. 2009;132:286-288. 


\section{DATA SUPPLEMENT}

\section{Expanded methods of the study protocol}

This study was performed in 81 consecutive hypertensive patients who underwent diagnostic renal angiography to exclude renal artery stenosis. Patients were angiographically evaluated for suspicion of renal artery stenosis based on one or more of the following clinical clues: hypertension despite treatment with at least three antihypertensive agents, (recent) hypertensive crisis, or hypertension with evident peripheral vascular disease, the presence of an abdominal bruit or unexplained renal function deterioration, e.g. in response to antihypertensive treatment. For reasons of standardization, all antihypertensive medication was discontinued for three weeks and patients were requested to adhere to a sodium-restricted (55 mmol/24-h) diet during one-week prior to renal angiography. Metformin was discontinued two days before angiography. Other medication, including statins, was allowed. On the day preceding renal angiography, a non-invasive ambulatory 24-h blood pressure (BP) measurement was performed (Spacelabs, ambulatory blood pressure monitor, Redmond, WA, USA) and 24-h urine was collected for the assessment of sodium and albumin excretion (UAE). The investigations were performed in accordance with the principles outlined in the Declaration of Helsinki. All patients gave their written informed consent prior to inclusion and the institutional ethics committee approved the study.

\section{${ }^{133}$ Xenon washout}

After the blood sampling, we measured selective mean renal blood flow (MRBF) using the ${ }^{133}$ Xenon washout technique, as described previously. ${ }^{1}$ In short, after infusion of a bolus of ${ }^{133}$ Xenon (37 MBq, IDB Holland bv, Baarle-Nassau, The Netherlands) directly into the renal artery, ${ }^{133}$ Xenon washout curves were recorded using an extra corporeal scintillation counter. The ${ }^{133}$ Xenon washout curves were analyzed off-line. After subtraction of background radiation, the disappearance of ${ }^{133}$ Xenon from the kidney was analyzed mathematically using either a two-phase or one-phase exponential decay model, depending on which one fits best (using Graphpad Software (Graphpad Software, Inc., San Diego, CA)). From this model we calculated MRBF and mean renal plasma flow (MRPF, calculated as MRBF $x$ (1 - hematocrit)) both expressed as $\mathrm{ml} / \mathrm{min} / 100 \mathrm{~g}$ kidney. The ${ }^{133}$ Xenon washout technique provides accurate estimates of renal blood flow and, in our hands, has a coefficient of variation of $8 \%$ for repeated measurements. Renal vascular resistance (RVR) was calculated as mean arterial pressure (MAP) / MRBF and expressed in arbitrary units (AU). Each patient underwent the same procedure, by which we measured first baseline MRBF in the left and thereafter in the right kidney. 


\section{Infusion of eprosartan or vehicle control}

For reasons of standardization, intrarenal infusion of eprosartan or vehicle control was done in the right kidney. After baseline blood sampling and MRBF measurements, the arterial catheter was relocated in the right kidney. Through the arterial catheter, patients received a thirty minutes lasting infusion of the ARB eprosartan (dissolved in $5 \%$ glucose solution, total dose $195 \mu \mathrm{g} / \mathrm{kg}$, Solvay Pharma B.V., Weesp, the Netherlands). We chose this relatively low dose to minimize the effect on systemic BP. ${ }^{2}$ After 30 minutes of infusion, we measured MRBF of the right kidney and we drew arterial (aorta, (A)) and venous (right kidney, (V)) blood samples for the determination of ADMA, SDMA, L-arginine and Citrulline.

Although several previous studies of our group showed no effect of vehicle (saline or glucose solution) infusion/bolus on renal hemodynamics (MRBF, RVR), or glomerular filtration rate $(G F R)))^{3-5}$ we administered a single intra-arterial bolus of $7.5 \mathrm{ml} 5 \%$ glucose as vehicle control in the right kidney in 11 patients, to exclude possible changes in arterial or venous concentrations of ADMA, SDMA, L-arginine or Citrulline by direct effects of the catheter procedure itself. These patients were included at the end of the study after 70 patients that received eprosartan infusion. After 30 minutes we measured MRBF and drew arterial (aorta) and venous (right kidney) blood samples for the determination of ADMA, SDMA, L-arginine and Citrulline.

Table 6.S1 Additional characteristics and drug treatments of the 43 hypertensive patients that received intrarenal eprosartan infusion

\begin{tabular}{lc}
\hline & Eprosartan $(\mathrm{n}=43)$ \\
\hline Male/Female & $28 / 15(65 / 35 \%)$ \\
Premenopausal women & $5(33 \%$ of the women) \\
Postmenopausal women & $10(67 \%$ of the women) \\
Number of classes of antihypertensive drugs prior to & $3(2-4)$ \\
Mean treatment duration (years) & $7(4-10)$ \\
Angiotensin Il type 1 receptor blocker* & $18(42 \%)$ \\
Angiotensin-Converting-Enzyme inhibitor* & $17(40 \%)$ \\
Calcium-channel-antagonist* & $29(67 \%)$ \\
B-blocker* & $36(84 \%)$ \\
Diuretic* & $27(63 \%)$ \\
Other ( $\alpha$-blockers, renin inhibitors)* & $3(7 \%)$ \\
Statin & $15(35 \%)$ \\
Myocardial infarction & $5(12 \%)$ \\
Stroke & $2(5 \%)$ \\
Extra-renal atherosclerosis & $20(47 \%)$ \\
\hline
\end{tabular}

Data are presented as number (\% of group) or median (interquartile range), as appropriate.

*Antihypertensive medication use before the three weeks discontinuation 
CHAPTER 6

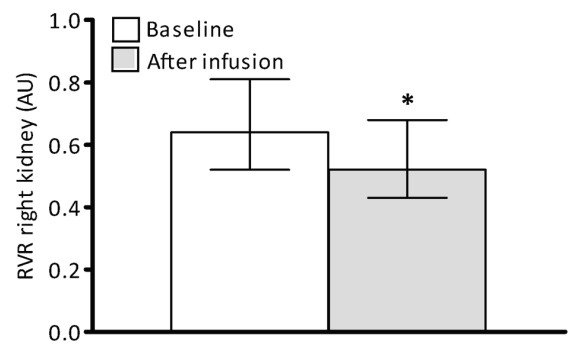

Figure 6.S1 The effect of 30 minutes infusion of eprosartan on RVR (right kidney). Bars represent means and error bars represent standard deviations. White bars indicate baseline RVR and grey bars indicate RVR after eprosartan infusion. $+P=0.002$ vs. baseline RVR. AU, arbitrary units; RVR, renal vascular resistance

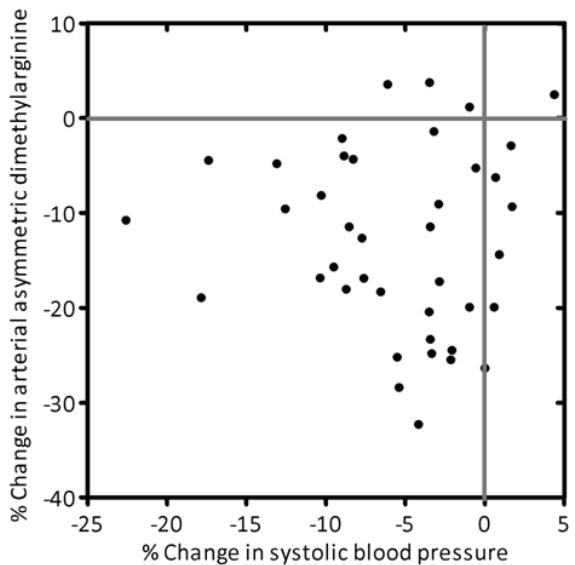

Figure 6.S2 There was no correlation between the \% change in mean arterial pressure and \% change in arterial asymmetric dimethylarginine due to 30 minutes of intrarenal eprosartan infusion 

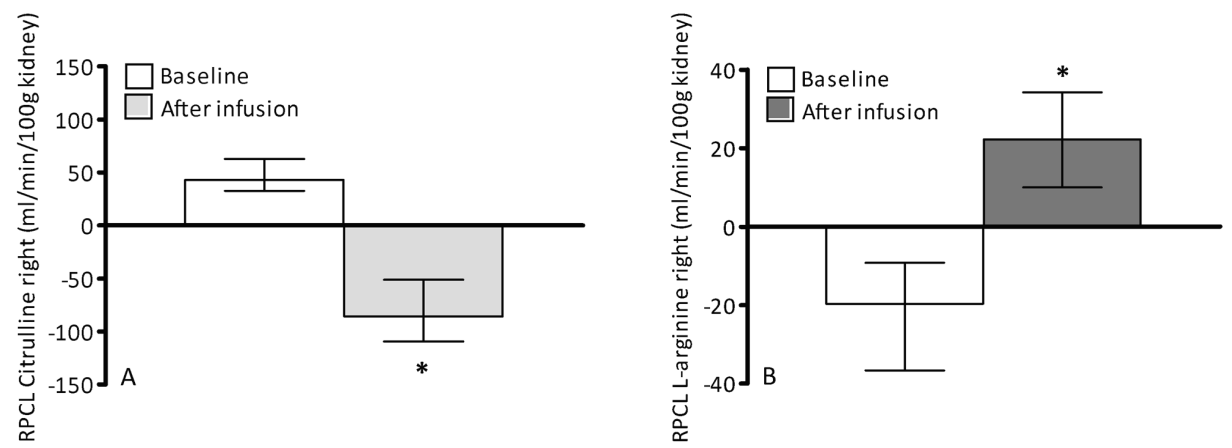

Figure 6.S3 The significant effect of 30 minutes infusion of eprosartan on the RPCL (right kidney) of Citrulline (A) and L-arginine (B). Bars represent means and error bars represent standard deviations. White bars indicate baseline RPCL and grey bars indicate RPCL after eprosartan infusion. ${ }^{*} \mathrm{P}<0.001$ vs. baseline RPCL. A positive RPCL indicates net renal clearance of the substance from the blood whereas a negative RPCL indicates net renal release into the blood. RPCL, renal plasma clearance.

\section{REFERENCES}

1. Blaufox MD, Fromowitz A, Gruskin A, Meng CH, Elkin M. Validation of use of xenon 133 to measure intrarenal distribution of blood flow. Am J Physiol. 1970;219:440-444.

2. Dielis AW, Smid M, Spronk HM, Houben AJ, Hamulyák K, Kroon AA, Ten Cate H, de Leeuw PW. Changes in fibrinolytic activity after angiotensin II receptor blockade in therapy-resistant hypertensive patients. J Thromb Haemost. 2007;5:1509-1515.

3. de Leeuw PW, de Bos R, van Es PN, Birkenhäger WH. Effect of sympathetic stimulation and intrarenal alpha-blockade on the secretion of renin by the human kidney. Eur J Clin Invest. 1985;15:166-170.

4. de Leeuw PW, van Es PN, de Bos R, Birkenhäger WH. Role of alpha 1- and alpha 2-adrenergic receptors in the human hypertensive kidney. Hypertension. 1987;9:III210-212.

5. van der Zander K, Houben AJ, Kroon AA, Wierema TK, Fuss-Lejeune MJ, Koster D, de Leeuw PW. Does brain natriuretic peptide have a direct renal effect in human hypertensives? Hypertension. 2003;41:119-123. 

Salt intake does not influence the renal handling of asymmetric dimethylarginine in hypertensive Caucasians

\author{
Rianne A. Ronden \\ Daan J.L. van Twist \\ Alfons J.H.M. Houben \\ Jaap A. Bakker \\ Jörgen Bierau \\ Coen D.A. Stehouwer \\ Peter W. de Leeuw \\ Abraham A. Kroon
}

Submitted 


\section{CHAPTER 7}

\section{ABSTRACT}

Background and objective - High dietary salt intake negatively influences nitric oxide (NO) production and increases plasma concentrations of the NO synthase inhibitor asymmetric dimethylarginine (ADMA) in non-Caucasians. We investigated, in hypertensive Caucasians, the influence of dietary salt intake on plasma ADMA and the renal handling of ADMA.

Methods - We included 120 hypertensive Caucasians, scheduled for renal angiography. Patients were assigned to either a high-salt diet (11.5g of $\mathrm{NaCl}$ per day, $\mathrm{n}=60)$ or a low-salt diet $(3.2 \mathrm{~g}$ of $\mathrm{NaCl}$ per day, $\mathrm{n}=60$ ) during one week before measurements. We drew blood samples from the aorta and both renal veins for measurement of ADMA, symmetric dimethylarginine, L-arginine, creatinine and renin. Renal blood flow was measured using the ${ }^{133}$ Xenon washout and renal plasma clearance (RPCL) was calculated using arteriovenous concentration differences.

Results - Because of substantial overlap of 24-h urinary sodium excretion (USE) between both prescribed diets, probably due to non-adherence, we decided to use 24-h USE as a proxy for salt intake and performed multiple regression analyses. Indeed, higher 24-h USE was positively associated with intra-arterial blood pressure $(\beta=0.22$ [95\% Cl $0.05 ; 0.39], P=0.013$ for systolic blood pressure and $\beta=0.23[0.06 ; 0.41], P=0.011$ for mean arterial pressure and inversely associated with plasma renin $(\beta=-0.30[-0.48 ;-0.22], P=0.001)$. However, there was no significant association between 24-h USE and plasma ADMA or RPCL of ADMA.

Conclusion - This study indicates that in hypertensive Caucasians, (moderate) high-salt intake results in higher blood pressure and lower plasma renin levels, but is neither associated with higher plasma ADMA nor lower RPCL of ADMA. 


\section{INTRODUCTION}

In non-Caucasian, salt-sensitive and salt-resistant hypertensive patients, high daily salt intake is associated with a decreased nitric oxide (NO) bioavailability and increased plasma concentration of the nitric oxide synthase (NOS) inhibitor asymmetric dimethylarginine (ADMA). ${ }^{1-3}$ These observations suggest a role for ADMA in the suppressant effect of high-salt intake on NO production or bioavailability. However, whether this effect of salt intake is also is true for Caucasians is unknown and furthermore, the origin of the increased plasma ADMA concentration is unknown.

Given the facts that dietary salt intake has a profound effect on renal hemodynamics, ${ }^{4}$ expression of NOS and the enzyme $N^{G} N^{G}$-dimethylarginine dimethylaminohydrolase (DDAH, the main degradation pathway of ADMA) in hypertensive rat kidneys, ${ }^{5-7}$ and that the kidneys may play an essential role in the plasma regulation of ADMA. ${ }^{8-10} \mathrm{We}$ hypothesized that under circumstances of high-salt intake one of the contributing factors of increased plasma ADMA is decreased renal plasma clearance (RPCL). Therefore, the aim of the present study was to investigate the effects of salt intake on plasma concentrations and RPCL of ADMA in hypertensive Caucasians. Additionally, we investigated above-mentioned aims for symmetric dimethylarginine (SDMA) and the NOS substrate L-arginine.

\section{METHODS}

\section{Patients and study protocol}

Over a three-year period, we prospectively collected data from all hypertensive patients who underwent diagnostic renal angiography in our hospital according to a standardized clinical protocol. This protocol includes selective blood sampling of the aorta, left and right renal veins, selective mean renal blood flow (MRBF) measurements, and renal angiography. Patients were angiographically evaluated for suspicion of renal artery stenosis based on one or more of the following clinical clues: hypertension despite treatment with at least three antihypertensive agents, (recent) hypertensive crisis, or hypertension with evident peripheral vascular disease, the presence of an abdominal bruit, renal function deterioration, e.g. in response to antihypertensive treatment. All antihypertensive medication was discontinued for three weeks prior to the angiography. In patients with diabetes mellitus, the use of metformin was discontinued two days before renal angiography to lower the risk of contrast medium-induced nephropathy. Other medication was continued. Patients were randomly requested to adhere to either a low-salt diet $(55 \mathrm{mmol}$ sodium or $3.2 \mathrm{~g}$ $\mathrm{NaCl}$ per day) or a high-salt diet $(200 \mathrm{mmol}$ sodium or $11.5 \mathrm{~g} \mathrm{NaCl}$ per day) during the week before the measurements. Patients received instructions for a 7-day diet plan 


\section{CHAPTER 7}

with standardized daily menus containing the prescribed amounts of sodium chloride One day before renal angiography, we performed a non-invasive ambulatory 24-h blood pressure measurement (SpaceLabs, ambulatory blood pressure monitor, Redmond, WA, USA) and patients collected 24-h urine, in which we measured concentration of sodium (to monitor dietary compliance), creatinine (to monitor urine collection) and albumin. We measured urinary albumin excretion since proteinuria is associated with higher plasma concentrations of ADMA. ${ }^{11}$ Furthermore, patients filled in a questionnaire on smoking habits, cardiovascular history and use of medication. The investigations were performed in accordance with the principles outlined in the Declaration of Helsinki. All patients gave their informed consent, and the local ethical committee approved the study.

\section{Study measurements}

All patients were admitted to our ward one day prior to the angiography. After an overnight fast, the aorta and both renal veins were cannulated via the femoral route. Subsequently, we drew blood samples from the aorta and renal veins simultaneously for the measurement of ADMA, SDMA, L-arginine, creatinine and active plasma renin concentration (APRC). After centrifugation, plasma samples were immediately stored at $-80{ }^{\circ} \mathrm{C}$ until analysis. In addition, we draw venous blood samples from the antecubital vein for determination of fasting glucose, serum creatinine, lipid profile and hematocrit. Next, we selectively measured right and left MRBF using the ${ }^{133}$ Xenon washout technique, as described previously. ${ }^{12,13}$ In short, after infusion of a bolus of ${ }^{133}$ Xenon (IDB Holland bv, Baarle-Nassau, The Netherlands) directly into the renal artery, ${ }^{133}$ Xenon washout curves were recorded using an extra corporeal scintillation counter. After subtraction of background radiation, the disappearance of ${ }^{133}$ Xenon from the kidney was analyzed mathematically using either a two-phase or one-phase exponential decay model, depending on which one fits best (using Graphpad Software (Graphpad Software, Inc., San Diego, CA)). From this model we calculated MRBF and mean renal plasma flow (MRPF, calculated as MRBF x (1 - hematocrit)) both expressed as $\mathrm{ml} / \mathrm{min} / 100 \mathrm{~g}$ kidney. Renal vascular resistance (RVR) was calculated as mean arterial pressure (MAP) / MRBF and expressed in arbitrary units (AU). During the renal blood flow measurements, heart rate and intra-arterial blood pressure were continuously monitored. No contrast agents were administered before all aforementioned measurements were completed. Finally, we performed the renal angiography, using a digital subtraction system. An experienced radiologist reported renal (artery) anomalies. 


\section{Biochemical analyses}

Plasma concentrations of ADMA, SDMA and L-arginine were determined using an Acquity UPLC (ultra-performance liquid chromatography) separation module coupled to a Quattro Premier ESI-MSMS (Waters, Etten-Leur, The Netherlands). ${ }^{14,15}$ Intra- and inter-assay variations at physiological concentrations were less than $5 \%$ for ADMA, SDMA and L-arginine. Active plasma renin concentration was determined by a two-side immunoradiometric assay method. ${ }^{16}$ Standard clinical chemistry methods were used for assessment of fasting glucose, (micro)albumin, creatinine and lipid profile. Urinary concentrations of sodium were measured by flame photometer, and 24-h urinary excretion of sodium was calculated by multiplying the concentration by the $24-\mathrm{h}$ total urine volume.

\section{Calculations}

Glomerular filtration rate (GFR) in $\mathrm{ml} / \mathrm{min} / 1.73 \mathrm{~m}^{2}$ was estimated by the Chronic Kidney Disease Epidemiology Collaboration equation (CKD-EPI). ${ }^{17} \mathrm{RPCL}$ of ADMA, SDMA, L-arginine, creatinine and APRC (in $\mathrm{ml} / \mathrm{min} / 100 \mathrm{~g}$ kidney) of both kidneys was calculated as described previously. ${ }^{18,19}$ This calculation corrects a possible overestimation of the fractional renal extraction (calculated as ( $\mathrm{A}-\mathrm{V}$ ) / $\mathrm{A} \times 100 \%^{9,20,21}$ where $A$ and $V$ represent arterial and renal vein plasma concentrations, respectively) in cases of a low renal plasma flow. ${ }^{22}$ A positive RPCL indicates net clearance of the substance from the blood whereas a negative RPCL indicates net release into the blood. The L-arginine/ADMA ratio was calculated as well, because NO production is determined by both substrate availability (L-arginine) and the presence of inhibitor (ADMA), which may be adequately reflected by this ratio. ${ }^{23}$

\section{Statistical analyses}

Normally distributed variables were analyzed using parametric tests and expressed as mean \pm standard deviation (SD). Skewed distributed variables were analyzed using non-parametric tests and expressed as median (interquartile range). First, we compared the patients who were instructed to adhere to a low-salt diet vs. a high-salt diet. Second, since there was substantial overlap in urinary sodium excretion between both groups and 24-h urinary sodium excretion could serve as a proxy for salt intake, ${ }^{24}$ multiple linear regression analysis was used to investigate the association between 24$h$ urinary sodium excretion and arterial plasma concentrations of ADMA, SDMA, Larginine, L-arginine/ADMA ratio and APRC. Furthermore, associations between 24-h urinary sodium excretion and RPCL of aforementioned variables were investigated. Finally, we also investigated the associations between 24-h urinary sodium excretion and renal hemodynamic variables (intra-arterial blood pressure, MRBF and RVR). 


\section{CHAPTER 7}

Variables with a skewed distribution used in the multiple linear regression analyses were $\log _{e}$ transformed prior to further analyses (MRBF, RVR, APRC, RPCL of al variables and 24-h urinary sodium excretion). All associations were primary analyzed without adjustments and then with adjustments for potential confounders: age, gender, Body Mass Index (BMI), intra-arterial mean arterial pressure (MAP), estimated GFR and APRC, as appropriate. All results are expressed in standardized regression coefficients ( $\beta$ ) $[95 \%$ confidence intervals $(\mathrm{Cls})]$. A two-tailed $\mathrm{P}<0.05$ was considered statistically significant. All data were analyzed using SPSS software (release 18; SPSS Inc. Chicago, IL, USA).

\section{RESULTS}

\section{Patients}

Over a three-year period, 179 patients underwent renal angiography with measurements of selective renal blood flow according to the standardized clinical protocol. Fifty-three patients had atherosclerotic renal artery stenosis with more than $50 \%$ luminal reduction or fibromuscular dysplasia and one previously underwent a nephrectomy. Finally, data from 120 hypertensive patients (all Caucasian) was suitable for analyses. The excluded patients did not differ from the total group of patients for BMI, smoking behavior, history of cardiovascular events, 24-h blood pressure, lipid profile, fasting glucose or 24-h urinary sodium excretion (data not shown). As expected, the excluded patients had a lower estimated GFR ( $P<0.001$, mainly due to the presence of atherosclerotic renal artery stenosis).

Table 7.1 Patient characteristics

\begin{tabular}{lcc}
\hline & Low salt & High salt \\
\hline Number male/female & $40 / 23$ & $37 / 26$ \\
Age (years) & $54 \pm 13$ & $56 \pm 11$ \\
Body mass index $\left(\mathrm{kg} / \mathrm{m}^{2}\right)$ & $29 \pm 4$ & $28 \pm 4$ \\
Current smoking & $24(41 \%)$ & $23(38 \%)$ \\
Diabetes mellitus & $8(14 \%)$ & $12(20 \%)$ \\
History of cardiovascular events & $12(20 \%)$ & $13(21 \%)$ \\
Mean 24-h systolic blood pressure $(\mathrm{mmHg})$ & $162 \pm 22$ & $166 \pm 21$ \\
Mean 24-h diastolic blood pressure $(\mathrm{mmHg})$ & $98 \pm 13$ & $97 \pm 13$ \\
Mean 24-h mean arterial pressure $(\mathrm{mmHg})$ & $120 \pm 15$ & $121 \pm 14$ \\
Fasting glucose (mmol/l) & $5.3(5.1-5.9)$ & $5.6(5.1-6.3)$ \\
Total cholesterol (mmol/l) & $5.2(4.2-5.8)$ & $5.3(4.4-5.8)$ \\
High-density lipoprotein $(\mathrm{mmol} / \mathrm{l})$ & $1.1(0.9-1.4)$ & $1.2(1.0-1.6)$ \\
Low-density lipoprotein $(\mathrm{mmol} / \mathrm{l})$ & $3.1 \pm 0.9$ & $3.1 \pm 1.0$ \\
Estimated glomerular filtration rate $\left(\mathrm{ml} / \mathrm{min} / 1.73 \mathrm{~m}^{2}\right)$ & $79 \pm 21$ & $74 \pm 19$ \\
Urinary albumin excretion $(\mathrm{mg} / 24-\mathrm{h})$ & $18(8-92)$ & $31(13-158)$ \\
\hline
\end{tabular}

Data are expressed as means \pm SD or medians (interquartile ranges) or numbers (\%group). 
Of the included patients, 61 patients were assigned to adhere to high-salt diet and 59 patients were assigned to adhere to low-salt diet. Patient characteristics are listed in Table 7.1. There were no statistically significant differences between both groups. All included patients had a relative good but mildly reduced renal function; estimated GFR was $79 \pm 21 \mathrm{ml} / \mathrm{min} / 1.73 \mathrm{~m}^{2}$ in the low-salt group and $74 \pm 19 \mathrm{ml} / \mathrm{min} / 1.73 \mathrm{~m}^{2}$ in the high-salt group. Fourteen ( 6 in the low-salt group, 8 in the high-salt group) patients had proteinuria (>1g albumin/24-h).

\section{Analysis according allocation group}

Median 24-h urinary sodium excretion was $78 \mathrm{mmol} / 24-\mathrm{h}$ (interquartile range, (55$106)$ in the low-salt group vs. $178(127-230) \mathrm{mmol} / 24-\mathrm{h}$ in the high-salt group $(\mathrm{P}<$ 0.001 ). Figure 7.1 shows that there was substantial overlap in 24-h urinary sodium excretion between both groups, illustrated by a range of $13-264 \mathrm{mmol} / 24-\mathrm{h}$ urinary sodium excretion in the low-salt group and a range of $22-373 \mathrm{mmol} / 24-\mathrm{h}$ in the highsalt group.

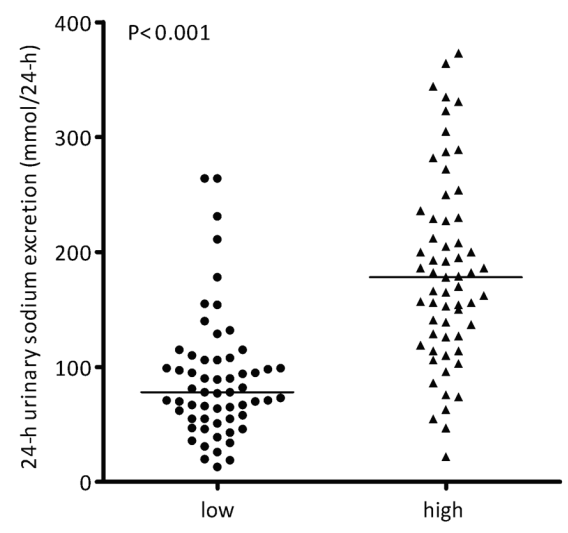

Figure 7.1 Twenty-four hour urinary sodium excretion of the low salt group and the high salt group. Line at median 


\section{CHAPTER 7}

There were neither significant differences in MRBF, RVR or intra-arterial blood pressure between both groups, nor significant differences in arterial plasma concentrations of ADMA, SDMA, L-arginine, L-arginine/ADMA ratio, creatinine between groups (Table S1 of the online only data supplement). APRC was significantly lower in the high-salt group $(P=0.016)$. RPCL of ADMA was significantly lower in the high-salt group compared to the low-salt group (25 (12-42) vs. $31 \mathrm{ml} / \mathrm{min} / 100 \mathrm{~g}$ kidney (21-46), $\mathrm{P}=0.031$ ). RPCL of other variables including APRC did not differ significantly between groups (data not shown).

\section{Multiple regression analyses}

Since there was substantial overlap between both groups (probably due to nonadherence) as illustrated in Figure 7.1 and given the fact that 24-h urinary sodium excretion could serve as proxy for salt intake, we performed multiple regression analyses for possible associations between 24-h urinary sodium excretion and measured variables.

Based on the 24-h urinary sodium excretion, the salt intake of our study population ranged between approximately 1 and $23 \mathrm{~g} / 24-\mathrm{h}$. Crude analysis showed a positive association between 24-h urinary sodium excretion and intra-arterial SBP $(\beta=0.26$ [0.08;0.43], $P=0.005$, Figure 7.2A) and intra-arterial MAP $(\beta=0.26[0.08 ; 0.43], P=0.005)$. After correction for potential confounders (age, sex, BMI, estimated GFR and arterial APRC) these associations remained present $(\beta=0.22[0.05 ; 0.39], P=0.013$ for intraarterial SBP and $\beta=0.23[0.06 ; 0.41], P=0.011$ for intra-arterial MAP). Furthermore, higher 24-h urinary sodium excretion was significantly associated with lower arterial APRC (Crude analysis $\beta=-0.27[-0.45 ;-0.10], P=0.003$, Figure 7.2B) after correction for confounders (age, sex, BMI, estimated GFR and intra-arterial MAP, $\beta=-0.30[-0.48$;0.22 ], $P=0.001$ ). There was no independent association between $24-h$ urinary sodium excretion and other variables related to renal hemodynamics (MRBF, RVR or intraarterial DBP).

Crude analyses showed neither a significant association between 24-h urinary sodium excretion and arterial plasma concentration of ADMA (Figure 7.2C), SDMA, L-arginine, L-arginine/ADMA ratio and creatinine (data not shown) before, nor after adjustment for potential confounders. Furthermore, there was no independent association between 24-h urinary sodium excretion and RPCL of the studied variables before or after adjustment for potential confounders (Table 7.2 and Figure 7.2D).

\section{Additional analyses}

There was no effect modification by the presence of proteinuria in the association between 24-h urinary sodium excretion and plasma ADMA ( $P$ for proteinuria interaction $=0.365$ ). 

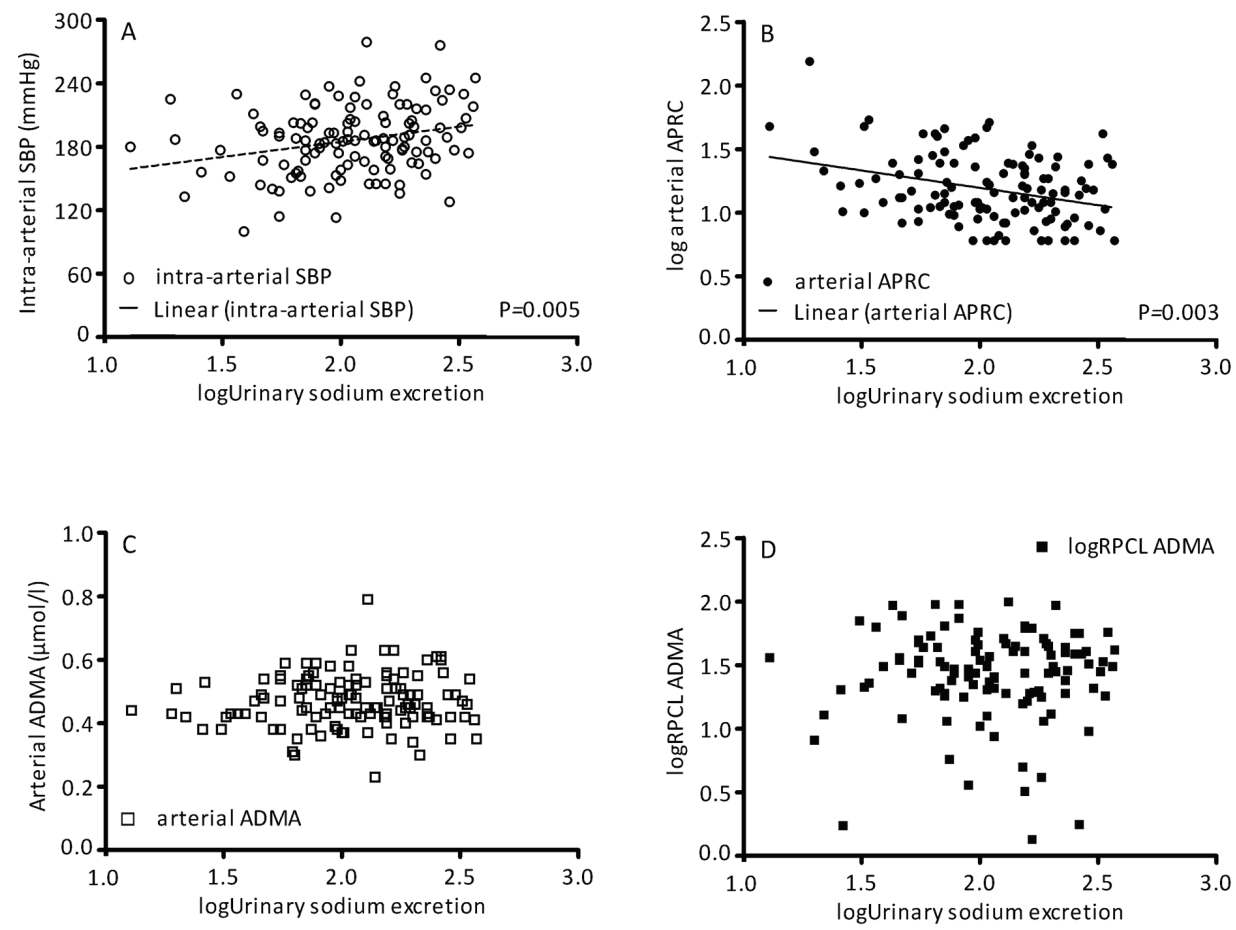

Figure 7.2 Crude linear regression between log24-h urinary sodium excretion and intra-arterial SBP (A), $\log 24-h$ logarterial APRC (B), arterial ADMA (C) and, logRPCL ADMA (D). The linear regression coefficients $B$ for intra-arterial SBP was $\beta=0.26$ [95\% Cl 0.08;0.43], $(P=0.005)$ and $-0.27[-0.45 ;-0.10],(P=0.003)$ for arterial APRC. This means that for every 1 SD increase in log24-h urinary sodium excretion, there was a 0.26 SD increase in intra-arterial SBP. For every 1 SD decrease in log24-h urinary sodium excretion, there was 0.27 SD increase in logarterial APRC. There was no association between log24-h urinary sodium excretion and both arterial ADMA and RPCL of ADMA. ADMA, asymmetric dimethylarginine; APRC, active renin plasma concentration; RPCL, renal plasma clearance 


\section{CHAPTER 7}

Table 7.2: Association between 24-h urinary sodium excretion and RPCL of ADMA, SDMA, L-arginine, creatinine and APRC

\begin{tabular}{lccccc}
\hline & \multicolumn{2}{c}{ Model 1} & & \multicolumn{2}{c}{ Model 2} \\
\cline { 2 - 3 } \cline { 5 - 6 } RPCL & $\beta^{\mathrm{a}}(95 \% \mathrm{Cl})$ & $\mathrm{P}$ value & & $\beta^{\mathrm{a}}(95 \% \mathrm{Cl})$ & $\mathrm{P}$ value \\
\hline ADMA & $-0.01[-0.19 ; 0.18]$ & 0.956 & & $0.05[-0.15 ; 0.25]$ & 0.606 \\
SDMA & $0.09[-0.11 ; 0.28]$ & 0.387 & & $0.11[-0.11 ; 0.33]$ & 0.301 \\
L-arginine & $-0.07[-0.27 ; 0.12]$ & 0.470 & & $-0.01[-0.23 ; 0.21]$ & 0.943 \\
Creatinine & $-0.18[-0.36 ; 0.01]$ & 0.062 & & $-0.14[-0.35 ; 0.06]$ & 0.162 \\
APRC & $-0.09[-0.29 ; 0.10]$ & 0.344 & & $-0.06^{\mathrm{b}}[-0.26 ; 0.14]$ & 0.540 \\
\hline
\end{tabular}

${ }^{a} \beta$, standardized regression coefficient: indicates increase (in SDs) of RPCL of ADMA, SDMA, L-arginine or APRC per 1 SD increase in $24 \mathrm{~h}$ urinary sodium excretion. ADMA, asymmetric dimethylarginine; APRC; active plasma renin concentrations; RPCL, renal plasma clearance; SDMA, symmetric dimethylarginine. Model 1: univariate analysis; Model 2: model 1 + adjustments for age, sex, body mass index, intra-arterial mean arterial pressure, estimated glomerular filtration rate and APRC. ${ }^{b}$ Model 2: model $1+$ adjustments for age, sex, body mass index, intra-arterial mean arterial pressure and estimated glomerular filtration rate

\section{DISCUSSION}

In a population of 120 Caucasian, predominately difficult-to-treat hypertensive patients with a mildly reduced renal function, within a range of low to (moderate) high-salt intake, higher salt intake is associated with higher intra-arterial blood pressure and lower plasma renin concentration. However, we neither found a significant association between salt intake and plasma ADMA nor a significant association between salt intake and RPCL of ADMA. This indicates that in hypertensive Caucasians high-salt intake results in higher blood pressure and lower plasma renin levels, but that high-salt intake results neither in higher plasma ADMA nor lower RPCL of ADMA.

ADMA is an endogenous inhibitor of all isoforms of NOS, which convert L-arginine into citrulline and NO. ADMA and its structural isomer SDMA (which cannot inhibit NOS) are synthesized during post-transcriptional methylation of protein arginine residues catalyzed by protein arginine methyltransferases (PRMTs). The main elimination pathway for ADMA is intracellular degradation into citrulline and dimethylamine by the enzyme DDAH, which is heavily expressed in specific sites in the kidney that correspond to those of NOS expression. ${ }^{6,25-28}$ In addition, both ADMA and SDMA are excreted in the urine and plasma concentrations are particularly high in patients with chronic kidney disease. ${ }^{10}$ For SDMA, urinary excretion is the main elimination pathway since SDMA cannot be degradated by DDAH. ${ }^{9}$ Therefore, the kidneys have been considered as a possible important regulator of plasma ADMA (and SDMA) which has further been demonstrated by substantial plasma clearance of both dimethylarginines by the kidneys. ${ }^{9}$ On the other hand, in hypertensive patients with mild to moderate renal insufficiency RPCL of ADMA appears of minor importance in the plasma regulation of ADMA. ${ }^{19}$ 
In the literature, there is convincing evidence that, in hypertensives, salt loading is associated with decreased production of $\mathrm{NO}$ and elevated plasma concentrations of ADMA which has been postulated as the underlying mechanism that may explain why excess salt intake impairs vasodilatation, resulting in reduction of blood flow and elevation of blood pressure. ${ }^{1,2,29,30}$ However, contrary to these studies, our study revealed no independent association between the amount of salt intake and plasma ADMA or the L-arginine/ADMA ratio. There are several differences between these studies and the present one that may explain the discrepancies in findings.

First, to the best of our knowledge, a significant effect of salt intake/salt loading on ADMA or NO-production has only been demonstrated in hypertensive or normotensive Asian $^{2,30,31}$ and Afro-American ${ }^{1,29,32}$ subjects, but not in Caucasians. Indeed, in agreement with the present study results, a small study that investigated the influence of salt intake on plasma ADMA in Caucasians (normotensive postmenopausal women $(n=15))$ neither reported a plasma ADMA difference between a low-salt diet and a high-salt diet. ${ }^{33}$ Therefore, the differences in outcome may be explained by racial difference. Race is an important factor in salt-sensitivity and the influence of salt intake on $\mathrm{GFR}^{29,34}$ for that reason we hypothesize that salt intake is not a major factor in NOSinhibition in hypertensive Caucasians, but only in Asian and Afro-American hypertensives. Future research is required to confirm this hypothesis.

Second, the present study is different in design. Aforementioned studies investigated the effect of salt loading on plasma ADMA from a cross-over design, an excellent design to investigate the effect of a shift in salt intake on plasma ADMA. ${ }^{1,2,29-32}$ However, this study was designed to investigate an underlying mechanism of salt intake on plasma ADMA and not the effect of salt intake on plasma ADMA.

Third, in the present study, prescribed salt intake was $3.2 \mathrm{~g}$ and $11.5 \mathrm{~g} \mathrm{NaCl}$ per day. Aforementioned studies used considerably higher or lower amounts of sodium than the present one. ${ }^{1,2,29-32}$ The only study that reported no differences in ADMA between salt diets used amounts of salt quite comparable to our study $(4.1$ and $15.2 \mathrm{~g} \mathrm{NaCl}$ per day). ${ }^{33}$ This indicates that a dose-effect relationship may be present. Although it has to be mentioned that the range of urinary sodium excretion as a proxy for salt intake used in the multiple regression analyses (between approximately 1 and $23 \mathrm{~g}$ of $\mathrm{NaCl}$ per day) includes comparable high and low amounts of salt intake as these studies and still there was no association between 24-h urinary sodium excretion and plasma ADMA.

Still, the underlying mechanism of the reported high ADMA plasma concentrations after salt loading is unknown. The present study showed within a range of low to (moderate) high salt intake that there appears to be no association between higher amounts of salt intake and lower RPCL of ADMA. Based on our results it is unlikely that 


\section{CHAPTER 7}

changes in the plasma regulation of ADMA by the kidneys are responsible for the increase in ADMA plasma concentrations in case of high salt intake or salt loading. Although we must bear in mind that 1) the absence of higher ADMA plasma concentrations along with higher salt intake obscures possible relationships. Other, yet to be investigated causes for an increase of plasma ADMA after salt loading or high-salt intake are related to the synthesis by PRMTs and degradation by DDAH of ADMA. Animal studies addressing the latter are however conflicting. ${ }^{5,35}$ In human, these mechanisms need further investigation.

Within the range of salt intake of the present study, we showed a significant association between urinary sodium excretion, and both blood pressure and plasma rennin concentration. Still, there appeared no effect on MRBF or RVR. This may indicate that large part of our population is a so-called non-modulator (no increase in renal blood flow in response to salt loading), which is the case in a substantial part of the hypertensive population. ${ }^{36}$

There is a limitation to our study. In this study we were not able to perform a crossover study, as it would require another invasive procedure and additional risk for the patients. Consequently, we do not have any information about the individual changes in response to the shift in salt intake.

In conclusion, this cross-sectional study among hypertensive Caucasians shows that higher amounts of dietary salt intake are associated with higher blood pressure and lower plasma renin concentrations. However, there was no relation between urinary sodium excretion and plasma concentrations of ADMA. Since it indeed has been shown that ADMA plasma concentration rises in response to very high salt loading in Asians and Afro-American subjects, racial influence cannot be ruled out. Still, a reduced renal plasma clearance of ADMA as an explanation for higher ADMA plasma concentrations due to high-salt intake is very unlikely.

\section{Acknowledgements}

The authors gratefully acknowledge M. Fuss-Lejeune for her assistance in the blood sampling and measurements during renal angiography. This study was supported by a "clinical established investigator" grant from the Dutch Heart Foundation (DHF; Grant No. 2004T058) obtained by Dr. A.A. Kroon. 


\section{REFERENCES}

1. Campese VM, Amar M, Anjali C, Medhat T, Wurgaft A. Effect of L-arginine on systemic and renal haemodynamics in salt-sensitive patients with essential hypertension. J Hum Hypertens. 1997;11:527532.

2. Fujiwara N, Osanai T, Kamada T, Katoh T, Takahashi K, Okumura K. Study on the relationship between plasma nitrite and nitrate level and salt sensitivity in human hypertension : modulation of nitric oxide synthesis by salt intake. Circulation. 2000;101:856-861.

3. Toda N, Arakawa K. Salt-induced hemodynamic regulation mediated by nitric oxide. J Hypertens. 2011;29:415-424.

4. Beard DA, Mescam M. Mechanisms of pressure-diuresis and pressure-natriuresis in Dahl salt-resistant and Dahl salt-sensitive rats. BMC Physiol. 2012;12:6.

5. Tojo A, Kimoto M, Wilcox CS. Renal expression of constitutive NOS and DDAH: separate effects of salt intake and angiotensin. Kidney Int. 2000;58:2075-2083.

6. Tojo A, Welch WJ, Bremer V, Kimoto M, Kimura K, Omata M, Ogawa T, Vallance P, Wilcox CS. Colocalization of demethylating enzymes and NOS and functional effects of methylarginines in rat kidney. Kidney Int. 1997;52:1593-1601.

7. Wilcox $C S$, Deng $X$, Welch WJ. NO generation and action during changes in salt intake: roles of nNOS and macula densa. Am J Physiol. 1998;274:R1588-1593.

8. Kakimoto $\mathrm{Y}$, Akazawa S. Isolation and identification of N-G,N-G- and N-G,N'-G-dimethyl-arginine, Nepsilon-mono-, di-, and trimethyllysine, and glucosylgalactosyl- and galactosyl-delta-hydroxylysine from human urine. J Biol Chem. 1970;245:5751-5758.

9. Nijveldt RJ, Van Leeuwen PA, Van Guldener C, Stehouwer CD, Rauwerda JA, Teerlink T. Net renal extraction of asymmetrical (ADMA) and symmetrical (SDMA) dimethylarginine in fasting humans. Nephrol Dial Transplant. 2002;17:1999-2002.

10. Vallance P, Leone A, Calver A, Collier J, Moncada S. Accumulation of an endogenous inhibitor of nitric oxide synthesis in chronic renal failure. Lancet. 1992;339:572-575.

11. Yilmaz MI, Sonmez A, Saglam M, Qureshi AR, Carrero JJ, Caglar K, Eyileten T, Cakir E, Oguz Y, Vural A, Yenicesu M, Lindholm B, Stenvinkel P, Axelsson J. ADMA levels correlate with proteinuria, secondary amyloidosis, and endothelial dysfunction. J Am Soc Nephrol. 2008;19:388-395.

12. Ladefoged J. Measurements of the renal blood flow in man with the 133 xenon wash-out technique. A description of the method. Scand J Clin Lab Invest. 1966;18:299-315.

13. de Leeuw PW, Birkenhager WH. Use of the xenon-133 washout technique in diagnosing renovascular disease in hypertension. Nephron. 1986;44 Suppl 1:5-7.

14. Waterval WA SJ, Ortmans-Ploemen MM, Habets-van der Poel CD, Bierau J. Quantitative UPLC-MS/MS analysis of underivatised amino acids in body fluids is a reliable tool for the diagnosis and follow-up of patients with inborn errors of metabolism. . Clinica chimica acta. 2009;407:36-42.

15. Martens-Lobenhoffer J B-BS. Chromatographic-mass spectrometric methods for the quantification of L-arginine and its methylated metabolites in biological fluids. Journal of chromatography 2007;851:30-41.

16. Deinum J, Derkx FH, Schalekamp MA. Improved immunoradiometric assay for plasma renin. Clin Chem. 1999;45:847-854.

17. Levey AS, Stevens LA, Schmid CH, Zhang YL, Castro AF, 3rd, Feldman HI, Kusek JW, Eggers P, Van Lente $\mathrm{F}$, Greene T, Coresh J. A new equation to estimate glomerular filtration rate. Ann Intern Med. 2009;150:604-612.

18. Rennenberg RJ, Schurgers LJ, Vermeer C, Scholte JB, Houben AJ, de Leeuw PW, Kroon AA. Renal handling of matrix Gla-protein in humans with moderate to severe hypertension. Hypertens Res. 2008;31:1745-1751. 


\section{CHAPTER 7}

19. Ronden RA, Houben AJ, Teerlink T, Bakker JA, Bierau J, Stehouwer CD, De Leeuw PW, Kroon AA. Reduced renal plasma clearance does not explain increased plasma asymmetric dimethylarginine in hypertensive subjects with mild to moderate renal insufficiency. Am J Physiol Renal Physiol. 2012;303:F149-156.

20. Yeung KK, De Gouyon Matignon C, Renwarin L, Tjon AFMR, Teerlink T, van Leeuwen PA, Musters RJ, Wisselink W, Tangelder GJ. Hypothermic renal perfusion during aortic surgery reduces the presence of lipocalin-2 and preserves renal extraction of dimethylarginines in rats. Am J Physiol Renal Physiol. 2011;301:F1231-1241.

21. Siroen MP, van der Sijp JR, Teerlink T, van Schaik C, Nijveldt RJ, van Leeuwen PA. The human liver clears both asymmetric and symmetric dimethylarginine. Hepatology. 2005;41:559-565.

22. Andersson LG, Bratteby LE, Ekroth R, Wesslen O, Hallhagen S. Calculation of renal extraction during high diuresis and low renal plasma flow conditions. Clin Physiol. 1994;14:79-85.

23. Siroen MP, Teerlink T, Nijveldt RJ, Prins HA, Richir MC, van Leeuwen PA. The clinical significance of asymmetric dimethylarginine. Annu Rev Nutr. 2006;26:203-228.

24. Kesteloot $\mathrm{H}$, Joossens JV. The relationship between dietary intake and urinary excretion of sodium, potassium, calcium and magnesium: Belgian Interuniversity Research on Nutrition and Health. $J$ Hum Hypertens. 1990;4:527-533.

25. Kimoto $M$, Tsuji $H$, Ogawa $T$, Sasaoka K. Detection of NG,NG-dimethylarginine dimethylaminohydrolase in the nitric oxide-generating systems of rats using monoclonal antibody. Arch Biochem Biophys. 1993;300:657-662.

26. Leiper JM, Santa Maria J, Chubb A, MacAllister RJ, Charles IG, Whitley GS, Vallance P. Identification of two human dimethylarginine dimethylaminohydrolases with distinct tissue distributions and homology with microbial arginine deiminases. Biochem J. 1999;343 Pt 1:209-214.

27. Tran CT, Fox MF, Vallance $P$, Leiper JM. Chromosomal localization, gene structure, and expression pattern of DDAH1: comparison with DDAH2 and implications for evolutionary origins. Genomics. 2000;68:101-105.

28. Hu X, Atzler D, Xu X, Zhang P, Guo H, Lu Z, Fassett J, Schwedhelm E, Boger RH, Bache RJ, Chen Y. Dimethylarginine dimethylaminohydrolase-1 is the critical enzyme for degrading the cardiovascular risk factor asymmetrical dimethylarginine. Arterioscler Thromb Vasc Biol. 2011;31:1540-1546.

29. Campese VM, Tawadrous M, Bigazzi R, Bianchi S, Mann AS, Oparil S, Raij L. Salt intake and plasma atrial natriuretic peptide and nitric oxide in hypertension. Hypertension. 1996;28:335-340.

30. Osanai T, Fujiwara N, Saitoh M, Sasaki S, Tomita H, Nakamura M, Osawa H, Yamabe H, Okumura K. Relationship between salt intake, nitric oxide and asymmetric dimethylarginine and its relevance to patients with end-stage renal disease. Blood Purif. 2002;20:466-468.

31. Fang Y, Mu JJ, He LC, Wang SC, Liu ZQ. Salt loading on plasma asymmetrical dimethylarginine and the protective role of potassium supplement in normotensive salt-sensitive asians. Hypertension. 2006;48:724-729.

32. Schmidlin O, Forman A, Leone A, Sebastian A, Morris RC, Jr. Salt sensitivity in blacks: evidence that the initial pressor effect of $\mathrm{NaCl}$ involves inhibition of vasodilatation by asymmetrical dimethylarginine. Hypertension. 2011;58:380-385.

33. Scuteri A, Stuehlinger MC, Cooke JP, Wright JG, Lakatta EG, Anderson DE, Fleg JL. Nitric oxide inhibition as a mechanism for blood pressure increase during salt loading in normotensive postmenopausal women. J Hypertens. 2003;21:1339-1346.

34. Parmer RJ, Stone RA, Cervenka JH. Renal hemodynamics in essential hypertension. Racial differences in response to changes in dietary sodium. Hypertension. 1994;24:752-757.

35. Matsuoka H, Itoh S, Kimoto M, Kohno K, Tamai O, Wada Y, Yasukawa H, Iwami G, Okuda S, Imaizumi T. Asymmetrical dimethylarginine, an endogenous nitric oxide synthase inhibitor, in experimental hypertension. Hypertension. 1997;29:242-247. 
SALT AND RENAL ADMA

36. Williams GH, Hollenberg NK. Are non-modulating patients with essential hypertension a distinct subgroup? Implications for therapy. Am J Med. 1985;79:3-9. 


\section{CHAPTER 7}

\section{DATA SUPPLEMENT}

Table 7.S1 Renal hemodynamics and arterial concentrations in the low and high salt group

\begin{tabular}{lccc}
\hline & Low sodium & High sodium & P value * \\
\hline Intra-arterial systolic blood pressure $(\mathrm{mmHg})$ & $182 \pm 37$ & $190 \pm 28$ & 0.209 \\
Intra-arterial diastolic blood pressure $(\mathrm{mmHg})$ & $98 \pm 17$ & $100 \pm 14$ & 0.352 \\
Intra-arterial mean arterial pressure $(\mathrm{mmHg})$ & $130 \pm 24$ & $136 \pm 19$ & 0.131 \\
MRBF left (ml/min/100g kidney) & $191(146-223)$ & $194(150-241)$ & 0.510 \\
MRBF right (ml/min/100g kidney) & $227(192-280)$ & $219(172-273)$ & 0.300 \\
Renal vascular resistance left $(\mathrm{AU})$ & $0.69(0.58-0.98)$ & $0.70(0.57-0.94)$ & 0.969 \\
Renal vascular resistance right $(\mathrm{AU})$ & $0.56(0.46-0.69)$ & $0.64(0.50-0.75)$ & 0.096 \\
Arterial ADMA ( $\mu \mathrm{mol} / \mathrm{I})$ & $0.48 \pm 0.08$ & $0.46 \pm 0.09$ & 0.116 \\
Arterial SDMA ( $\mu \mathrm{mol} / \mathrm{l})$ & $0.61 \pm 0.17$ & $0.60 \pm 0.19$ & 0.739 \\
Arterial L-arginine ( $\mu \mathrm{mol} / \mathrm{I})$ & $78 \pm 19$ & $81 \pm 20$ & 0.401 \\
Arterial L-arginine/ADMA ratio & $158(139-178)$ & $165(148-207)$ & 0.085 \\
Arterial creatinine $(\mu \mathrm{mol} / \mathrm{I})$ & $86 \pm 19$ & $87 \pm 23$ & 0.785 \\
Arterial APRC (mU/I) & $16(11-26)$ & $12(8-21)$ & 0.016 \\
\hline
\end{tabular}

Normally distributed values expressed as mean \pm SD; non-normally distributed values as median (interquartile range). ADMA, asymmetric dimethylarginine; APRC, active plasma renin concentrations; $A U$, arbitrary units; MRBF, mean renal blood flow; SDMA, symmetric dimethylarginine. * independent Student's t-test or Mann-Whitney $U$ test, as appropriate 


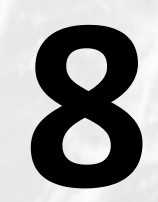

General discussion 
CHAPTER 8 


\section{MAIN FINDINGS IN PERSPECTIVE}

In this thesis we focused on the role of the kidney as a potential underlying cause of increased plasma concentrations of the endogenous nitric oxide synthase (NOS) inhibitor asymmetric dimethylarginine (ADMA). Clarification of the underlying mechanisms that lead to increase of plasma ADMA will play a crucial role in the evidence needed to evolve ADMA from a cardiovascular risk marker to a possible clinically useful risk factor in cardiovascular disease.

The studies in this thesis describe the relationship between renal ADMA handling and plasma ADMA in a population of patients with atherosclerotic renal artery disease (CHAPTER 3) and hypertensive patients with mild to moderate renal insufficiency (CHAPTER 4 and 5). To unravel the influence of the renin-angiotensin system (RAS) on the renal ADMA handling and plasma concentrations of ADMA, we investigated in CHAPTER 6 and 7 the effects of RAS "modulation" by the angiotensin II type 1 receptor blocker eprosartan and by dietary salt intake. This final chapter discusses he current knowledge on ADMA and the kidney, and how our study findings contribute to knowledge on plasma ADMA regulation.

\section{CLINICAL SIGNIFICANCE Of ADMA}

Although mortality from cardiovascular diseases consistently decreased over the last decades, cardiovascular disease is still the leading cause of death in Europe and the second major cause of death in the Netherlands. ${ }^{1,2}$ Many major risk factors have already been identified and successful treatment of these factors evidently contributed to the observed decrease in mortality. Nevertheless, these (traditional) risk factors cannot explain the total cardiovascular risk of individual patients. Therefore, we need to identify, and further investigate other possible risk factors. One of these may the plasma concentration of ADMA which is associated with cardiovascular disease. However, we need to know more on the biology and physiological consequences of increased plasma concentrations of ADMA. Before we can conclude that the plasma ADMA is important and before we can explore whether lowering plasma ADMA will reduce cardiovascular risk. One of the vital steps in this process is knowledge on mechanisms that regulate plasma ADMA and on how to modify these.

\section{WHAT IS ALREADY KNOWN ABOUT ADMA?}

Over the past two decades, ADMA has emerged as a risk marker of cardiovascular disease. Plasma concentrations of ADMA are increased in patients with augmented risk of or established cardiovascular diseases e.g. in patients with hypertension, hypercholesterolemia, renal insufficiency, diabetes mellitus or atherosclerosis. ${ }^{3-19}$ Furthermore, there is convincing evidence that ADMA plays a significant role in 
cardiovascular disease by reducing nitric oxide (NO) availability and inducing endothelial dysfunction. ${ }^{4,20}$ Finally, the observation that in prospective cohort, studies plasma concentrations of ADMA predict cardiovascular events and mortality independently of traditional risk factors adds to the possibility that ADMA is a marker, if not mediator or regulator of cardiovascular disease. ${ }^{21-36}$ Therefore, a better understanding of the underlying mechanisms that lead to increased plasma concentrations of ADMA may contribute to the development of (specific) pharmacological therapies that can modify plasma ADMA. The latter is crucial because this could lead to studies that investigate whether preventing or treating a rise in plasma ADMA actually can lower cardiovascular risk.

Ever since the isolation and fully characterization of ADMA in human urine, ${ }^{37}$ the kidneys and ADMA are inextricably linked in ADMA research, not the least because the description of biological relevance of ADMA was first described in patients with chronic kidney disease (CKD). ${ }^{4}$ This was also the first population in which researchers reported an 8-fold increase of plasma ADMA as compared to healthy controls. ${ }^{4}$ Moreover, further investigation that focused on the kidney as a possible plasma ADMA clearing organ showed significant clearance of ADMA in the urine ${ }^{38}$ and substantial renal clearance of $16 \%$ measured by renal arteriovenous concentration differences. ${ }^{39}$ Subsequently, the discovery of an additional metabolic ADMA degradation pathway by $N^{G}, N^{G}$-dimethylarginine dimethylaminohydrolase (DDAH, $)^{40-42}$ which is highly expressed in the kidneys, ${ }^{43-46}$ and which is probably the most important degradation pathway for ADMA, confirmed again the significance of the kidneys as a plasma ADMA regulating organ. In the mean time, large prospective cohort studies showed that, in patients with CKD, higher plasma ADMA was associated with faster progression of kidney failure. ${ }^{27,47}$ Finally, the renal presence of alanine-glyoxylate aminotransferase 2 (AGXT2), the other metabolic degradation pathway of ADMA, illustrated that really all known routes of ADMA clearance are available in the kidneys. ${ }^{42,48,49}$

\section{WHAT DOES THIS THESIS ADD TO CURRENT KNOWLEDGE?}

Although our knowledge of ADMA as a biomarker, if not mediator, of pathophysiology in (cardiovascular) disease has increased substantially, the exact mechanisms that may cause increased plasma ADMA concentrations are not completely understood. In this respect, the kidney as a clearing organ may play a pivotal role. So far, many studies have addressed the relationship between (estimated) glomerular filtration rate (GFR) and plasma $A D M A,{ }^{38,47,50,51}$ but it remains unknown whether the kidneys are really responsible for the increased plasma concentrations of ADMA in these patients. Therefore, in this thesis we aimed to investigate the role of the kidney as a potential underlying source of increased plasma ADMA in hypertensive patients with mild to 
moderate renal insufficiency and in patients with atherosclerotic renal artery disease (ARAS).

\section{The kidney as a plasma ADMA regulating organ}

Increased plasma ADMA has been reported in a wide range of cardiovascular disorders. ${ }^{5,7,11,52}$ Among these conditions, plasma ADMA is particularly high in patients with CKD. ${ }^{4}$ Additionally, in many observational studies, (estimated) GFR is inversely associated with plasma ADMA. ${ }^{38,47,50,51}$ This, in combination with the commonly held view that the kidney plays an important role in the plasma regulation and clearance of ADMA, ${ }^{4,38,39,50,53}$ led to our hypothesis that reduced renal plasma clearance of ADMA may explain, at least in part, the rise in plasma concentrations of ADMA in patients with (mild to moderate) reduced renal function.

However, the data in CHAPTER 4 and 5 prove that we have to reject this hypothesis. We demonstrated, first, that renal plasma clearance of ADMA is independent of renal function (defined as estimated GFR), and mainly determined by metabolic ADMA degradation processes rather than by urinary clearance of ADMA. Second, reduced renal plasma clearance of ADMA (the net outcome of all clearing mechanisms including metabolic degradation processes and urinary excretion) could not explain the increase of plasma ADMA in our population of hypertensive patients with mild to moderate renal insufficiency. This is in line with the results of studies in sub-nephrectomized ${ }^{54}$ and totally nephrectomized ${ }^{55}$ rats. Apparently, renal ADMA clearance does not determine the total body plasma clearance of ADMA. Thus, the kidney is of lesser importance for the regulation of plasma ADMA then we initially thought. In other words, there are (compensatory) systemic mechanisms that can regulate plasma ADMA in the presence of renal insufficiency.

Several other studies from our laboratory in which we investigated the renal clearance of small peptides demonstrated that renal plasma clearance of such peptides is independent of renal function, ${ }^{56-58}$ and that there is no association between renal plasma clearance and plasma concentrations of these peptides. ${ }^{58}$ This indicates that small molecules are sufficiently cleared by the kidney even when renal function is reduced. Altogether, there is consistent evidence that increased plasma ADMA in mild to moderate renal insufficiency is not due to the failure of the kidney as a plasma regulating or clearing organ. Nevertheless, we must bear in mind that this may be different in patients with more severe renal insufficiency. 


\section{The relation between renal function and plasma ADMA}

Regardless of the aforementioned discussion, the question remains why there is an independent association between (estimated) GFR and plasma ADMA as described in CHAPTER 4 and 5 and in many other observational studies. ${ }^{38,47,50,51}$ In the subsequent paragraphs we would like to discuss some possible explanations.

If the kidney is not the cause of increased plasma ADMA in patients with renal impairment, we have to focus on possible extrarenal causes of the increased plasma ADMA in this population. In humans, the liver is also an important plasma ADMAclearing (and regulating) organ. ${ }^{59-61}$ Furthermore, a recent animal study demonstrated that metabolism of ADMA by the pulmonary system may contribute to plasma ADMA clearance. ${ }^{62}$ However, little is known about interactions between these ADMA regulating organs. One study demonstrated that after subtotal nephrectomy in rats, hepatic expression of the protein arginine methyltransferases (PRMTs, responsible for ADMA synthesis ${ }^{63,64}$ ) increased, whereas hepatic expression levels of DDAH (responsible for $80-90 \%$ of ADMA degradation ${ }^{40-42}$ ) decreased. ${ }^{54}$ This study suggests that there may be an interaction between the kidney and the liver under conditions of renal insufficiency, but more studies are needed to further explore this phenomenon.

An alternative explanation of increased plasma ADMA in CKD is an overall increased extrarenal synthesis by PRMTs, or impaired degradation by DDAH. In CKD, oxidative stress is one of the potential factors that may initiate an imbalance between synthesis and degradation. In the presence of cardiovascular risk factors such as hypertension, hypercholesterolemia, smoking, diabetes mellitus, aging, and CKD, oxidative stress is increased. ${ }^{65,66}$ Recent studies investigating the interaction between reactive oxygen species (ROS) and ADMA showed that ROS can increase activity of PRMTs, and decrease DDAH activity, thereby increasing cellular ADMA concentrations. ${ }^{67-69}$ Over time, this could be accompanied by an increase in the plasma concentration of ADMA. ${ }^{70}$ Although a role for oxidative stress in the increase of plasma concentrations of ADMA in a population of patients with (mild to moderate) CKD is plausible, again more studies are necessary to confirm this hypothesis.

\section{The relation between atherosclerotic renal artery stenosis and ADMA}

In CHAPTER 3, we further investigated the relation between renal ADMA clearance and plasma ADMA in the more extensively damaged kidneys of patients with ARAS. It is generally accepted that reduced NO bioavailability plays a crucial role in preatherogenic endothelial dysfunction and atherogenesis. ${ }^{71}$ The demonstration that ADMA can inhibit NO synthesis in vitro ${ }^{72}$ and in vivo ${ }^{4}$ suggests that this substance may play a significant role in preatherogenic endothelial dysfunction and atherogenesis. 
So far, the evidence for a role of ADMA in atherogenesis comes particularly from animal $^{73-75}$ and human studies that investigated coronary, 8 ,76-79 and peripheral artery disease. $^{10,33}$ These studies showed that plasma ADMA is increased in systemic and carotid atherosclerosis and that plasma ADMA correlates with the severity of the plaques. ${ }^{10,33,77,78}$ Moreover, the finding of local ADMA production at the site of coronary plaques supports the theory of a pathophysiological role for ADMA in atherogenesis. ${ }^{80}$ Not unexpectedly, CHAPTER 3 shows that plasma ADMA is increased in patients with ARAS as well.

Even interestingly are the results of CHAPTER 3 regarding the renal ADMA handling of the individual kidneys in unilateral and bilateral ARAS. In unilateral ARAS, we saw a marked difference in renal ADMA clearance between the stenotic and the contralateral non-stenotic kidney. However, the renal ADMA clearance of both kidneys together was not significantly different from that in hypertensive control subjects. This suggests a compensatory effect of the contralateral kidney. These observations added new understanding to a previous study in which we demonstrated that in unilateral ARAS, renal blood flow is not NO-dependent in the stenotic kidney, as opposed to the non-stenotic kidney, in which renal blood flow is strongly NO-dependent. ${ }^{81}$ Therefore, we hypothesized that either ADMA synthesis by the plaque or lower renal clearance of ADMA in the stenotic kidney or both are responsible for the observed difference in NO-dependency of renal blood flow between the stenotic and the non-stenotic kidney.

With respect to patients with bilateral ARAS, however, a compensatory mechanism of the contralateral kidney is obviously impossible. This may be the explanation for the fact that overall renal ADMA clearance is decreased as compared to the hypertensive control subjects (CHAPTER 3). However, this would be in contrast with our previous study where we observed increased NO-dependency of renal blood flow in both stenotic kidneys as compared to that in stenotic kidneys of patients with unilateral ARAS. $^{81}$ Apparently, ADMA is not the only regulating factor of NOS and thus NO synthesis in a kidney with ARAS. This corresponds with the concept that Angiotensin II (AngII) importantly mediates the response to NOS inhibition as well ${ }^{82,83}$ and that higher Angll levels correlated with more NOS-activity in kidneys with ARAS. ${ }^{81,84}$ 


\section{Modulation of plasma concentrations and renal handling of ADMA}

Finally, we investigated whether modulation of the RAS may influence renal ADMA handling and plasma concentrations of ADMA. Numerous cardiovascular drugs have been shown to influence plasma ADMA in humans, in particular the ones that target the RAS (CHAPTER 1). The mechanisms by which RAS inhibitors modulate plasma ADMA are not clear yet. In CHAPTER 6, we tested the hypothesis that the angiotensin II type 1 receptor blocker (ARB) eprosartan lowers plasma ADMA by increasing renal plasma clearance of ADMA in hypertensive patients. We used the human kidney as (pathophysiological) model and investigated the effects of direct intrarenal eprosartan infusion on plasma ADMA and its renal clearance. As expected, intrarenal infusion of eprosartan lowered the plasma concentration of ADMA. On the other hand, we observed an unexpected effect on the renal ADMA plasma clearance which shifted from net renal clearance to net renal release of ADMA into the blood. Although we could not completely explain this shift from net renal clearance to net renal release of ADMA after intrarenal eprosartan infusion, the findings in CHAPTER 6 confirmed once more that plasma regulation of ADMA is not primarily determined by the kidneys. Furthermore, we concluded that increased renal ADMA plasma clearance is not the mechanism that leads to decreased plasma concentrations of ADMA in patients treated with eprosartan. Again, this confirms that we need to focus on other (extrarenal) mechanisms regulating ADMA.

So far, the results of few animal studies indicate that the ADMA lowering effect of RAS inhibitors like ARBs may be initiated by the direct effect of these drugs on PRMT and DDAH activity ${ }^{85,86}$ or via a direct effect on the transcellular transport of ADMA by cationic amino acid transporters (CATs). ${ }^{87,88}$ Still, in humans, the effects of RAS inhibition on plasma ADMA regulation by these enzymes and transporters are largely unknown. Other (animal and human) studies emphasize that RAS inhibitors may lower ADMA by reducing oxidative stress and thereby indirectly change PRMT and/or DDAH activity. Indeed, oxidative stress inhibits intracellular degradation of ADMA by DDAH and stimulates intracellular synthesis of ADMA by PRMTs. ${ }^{67-69}$ However, this possibility needs further confirmation by prospective studies. All together, we do not know whether the plasma ADMA lowering effect of RAS inhibitors is related to a direct effect on plasma ADMA regulation by PRMT and/or DDAH, or indirectly related via the effects of these drugs on other mechanism like oxidative stress that influence the activity of the enzymes.

Dietary salt intake is known for its pronounced effect on the RAS. In the study presented in CHAPTER 7, we tried to modulate plasma ADMA and its renal clearance by varying dietary salt intake. As expected, a higher salt intake was associated with higher intra-arterial blood pressure and lower plasma renin concentration. 
However, we did not find a significant association between salt intake and plasma ADMA or a significant association between salt intake and renal plasma clearance of ADMA. These findings are in contrast with the results of previous studies that showed a significant effect of salt intake/salt loading on ADMA or NO-production. ${ }^{89-91,92-94}$ It is of note that the latter studies included solely hypertensive or normotensive Asian ${ }^{89-91}$ and Afro-American ${ }^{92-94}$ subjects. To the best of our knowledge, the only study in Caucasians (normotensive postmenopausal women), did not report a plasma ADMA difference between a low-salt diet and a high-salt diet either. ${ }^{95}$ Therefore, salt intake may not inhibit NOS in hypertensive Caucasians, while it does in Asian and AfroAmerican hypertensives. Finally, based on our results in CHAPTER 7 it is unlikely that changes in the plasma regulation of ADMA by the kidneys are responsible for the increase in ADMA plasma concentrations in case of high salt intake or salt loading. Again, other, (yet unknown) causes may be responsible for increased plasma ADMA after salt loading or high-salt intake. However, animal studies addressing the relationship between salt-intake and ADMA synthesis by PRMTs or degradation by DDAH are conflicting ${ }^{96,97}$ Therefore, there is a need for human studies addressing the role of these enzymes in regulating ADMA under conditions of different amounts of salt intake.

\section{LIMITATIONS OF OUR STUDIES}

Although limitations of the separate studies were discussed in the different chapters, some considerations apply to the whole thesis. First, we performed our studies in a highly specific group of hypertensive patients. All, difficult-to-treat hypertensive patients were angiographically evaluated for suspicion of renal artery stenosis. Second, the lack of peripheral venous samples limited a comparison between our results and those from other studies. We noticed that our arterial samples showed lower plasma ADMA concentrations as compared to venous blood samples (antecubital vein) in other (hypertensive) populations and were even within the "normal" range of ADMA, compared to healthy adults. ${ }^{98,99,100}$ Overall, there has been considerable uncertainty about the "normal" ranges of plasma ADMA in different populations, and therefore, the degree of risk associated with an increase of ADMA is difficult to quantify. Third, the specific group of patients restricted us in the design of our studies. Regrettably, the invasive nature of the selective renal blood sampling and renal plasma flow measurements during renal angiography prohibited a longitudinal study design which would allow more robust conclusions about causal relationships. Still, the highly standardized clinical protocol and unique design provided the opportunity to measure arteriovenous concentration differences and selective renal blood flow measurements of each kidney separately, with high reproducibility, in humans. 


\section{FUTURE DIRECTIONS}

Our study findings add new insights to the current knowledge on renal ADMA handling and its relationship with plasma ADMA in humans. Particularly because our studies strongly indicate that the kidney is less important for plasma ADMA regulation as we initially thought it was, we challenge the commonly held view that the kidney has primacy as a metabolic organ for plasma ADMA regulation. This implies that future studies should focus on other (extrarenal) plasma regulating mechanisms (i.e. PRMTs and DDAH). In addition, studies should explore whether it is possible to develop (specific) pharmacological therapies that lower plasma ADMA. Especially the plasma ADMA regulating role of DDAH appears very promising in this respect. First, DDAH established itself as a critical modulator of plasma concentrations of ADMA. Studies have shown that inhibition of DDAH activity leads to accumulation of ADMA and vascular damage. ${ }^{101}$ The opposite is observed when DDAH is overexpressed in experimental models. Second, numerous cardiovascular drugs for the management of cardiovascular disorders e.g. antihypertensive, antiplatelet, lipid lowering, and hypoglycemic drugs already proved that they positively modulate DDAH activity and expression. ${ }^{102-104}$ However, it remains challenging to confirm that the abovementioned drugs really lower plasma ADMA by stimulating DDAH activity. Finally, the current development of specific DDAH activators ${ }^{102}$ will contribute to the initiation of trials that may prove that modifying plasma ADMA confers cardiovascular benefit.

With respect to plasma ADMA and patients with ARAS, the results in these thesis indicate a role for ADMA in this atherosclerotic process located in the kidneys. Especially in patients with bilateral ARAS, reduced renal clearance may really contribute to the observed increased plasma ADMA in this population. Even though prospective research should confirm this in a larger group of ARAS patients. In addition, future studies that address the ADMA gradient across ARAS and the role of DDAH activity in this matter will further expand the knowledge on the role of ADMA in ARAS and the associated renal damage. 


\section{KEY MESSAGES OF THIS THESIS}

- The kidney is of minor importance for the regulation of plasma ADMA and kidney function cannot explain the increased plasma ADMA concentrations in hypertensive patients with mild to moderate renal insufficiency.

- Reduced renal clearance of ADMA may contribute to increased plasma concentrations of ADMA in patients with bilateral ARAS.

- The potential plasma ADMA lowering effect of RAS inhibition is probably not related to the renal handling of ADMA.

- Future research should focus on the extrarenal plasma regulators of ADMA as potential target of plasma ADMA lowering therapy of which the enzyme DDAH is the most promising target. 


\section{CHAPTER 8}

\section{REFERENCES}

1. Dutch Heart Foundation. Hart- en vaatziekten in Nederland 2009. Cijfers over leefstijl- en risicofactoren, ziekte en sterfte. Dutch Heart Foundation; 2009.

2. Nichols M, Townsend N, Scarborough $P$, Luengo-Fernandez R, Leal J, Gray A, Rayner M. European Cardiovascular Disease Statistics 2012. European Heart Network, Brussels, European Society of Cardiology; 2012.

3. Aucella F, Maas R, Vigilante M, Tripepi G, Schwedhelm E, Margaglione M, Gesualdo L, Boeger R, Zoccali C. Methylarginines and mortality in patients with end stage renal disease: a prospective cohort study. Atherosclerosis. 2009;207:541-545.

4. Vallance $P$, Leone A, Calver A, Collier J, Moncada S. Accumulation of an endogenous inhibitor of nitric oxide synthesis in chronic renal failure. Lancet. 1992;339:572-575.

5. Zoccali C, Bode-Boger S, Mallamaci F, Benedetto F, Tripepi G, Malatino L, Cataliotti A, Bellanuova I, Fermo I, Frolich J, Boger R. Plasma concentration of asymmetrical dimethylarginine and mortality in patients with end-stage renal disease: a prospective study. Lancet. 2001;358:2113-2117.

6. Kielstein JT, Boger RH, Bode-Boger SM, Schaffer J, Barbey M, Koch KM, Frolich JC. Asymmetric dimethylarginine plasma concentrations differ in patients with end-stage renal disease: relationship to treatment method and atherosclerotic disease. J Am Soc Nephrol. 1999;10:594-600.

7. Miyazaki H, Matsuoka H, Cooke JP, Usui M, Ueda S, Okuda S, Imaizumi T. Endogenous nitric oxide synthase inhibitor: a novel marker of atherosclerosis. Circulation. 1999;99:1141-1146.

8. Schulze F, Lenzen $H$, Hanefeld C, Bartling A, Osterziel KJ, Goudeva L, Schmidt-Lucke C, Kusus M, Maas R, Schwedhelm E, Strodter D, Simon BC, Mugge A, Daniel WG, Tillmanns H, Maisch B, Streichert T, Boger RH. Asymmetric dimethylarginine is an independent risk factor for coronary heart disease: results from the multicenter Coronary Artery Risk Determination investigating the Influence of ADMA Concentration (CARDIAC) study. Am Heart J. 2006;152:493 e491-498.

9. Boger RH, Bode-Boger SM, Thiele W, Creutzig A, Alexander K, Frolich JC. Restoring vascular nitric oxide formation by L-arginine improves the symptoms of intermittent claudication in patients with peripheral arterial occlusive disease. J Am Coll Cardiol. 1998;32:1336-1344.

10. Boger RH, Bode-Boger SM, Thiele W, Junker W, Alexander K, Frolich JC. Biochemical evidence for impaired nitric oxide synthesis in patients with peripheral arterial occlusive disease. Circulation. 1997;95:2068-2074.

11. Boger RH, Bode-Boger SM, Szuba A, Tsao PS, Chan JR, Tangphao O, Blaschke TF, Cooke JP. Asymmetric dimethylarginine (ADMA): a novel risk factor for endothelial dysfunction: its role in hypercholesterolemia. Circulation. 1998;98:1842-1847.

12. Vladimirova-Kitova L, Deneva T, Angelova E, Nikolov F, Marinov B, Mateva N. Relationship of asymmetric dimethylarginine with flow-mediated dilatation in subjects with newly detected severe hypercholesterolemia. Clin Physiol Funct Imaging. 2008;28:417-425.

13. Goonasekera CD, Rees DD, Woolard P, Frend A, Shah V, Dillon MJ. Nitric oxide synthase inhibitors and hypertension in children and adolescents. J Hypertens. 1997;15:901-909.

14. Perticone F, Sciacqua A, Maio R, Perticone M, Maas R, Boger RH, Tripepi G, Sesti G, Zoccali C. Asymmetric dimethylarginine, L-arginine, and endothelial dysfunction in essential hypertension. $J \mathrm{Am}$ Coll Cardiol. 2005;46:518-523.

15. Surdacki A, Nowicki M, Sandmann J, Tsikas D, Boeger RH, Bode-Boeger SM, Kruszelnicka-Kwiatkowska $\mathrm{O}$, Kokot F, Dubiel JS, Froelich JC. Reduced urinary excretion of nitric oxide metabolites and increased plasma levels of asymmetric dimethylarginine in men with essential hypertension. J Cardiovasc Pharmacol. 1999;33:652-658.

16. Abbasi F, Asagmi T, Cooke JP, Lamendola C, McLaughlin T, Reaven GM, Stuehlinger M, Tsao PS. Plasma concentrations of asymmetric dimethylarginine are increased in patients with type 2 diabetes mellitus. Am J Cardiol. 2001;88:1201-1203. 
17. Altinova AE, Arslan M, Sepici-Dincel A, Akturk M, Altan N, Toruner FB. Uncomplicated type 1 diabetes is associated with increased asymmetric dimethylarginine concentrations. J Clin Endocrinol Metab. 2007;92:1881-1885.

18. Eid HM, Eritsland J, Larsen J, Arnesen H, Seljeflot I. Increased levels of asymmetric dimethylarginine in populations at risk for atherosclerotic disease. Effects of pravastatin. Atherosclerosis. 2003;166:279284.

19. Sugai M, Ohta A, Ogata $Y$, Nakanishi M, Ueno S, Kawata T, Saito N, Tanaka Y. Asymmetric dimethylarginine (ADMA) in the aqueous humor of diabetic patients. Endocr J. 2007;54:303-309.

20. Caplin B, Leiper J. Endogenous nitric oxide synthase inhibitors in the biology of disease: markers, mediators, and regulators? Arterioscler Thromb Vasc Biol. 2012;32:1343-1353.

21. Boger RH, Sullivan LM, Schwedhelm E, Wang TJ, Maas R, Benjamin EJ, Schulze F, Xanthakis V, Benndorf RA, Vasan RS. Plasma asymmetric dimethylarginine and incidence of cardiovascular disease and death in the community. Circulation. 2009;119:1592-1600.

22. Cavusoglu E, Ruwende C, Chopra V, Poludasu S, Yanamadala S, Frishman WH, Eng C, Pinsky DJ, Marmur JD. Relation of baseline plasma ADMA levels to cardiovascular morbidity and mortality at two years in men with diabetes mellitus referred for coronary angiography. Atherosclerosis. 2010;210:226-231.

23. Cavusoglu E, Ruwende C, Chopra V, Yanamadala S, Eng C, Pinsky DJ, Marmur JD. Relationship of baseline plasma ADMA levels to cardiovascular outcomes at 2 years in men with acute coronary syndrome referred for coronary angiography. Coron Artery Dis. 2009;20:112-117.

24. Kielstein JT, Bode-Boger SM, Hesse G, Martens-Lobenhoffer J, Takacs A, Fliser D, Hoeper MM. Asymmetrical dimethylarginine in idiopathic pulmonary arterial hypertension. Arterioscler Thromb Vasc Biol. 2005;25:1414-1418.

25. Lajer M, Tarnow L, Jorsal A, Teerlink $T$, Parving HH, Rossing P. Plasma concentration of asymmetric dimethylarginine (ADMA) predicts cardiovascular morbidity and mortality in type 1 diabetic patients with diabetic nephropathy. Diabetes Care. 2008;31:747-752.

26. Lu TM, Ding YA, Lin SJ, Lee WS, Tai HC. Plasma levels of asymmetrical dimethylarginine and adverse cardiovascular events after percutaneous coronary intervention. Eur Heart J. 2003;24:1912-1919.

27. Ravani P, Tripepi G, Malberti F, Testa S, Mallamaci F, Zoccali C. Asymmetrical dimethylarginine predicts progression to dialysis and death in patients with chronic kidney disease: a competing risks modeling approach. J Am Soc Nephrol. 2005;16:2449-2455.

28. Schnabel R, Blankenberg S, Lubos E, Lackner KJ, Rupprecht HJ, Espinola-Klein C, Jachmann N, Post F, Peetz D, Bickel C, Cambien F, Tiret L, Munzel T. Asymmetric dimethylarginine and the risk of cardiovascular events and death in patients with coronary artery disease: results from the AtheroGene Study. Circ Res. 2005;97:e53-59.

29. Young JM, Terrin N, Wang X, Greene T, Beck GJ, Kusek JW, Collins AJ, Sarnak MJ, Menon V. Asymmetric dimethylarginine and mortality in stages 3 to 4 chronic kidney disease. Clin J Am Soc Nephrol. 2009;4:1115-1120.

30. Leong T, Zylberstein D, Graham I, Lissner L, Ward D, Fogarty J, Bengtsson C, Bjorkelund C, Thelle D. Asymmetric dimethylarginine independently predicts fatal and nonfatal myocardial infarction and stroke in women: 24-year follow-up of the population study of women in Gothenburg. Arterioscler Thromb Vasc Biol. 2008;28:961-967.

31. Maas R, Quitzau K, Schwedhelm E, Spieker L, Rafflenbeul W, Steenpass A, Luscher TF, Boger RH. Asymmetrical dimethylarginine (ADMA) and coronary endothelial function in patients with coronary artery disease and mild hypercholesterolemia. Atherosclerosis. 2007;191:211-219.

32. Valkonen VP, Paiva H, Salonen JT, Lakka TA, Lehtimaki T, Laakso J, Laaksonen R. Risk of acute coronary events and serum concentration of asymmetrical dimethylarginine. Lancet. 2001;358:2127-2128. 


\section{CHAPTER 8}

33. Wilson AM, Shin DS, Weatherby C, Harada RK, Ng MK, Nair N, Kielstein J, Cooke JP. Asymmetric dimethylarginine correlates with measures of disease severity, major adverse cardiovascular events and all-cause mortality in patients with peripheral arterial disease. Vasc Med. 2010;15:267-274.

34. Krzyzanowska K, Mittermayer F, Wolzt M, Schernthaner G. Asymmetric dimethylarginine predicts cardiovascular events in patients with type 2 diabetes. Diabetes Care. 2007;30:1834-1839.

35. Mittermayer F, Krzyzanowska K, Exner M, Mlekusch W, Amighi J, Sabeti S, Minar E, Muller M, Wolzt M, Schillinger M. Asymmetric dimethylarginine predicts major adverse cardiovascular events in patients with advanced peripheral artery disease. Arterioscler Thromb Vasc Biol. 2006;26:2536-2540.

36. Boger RH, Maas R, Schulze F, Schwedhelm E. Asymmetric dimethylarginine (ADMA) as a prospective marker of cardiovascular disease and mortality--an update on patient populations with a wide range of cardiovascular risk. Pharmacol Res. 2009;60:481-487.

37. Kakimoto $\mathrm{Y}$, Akazawa S. Isolation and identification of N-G,N-G- and N-G,N'-G-dimethyl-arginine, Nepsilon-mono-, di-, and trimethyllysine, and glucosylgalactosyl- and galactosyl-delta-hydroxylysine from human urine. J Biol Chem. 1970;245:5751-5758.

38. Al Banchaabouchi M, Marescau B, Possemiers I, D'Hooge R, Levillain O, De Deyn PP. NG, NGdimethylarginine and NG, NG-dimethylarginine in renal insufficiency. Pflugers Arch. 2000;439:524-531.

39. Nijveldt RJ, Van Leeuwen PA, Van Guldener C, Stehouwer CD, Rauwerda JA, Teerlink T. Net renal extraction of asymmetrical (ADMA) and symmetrical (SDMA) dimethylarginine in fasting humans. Nephrol Dial Transplant. 2002;17:1999-2002.

40. Achan V, Broadhead M, Malaki M, Whitley G, Leiper J, MacAllister R, Vallance P. Asymmetric dimethylarginine causes hypertension and cardiac dysfunction in humans and is actively metabolized by dimethylarginine dimethylaminohydrolase. Arterioscler Thromb Vasc Biol. 2003;23:1455-1459.

41. Ogawa $T$, Kimoto $M$, Sasaoka K. Occurrence of a new enzyme catalyzing the direct conversion of NG,NG-dimethyl-L-arginine to L-citrulline in rats. Biochem Biophys Res Commun. 1987;148:671-677.

42. Ogawa $T$, Kimoto $M$, Sasaoka K. Purification and properties of a new enzyme, NG,NG-dimethylarginine dimethylaminohydrolase, from rat kidney. J Biol Chem. 1989;264:10205-10209.

43. Kimoto M, Tsuji H, Ogawa T, Sasaoka K. Detection of NG,NG-dimethylarginine dimethylaminohydrolase in the nitric oxide-generating systems of rats using monoclonal antibody. Arch Biochem Biophys. 1993;300:657-662.

44. Leiper JM, Santa Maria J, Chubb A, MacAllister RJ, Charles IG, Whitley GS, Vallance P. Identification of two human dimethylarginine dimethylaminohydrolases with distinct tissue distributions and homology with microbial arginine deiminases. Biochem J. 1999;343 Pt 1:209-214.

45. Tran $\mathrm{CT}$, Fox MF, Vallance $\mathrm{P}$, Leiper JM. Chromosomal localization, gene structure, and expression pattern of DDAH1: comparison with DDAH2 and implications for evolutionary origins. Genomics. 2000;68:101-105.

46. Hu X, Atzler D, Xu X, Zhang P, Guo H, Lu Z, Fassett J, Schwedhelm E, Boger RH, Bache RJ, Chen Y. Dimethylarginine dimethylaminohydrolase-1 is the critical enzyme for degrading the cardiovascular risk factor asymmetrical dimethylarginine. Arterioscler Thromb Vasc Biol. 2011;31:1540-1546.

47. Fliser D, Kronenberg F, Kielstein JT, Morath C, Bode-Boger SM, Haller H, Ritz E. Asymmetric dimethylarginine and progression of chronic kidney disease: the mild to moderate kidney disease study. J Am Soc Nephrol. 2005;16:2456-2461.

48. Lee IS, Muragaki Y, Ideguchi T, Hase T, Tsuji M, Ooshima A, Okuno E, Kido R. Molecular cloning and sequencing of a cDNA encoding alanine-glyoxylate aminotransferase 2 from rat kidney. $J$ Biochem. 1995;117:856-862.

49. Rodionov RN, Murry DJ, Vaulman SF, Stevens JW, Lentz SR. Human alanine-glyoxylate aminotransferase 2 lowers asymmetric dimethylarginine and protects from inhibition of nitric oxide production. J Biol Chem. 2010;285:5385-5391. 
50. Marescau B, Nagels G, Possemiers I, De Broe ME, Becaus I, Billiouw JM, Lornoy W, De Deyn PP. Guanidino compounds in serum and urine of nondialyzed patients with chronic renal insufficiency. Metabolism. 1997;46:1024-1031.

51. Nanayakkara PW, Teerlink T, Stehouwer CD, Allajar D, Spijkerman A, Schalkwijk C, ter Wee PM, van Guldener C. Plasma asymmetric dimethylarginine (ADMA) concentration is independently associated with carotid intima-media thickness and plasma soluble vascular cell adhesion molecule-1 (sVCAM-1) concentration in patients with mild-to-moderate renal failure. Kidney Int. 2005;68:2230-2236.

52. Tarnow L, Hovind $P$, Teerlink $T$, Stehouwer CD, Parving HH. Elevated plasma asymmetric dimethylarginine as a marker of cardiovascular morbidity in early diabetic nephropathy in type 1 diabetes. Diabetes Care. 2004;27:765-769.

53. MacAllister RJ, Rambausek MH, Vallance P, Williams D, Hoffmann KH, Ritz E. Concentration of dimethyl-L-arginine in the plasma of patients with end-stage renal failure. Nephrol Dial Transplant. 1996;11:2449-2452.

54. Matsuguma K, Ueda S, Yamagishi S, Matsumoto Y, Kaneyuki U, Shibata R, Fujimura T, Matsuoka H, Kimoto M, Kato S, Imaizumi T, Okuda S. Molecular mechanism for elevation of asymmetric dimethylarginine and its role for hypertension in chronic kidney disease. J Am Soc Nephrol. 2006;17:2176-2183.

55. Carello KA, Whitesall SE, Lloyd MC, Billecke SS, D'Alecy LG. Asymmetrical dimethylarginine plasma clearance persists after acute total nephrectomy in rats. Am J Physiol Heart Circ Physiol. 2006;290:H209-216.

56. Fogteloo AJ, Meinders AE, Pijl H, Kroon AA, Frolich M, De Leeuw PW. Renal clearance of endogenous leptin in hypertensive humans with or without renal artery stenosis. Am J Physiol Endocrinol Metab. 2001;281:E400-404.

57. Rennenberg RJ, Schurgers $L$, Vermeer C, Scholte JB, Houben AJ, de Leeuw PW, Kroon AA. Renal handling of matrix Gla-protein in humans with moderate to severe hypertension. Hypertens Res. 2008;31:1745-1751.

58. van Kimmenade RR, Januzzi JL, Jr., Bakker JA, Houben AJ, Rennenberg R, Kroon AA, Crijns HJ, van Dieijen-Visser MP, de Leeuw PW, Pinto YM. Renal clearance of B-type natriuretic peptide and amino terminal pro-B-type natriuretic peptide a mechanistic study in hypertensive subjects. J Am Coll Cardiol. 2009;53:884-890.

59. Nijveldt RJ, Siroen MP, Teerlink T, van Leeuwen PA. Elimination of asymmetric dimethylarginine by the kidney and the liver: a link to the development of multiple organ failure? J Nutr. 2004;134:2848S2852S; discussion 2853S.

60. Siroen MP, van der Sijp JR, Teerlink T, van Schaik C, Nijveldt RJ, van Leeuwen PA. The human liver clears both asymmetric and symmetric dimethylarginine. Hepatology. 2005;41:559-565.

61. Richir MC, Bouwman RH, Teerlink T, Siroen MP, de Vries TP, van Leeuwen PA. The prominent role of the liver in the elimination of asymmetric dimethylarginine (ADMA) and the consequences of impaired hepatic function. JPEN J Parenter Enteral Nutr. 2008;32:613-621.

62. Bulau P, Zakrzewicz D, Kitowska K, Leiper J, Gunther A, Grimminger F, Eickelberg O. Analysis of methylarginine metabolism in the cardiovascular system identifies the lung as a major source of ADMA. Am J Physiol Lung Cell Mol Physiol. 2007;292:L18-24.

63. Clarke S. Protein methylation. Curr Opin Cell Biol. 1993;5:977-983.

64. McBride AE, Silver PA. State of the arg: protein methylation at arginine comes of age. Cell. 2001;106:58.

65. Oberg BP, McMenamin E, Lucas FL, McMonagle E, Morrow J, Ikizler TA, Himmelfarb J. Increased prevalence of oxidant stress and inflammation in patients with moderate to severe chronic kidney disease. Kidney Int. 2004;65:1009-1016.

66. Forstermann U. Nitric oxide and oxidative stress in vascular disease. Pflugers Arch. 2010;459:923-939. 


\section{CHAPTER 8}

67. Boger RH, Sydow K, Borlak J, Thum T, Lenzen H, Schubert B, Tsikas D, Bode-Boger SM. LDL cholesterol upregulates synthesis of asymmetrical dimethylarginine in human endothelial cells: involvement of Sadenosylmethionine-dependent methyltransferases. Circ Res. 2000;87:99-105.

68. Luo Z, Teerlink T, Griendling K, Aslam S, Welch WJ, Wilcox CS. Angiotensin II and NADPH oxidase increase ADMA in vascular smooth muscle cells. Hypertension. 2010;56:498-504.

69. Wilcox CS. Asymmetric dimethylarginine and reactive oxygen species: unwelcome twin visitors to the cardiovascular and kidney disease tables. Hypertension. 2012;59:375-381.

70. Teerlink T, Luo Z, Palm F, Wilcox CS. Cellular ADMA: regulation and action. Pharmacol Res. 2009;60:448-460.

71. Napoli C, Ignarro LJ. Nitric oxide and atherosclerosis. Nitric Oxide. 2001;5:88-97.

72. MacAllister RJ, Whitley GS, Vallance P. Effects of guanidino and uremic compounds on nitric oxide pathways. Kidney Int. 1994;45:737-742.

73. Boger RH, Bode-Boger SM, Sydow K, Heistad DD, Lentz SR. Plasma concentration of asymmetric dimethylarginine, an endogenous inhibitor of nitric oxide synthase, is elevated in monkeys with hyperhomocyst(e)inemia or hypercholesterolemia. Arterioscler Thromb Vasc Biol. 2000;20:1557-1564.

74. Jacobi J, Maas R, Cardounel AJ, Arend M, Pope AJ, Cordasic N, Heusinger-Ribeiro J, Atzler D, Strobel J, Schwedhelm E, Boger RH, Hilgers KF. Dimethylarginine dimethylaminohydrolase overexpression ameliorates atherosclerosis in apolipoprotein E-deficient mice by lowering asymmetric dimethylarginine. Am J Pathol. 2010;176:2559-2570.

75. Yu XJ, Li YJ, Xiong Y. Increase of an endogenous inhibitor of nitric oxide synthesis in serum of high cholesterol fed rabbits. Life Sci. 1994;54:753-758.

76. Krempl TK, Maas R, Sydow K, Meinertz T, Boger RH, Kahler J. Elevation of asymmetric dimethylarginine in patients with unstable angina and recurrent cardiovascular events. Eur Heart J. 2005;26:1846-1851.

77. Lu TM, Ding YA, Charng MJ, Lin SJ. Asymmetrical dimethylarginine: a novel risk factor for coronary artery disease. Clin Cardiol. 2003;26:458-464.

78. Sahinarslan A, Cengel A, Biberoglu G, Hasanoglu A, Turkoglu S, Timurkaynak T. Plasma asymmetric dimethylarginine level and extent of lesion at coronary angiography. Coron Artery Dis. 2006;17:605609.

79. Wang J, Sim AS, Wang XL, Salonikas C, Moriatis M, Naidoo D, Wilcken DE. Relations between markers of renal function, coronary risk factors and the occurrence and severity of coronary artery disease. Atherosclerosis. 2008;197:853-859.

80. Joyal D, Leya F, Obada Al-Chekakie M, Arab D, Dieter RS, Morshedi-Meibodi A, Lewis B, Steen L, Fareed J, Hoppenstead D, Akar JG. Presence of asymmetric dimethylarginine gradients across high-grade lesions in patients with coronary artery disease. Coron Artery Dis. 2007;18:471-475.

81. Wierema TK, Houben AJ, Kroon AA, Koster D, van der Zander K, van Engelshoven JM, de Leeuw PW. Nitric oxide dependence of renal blood flow in patients with renal artery stenosis. J Am Soc Nephrol. 2001;12:1836-1843.

82. Sigmon $\mathrm{DH}$, Beierwaltes $\mathrm{WH}$. Renal nitric oxide and angiotensin II interaction in renovascular hypertension. Hypertension. 1993;22:237-242.

83. Sigmon $\mathrm{DH}$, Carretero $\mathrm{OA}$, Beierwaltes $\mathrm{WH}$. Plasma renin activity and the renal response to nitric oxide synthesis inhibition. J Am Soc Nephrol. 1992;3:1288-1294.

84. Wierema TK, de Leeuw PW. Renal artery stenosis: today's questions. Curr Opin Pharmacol. 2006;6:197201.

85. Chen GF, Wagner L, Sasser JM, Zharikov S, Moningka NC, Baylis C. Effects of angiotensin type 1 receptor blockade on arginine and ADMA synthesis and metabolic pathways in fawn-hooded hypertensive rats. Nephrol Dial Transplant. 2010;25:3518-3525. 
86. Onozato ML, Tojo A, Leiper J, Fujita T, Palm F, Wilcox CS. Expression of NG,NG-dimethylarginine dimethylaminohydrolase and protein arginine $\mathrm{N}$-methyltransferase isoforms in diabetic rat kidney: effects of angiotensin II receptor blockers. Diabetes. 2008;57:172-180.

87. Helle F, Hultstrom M, Skogstrand T, Palm F, Iversen BM. Angiotensin II-induced contraction is attenuated by nitric oxide in afferent arterioles from the nonclipped kidney in 2K1C. Am J Physiol Renal Physiol. 2009;296:F78-86.

88. Hultstrom $M$, Helle $F$, Iversen BM. AT(1) receptor activation regulates the mRNA expression of CAT1, CAT2, arginase-1, and DDAH2 in preglomerular vessels from angiotensin II hypertensive rats. Am J Physiol Renal Physiol. 2009;297:F163-168.

89. Fang Y, Mu JJ, He LC, Wang SC, Liu ZQ. Salt loading on plasma asymmetrical dimethylarginine and the protective role of potassium supplement in normotensive salt-sensitive asians. Hypertension. 2006;48:724-729.

90. Fujiwara N, Osanai T, Kamada T, Katoh T, Takahashi K, Okumura K. Study on the relationship between plasma nitrite and nitrate level and salt sensitivity in human hypertension : modulation of nitric oxide synthesis by salt intake. Circulation. 2000;101:856-861.

91. Osanai T, Fujiwara N, Saitoh M, Sasaki S, Tomita H, Nakamura M, Osawa H, Yamabe H, Okumura K. Relationship between salt intake, nitric oxide and asymmetric dimethylarginine and its relevance to patients with end-stage renal disease. Blood Purif. 2002;20:466-468.

92. Campese VM, Amar M, Anjali $C$, Medhat T, Wurgaft A. Effect of L-arginine on systemic and renal haemodynamics in salt-sensitive patients with essential hypertension. $J$ Hum Hypertens. 1997;11:527532.

93. Campese VM, Tawadrous M, Bigazzi R, Bianchi S, Mann AS, Oparil S, Raij L. Salt intake and plasma atrial natriuretic peptide and nitric oxide in hypertension. Hypertension. 1996;28:335-340.

94. Schmidlin O, Forman A, Leone A, Sebastian A, Morris RC, Jr. Salt sensitivity in blacks: evidence that the initial pressor effect of $\mathrm{NaCl}$ involves inhibition of vasodilatation by asymmetrical dimethylarginine. Hypertension. 2011;58:380-385.

95. Scuteri A, Stuehlinger MC, Cooke JP, Wright JG, Lakatta EG, Anderson DE, Fleg JL. Nitric oxide inhibition as a mechanism for blood pressure increase during salt loading in normotensive postmenopausal women. J Hypertens. 2003;21:1339-1346.

96. Matsuoka H, Itoh S, Kimoto M, Kohno K, Tamai O, Wada Y, Yasukawa H, Iwami G, Okuda S, Imaizumi T. Asymmetrical dimethylarginine, an endogenous nitric oxide synthase inhibitor, in experimental hypertension. Hypertension. 1997;29:242-247.

97. Tojo A, Kimoto M, Wilcox CS. Renal expression of constitutive NOS and DDAH: separate effects of salt intake and angiotensin. Kidney Int. 2000;58:2075-2083.

98. Di Gangi IM, Chiandetti L, Gucciardi A, Moret V, Naturale M, Giordano G. Simultaneous quantitative determination of $\mathrm{N}(\mathrm{G}), \mathrm{N}(\mathrm{G})$-dimethyl-L-arginine or asymmetric dimethylarginine and related pathway's metabolites in biological fluids by ultrahigh-performance liquid chromatography/electrospray ionization-tandem mass spectrometry. Anal Chim Acta. 2010;677:140-148.

99. Schwedhelm E, Xanthakis V, Maas R, Sullivan LM, Schulze F, Riederer U, Benndorf RA, Boger RH, Vasan RS. Asymmetric dimethylarginine reference intervals determined with liquid chromatography-tandem mass spectrometry: results from the Framingham offspring cohort. Clin Chem. 2009;55:1539-1545.

100. Teerlink T. HPLC analysis of ADMA and other methylated L-arginine analogs in biological fluids. J Chromatogr B Analyt Technol Biomed Life Sci. 2007;851:21-29.

101. Dayoub H, Achan V, Adimoolam S, Jacobi J, Stuehlinger MC, Wang BY, Tsao PS, Kimoto M, Vallance P, Patterson AJ, Cooke JP. Dimethylarginine dimethylaminohydrolase regulates nitric oxide synthesis: genetic and physiological evidence. Circulation. 2003;108:3042-3047.

102. Wadham C, Mangoni AA. Dimethylarginine dimethylaminohydrolase regulation: a novel therapeutic target in cardiovascular disease. Expert Opin Drug Metab Toxicol. 2009;5:303-319. 


\section{CHAPTER 8}

103. Blackwell S. The biochemistry, measurement and current clinical significance of asymmetric dimethylarginine. Ann Clin Biochem. 2010;47:17-28.

104. Leiper J, Nandi M. The therapeutic potential of targeting endogenous inhibitors of nitric oxide synthesis. Nat Rev Drug Discov. 2011;10:277-291. 
S

Samenvatting 
NEDERLANDSE SAMENVATTING 


\section{SAMENVATTING}

Ondanks het gegeven dat de mortaliteit aan hart- en vaatziekten (cardiovasculaire ziekten) sterk gedaald is in de afgelopen decennia, vormen cardiovasculaire ziekten nog steeds de belangrijkste doodsoorzaak in Europa en de op één na belangrijkste doodsoorzaak in Nederland. ${ }^{1,2}$ Veel belangrijke risicofactoren zoals hoge bloeddruk (hypertensie), roken, verhoogd cholesterol- en bloedsuikergehalte (diabetes mellitus), weinig bewegen en overgewicht zijn reeds geïdentificeerd. Succesvolle behandeling van deze factoren heeft duidelijk bijgedragen aan de waargenomen daling in mortaliteit. Toch kunnen deze traditionele risicofactoren het totale cardiovasculaire risico van de individuele patiënt niet geheel verklaren. Daarom is het belangrijk dat we andere, "nieuwe" risicofactoren onderzoeken, die mogelijkerwijs bijdragen aan een verbetering van het inschatten van het totale cardiovasculaire risico. Eén van deze factoren zou asymmetrisch dimethylarginine (ADMA) kunnen zijn, een aminozuur dat o.a. betrokken is bij het ontstaan van slagaderverkalking (atherosclerose), de belangrijkste oorzaak van cardiovasculaire ziekten.

ADMA remt de productie van stikstofoxide (NO), de belangrijkste vaatverwijder in ons lichaam. NO speelt een belangrijke rol bij het regelen van de regionale bloedstroom in organen (o.a. de nieren), de vaatspanning van bloedvaten (bloeddruk) en diverse processen die de vorming van atherosclerose tegengaan. ${ }^{3}$ Daarom is het voorstelbaar dat een verhoogde concentratie van ADMA in het bloed, een verminderde productie van NO veroorzaakt, waardoor het risico op cardiovasculaire ziekten wordt verhoogd. Voordat we evenwel kunnen concluderen dat ADMA echt belangrijk is voor het inschatten van het cardiovasculaire risico en voordat we kunnen nagaan of het verlagen van ADMA in het bloed het risico op cardiovasculaire ziekten vermindert, moeten we meer te weten komen over de mechanismen die de concentratie van ADMA in het bloed reguleren en hoe we deze kunnen beïnvloeden.

In dit proefschrift gingen we uit van de veronderstelling dat de nieren een belangrijke rol spelen bij de regulatie van ADMA concentraties in het bloed en in die zin dat al bij milde nierfunctiestoornissen de concentraties van ADMA in het bloed stijgen. In HOOFDSTUK 1 bespreken we de huidige kennis met betrekking tot ADMA en cardiovasculaire ziekten. Daarnaast geven we een overzicht van alle mechanismen die ADMA concentraties in het bloed reguleren en beïnvloeden, met daarbij extra aandacht voor de rol van de nieren als regulator. 


\section{ADMA en atherosclerose van de nier}

Atherosclerose van de nierarterie (nierarteriestenose) is een belangrijke oorzaak van hypertensie en schade aan de nieren. ${ }^{4,5}$ In HOOFDSTUK 2 beschrijven we de resultaten van een meta-analyse van prospectieve studies. Deze studies onderzochten of klinische kenmerken van patiënten zouden kunnen dienen als voorspellers van de bloeddruk- of nierfunctieverbetering na het plaatsen van een buisje (stent) in de nierslagader (nierarterie) bij patiënten met een nierarteriestenose. ${ }^{6}$ De gecombineerde resultaten van deze studies lieten zien dat er geen klinische kenmerken zijn, die een verbetering in nierfunctie kunnen voorspellen. Daarnaast bleek dat een hoge polsdruk (bovendruk-onderdruk van de bloeddruk) voor het plaatsen van een stent een kleinere afname in bovendruk (systolische bloeddruk) na de interventie voorspelde. De beste klinische voorspeller voor een grotere afname in onderdruk (diastolische bloeddruk) na interventie bleek een hoge diastolische bloeddruk voor het plaatsen van een stent te zijn. Hieruit blijkt dat bepaalde patiëntengroepen zouden kunnen profiteren van het plaatsen van een stent in de nierarterie en daarom is het belangrijk dat we in de toekomst deze populaties verder definiëren. Daarbij zou de ADMA concentratie in het bloed kunnen bijdragen om zo de patiënten te selecteren, die mogelijk baat hebben bij het plaatsen van een stent.

In HOOFDSTUK 3 gaan we dieper in op de relatie tussen ADMA en nierarteriestenose. De literatuur beschrijft dat concentraties van ADMA in het bloed hoger zijn bij patiënten met atherosclerose in de bloedvaten van de benen en het hart. ${ }^{7-13}$ Uit HOOFDSTUK 3 blijkt dat de ADMA concentraties in het bloed ook verhoogd zijn bij hypertensiepatiënten met een eenzijdige (unilaterale) of dubbelzijdige (bilaterale) nierarteriestenose in vergelijking tot hypertensie patiënten zonder een nierarteriestenose. Daarnaast onderzochten wij in dit hoofdstuk of een verminderde ADMA-klaring door de nieren de verhoogde ADMA concentraties in het bloed van deze populatie kon verklaren. De nieren zijn in staat om op 2 manieren ADMA uit het bloed te verwijderen. Enerzijds kan ADMA in zijn geheel door de nieren in de urine worden uitgescheiden en anderzijds kunnen de nieren ADMA afbreken met behulp van het enzym $N^{G}, N^{G}$-dimethylarginine dimethylaminohydrolase (DDAH) dat in hoge concentraties in de nier voorkomt (metabole afbraakprocessen). Het resultaat van deze processen samen (uitscheiding+metabole afbraak) wordt de nier (renale) klaring van ADMA genoemd. Wij veronderstelden dat door de nierschade, die de aanwezigheid van een nierarteriestenose in de nier veroorzaakt, de renale ADMAklaring verminderd is bij patiënten met een nierarteriestenose. Hierdoor stijgen de ADMA concentraties in het bloed.

De resultaten in HOOFDSTUK 3 tonen verder een opmerkelijk verschil tussen de renale ADMA klaring bij patiënten met unilaterale en bilaterale nierarteriestenose. Bij 
patiënten met een unilaterale nierarteriestenose zagen we een duidelijk verschil in renale ADMA-klaring tussen de vernauwde (stenotische) en de contralaterale nietstenotische nier. De ADMA-klaring door de stenotische nier was duidelijk lager ten opzichte van de ADMA-klaring door de contralaterale niet-stenotische nier. De totale renale ADMA-klaring van beide nieren samen was echter niet verschillend van de klaring bij hypertensieve controle patiënten. Dit suggereert een compenserend klarend effect van de contralaterale niet-stenotische nier. Bij patiënten met een bilaterale nierarteriestenose is dit compensatiemechanisme van de contralaterale nier uiteraard onmogelijk. Dit kan de verklaring zijn voor het feit dat de ADMA-klaring van beide nieren samen wel verminderd is bij patiënten met een bilaterale nierarteriestenose in vergelijking met de controlegroep van hypertensieve patiënten zonder een nierarteriestenose. Daarom concluderen wij dat een verminderde renale ADMA-klaring kan bijdragen aan de verhoogde ADMA concentraties in het bloed bij patiënten met een bilaterale nierarteriestenose.

\section{De nier als regulator van ADMA concentraties in het bloed}

ADMA concentraties in het bloed zijn bijzonder hoog bij patiënten met chronische nierziekten waarbij de nierklaring sterk is afgenomen. ${ }^{14}$ Daarnaast is het algemeen geaccepteerd dat de nieren een belangrijke rol spelen bij de regulatie van ADMA concentraties in het bloed. ${ }^{14-18}$ Daarom veronderstelden wij dat een verminderde renale ADMA-klaring mogelijk de verhoogde ADMA concentraties bij hypertensieve patiënten met een verminderde nierfunctie zou kunnen verklaren. Echter, de bevindingen in HOOFDSTUK 4 en 5 laten ten eerste zien dat de renale ADMA-klaring onafhankelijk is van de nierfunctie en dat de renale klaring voornamelijk wordt bepaald door metabole afbraakprocessen van ADMA in plaats van door de klaring van ADMA in de urine. Ten tweede bleek dat een verminderde renale ADMA-klaring niet de verhoogde ADMA concentraties in het bloed bij onze populatie van hypertensieve patiënten met een milde tot matig verminderde nierfunctie verklaarde. Dus concludeerden wij dat de nieren van minder belang lijken voor de regulering van ADMA concentraties in het bloed dan we aanvankelijk dachten. Met andere woorden, er zijn (compensatoire) mechanismen buiten de nieren die concentraties van ADMA in het bloed kunnen reguleren in het geval van nierfunctiestoornissen.

\section{Het moduleren van de renale ADMA klaring en ADMA concentraties in het bloed}

In HOOFDSTUK 6 en 7 hebben we onderzocht of het moduleren van het renineangiotensine systeem (RAS) de renale ADMA-klaring en ADMA concentraties in het bloed kan beïnvloeden. Het RAS is een hormonaal systeem dat o.a. verantwoordelijk is voor de bloeddrukregulatie en de water- en zouthuishouding door de nieren. Diverse 
studies hebben aangetoond dat geneesmiddelen die het RAS remmen, ADMA concentraties in het bloed kunnen verlagen. De mechanismen waarop deze RASremmers ADMA concentraties verlagen zijn echter nog niet duidelijk.

In HOOFDSTUK 6 zijn we nagegaan of de angiotensine II type 1 receptorblokker eprosartan (RAS-remmer) ADMA concentraties in het bloed verlaagt door het verhogen van renale ADMA-klaring. We gebruikten de menselijke nier als pathofysiologisch model en onderzochten de effecten van directe intrarenale eprosartan infusie op ADMA concentraties in het bloed en de renale ADMA-klaring. Zoals verwacht, verlaagde intrarenale infusie van eprosartan de concentratie van ADMA in het bloed. Aan de andere kant namen we een onverwacht effect op de renale ADMA-klaring waar. De renale ADMA-klaring veranderde van een netto renale klaring van ADMA in een netto productie van ADMA door de nier. Hoewel we deze omslag niet geheel kunnen verklaren, bevestigen de bevindingen nogmaals dat de regulatie van ADMA concentraties in het bloed niet primair bepaald wordt door de nieren. Verder concluderen we dat een verhoogde renale ADMA-klaring niet het mechanisme is dat leidt tot verlaging van ADMA concentraties in het bloed bij patiënten die behandeld worden met de RAS-remmer eprosartan.

De dagelijkse zoutinname staat bekend om zijn uitgesproken effect op het RAS. In HOOFDSTUK 7 hebben we geprobeerd de ADMA concentraties in het bloed en de renale ADMA-klaring te beïnvloeden door te variëren in de hoeveelheid zout in de voeding. Zoals verwacht bleek er enerzijds een verband te bestaan tussen een hogere zoutinname en een hogere bloeddruk, daarnaast bestond er een relatie tussen een hogere zoutinname en een lagere concentratie van renine in het bloed (hormoon dat betrokken is bij de bloeddrukregulatie). Desalniettemin vonden we geen verband tussen de hoeveelheid zoutinname en ADMA concentraties in het bloed of de hoeveelheid zoutinname en de renale ADMA-klaring. Daarom lijkt het onwaarschijnlijk dat veranderingen in de ADMA klaring door de nieren verantwoordelijk zijn voor de verhoogde ADMA concentraties in het bloed bij een hoge zoutinname in de voeding.

\section{Algemene discussie}

HOOFDSTUK 8 is een algemene beschouwing van de bevindingen in dit proefschrift, daarnaast plaatsen we deze in perspectief. We speculeren over mogelijk toekomstig onderzoek, dat volgens ons vooral gericht moet zijn op het ontwikkelen van medicamenten die de concentraties van ADMA in het bloed verlagen door de metabole afbraakprocessen (het enzym DDAH) te stimuleren. Het beïnvloeden van de renale ADMA klaring lijkt ongeschikt om ADMA concentraties in het bloed te verlagen. 


\section{KERNBOODSCHAPPEN VAN DIT PROEFSCHRIFT}

- De nier is van ondergeschikt belang voor de regulatie van ADMA concentraties in het bloed en een verminderde nierfunctie biedt geen verklaring voor de verhoogde ADMA concentraties in het bloed bij hypertensieve patiënten met milde tot matige nierfunctiestoornissen.

- Een verminderde renale ADMA-klaring kan bijdragen aan verhoogde concentraties van ADMA in het bloed bij patiënten met een bilaterale nierarteriestenose.

- Het potentiële ADMA verlagende effect via RAS remming is waarschijnlijk niet gerelateerd aan de renale ADMA-klaring.

- Toekomstig onderzoek moet zich richten op ADMA-regulerende mechanismen buiten de nieren als target om ADMA concentraties in het bloed te verlagen. Het meest veelbelovende target van ADMA verlagende therapie lijkt het enzym DDAH te zijn. 


\section{NEDERLANDSE SAMENVATTING}

\section{REFERENCES}

1. Dutch Heart Foundation. Hart- en vaatziekten in Nederland 2009. Cijfers over leefstijl- en risicofactoren, ziekte en sterfte. Dutch Heart Foundation; 2009.

2. Nichols M, Townsend N, Scarborough P, Luengo-Fernandez R, Leal J, Gray A, Rayner M. European Cardiovascular Disease Statistics 2012. European Heart Network, Brussels, European Society of Cardiology; 2012.

3. Napoli C, Ignarro L. Nitric oxide and atherosclerosis. Nitric Oxide. 2001;5:88-97.

4. Garovic VD, Textor SC. Renovascular hypertension and ischemic nephropathy. Circulation. 2005;112:1362-1374.

5. Safian RD, Textor SC. Renal-artery stenosis. N Engl J Med. 2001;344:431-442.

6. Ronden RA, Houben AJ, Kessels AG, Stehouwer CD, de Leeuw PW, Kroon AA. Predictors of clinical outcome after stent placement in atherosclerotic renal artery stenosis: a systematic review and metaanalysis of prospective studies. J Hypertens. 2010;28:2370-2377.

7. Schulze F, Lenzen H, Hanefeld C, Bartling A, Osterziel KJ, Goudeva L, Schmidt-Lucke C, Kusus M, Maas R, Schwedhelm E, Strodter D, Simon BC, Mugge A, Daniel WG, Tillmanns H, Maisch B, Streichert T, Boger RH. Asymmetric dimethylarginine is an independent risk factor for coronary heart disease: results from the multicenter Coronary Artery Risk Determination investigating the Influence of ADMA Concentration (CARDIAC) study. Am Heart J. 2006;152:493 e491-498.

8. Krempl TK, Maas R, Sydow K, Meinertz T, Boger RH, Kahler J. Elevation of asymmetric dimethylarginine in patients with unstable angina and recurrent cardiovascular events. Eur Heart J. 2005;26:1846-1851.

9. Lu TM, Ding YA, Charng MJ, Lin SJ. Asymmetrical dimethylarginine: a novel risk factor for coronary artery disease. Clin Cardiol. 2003;26:458-464.

10. Sahinarslan A, Cengel A, Biberoglu G, Hasanoglu A, Turkoglu S, Timurkaynak T. Plasma asymmetric dimethylarginine level and extent of lesion at coronary angiography. Coron Artery Dis. 2006;17:605609.

11. Wang J, Sim AS, Wang XL, Salonikas C, Moriatis M, Naidoo D, Wilcken DE. Relations between markers of renal function, coronary risk factors and the occurrence and severity of coronary artery disease. Atherosclerosis. 2008;197:853-859.

12. Boger RH, Bode-Boger SM, Thiele W, Junker W, Alexander K, Frolich JC. Biochemical evidence for impaired nitric oxide synthesis in patients with peripheral arterial occlusive disease. Circulation. 1997;95:2068-2074.

13. Wilson AM, Shin DS, Weatherby C, Harada RK, Ng MK, Nair N, Kielstein J, Cooke JP. Asymmetric dimethylarginine correlates with measures of disease severity, major adverse cardiovascular events and all-cause mortality in patients with peripheral arterial disease. Vasc Med. 2010;15:267-274.

14. Vallance P, Leone A, Calver A, Collier J, Moncada S. Accumulation of an endogenous inhibitor of nitric oxide synthesis in chronic renal failure. Lancet. 1992;339:572-575.

15. Al Banchaabouchi M, Marescau B, Possemiers I, D'Hooge R, Levillain O, De Deyn PP. NG, NGdimethylarginine and NG, NG-dimethylarginine in renal insufficiency. Pflugers Arch. 2000;439:524-531.

16. Nijveldt RJ, Van Leeuwen PA, Van Guldener C, Stehouwer CD, Rauwerda JA, Teerlink T. Net renal extraction of asymmetrical (ADMA) and symmetrical (SDMA) dimethylarginine in fasting humans. Nephrol Dial Transplant. 2002;17:1999-2002.

17. Marescau B, Nagels G, Possemiers I, De Broe ME, Becaus I, Billiouw JM, Lornoy W, De Deyn PP. Guanidino compounds in serum and urine of nondialyzed patients with chronic renal insufficiency. Metabolism. 1997;46:1024-1031.

18. MacAllister RJ, Rambausek MH, Vallance P, Williams D, Hoffmann KH, Ritz E. Concentration of dimethyl-L-arginine in the plasma of patients with end-stage renal failure. Nephrol Dial Transplant. 1996;11:2449-2452. 


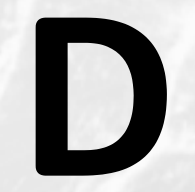

Dankwoord 
DANKWOORD 
En dan nu, last but not least, HET DANKWOORD. Misschien het minst wetenschappelijke hoofdstuk van mijn proefschrift, maar daarom zeker niet minder belangrijk. Ik heb uitgekeken naar het moment dat ik dit speciale hoofdstuk kon gaan schrijven. Niet alleen omdat het betekent dat mijn proefschrift echt "af" is, maar ook omdat ik op deze manier iedereen kan bedanken, die bijgedragen heeft aan dit proefschrift en mijn geweldige tijd als promovenda bij de Interne Geneeskunde in Maastricht.

Allereerst wil ik alle patiënten bedanken, die belangeloos hebben meegewerkt aan de verschillende studies. Zonder jullie bijdrage was dit proefschrift nooit tot stand gekomen!

Prof. dr. P.W. de Leeuw, promotor. Beste Peter, de lange lijst promovendi die je hebt opgeleid weerspiegelt je ervarenheid als promotor. Ik ben trots dat ik één van de personen ben die onder jouw begeleiding aan de wetenschap heeft mogen proeven. Enerzijds heb je me altijd de ruimte gegeven om het promotietraject in te richten zoals ik het wilde. Anderzijds zorgde jouw altijd kritische blik voor betere manuscripten en verdieping in de gedachtegang. Doorgaans verliet ik je kamer na onze brainstormsessies of manuscriptbesprekingen met nieuwe energie en ideeën voor mijn proefschrift. Soms, echter, liep ik met een meer wanhopig gevoel terug naar mijn kamer als ik weer alles kon gaan herschrijven vanwege je "voortschrijdende inzichten". Gelukkig waren deze laatste momenten in de minderheid en heb ik juist veel geleerd van je onuitputtelijke kennis over de nieren en de medisch wetenschappelijke wereld. Ik had me geen betere promotor kunnen wensen. Bedankt!

Dr. A.A. Kroon, copromotor. Beste Bram, als ik maar één iemand zou mogen bedanken in dit dankwoord, dan zou jij dat zijn! Dit proefschrift is het resultaat van alle werk en tijd die we samen hebben gestoken in het onderzoek naar ADMA en de nieren. Door de intensieve samenwerking van de afgelopen jaren heb ik enorm veel respect en waardering gekregen voor jou als internist, wetenschapper en persoon. Je deur stond letterlijk altijd open en ondanks je drukke schema heb ik altijd het gevoel gehad dat je er was, als ik je nodig had. Bedankt hiervoor!

Dr. A.J.H.M. Houben, copromotor. Beste Boy, vanaf dag 1 nam je mij op sleeptouw en leerde je me alles over de ${ }^{133}$ Xenon metingen en het meten van de onderarm doorbloeding met de plethysmograaf. Later kon ik altijd een beroep op je doen als "de apparatuur" (werken met MS-DOS hoort eigenlijk gemakkelijk te zijn?!) mij in de steek liet. Je had gelukkig altijd een oplossing. Verder wil ik je bedanken voor je positieve instelling, je relativeringsvermogen en gezelligheid, iets dat ik erg waardeer. 


\section{DANKWOORD}

Prof. dr. C.D.A. Stehouwer. Beste Coen, ondanks dat we elkaar niet heel vaak spraken, heb ik altijd veel waarde gehecht aan je adviserende rol tijdens mijn promotietraject. Ik heb heel veel respect voor de wijze waarop je promovendi begeleidt en altijd (ongekend snel!) bereikbaar bent wanneer een AIO je nodig heeft. Ik vind het erg jammer dat je uiteindelijk niet mijn promotor kon zijn.

Alle leden van de beoordelingscommissie: Prof. dr. T. Unger, prof. dr. H.J.G.M. Crijns, prof. dr. M.W. de Haan, prof. dr. G.J. Navis en dr. C.T. Postma wil ik hartelijk bedanken voor het kritisch lezen en beoordelen van dit proefschrift.

Dr. T. Teerlink. Beste Tom, bedankt voor het kritisch lezen van de manuscripten en het analyseren van de ADMA samples voor verschillende studies. Jouw expertise over ADMA is heel erg waardevol geweest voor mijn proefschrift.

Dr. J.A. Bakker en Dr. J. Bierau. Beste Jaap en Jörgen, jullie wil ik bedanken voor de betrokkenheid bij diverse hoofdstukken uit dit proefschrift en het analyseren van ADMA/L-arginine/SDMA/L-NMMA uit een grote hoeveelheid bloedsamples.

De medewerkers en interventieradiologen van het Angio \& Interventie team wil ik bedanken voor de ondersteuning tijdens de ${ }^{133}$ Xenon metingen. Altijd behulpzaam en geduldig als ik met alle (lawaaierige) apparatuur op donderdagochtend de ${ }^{133}$ Xenon metingen kwam uitvoeren.

Collega's en oud-collega's van het Circulatielab, Claudia, Monique, Stella, Jolanda, Daniëlle, Peggy, Ellen, Heidi, Veronique, Ingrid, Leon, Marian, Teba en Barry. Bedankt voor de fijne samenwerking, hulp en steun tijdens mijn promotietraject. Tevens wil ik jullie natuurlijk ook bedanken voor de gezelligheid tijdens uitjes, ESH congressen, kerstlunches en "vlaaimomenten" op het circulatielab, onvergetelijk! Lieve Monique, jouw expertise en hulp op het gebied van de ${ }^{133}$ Xenonmetingen, bloedsampling en patiëntenplanning is voor mij van onschatbare waarde geweest. Altijd stond je klaar om alle soms bijna "verjaarde", maar altijd zeer zorgvuldig opgeborgen data of samples boven water te krijgen. Dank je wel! Teba, heel veel succes met het laatste deel van je promotietraject, ik kijk uit naar jouw mooie boekje! Barry, we hebben samen geneeskunde gestudeerd, samen een promotietraject gevolgd bij de Interne Geneeskunde en nu gaan we beide voor een carrière als gepromoveerde Huisarts. Ik heb heel veel respect voor de wijze waarop je ondanks alle tegenslagen tijdens je promotietraject doorgaat en daarom heb ik er alle vertrouwen in, dat ik binnenkort jouw boekje kan gaan lezen. 
Daan, Laura en Carolien, hardwerkende WESP studenten, die heel veel werk hebben verzet voor de verschillende studies. Heel erg bedankt hiervoor en veel succes met jullie eigen (wetenschappelijke) carrière.

Collega's en oud-collega's van de Vasculaire Geneeskunde, Ester, Guido, Sander, Fahima, Antonie, Floris, Robbie, Femke, Marit en Renske. Enorm bedankt dat jullie tijdens jullie drukke polischema's ook nog aandacht hadden voor eventueel geschikte patiënten voor de verschillende studies. Daarnaast wil ik iedereen bedanken voor de goede sfeer, waardoor ik me als onderzoeker altijd thuis heb gevoeld bij de Vasculaire Geneeskunde. Roger, jou wil ik bedanken voor je voorbeeldfunctie als "ouderejaars" AIO en internist. Jouw gedrevenheid en passie voor je vak is echt bewonderenswaardig. Guy, bedankt voor de fijne samenwerking en hulp tijdens mijn promotietraject. In de toekomst zullen we elkaar vast nog regelmatig (telefonisch) spreken als ik advies nodig heb van de Interne Geneeskunde in Heerlen. Thomas, je hebt wel eens gezegd m.b.t. je eigen boekje: "Wie doet daar nu nog iets mee?" Nou, ik denk dat jouw boekje het proefschrift is, dat ik het meest intensief heb gelezen en gebruikt voor mijn eigen proefschrift. Alleen daarom al, bedankt!

Mede "gangbewoners" en (oud)-collega's van de Interne Geneeskunde, bedankt voor de altijd goede (werk)sfeer en gezelligheid, de gedenkwaardige labuitjes zijn hier een goed voorbeeld van, in één woord onvergetelijk! In het bijzonder wil ik Lian, Roel, Johanna, Nordin, Marcelle en Bas bedanken. Ik weet niet wat jullie af en toe dachten als ik weer eens binnen kwam vallen met een statistische of andere vraag. Ik weet wel dat ik heel erg blij ben dat jullie altijd weer de tijd en het geduld hadden om mij weer op weg te helpen. Bedankt! Marcella en Matthijs, bedankt voor de leuke avondjes, etentjes en terrasbezoekjes. Misschien wordt het eens tijd voor een reünie nu we allemaal gepromoveerd zijn! Jean, bedankt voor het ontwerpen van de mooie cover voor dit proefschrift. Ik ben er heel erg trots op.

Lieve Amy, eigenlijk zegt het al genoeg dat ik moeilijk een keuze kon maken (Ja, ik heb daar ook wel eens last van ;-) ), waar ik het stukje over jou in dit dankwoord moest plaatsen. Daarom een eigen alinea voor jou. Naast mijn lieve collega, kamergenootje, congres- en koffiemaatje, ben je ook een belangrijke vriendin voor mij geworden in de afgelopen jaren. Jouw optimisme, gedrevenheid, humor, heerlijke besluiteloosheid, en vriendelijke persoonlijkheid met "karakter" (en dat allemaal op hoge hakken) zorgen dat er altijd iets te beleven valt. De keuze voor jou als mijn paranimf was dan ook vanzelfsprekend. Ik heb de agenda klaar liggen om een weekendje/dagje in Amsterdam/Heerlen/of halverwege te plannen! 
Mijn lieve kamergenootjes Stephanie en Birgit, de altijd goede sfeer op onze kamer heeft er "significant" aan bijgedragen dat ik met heel veel plezier naar mijn werk kwam. Daarnaast denk ik dat we zeker hebben laten zien dat vrouwen goed kunnen multitasken. Gezellig praten over trouwen, verbouwen, schoenen, huisdieren, lekker eten en sporten kan altijd en op ieder moment worden gecombineerd met koffie drinken en hard werken.

Mijn paranimfen Bas en Olaf, ik ben vereerd dat jullie naast mij willen staan op deze belangrijke en spannende dag. Lieve Bas, volgens mij heb ik jou bijna 5 jaar geleden bij de start van mijn promotietraject al laten weten dat jij mijn paranimf zou worden. Onze vriendschap die we hebben opgebouwd de afgelopen jaren is heel belangrijk voor mij en daarom ben ik heel erg blij dat je mijn paranimf wilt zijn. Zullen we het tafeltje bij Beluga alvast reserveren? Lieve Olaf, naast Bernardijn, promotieonderzoek/ werken in Maastricht en wonen in Heerlen hebben we nog iets belangrijks gemeen, lekker eten/drinken en genieten van het leven! Jou wil ik in het bijzonder bedanken dat je mijn paranimf wilt zijn en ik wil je nogmaals laten weten dat je voor mij geen "reserve" plaats inneemt.

Lieve vrienden, al was het voor sommige van jullie niet altijd even duidelijk wat ik nu eigenlijk deed in Maastricht, jullie waren altijd geïnteresseerd in mijn belevenissen, "triomfen" en tegenslagen. Daarnaast herinnerden jullie mij er gelukkig vaak genoeg aan dat er meer is in het leven dan onderzoek doen.

Claudia en Ramon, nu kan ik jullie eindelijk nog een keer bedanken voor jullie vriendschap, die heel erg belangrijk voor mij is. Eva, Ernie en Loon bedankt voor jullie vriendschap en o.a. de onvergetelijke (tjielp!!!) uitjes naar de Champagne streek, Euro Disney en de altijd gezellige etentjes/BBQ's. Daarnaast wil ik mijn medebestuursleden van de Z.L.R.J.V. bedanken voor het begrip wanneer ik weer eens meer op de achtergrond meedraaide vanwege promotiewerkzaamheden.

Lieve Hester, je hebt vaak je bewondering uitgesproken over mijn keuze om te promoveren, daarom wil ik nu mijn bewondering uitspreken over jouw keuzes en reislust. Je bent een schat! Jan, Nicole en Paulien, bedankt voor alle gezellige etentjes, avonden en vakanties. Jullie zijn op culinair gebied geweldig, maar blinken nog meer uit in jullie vriendschap. Ruud, Saskia en Manou wil ik bedanken voor alle geweldige wintersportvakanties. Ik hoop dat we deze winter weer samen op de piste staan (nu zonder dat ik's avonds aan mijn proefschrift moet werken). 
Natuurlijk wil ik ook iedereen van de Huisartsenpraktijk te Bocholtz bedanken voor mijn geweldige jaar als eerstejaars huisarts in opleiding (met een nog af te "ronden" promotietraject). Huub en Emile, dank je wel voor het vertrouwen in mij, jullie zijn geweldige opleiders! Verder wil ik Koen, Angelique en mijn "AIOS-groepje" bedanken voor de leerzame, leuke, maar zeker ook "wetenschappelijk verantwoorde" terugkomdagen in Maastricht. Ik hoop dat we elkaar in de toekomst nog vaak zullen zien.

Mijn lieve schoonouders, Els en Leo, bedankt voor jullie onvoorwaardelijke en liefdevolle hulp op momenten dat ik het even te druk had. Guus en Christiane, ik hoop dat we snel weer eens langs kunnen komen nu ik eindelijk mijn promotieonderzoek heb afgerond.

Lieve papa en mama, bedankt dat jullie er altijd voor mij zijn. Jullie onuitputtelijke liefdevolle steun, hulp en adviezen maken mij tot wie ik nu ben. Zonder de geweldige basis die jullie me meegegeven hebben was ik nooit zover gekomen. Daarom is dit proefschrift ook van jullie. Ik hou van jullie!

Tessa en Janneke, mijn lieve zusjes, dank je wel voor alle support en interesse, jullie zijn heel erg belangrijk voor mij en ik ben trots op jullie. Evert, jij hoort net zo goed bij de familie, bedankt voor je interesse in mijn proefschrift perikelen, we weten allebei dat "de laatste loodjes" het zwaarst zijn! Helga, het is goed te zien dat papa het zo fijn heeft samen met jou, geniet samen lekker van jullie pensioen.

Lieve John, je bent mijn man, mijn soul mate, mijn steun en toeverlaat en de liefde van mijn leven. Samen kunnen we alles aan! Daarom wil ik je bedanken voor wie je bent, je maakt me heel gelukkig.

\section{Rianne}





\section{Curriculum Vitae}


CURRICULUM VITAE 


\section{CURRICULUM VITAE}

Rianne Aimée Ronden werd geboren op 20 september 1982 te Maastricht. Zij groeide op in Heerlen, waar zij in 2001 haar VWO diploma behaalde aan het Bernardinuscollege. Voordat zij in 2002 begon met de opleiding Geneeskunde behaalde zij haar propedeuse Gezondheidsheidswetenschappen (2001-2002) aan de Universiteit Maastricht. Gedurende de laatste twee jaar van haar Geneeskunde studie in Maastricht deed zij al onderzoek naar de nierdoorbloeding van hypertensiepatiënten met een nierarteriestenose bij de onderzoeksgroep Vasculaire Geneeskunde onder leiding van prof. dr. de Leeuw en dr. A.A. Kroon. In september 2008 behaalde zij cum laude het basisartsexamen, waarna zij direct aansluitend startte met haar vier jaar durende promotie onderzoek bij de afdeling Algemene Interne Geneeskunde (onderzoeksgroep Vasculaire Geneeskunde) van het Maastricht Universitair Medisch Centrum en het Cardiovascular Research Institute Maastricht. De resultaten van dit promotietraject staan beschreven in dit proefschrift. Rianne voerde dit wetenschappelijk onderzoek uit onder begeleiding van haar promotor prof. dr. de Leeuw en copromotores dr. A.A. Kroon en dr. A.J.H.M. Houben. Momenteel is zij bezig met de opleiding tot Huisarts aan de Universiteit Maastricht. Rianne is getrouwd met John Gerrits en woont in Heerlen. 

List of abbreviations 


$\begin{array}{ll}\text { ACE } & \text { angiotensin converting enzyme } \\ \text { ADMA } & \text { asymmetric dimethylarginine } \\ \text { AGXT2 } & \text { alanine-glyoxylate aminotransferase } \\ \text { APRC } & \text { active plasma renin concentration } \\ \text { ARAS } & \text { atherosclerotic renal artery stenosis } \\ \text { ARB } & \text { angiotensin Il type 1 receptor blocker } \\ \text { BMI } & \text { body mass index } \\ \text { BP } & \text { blood pressure } \\ \text { CAT } & \text { cationic amino acid transporters } \\ \text { CKD } & \text { chronic kidney disease } \\ \text { DBP } & \text { diastolic blood pressure } \\ \text { DDAH } & \text { dimethylarginine dimethylaminohydrolase } \\ \text { DM } & \text { diabetes mellitus } \\ \text { eGFR } & \text { estimated glomerular filtration rate } \\ \text { eNOS } & \text { endothelium-derived nitric oxide synthase } \\ \text { FRE } & \text { fractional renal extraction } \\ \text { GFR } & \text { glomerular filtration rate } \\ \text { HDL } & \text { high-density lipoprotein } \\ \text { LDL } & \text { low-density lipoprotein } \\ \text { L-NMMA } & \text { L-N }{ }^{G} \text {-monomethyl-arginine } \\ \text { MAP } & \text { mean arterial pressure } \\ \text { MRBF } & \text { mean renal blood flow } \\ \text { MRPF } & \text { mean renal plasma flow } \\ \text { NO } & \text { nitric oxide } \\ \text { NOS } & \text { nitric oxide synthase } \\ \text { PRMTs } & \text { protein arginine methyltransferases } \\ \text { PTRA } & \text { percutaneous transluminal renal angioplasty } \\ \text { PTRAS } & \text { percutaneous transluminal renal angioplasty with stenting } \\ \text { RAS } & \text { renin-angiotensin system } \\ \text { RBF } & \text { renal blood flow } \\ \text { ROS } & \text { reactive oxygen species } \\ \text { RVR } & \text { renal vascular resistance } \\ \text { SBP } & \text { systolic blood pressure } \\ \text { SCR } & \text { serum creatinine } \\ \text { UDMA } & \text { symmetric dimethylarginine } \\ \text { Urinary albumin excretion } \\ \text { URE clearance }\end{array}$

